\title{
Pacing-induced dyssynchrony, blessing or curse?
}

Citation for published version (APA):

Vanagt, W. Y. (2007). Pacing-induced dyssynchrony, blessing or curse? [Doctoral Thesis, Maastricht University]. Datawyse / Universitaire Pers Maastricht. https://doi.org/10.26481/dis.20071221wv

Document status and date:

Published: 01/01/2007

DOI:

10.26481/dis.20071221wv

Document Version:

Publisher's PDF, also known as Version of record

\section{Please check the document version of this publication:}

- A submitted manuscript is the version of the article upon submission and before peer-review. There can be important differences between the submitted version and the official published version of record.

People interested in the research are advised to contact the author for the final version of the publication, or visit the DOI to the publisher's website.

- The final author version and the galley proof are versions of the publication after peer review.

- The final published version features the final layout of the paper including the volume, issue and page numbers.

Link to publication

\footnotetext{
General rights rights.

- You may freely distribute the URL identifying the publication in the public portal. please follow below link for the End User Agreement:

www.umlib.nl/taverne-license

Take down policy

If you believe that this document breaches copyright please contact us at:

repository@maastrichtuniversity.nl

providing details and we will investigate your claim.
}

Copyright and moral rights for the publications made accessible in the public portal are retained by the authors and/or other copyright owners and it is a condition of accessing publications that users recognise and abide by the legal requirements associated with these

- Users may download and print one copy of any publication from the public portal for the purpose of private study or research.

- You may not further distribute the material or use it for any profit-making activity or commercial gain

If the publication is distributed under the terms of Article $25 \mathrm{fa}$ of the Dutch Copyright Act, indicated by the "Taverne" license above, 


\title{
Pacing-induced dyssynchrony,
}

\author{
Blessing or curse?
}

Ward Vanagt 


\title{
Pacing-induced dyssynchrony,
}

\section{Blessing or curse?}

\author{
PROEFSCHRIFT \\ ter verkrijging van de graad van doctor \\ aan de Universiteit Maastricht, \\ op gezag van de Rector Magnificus, \\ Prof. mr. G.P.M.F. Mols \\ volgens het besluit van College van Decanen, \\ in het openbaar te verdedigen \\ op vrijdag 21 december 2007 om 16:00 uur \\ door \\ Ward Vanagt \\ Geboren op 7 februari 1975 \\ te Brugge, België

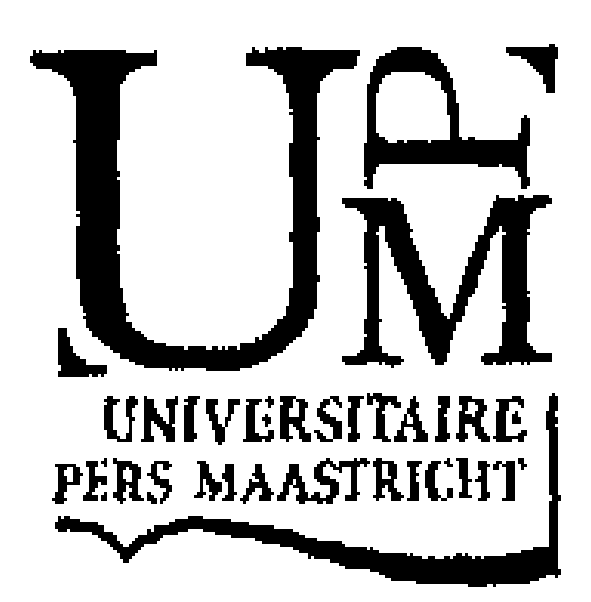




\section{Promotor}

Prof. dr. G.J. van der Vusse

\section{Copromotores \\ Dr. F.W. Prinzen \\ Dr. T. Delhaas}

\section{Beoordelingscommissie}

Prof. dr. J. Waltenberger (voorzitter)

Prof. dr. T. Arts

Prof. dr. D.J.G.M. Duncker, Erasmus Universiteit Rotterdam

Prof. dr. M. Gewillig, Katholieke Universiteit Leuven, België

Prof. dr. L.H.E.H. Snoeckx

The studies described in chapter 6-7 in this thesis were financially supported by Boston Scientific (St Paul, Minnesota, USA).

Financial support for the publication of this thesis by Boston Scientific (St Paul, Minnesota, USA), "Stichting Hartsvrienden RESCAR", and "Stichting Bevordering Kindergeneeskunde Maastricht" is gratefully acknowledged.

Additional support was granted by St Jude Medical Nederland. 


\section{CONTENTS}

Chapter 1

Background and aim of the thesis

\section{Chapter 2}

Theoretical background and animal experimental approach

\section{Chapter 3}

The left ventricular apex is the optimal site for pediatric pacing correlation with animal experience

\section{Chapter 4}

Left ventricular apex pacing cures overt right

ventricular pacing-induced heart failure - case report

\section{Chapter 5}

Structural and functional benefit of chronic left ventricular over right ventricular pacing in children

\section{Chapter 6}

Pacing-induced dyssynchrony preconditions rabbit

myocardium against ischemia / reperfusion injury

\section{Chapter 7}

Pacing-induced dyssynchrony during early reperfusion reduces infarct size

Chapter 8

General discussion

Summary

Samenvatting

Curriculum vitae

Publications 


\section{Pacing-induced dyssynchrony, blessing or curse?}

\section{Background and aim of the} thesis 


\section{CHAPTER 1}

\section{BACKGROUND}

In the normal heart, electrical activation of ventricular myocytes occurs through the specialized cardiac conduction system. The electrical impulse, originating from the atrium and the atrioventricular (AV) node, travels fast through the specialized conduction tissue. This results in almost synchronous electrical activation and, subsequently, synchronous contraction of ventricular cardiomyocytes. ${ }^{*}$

During ventricular pacing, the electrical activation wave bypasses the rapid conduction system and spreads through the ventricles from cardiomyocyte to cardiomyocyte. Conduction of the electrical impulse through the myocardium is $\sim 4$ times slower than through the specialized conduction system. This change in electrical conduction pattern results in electrical and mechanical dyssynchrony since myocytes in proximity of the ventricular pacing site are earlyactivated, whereas myocytes remote from the pacing site are late-activated. Mechanical dyssynchrony may be even more pronounced than electrical dyssynchrony, because during early systole the early-contracting myocardium stretches the late-activated regions. Subsequently, the late-activated myocytes contract powerfully due to their early-systolic stretch, recruiting the local FrankStarling mechanism. On its turn, the powerful contraction of late-activated myocytes results in stretching of early-activated myocytes during late systole. ${ }^{1}$ In this way, ventricular pacing induces a dyssynchronous left ventricular (LV) stretch and contraction pattern. ${ }^{1,2}$ To visualize these patterns, figure 1.1 shows a schematic representation of LV stretch and contraction following physiological ventricular activation and following right ventricular (RV) pacing.

"Footnote: Literally, "synchronous activation" denominates simultaneous activation of all ventricular myocytes, which is not achieved under physiological circumstances. Despite the rapid propagation of the electrical impulse through the conduction tissue, activation of the ventricles occurs over a certain amount of time. This is, among others, reflected by QRS-duration on the electrocardiogram. Therefore, the term "euchrony" would more correctly describe the normal timing of ventricular activation under physiological conditions. However, "electrical synchrony" and "synchronous activation" are generally used in the literature to denominate the physiological timing of electrical activation, and will therefore be used throughout this thesis. 
Early systole

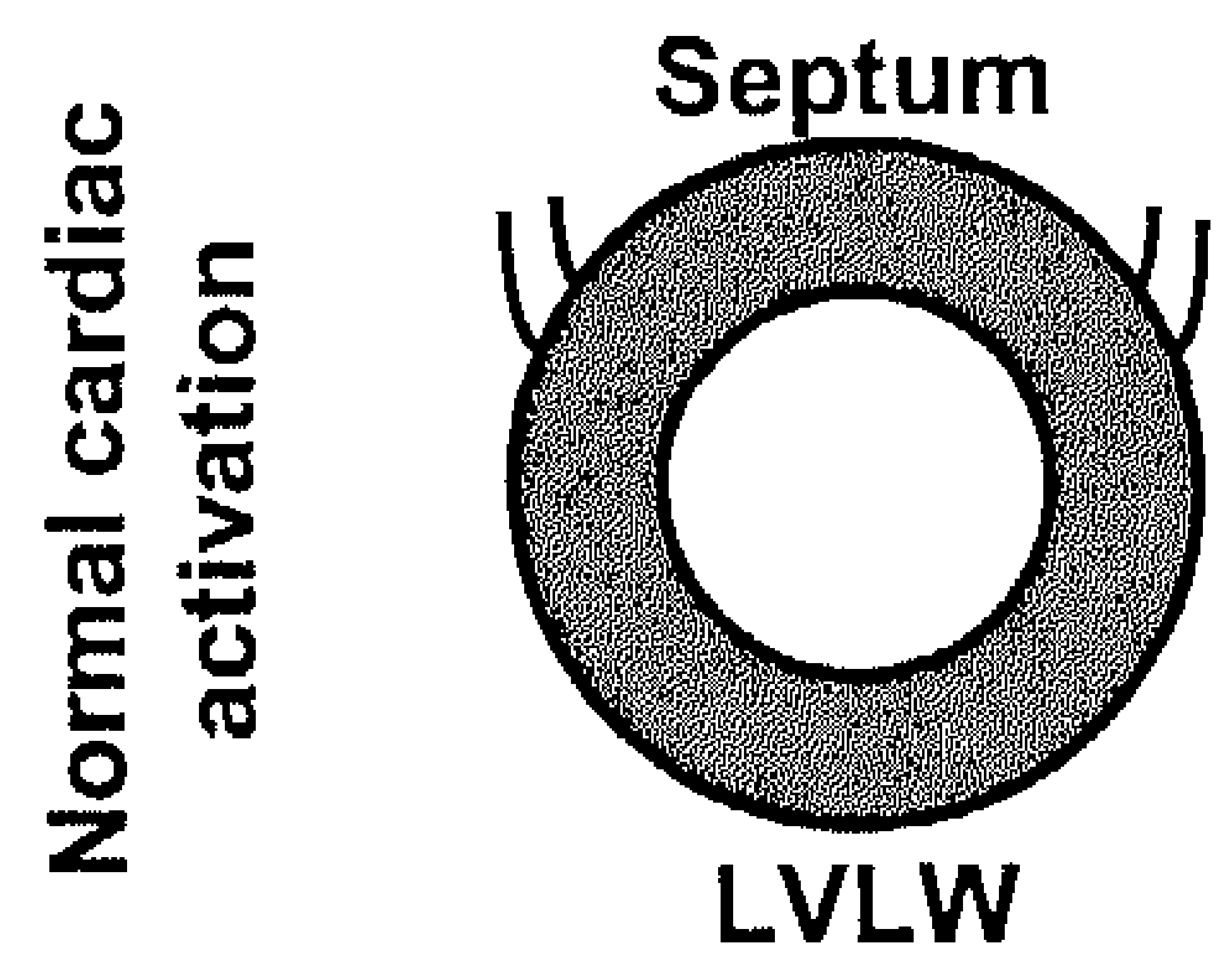

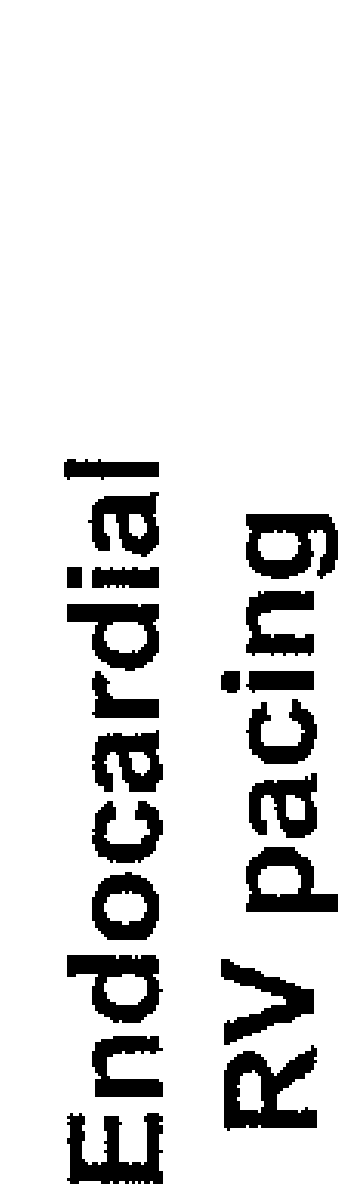

.RV Pacing lead

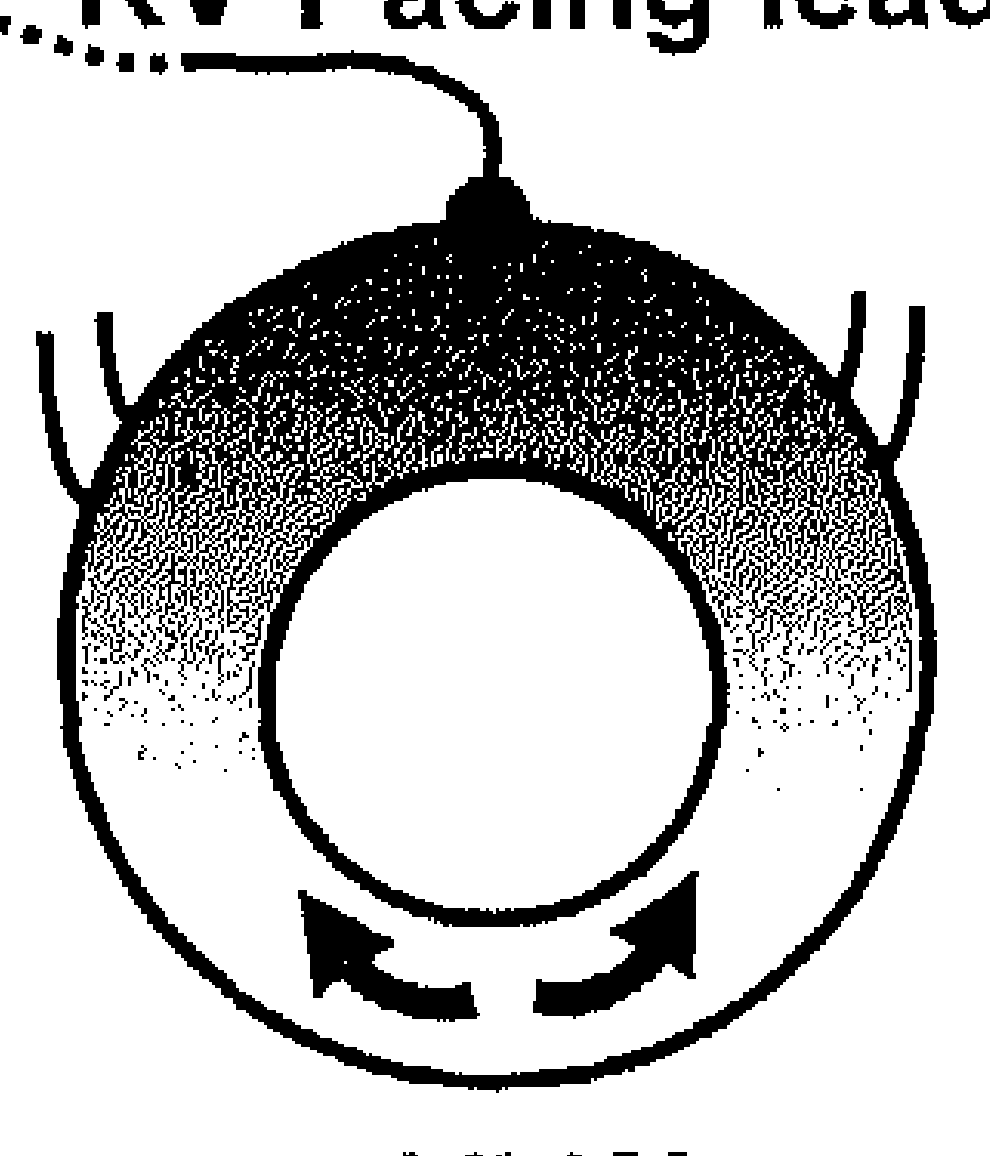

LVLW
Late systole

\section{Attachments}
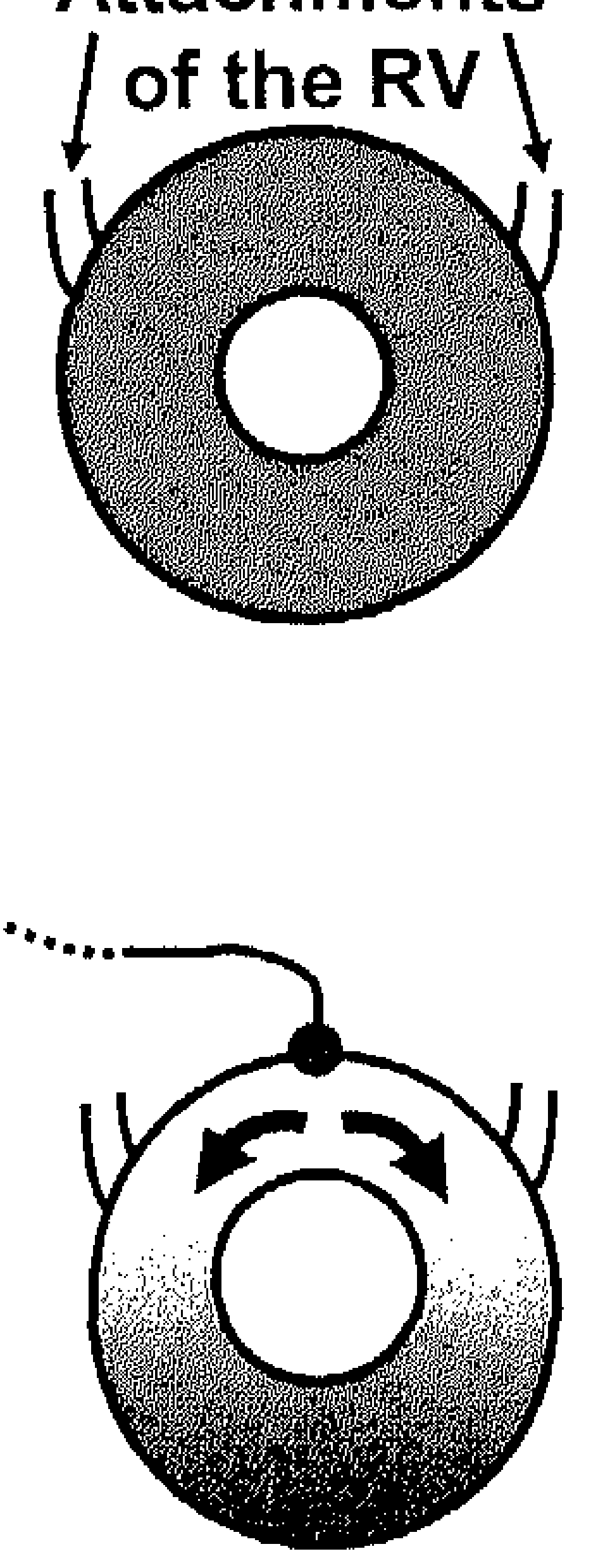

Systole
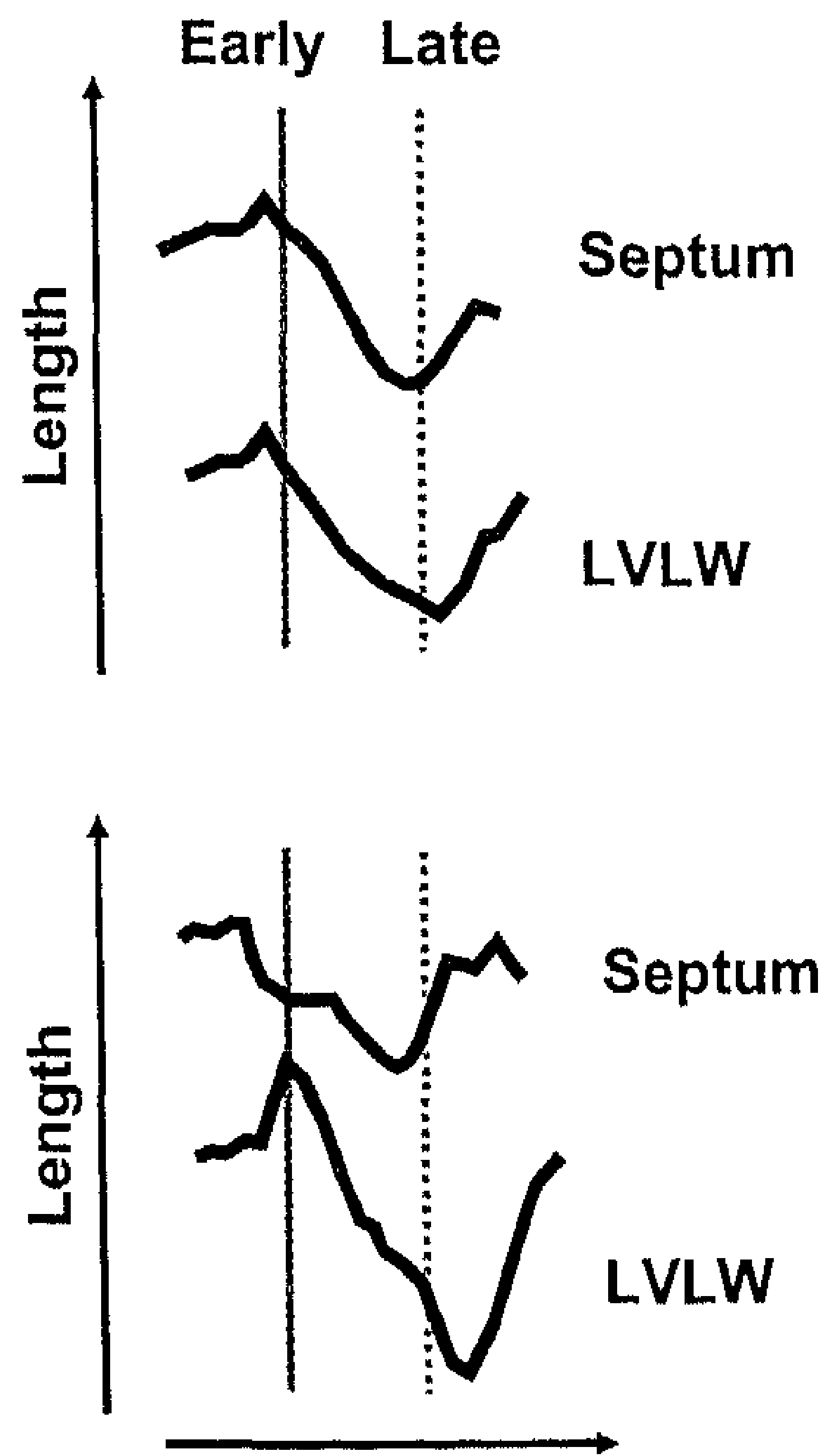

Time

Regional strain

Figure 1.1 Schematic representation of left ventricular (LV) contraction patterns following normal cardiac activation (upper panel) and endocardial right ventricular (RV) pacing (lower panel). Crosssections of the LV (left panel) during early and late systole show regional shortening (dark grey) and stretch (arrows and light grey) of the myocardial muscle fibers. The right panel depicts changes in segment length over time in the septum and LV lateral wall (LVLW) throughout the cardiac cycle. The solid and dashed grey lines in the right panel depict the time point in the cardiac cycle at which the cross-sections of the LV in the left panel are represented during early and late systole, respectively.

Following normal activation, the septum and LVLW contract almost synchronously. Following RV pacing, the septum starts to shorten early in systole, thereby stretching the LVLW. During late systole, the LVLW contracts powerfully, resulting in stretch of the interventricular septum. 


\section{AIMS OF THE THESIS}

\section{Pacing-induced dyssynchrony, curse for hemodynamic performance?}

The dyssynchronous stretch and contraction pattern following ventricular pacing is associated with deterioration of LV pump function. ${ }^{1-5}$ Ventricular pacing from any site induces dyssynchrony, but the extent of the decrease in cardiac function varies between different pacing sites. ${ }^{2,5-7}$ It is of note that the most commonly used pacing site in children and adults, the RV apex, is among the sites that lead to the most pronounced decrease in cardiac function. ${ }^{6}$ Although several alternative pacing sites have already been studied in animals, ${ }^{2}$ adults ${ }^{5}$ and children, ${ }^{6,8}$ the optimal ventricular pacing site in children is currently still unknown.

Previous animal studies in our research group have demonstrated favorable effects of LV pacing on cardiac pump function. ${ }^{2,9}$ As a bridge from the laboratory investigations to clinical pediatric practice, the first part of this thesis focuses on the effects of pacing at different LV sites on hemodynamic performance and cardiac geometry in children with heart disease.

\section{Pacing-induced dyssynchrony, blessing for ischemic tolerance?}

Several studies have shown that increased myocardial stretch ${ }^{10,11}$ and afterload $^{12}$ can increase the tolerance of the myocardium to ischemia. Since ventricular pacing substantially alters regional myocardial stretch and contraction patterns, ${ }^{1}$ we hypothesized that pacing-induced mechanical dyssynchrony exerts a beneficial effect on the ischemic / reperfused heart. This idea is supported by reports that dyssynchrony can activate molecular signaling pathways ${ }^{13}$ which are also involved in cardioprotection. ${ }^{14}$ In the second part of the thesis, it is therefore investigated whether intermittent pacing-induced mechanical dyssynchrony is potentially cardioprotective against ischemia / reperfusion injury. This hypothesis is tested in isolated rabbit hearts and in vivo in pigs using intermittent pacing as a cardioprotective stimulus. This stimulus is applied either prior to ischemia (preconditioning) or during early reperfusion (postconditioning). Myocardial infarct size as the consequence of ischemia and reperfusion is used as the primary end-point to study the protective potency of intermittent pacing-induced mechanical dyssynchrony. 


\section{OUTLINE OF THE THESIS}

In the general introduction (chapter 2), the effects of ventricular pacing on left ventricular stretch, contraction and pump function are described, and the background for the studies in this thesis is presented.

Since the ventricular pacing site is an important determinant of cardiac function, the first part of the thesis (chapter 3-5) contains our studies on ventricular pacing sites in children. Chapter 3 describes an acute study comparing the effects of pacing at different ventricular sites on LV function in children undergoing cardiac surgery. Given the acute beneficial hemodynamic effects of LV apex pacing, we subsequently treated a patient with heart failure using LV apex pacing. This patient is presented in the case-report in chapter 4 . The chronic effects of LV lateral wall pacing and RV pacing are compared in a retrospective study (chapter 5 ).

The second part of the thesis deals with the use of pacing-induced dyssynchrony as a preconditioning (chapter 6) and postconditioning (chapter 7) stimulus for mitigating ischemia / reperfusion injury.

In the general discussion (chapter 8), the abovementioned studies are put into a broader perspective, and some ideas for future investigations are presented. 


\section{REFERENCES}

1. Prinzen FW, Hunter WC, Wyman BT, McVeigh ER. Mapping of regional myocardial strain and work during ventricular pacing: experimental study using magnetic resonance imaging tagging. J Am Coll Cardiol 1999; 33:1735-1742.

2. Prinzen FW, Peschar M. Relation between the pacing induced sequence of activation and left ventricular pump function in animals. Pacing Clin Electrophysiol 2002; 25:484-498.

3. Wyman BT, Hunter WC, Prinzen FW, Faris OP, McVeigh ER. Effects of single- and biventricular pacing on temporal and spatial dynamics of ventricular contraction. Am J Physiol Heart Circ Physiol 2002; 282:H372-379.

4. Verbeek XA, Vernooy $K$, Peschar $M$, Cornelussen RN, Prinzen FW. Intra-ventricular resynchronization for optimal left ventricular function during pacing in experimental left bundle branch block. J Am Coll Cardiol 2003; 42:558-567.

5. Manolis AS. The deleterious consequences of right ventricular apical pacing: time to seek alternate site pacing. Pacing Clin Electrophysiol 2006; 29:298-315.

6. Karpawich PP. Chronic right ventricular pacing and cardiac performance: the pediatric perspective. Pacing Clin Electrophysiol 2004; 27:844-849.

7. Lister JW, Klotz DH, Jomain SL, Stuckey JH, Hoffman BF. Effect of Pacemaker Site on Cardiac Output and Ventricular Activation in Dogs with Complete Heart Block. Am J Cardiol 1964; 14:494503.

8. Karpawich PP, Mital S. Comparative left ventricular function following atrial, septal, and apical single chamber heart pacing in the young. Pacing Clin Electrophysiol 1997; 20:1983-1988.

9. Prinzen FW, Van Oosterhout MF, Vanagt WY, Storm C, Reneman RS. Optimization of ventricular function by improving the activation sequence during ventricular pacing. Pacing Clin Electrophysiol 1998; 21:2256-2260.

10. Ovize M, Kloner RA, Przyklenk K. Stretch preconditions canine myocardium. Am J Physiol 1994; 266:H137-146.

11. Gysembergh A, Margonari $H$, Loufoua J, Ovize A, Andre-Fouet X, Minaire Y, Ovize M. Stretchinduced protection shares a common mechanism with ischemic preconditioning in rabbit heart. Am J Physiol 1998; 274:H955-964.

12. Huang $\mathrm{CH}$, Wang JS, Chiang SC, Wang YY, Lai ST, Weng ZC. Brief pressure overload of the left ventricle preconditions rabbit myocardium against infarction. Ann Thorac Surg 2004; 78:628-633.

13. Spragg DD, Leclercq C, Loghmani M, Faris OP, Tunin RS, DiSilvestre D, McVeigh ER, et al. Regional alterations in protein expression in the dyssynchronous failing heart. Circulation 2003; 108:929-932.

14. Hausenloy DJ, Tsang A, Mocanu MM, Yellon DM. Ischemic preconditioning protects by activating prosurvival kinases at reperfusion. Am J Physiol Heart Circ Physiol 2005; 288:H971-976. 
(WE:

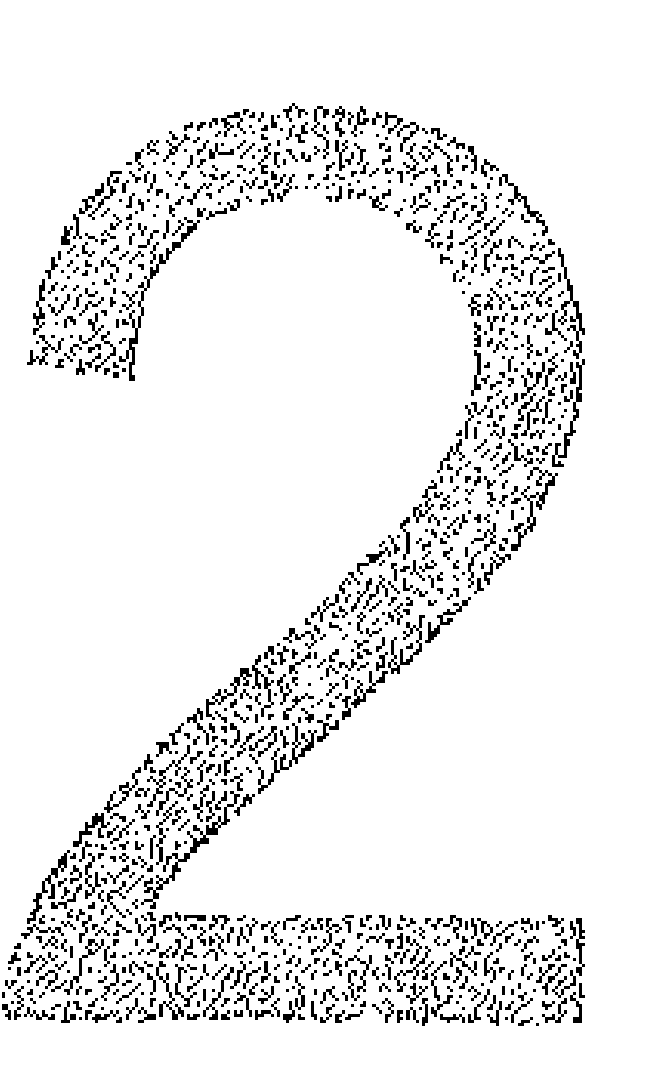

Theoretical background and animal experimental approach 


\section{OUTLINE OF THE CHAPTER}

Ventricular pacing induces marked electrical and contractile dyssynchrony. While ventricular pacing almost always induces dyssynchrony, the extent of the associated decrease in cardiac function varies between different pacing sites and is most pronounced during right ventricular (RV) apex pacing. ${ }^{1,2}$ The first part of this chapter describes the pathophysiology of ventricular pacing and presents an overview of the previously studied alternatives for RV apex pacing in the young. This provides the background for the studies in chapters 3-5 concerning hemodynamic performance during pacing at different left ventricular (LV) sites in children with heart disease.

The second part of this chapter focuses on the potential role of pacing-induced dyssynchrony as a pre- and postconditioning trigger aiming to reduce ischemia / reperfusion damage. Various cardioprotective stimuli are already known, such as ischemia, ${ }^{3}$ heat shock, ${ }^{4}$ and increased mechanical loading. ${ }^{5-8}$ The second part of this chapter provides the background for the studies in chapters 6-7, in which the hypothesis is tested that intermittent pacing-induced dyssynchrony (using ventricular pacing at physiological heart rate) induces protection against ischemia / reperfusion injury.

\section{Part 1. Pacing-induced dyssynchrony, curse for hemodynamic performance}

Based on: Physiology of cardiac pacing in children - the importance of the ventricular pacing site. Ward Y. Vanagt, Frits W. Prinzen and Tammo Delhaas. Pacing and Clinical Electrophysiology, 2007; in press.

\section{INTRODUCTION}

In children and adults in whom ventricular pacing is indicated for rate control, the ventricular pacing lead is traditionally positioned at the right ventricle (RV). RV pacing, however, acutely ${ }^{1,2,9-11}$ and chronically ${ }^{12}$ decreases left ventricular (LV) function both in animal experiments and in adult and juvenile patients. In chronically RV paced children, LV dilatation occurs over time ${ }^{13}$ (for review $\mathrm{se}^{2,14}$ ), leading to cardiac failure in $\sim 7 \%$ of chronically paced children. ${ }^{15-17}$ 


\section{PATHOPHYSIOLOGY OF VENTRICULAR PACING}

Under physiological circumstances, the ventricular myocardium is activated through the specialized cardiac conduction system (figure 2.1). Electrical impulse conduction through this system is fast, traveling at $\sim 3-4 \mathrm{~m} / \mathrm{s}$, and results in synchronous electrical activation and subsequent synchronous contraction of the ventricles. ${ }^{1}$ This synchrony is observed between the ventricles (interventricular synchrony), but also within each ventricle (intraventricular synchrony).

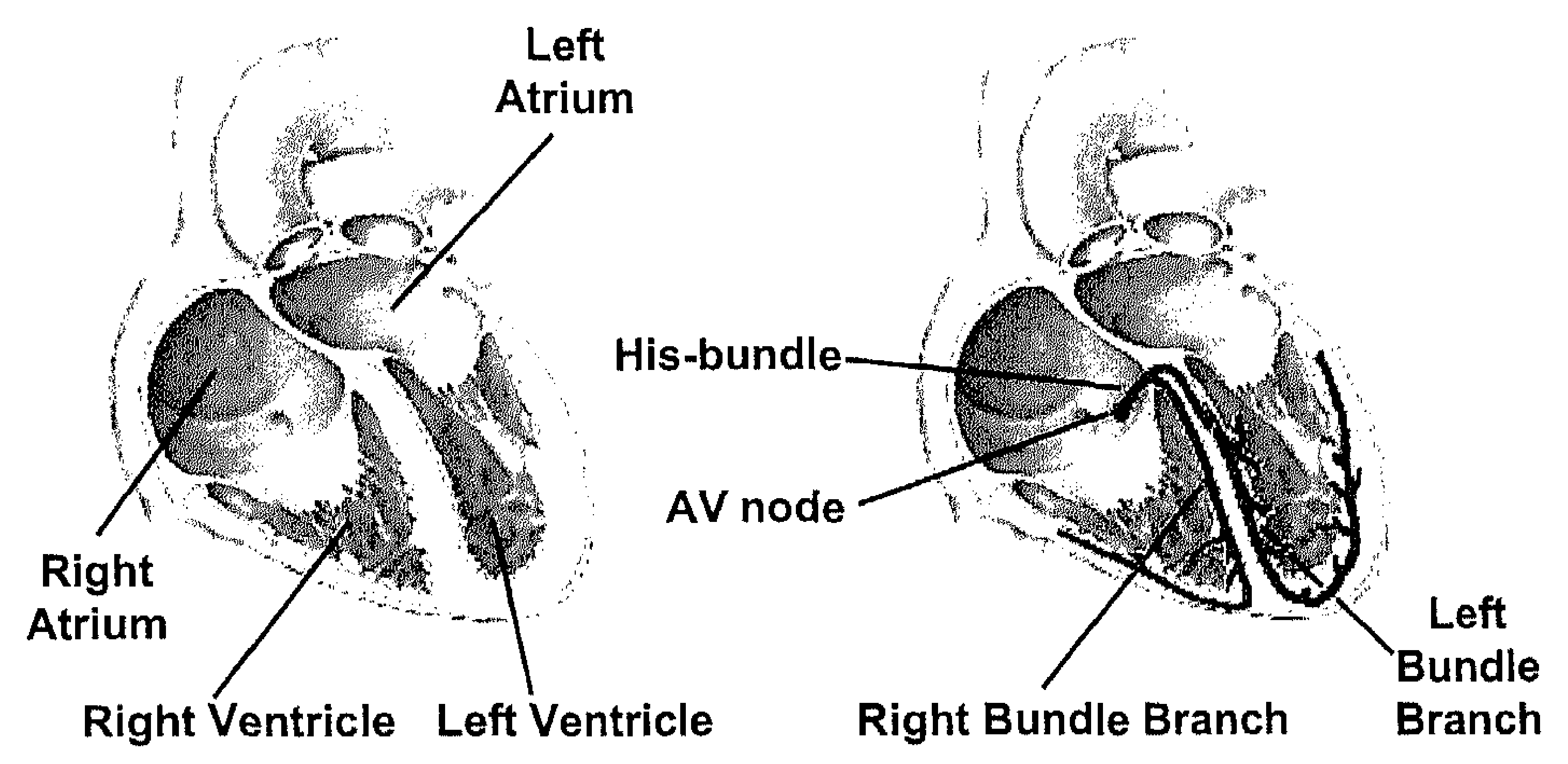

Figure 2.1 Normal cardiac anatomy showing the four chambers of the heart (left panel) and the specialized ventricular conduction system (right panel), consisting of the atrio-ventricular (AV) node, His-bundle, bundle branches and Purkinje fibers.

During ventricular pacing, the electrical activation wave spreads through the ventricles from cardiomyocyte to cardiomyocyte, and this conduction is approximately 4 times slower than through the specialized conduction system. In case of ventricular pacing, the slow conduction rate of the electrical impulse results in electrical dyssynchrony, with early-activated myocytes close to the pacing site, and late-activated myocytes remote from the pacing site (figure 2.2). The early-activated myocytes start to contract during early-systole, thereby stretching the late-activated myocytes ${ }^{1,18}$ (figure 2.3). When the remote myocytes are activated, they contract powerfully due to their earlysystolic stretch (local Frank-Starling effect ${ }^{1}$ ). The powerful contraction of the late-activated myocytes results in systolic stretching of the early-activated myocytes. Thus, during ventricular pacing, electrical dyssynchrony causes mechanical dyssynchrony. 


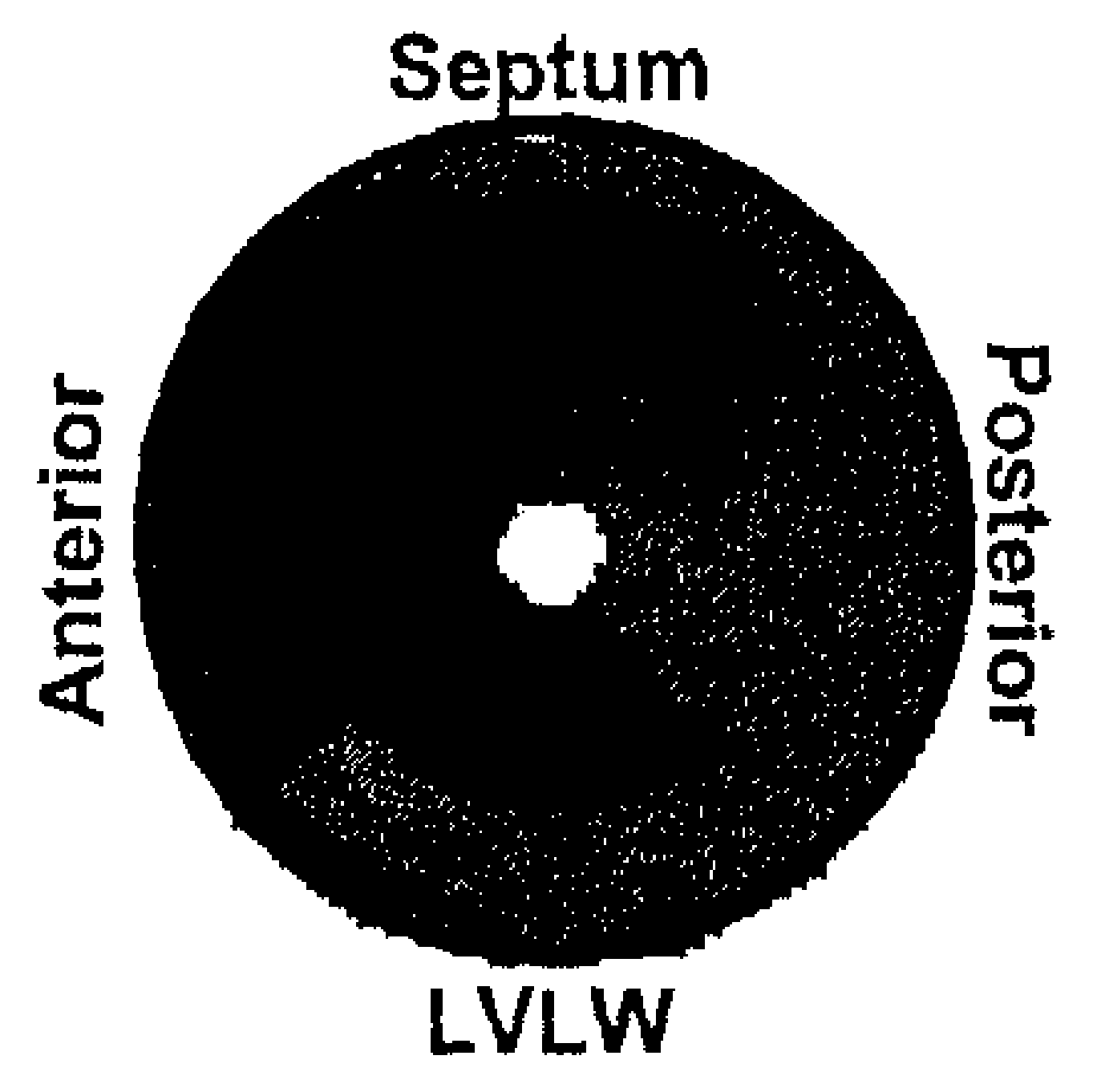

RA pacing

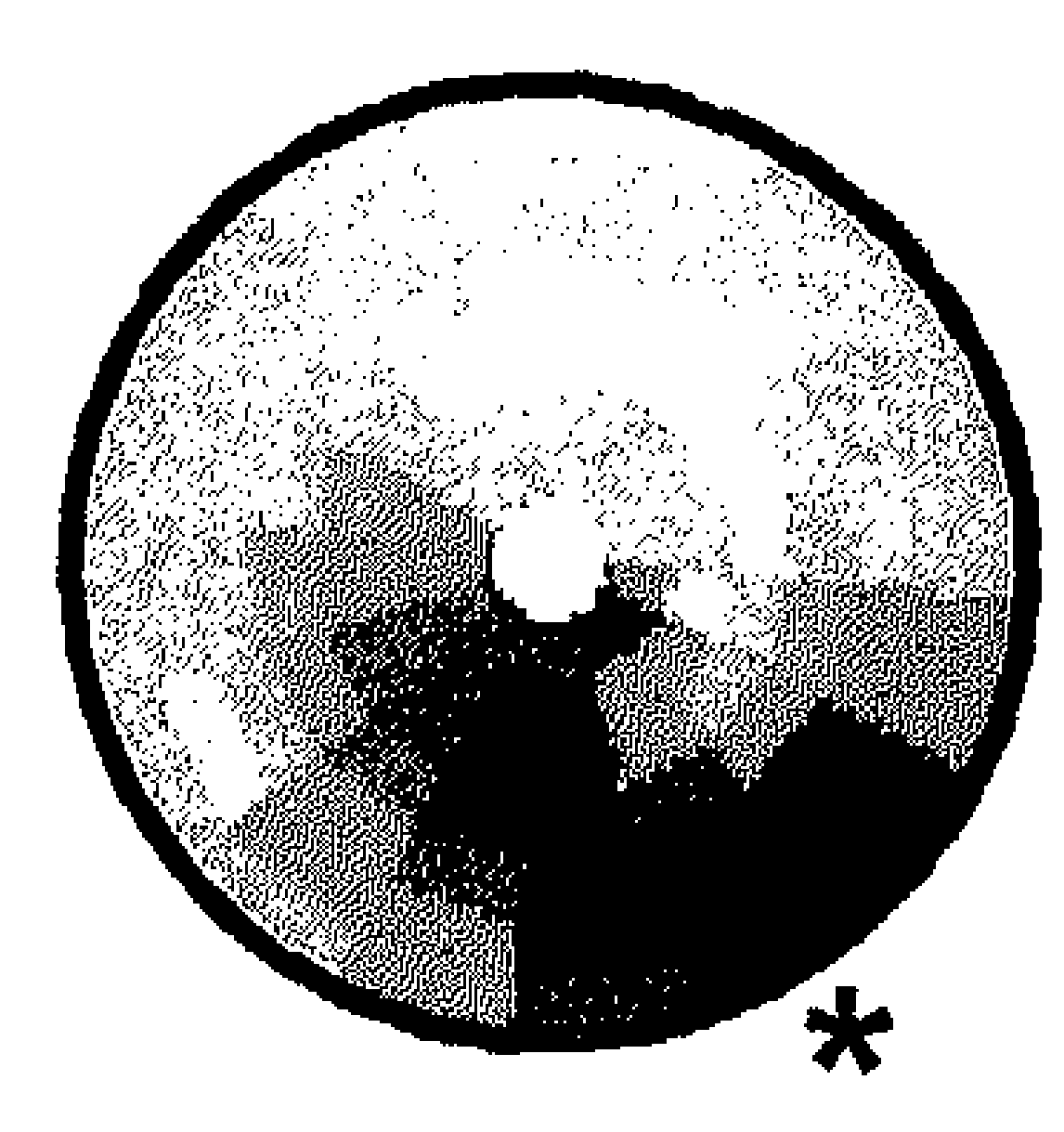

LV pacing
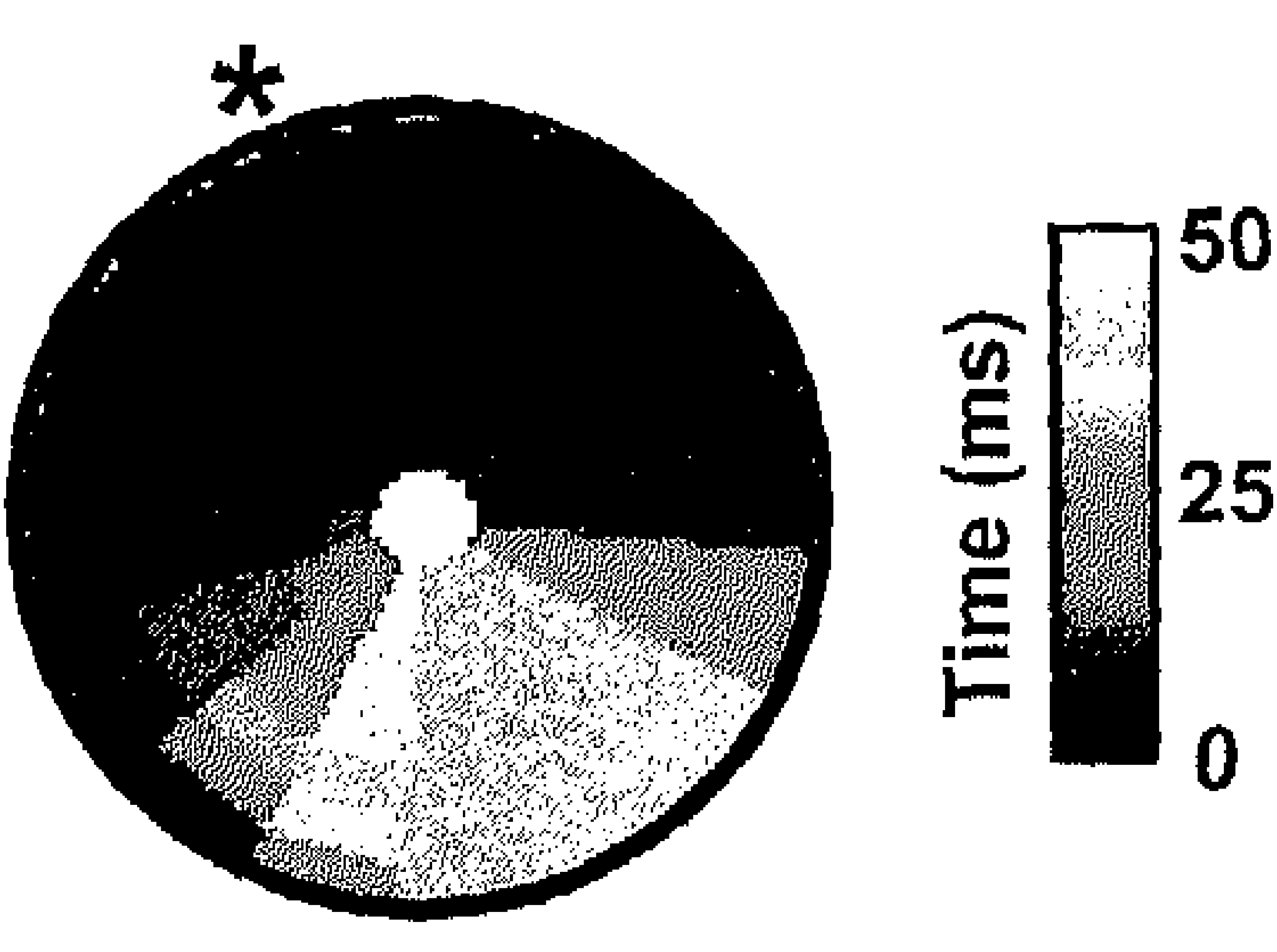

RV pacing

Figure 2.2 Left ventricular (LV) electrical activation mapping using an intraventricular mapping catheter in dogs during right atrial (RA), LV lateral wall (LVLW) and right ventricular (RV) pacing. LV endocardial activation maps are presented as bull's eye plots with the inner disc representing the LV apex and the outer disc representing the LV base. Electrical activation of the LV is fast and synchronous during RA pacing. During ventricular pacing, the region in proximity of the pacing site is earlyactivated, whereas myocardium remote from the pacing site is late-activated. ${ }^{*}=$ ventricular pacing site.

The dyssynchronous contraction during ventricular pacing is associated with a reduction in LV pump function. ${ }^{1,19}$ Furthermore, chronic ventricular pacing induces hypertrophy of late-activated cardiomyocytes in response to the increased regional loading conditions. ${ }^{13,20}$

Regardless of the exact position of the stimulation electrode, ventricular pacing results in considerably more electrical dyssynchrony than during normal activation, albeit that the degree of electrical dyssynchrony varies between ventricular pacing sites. Importantly, the most commonly used pacing site, the RV apex, is also the site that results in the worst functional outcome. ${ }^{2} \mathrm{RV}$ apex pacing decreases cardiac pump function acutely ${ }^{10}$ and chronically ${ }^{12}$ in children as well as in adults. During chronic RV pacing, LV remodeling is observed. Macroscopically, LV dilatation and asymmetric hypertrophy occur, ${ }^{13}$ whereas microscopically, abnormal mitochondria, fat deposition and fibrosis are noted. ${ }^{2}$, ${ }^{21,} 22$ Eventually, $\sim 7 \%$ of chronically paced children develop heart failure. ${ }^{15-17}$ Pacing initiated at birth has been reported to lead to heart failure in one patient after 11 months of pacing. ${ }^{17}$ In other studies, heart failure is found after RV pacing for an average of 8 to 15 years. ${ }^{15,16}$ 


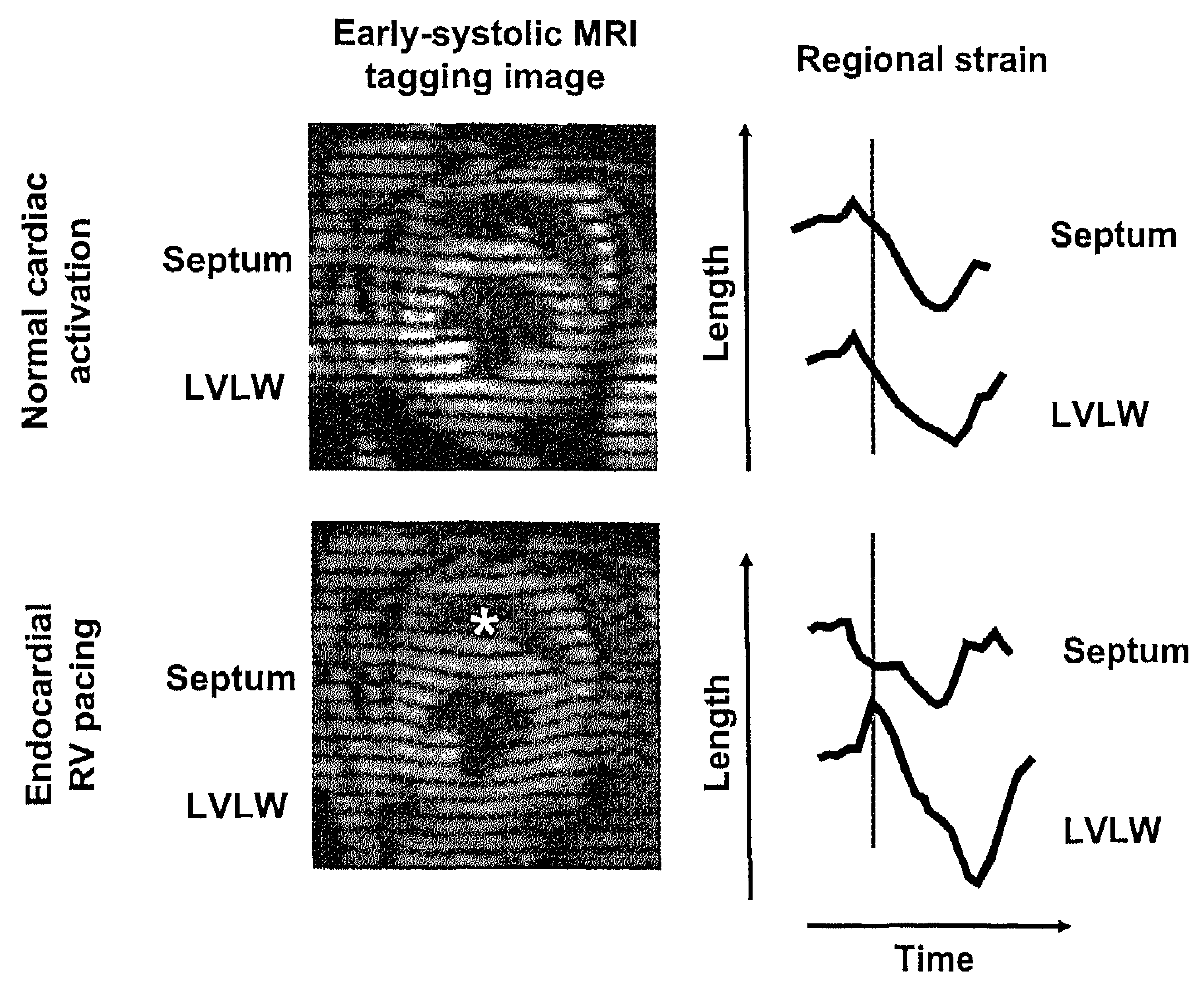

Figure 2.3 Left ventricular (LV) contraction patterns during normal cardiac activation (upper panels) and during endocardial right ventricular (RV) pacing (lower panels). In the early-systolic crosssections of a dog heart using MRI tagging (left panels) regional myocardial shortening can be noticed from inward bending of horizontal tag lines, whereas stretch is depicted by outward bending. The right panels depict myocardial strain in the septum and LV lateral wall (LVLW) throughout the cardiac cycle. The grey line in the strain figure indicates the time point in the cardiac cycle at which the early-systolic MRI-fragment is illustrated. This figure shows that during normal activation, the septum and LVLW synchronously contract, whereas during RV pacing, the septum and LVLW are out of phase. ${ }^{*}=\mathrm{RV}$ pacing site.

\section{ALTERNATIVE PACING SITES}

Increasing recognition of the unfavorable effects of RV apex pacing has initiated the search for alternative ventricular pacing sites that cause less electrical and contractile dyssynchrony. During His-bundle pacing, electrical activation is synchronous and results in good pump function, ${ }^{23,}{ }^{24}$ but the implantation procedure and lead stability are at present cumbersome and experience in children is lacking. During pacing in proximity of the His-bundle and bundle branches using RV outflow tract and RV septum pacing, electrical activation of 
the conduction system has not been reproducibly achieved. ${ }^{1}$ Therefore, current alternative pacing sites are located outside the specialized conduction system (figure 2.4). While ectopic pacing always creates abnormal ventricular activation, some pacing sites lead to better hemodynamic function than others. This prompted clinicians to search for the myocardial pacing site that provides the most favorable balance between interventricular dyssynchrony, ${ }^{25-27}$ intraventricular dyssynchrony (especially around the circumference of the $L V^{19,26}$ ) and the sequence of electrical activation. ${ }^{1,11}$

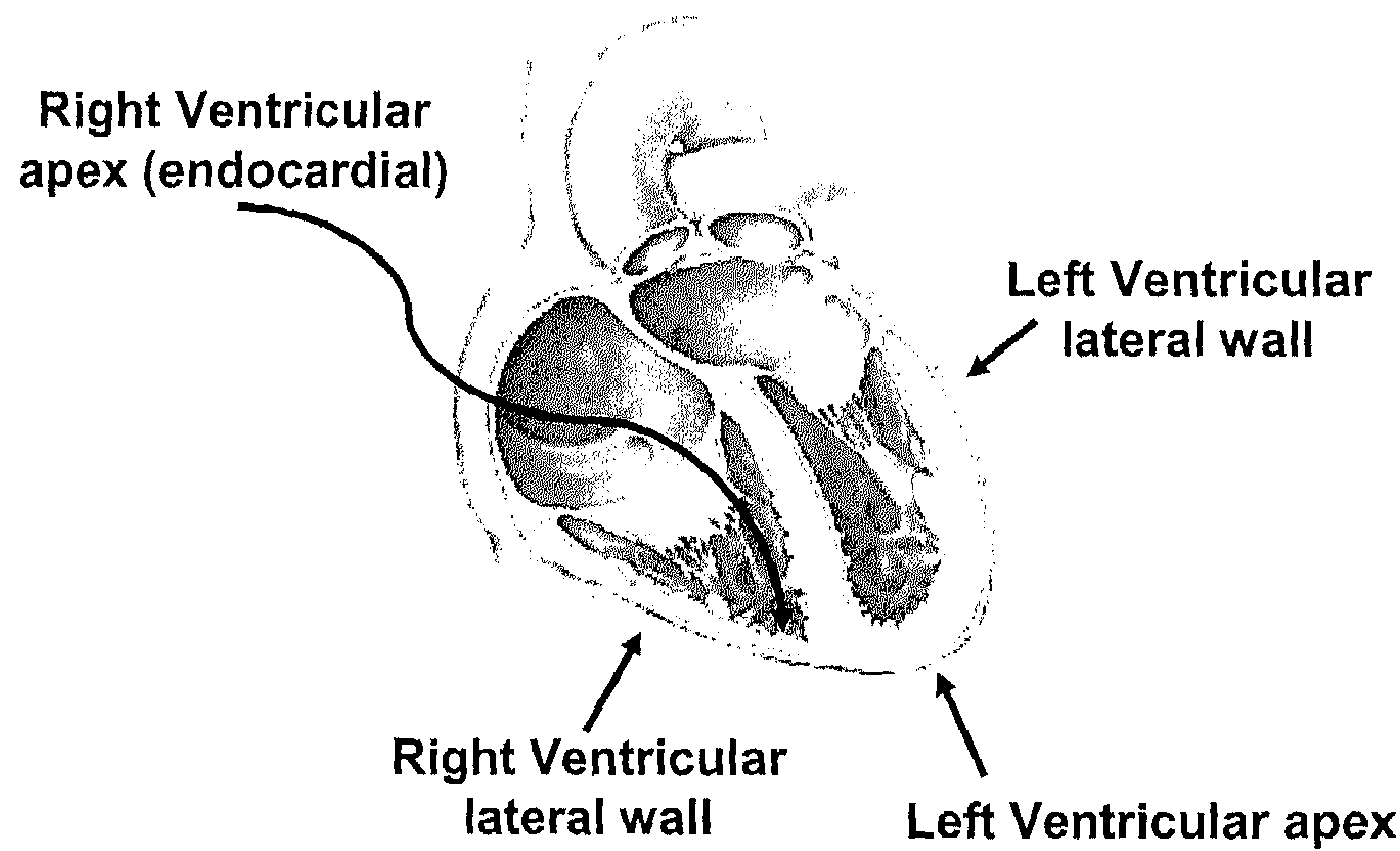

Figure 2.4 Schematical representation of the ventricular pacing sites used in the studies in this thesis.

Myocardial pacing at the RV outflow tract does not provide a consistent beneficial hemodynamic effect over RV apex pacing. ${ }^{9}$ During pacing at different RV septal sites, hemodynamic function varies widely, and the location of the RV septal site that leads to the less pronounced decrease in pump function also varies between hearts. ${ }^{28}$

Pacing either at the LV lateral wall or at the RV induces marked electrical and contractile dyssynchrony between the respective early- and late-activated areas. ${ }^{1}$ Since hemodynamic performance is generally better during LV lateral wall pacing as compared with RV pacing, ${ }^{11,29,30}$ the pathway of electrical activation appears to be an important denominator of cardiac function during pacing. ${ }^{11}$ Similarly, isolated left bundle branch block (during which the pathway of electrical activation is comparable to RV pacing ${ }^{1,2,14}$ ) compromises LV func- 
tion much more than isolated right bundle branch block. ${ }^{31,32}$ Beside the observation that $L V$ pacing sites are superior to RV pacing sites, ${ }^{1,11,29} \mathrm{LV}$ apex pacing results in better LV function as compared with other LV pacing sites. ${ }^{1{ }^{11}}$ In fact, LV contractility during LV apex pacing is as good as during physiologic activation. ${ }^{1,11}$ This outcome of LV apex pacing can be explained by the physiological apex-to-base sequence of electrical activation, ${ }^{1}$ which results in synchronous electrical activation ${ }^{26}$ and contraction ${ }^{19}$ at the circumferential level of the LV wall. To the best of our knowledge, LV apex pacing has not been applied in human subjects.

In children in whom a ventricular pacemaker is needed solely for rate control (e.g. congenital or acquired atrioventricular block), pacing from a single optimal site is indicated to prevent the deleterious changes in cardiac function and structure associated with RV apex pacing. In children with heart failure, however, biventricular pacing is increasingly being used and aims at minimizing interventricular and intraventricular dyssynchrony. In postoperative children, biventricular pacing acutely improves cardiac function. ${ }^{25,}{ }^{33}$ Chronic biventricular pacing increases LV pump function in children with heart failure ${ }^{34}$ and is also effective in treating children with RV pacing-induced heart failure. ${ }^{15} \mathrm{Al}-$ though biventricular pacing in children increases cardiac pump function in compromised hearts, ${ }^{15,33-35}$ it is currently unknown whether this technique provides a benefit over optimal single site pacing in juvenile hearts. It should be mentioned that in adults, LV lateral wall pacing alone is as effective as biventricular pacing. ${ }^{29,}{ }^{36}$ Moreover, in laboratory animals, LV apex pacing and biventricular pacing result in similar electrical synchrony and hemodynamic performance. ${ }^{1}$

The use of a single optimal ventricular pacing site provides practical advantages over biventricular pacing in children, such as lower pacemaker battery usage and a reduction in the number of necessary surgical access routes and consequent scar tissue formation. These factors are even more important when the expected growth of the child, the need for pacing for several decades and the pacemaker system replacements are taken into account.

Therefore, further studies are indicated to identify the optimal single pacing site, and to assess whether biventricular pacing provides a hemodynamic benefit over optimal single site pacing in the juvenile patient.

\section{PACING SITE SELECTION}

Although QRS-duration has been proposed as a parameter for cardiac resynchronization therapy, ${ }^{2}$ several studies in animals, ${ }^{1,11,28}$ adults $^{29}$ and children ${ }^{33}$ have shown the lack of a correlation between decreased QRS-duration and 
increased cardiac function during ventricular pacing. Since QRS-duration reflects biventricular activation time, changes in determinants of cardiac function such as intraventricular synchrony ${ }^{19,26}$ and the sequence of activation ${ }^{1,11}$ are not necessarily translated into changes in the length of the QRS complex during pacing. Rather than using QRS-duration as a tool for the selection of optimal pacing sites, we suggest to test various ventricular pacing sites during implantation procedures. This testing procedure can be performed using (tissue Doppler) echocardiography to assess global LV function as well as inter-and intraventricular dyssynchrony. For various ventricular pacing sites it has been shown that the associated acute and chronic hemodynamic effects correlate well. ${ }^{10,12,25,29,34,36}$ The permanent lead(s) can therefore be implanted at the pacing site(s) that results in acute optimal LV pump function.

\section{CONCLUSION AND RATIONALE FOR PEDIATRIC PACING STUDIES}

Ventricular pacing causes electrical and contractile dyssynchrony and is associated with an acute and chronic decrease in LV function. Especially during chronic RV apex pacing, macroscopical and microscopical adaptations occur. This remodeling process can eventually lead to heart failure in a substantial number of juvenile patients. Animal studies have shown superior hemodynamic effects of LV pacing as compared with RV pacing. The aim of the studies in the first part of this thesis (chapters 3-5) is to evaluate the hemodynamic effects of acute and chronic pacing at LV sites in juvenile patients. In chapter 3 , we describe a series of children with structural heart defects undergoing cardiac surgery. In this intra-operative study, the hemodynamic effects of pacing at the RV, LV lateral wall and LV apex are compared. Considering the favorable effects of LV apex pacing on LV contractility, we decided to treat a girl with heart failure using $L V$ apex pacing. The chronic effect of LV apex pacing in this patient is described in the case-report in chapter 4 . In chapter 5 , a retrospective study in chronically paced children is presented. At the University Children's Hospital in Zurich, Switzerland, children are either paced at the LV lateral wall or the RV. However, the chronic effects of LV lateral wall pacing in children have never been described in the literature. In close collaboration with the Pediatric Cardiology department in Zurich, we compared the long-term hemodynamic effects of chronic pacing at the LV and RV in the study in chapter 5 . 


\section{Part II. Pacing-induced dyssynchrony, blessing for ischemic tolerance?}

\section{MYOCARDIAL PRECONDITIONING AND POSTCONDITIONING}

\section{Cardioprotective stimuli}

In 1986, Murry et al. have described that brief sublethal cardiac ischemia prior to sustained ischemia reduces infarct size. These investigators termed this phenomenon preconditioning. ${ }^{3}$ In the canine model used by Murry et al., a significant reduction in infarct size after forty minutes of ischemia occurs if the heart has previously been submitted to four five-minute periods of ischemia ${ }^{3}$ (figure 2.5).

Later on, ischemic preconditioning has also been shown to occur in other animal species such as rats, rabbits and pigs. ${ }^{37}$ Beside ischemia as a stimulus for preconditioning, ${ }^{37-42}$ other cardioprotective stimuli are known, such as heat shock, ${ }^{4,43-45}$ volume overload, ${ }^{5,6,46}$ increased afterload, ${ }^{7,8}$ rapid ventricular pacing ${ }^{47-49}$ and pharmacological intervention. ${ }^{50-53}$

Control group

Infarct \%

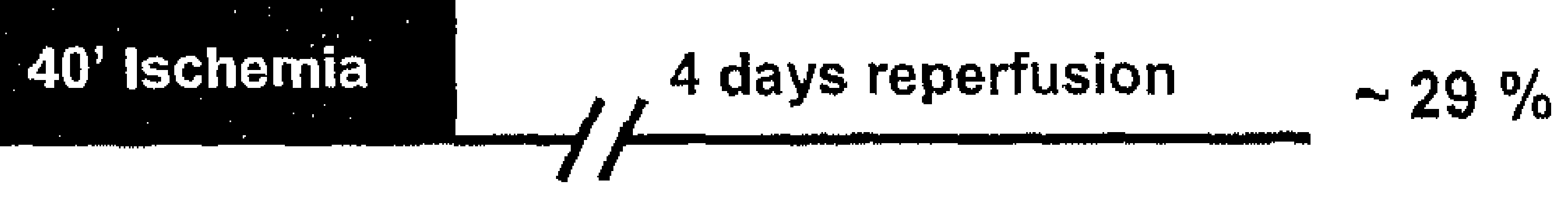

Ischemic preconditioning group

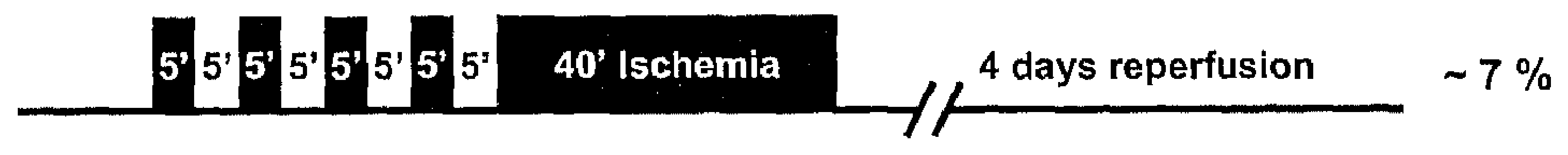

Figure 2.5 Preconditioning experiment in dogs, data from Murry et al. ${ }^{3}$ Infarct $\%$ expressed as per* centage of infarcted tissue within the area at risk.

Intriguingly, the protective effect of ischemic preconditioning is biphasic. The first window of protection is termed "classical preconditioning" or "early preconditioning" and lasts up to 4 hours to disappear subsequently. ${ }^{41,54,55}$ The protective effect of the same preconditioning stimulus that reappears 24 hours after the stimulus is termed the "second window of protection" (SWOP, delayed or late preconditioning) and lasts for 2-3 days. ${ }^{56}$

Despite the numerous reports showing the infarct-reducing effects of preconditioning in animal models, its application in clinical practice remains limited. 


\section{CHAPTER 2}

This is in large part due to the unexpectedness of most cardiac ischemic events. The attention for myocardial protection has received a new impulse by the recent discovery by Zhao et al. that brief intermittent ischemia during early reperfusion reduces infarct size to the same extent as ischemic preconditioning $^{57}$ (figure 2.6). This phenomenon is termed ischemic postconditioning, ${ }^{57,58}$ and has already been shown effective in other animal models. ${ }^{59-63}$ Also in humans with an acute myocardial infarction, cardioprotective effects of ischemic postconditioning have been shown, ${ }^{64,65}$ indicating the clinical potential of myocardial postconditioning.

\section{Control group}

Infarct \%

\section{0 ' Ischemia}

3 hours reperfusion $\sim 25 \%$

Ischemic preconditioning group

$10^{\prime}$

$60^{\prime}$ Ischemia

3 hours reperfusion $\sim 15 \%$

Ischemic postconditioning group

\section{0' Ischemia}

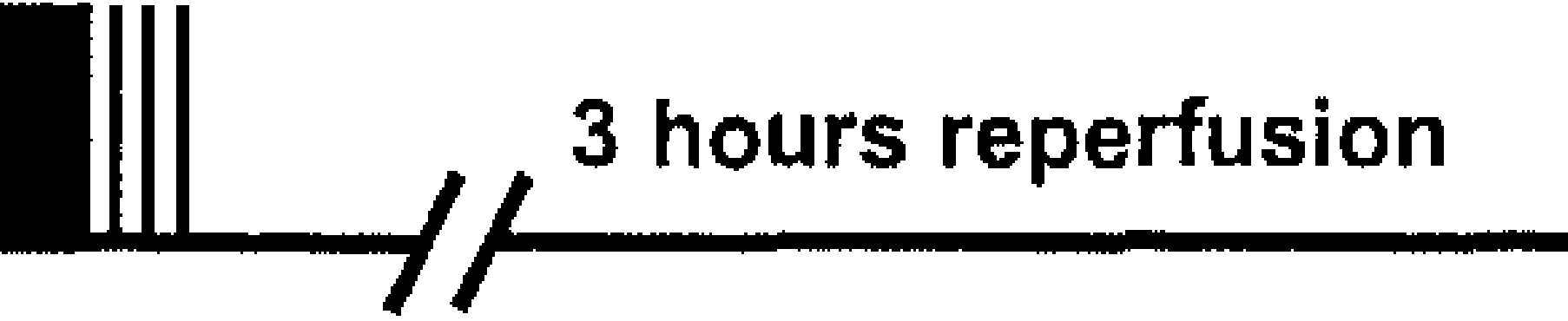
$\sim 14 \%$

Figure 2.6 Pre- and postconditioning experiment in dogs, data from Zhao et al. ${ }^{57}$ For legend see figure 2.5. Postconditioning consisted of $3 \times 30$ seconds of ischemia, interspersed with 30 seconds of reperfusion.

Some authors attributed the effect of ischemic postconditioning to "graded reperfusion" ${ }^{66}$ After all, more gradual reperfusion is a well known way to reduce infarct size considerably. ${ }^{67-69}$ However, non-ischemic postconditioning, like the administration of pharmacological agents during early reperfusion, is also cardioprotective. ${ }^{58,70,71}$

\section{Outcome measures of cardioprotective studies}

The pioneering studies of Murry et $a l^{3}$ and Zhao et al. ${ }^{57}$ have used myocardial infarct size as the primary outcome measure, and so have the vast majority of studies in this area. Beside the infarct-reducing effects of cardioprotective interventions, other end-points have also been assessed, such as the susceptibility to arrhythmias ${ }^{41}$ and the recovery of cardiac pump function. ${ }^{72}$ Further- 
more, studies in humans force investigators to use surrogate end-points such as ST-segment changes. ${ }^{41,73,74}$

Functional recovery after severe ischemia is determined by a combination of the amount of surviving myocardium and the degree to which it is stunned. Stunning refers to the temporary decrease in contractility after an ischemic event. ${ }^{41}$ Considering the transient nature of stunning, we estimate that loss of tissue is a more relevant outcome parameter with regards to long-term benefits of cardioprotective interventions. In studies on ischemic preconditioning ${ }^{38}$. ${ }^{72,75}$ and postconditioning, ${ }^{61,76}$ the difference between the infarct-reducing and the anti-stunning effect is well recognized. Therefore, a consensus has emerged that infarct size is a more reliable end-point of animal preconditioning studies than recovery of function. ${ }^{41,75}$

\section{Remote protection}

The protection afforded by ischemic preconditioning is not limited to myocardial regions that are subjected to the transient ischemia, but is also present in other regions of the heart. ${ }^{79}$ This phenomenon is termed "remote preconditioning". ${ }^{41}$ Remote preconditioning has been demonstrated by heating one part of the heart and observing protection at another part. ${ }^{43}$. Also, transfer of coronary effluent from a preconditioned to a recipient heart causes protection. ${ }^{80}$ Interestingly, the heart is also protected by preconditioning and postconditioning stimuli to other organs, such as creating limb ischemia ${ }^{81,82}$ and mesenteric artery occlusion. ${ }^{83}$ Remote cardioprotection is generally attributed to hormonal mediators (e.g. circulating endorphins ${ }^{41}$ or adenosine ${ }^{84}$ ) or the recruitment of a neural pathway. ${ }^{55}$ Support for the involvement of the latter comes from the observation that remote preconditioning can be abolished by ganglion blockade ${ }^{85,86}$ but the exact nature of the involved neural pathway has not been elucidated. The phenomenon of remote conditioning clearly indicates that the effects conferred by a protective stimulus are complicated, diverse and reach beyond the immediate surroundings of the stimulated tissue.

\section{SIGNAL TRANSDUCTION PATHWAYS OF CARDIOPROTECTION}

The various cardioprotective stimuli were shown to activate a complex molecular signaling cascade. Schematically, this cascade could be divided into 4 phases. ${ }^{87}$ The first phase comprises the triggers (metabolites and ligands) which are generated during the cardioprotective challenge. In the second phase, the activation of mediators (kinases and transcription factors) is involved. The third phase includes the effectors which confer the observed protection. Finally, the fourth phase comprises the beneficial end-effects of the 
upstream players of the signal transduction pathway. ${ }^{87}$ The following paragraphs contain some background information concerning the consecutive phases of the signal transduction pathways. For brevity, this background information focuses mainly on the players that might be involved in cardioprotection and cardiac pacing. For a wider perspective, excellent reviews have been published in recent years. ${ }^{41}$

\section{Triggers}

Biochemical cardioprotective triggers exert their action through binding to various receptors such as the $\mathrm{G}$ coupled protein receptor (adenosine, bradykinin, opioids) and the natriuretic peptide receptor-type A (NPR-A, receptor for brain natriuretic peptide (BNP)). Of the biochemical triggers, adenosine is best described in both preconditioning and postconditioning, ${ }^{87}$ and several adenosine receptors have been identified. ${ }^{88}$

Binding of BNP to the NPR-A results in an increase in intracellular cGMP levels, ${ }^{89}$ and the results of a study on the preconditioning effect of BNP are consistent with activation of the mitochondrial $\mathrm{K}_{\text {ATP }}^{+}$channel downstream in this cardioprotective signaling cascade..$^{90}$

\section{Mediators}

Following the activation of cardioprotective triggers, several mediators and transcription factors are activated and/or phosphorylated. These include protein kinase $C$, mitogen-activated kinases (MAPK family comprising p38, extracellular signal-regulated kinase (ERK1/2), C-Jun-N-terminal kinase (JNK) and big MAPK), nitric oxide synthases (NOS), p70S6K and the protein tyrosine kinases. ${ }^{41,87,91}$ The important role of the reperfusion injury survival kinases (RISK, comprising ERK1/2, phosphatidyl-inositol-3 kinase (PI3K) and Akt) has been demonstrated over the last few years. ${ }^{42,61,92,93}$ These kinases have been shown to couple to downstream effectors ${ }^{87}$ (figure 2.7). Although the mediators involved in cardioprotective signal transduction are progressively being identified, the regulatory mechanisms of these mediators have not been elucidated. It appears that interaction between different mediators exists, but at present the "cross-talk" between mediators is only partially known. ${ }^{94}$

\section{Effectors}

The exact nature of the effectors has not been elucidated yet, but next to nitric oxide synthases (NOS) the mitochondria certainly appear to be important players downstream in the cardioprotective signaling cascade. The crucial contribution of the mitochondria to the establishment of cardioprotection is demonstrated by the role of the mitochondrial $\mathrm{K}_{\text {ATP }}^{+}$channel and the mito- 
chondrial permeability transition pore (mPTP). Both appear to be located downstream of the RISK pathway. ${ }^{87}$

Mitochondrial $\mathrm{K}_{\text {ATP }}^{+}$channels possibly mediate the inhibition of MPTP opening. ${ }^{96}$ Opening of the MPTP in the inner mitochondrial membrane results in the collapse of the membrane potential and the release of pro-apoptotic and cytotoxic factors that may lead to apoptosis or necrosis. ${ }^{60}$ Currently, opening of the mPTP is considered a pivotal event in cardiomyocyte death after ischemia. ${ }^{95}$

\section{End-effects}

The outcome of cardioprotective interventions and their anti-apoptotic and antinecrotic effects has been expressed as the reduction of infarct size, as well as by improved recovery of function and by the decline in the incidence of arrhythmias (see above).

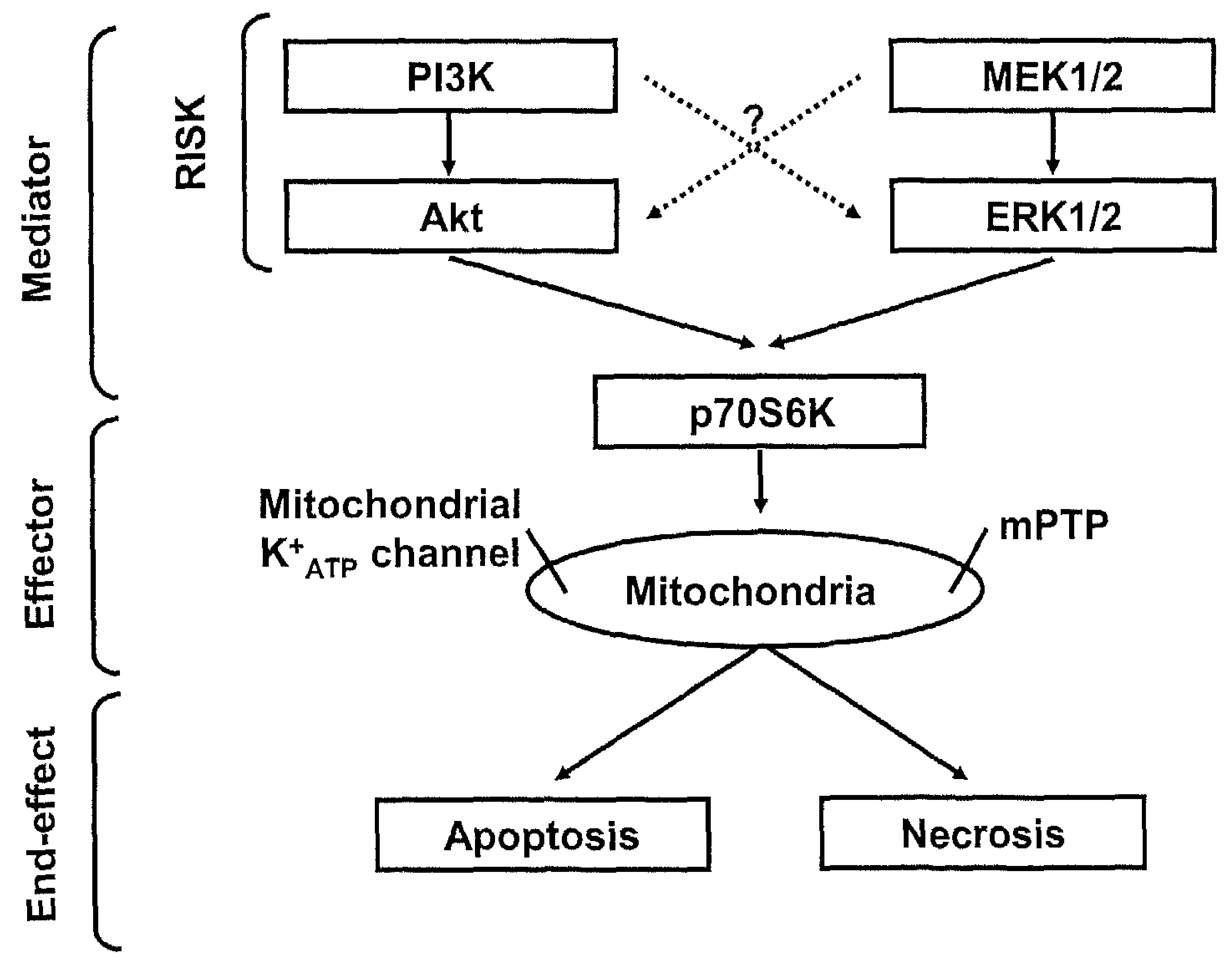

Figure 2.7 Simplified scheme illustrating the possible interaction between the reperfusion injury survival kinase (RISK) pathway, mitochondrial permeability transition pore (MPTP) and mitochondrial $\mathrm{K}_{\text {ATP }}^{+}$channel. 


\section{CARDIOPROTECTIVE POTENCY OF VENTRICULAR PACING?}

Our group has abundantly demonstrated that ventricular pacing creates abnormal regional stretch and contraction patterns in the LV. ${ }^{1,}{ }^{18}$ The above survey of the literature indicates that, among others, increased global stretch ${ }^{5,6}$ and afterload ${ }^{7.8}$ can precondition the heart. Therefore, we hypothesized that pacing-induced dyssynchrony is cardioprotective against ischemia / reperfusion injury. Interestingly, myocardial stretch ${ }^{97,98}$ and dyssynchrony ${ }^{99}$ are known to activate kinases such as ERK1/2, big MAPK and p38. These mediators have also been shown to be involved in hypertrophy ${ }^{97}$ and cardioprotection against ischemia / reperfusion injury. ${ }^{41,42,61,100,101}$ Furthermore, stretch induces the release and production of $\mathrm{BNP},{ }^{102}$ and administration of BNP induces preconditioning. ${ }^{90}$

It is well known that rapid ventricular pacing can precondition the heart, but this effect has generally been attributed to ischemia during tachycardia. However, a study by Koning et al. shows that rapid ventricular pacing also induces preconditioning in the absence of ischemia during rapid pacing. ${ }^{49}$ Interestingly, rapid atrial pacing did not result in a cardioprotective effect, ${ }^{103}$ providing support for the hypothesis that ventricular dyssynchrony rather than tachycardia protects the heart against ischemia / reperfusion injury.

\section{EXPERIMENTAL APPROACH}

Preconditioning and postconditioning studies have been performed in various animal species such as mice, rats, rabbits, pigs and dogs as well as in humans. Several studies clearly show that these animal models are adequate to study cardiac pre- and postconditioning effects and that these effects are not limited to a single species. Furthermore, cardioprotection is induced in isolated cardiomyocytes, isolated hearts as well as in hearts in vivo. In order to test our hypothesis that intermittent pacing-induced dyssynchrony protects the heart from ischemia / reperfusion injury, we selected the isolated ejecting rabbit heart model for our studies. The reasons for choosing this set-up are discussed below.

\section{Choice of our animal models to study cardioprotection}

The main advantage of the isolated heart set-up was that it permitted adequate control of several variables that are known cardioprotective triggers. These variables included heart rate, ${ }^{47-49}$ myocardial preload, ${ }^{5,6,46}$ afterload ${ }^{7,8}$ and temperature. ${ }^{4,43}$ Meticulous control of temperature is very important, since both hyperthermia ${ }^{104}$ and hypothermia ${ }^{105,106}$ are known to influence in- 
farct size. Furthermore, we wanted to assess whether a dyssynchrony-induced preconditioning effect, if any, would be limited to the stretched LV region or also extended to remote LV regions. In order to study this, we needed a global ischemia model, and this implied that the study had to be performed in isolated hearts. In isolated rabbit hearts, both global and regional ischemia can be created. Global ischemia is created by complete occlusion of the aorta and left atrial cannula. It is important to realize that the coronary arteries in rabbits are embedded in the epicardium, and can therefore not easily be exposed to snares or vascular clamps. In our set-up, regional ischemia is created by encircling the lateral descending coronary artery using a suture (figure 2.8). Within the loop at the epicardial surface, a deflated angioplasty balloon is positioned. Inflating the balloon reversibly occludes the coronary artery. Global ischemia was used in the experiments in chapter 6 , whereas the hearts in chapter 7 were subjected to regional ischemia.

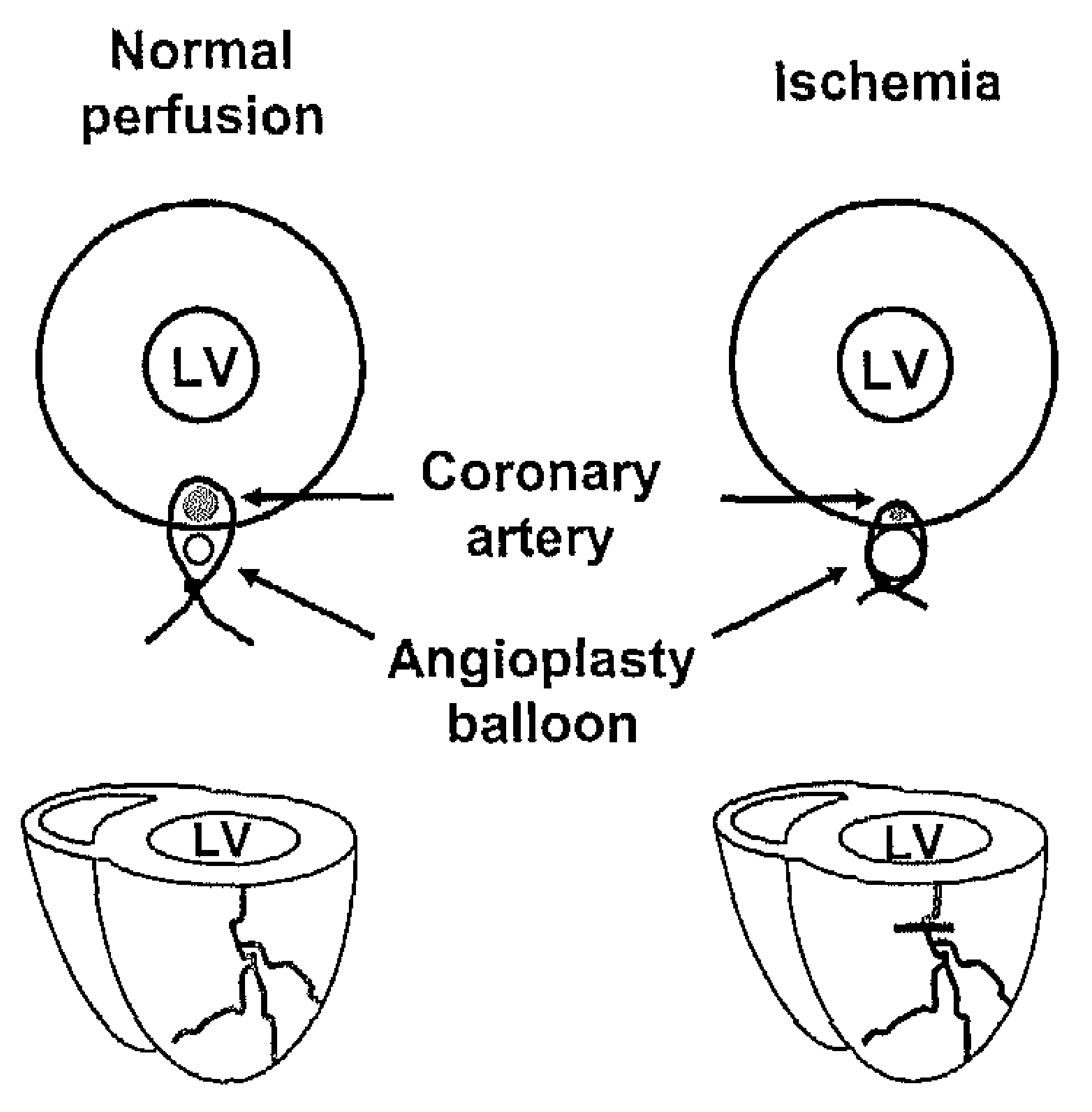

Figure 2.8 Schematic representation of the method used to create regional ischemia in isolated rabbit hearts. $L V=$ left ventricle.

Candidates for isolated heart experiments were animals of the size ranging from mice to rabbits. Beside the determination of infarct size in our studies, we also wanted to quantify the changes in myocardial stretch and contraction during ventricular pacing using epicardially implanted sonomicrometer crystals. This led to the choice for the rabbit heart, because the size of the heart of the smaller species would complicate the measurement of this parameter using our equipment. The studies were performed in ejecting hearts since myocardial contraction leads to shortening in this setting. In the isolated ejecting rabbit 
heart, it is therefore feasible that ventricular pacing leads to abnormal LV stretch and contraction which we hypothesize to be the stimulus for protection. A schematic overview and photographs of the isolated rabbit heart set-up and the performed measurements are presented in figures 2.9-2.11. We also wanted to translate our findings from isolated rabbit hearts to another species in the in vivo situation. For that reason, dyssynchrony-induced postconditioning was also studied in a small series of anesthetized pigs (chapter 7 ).

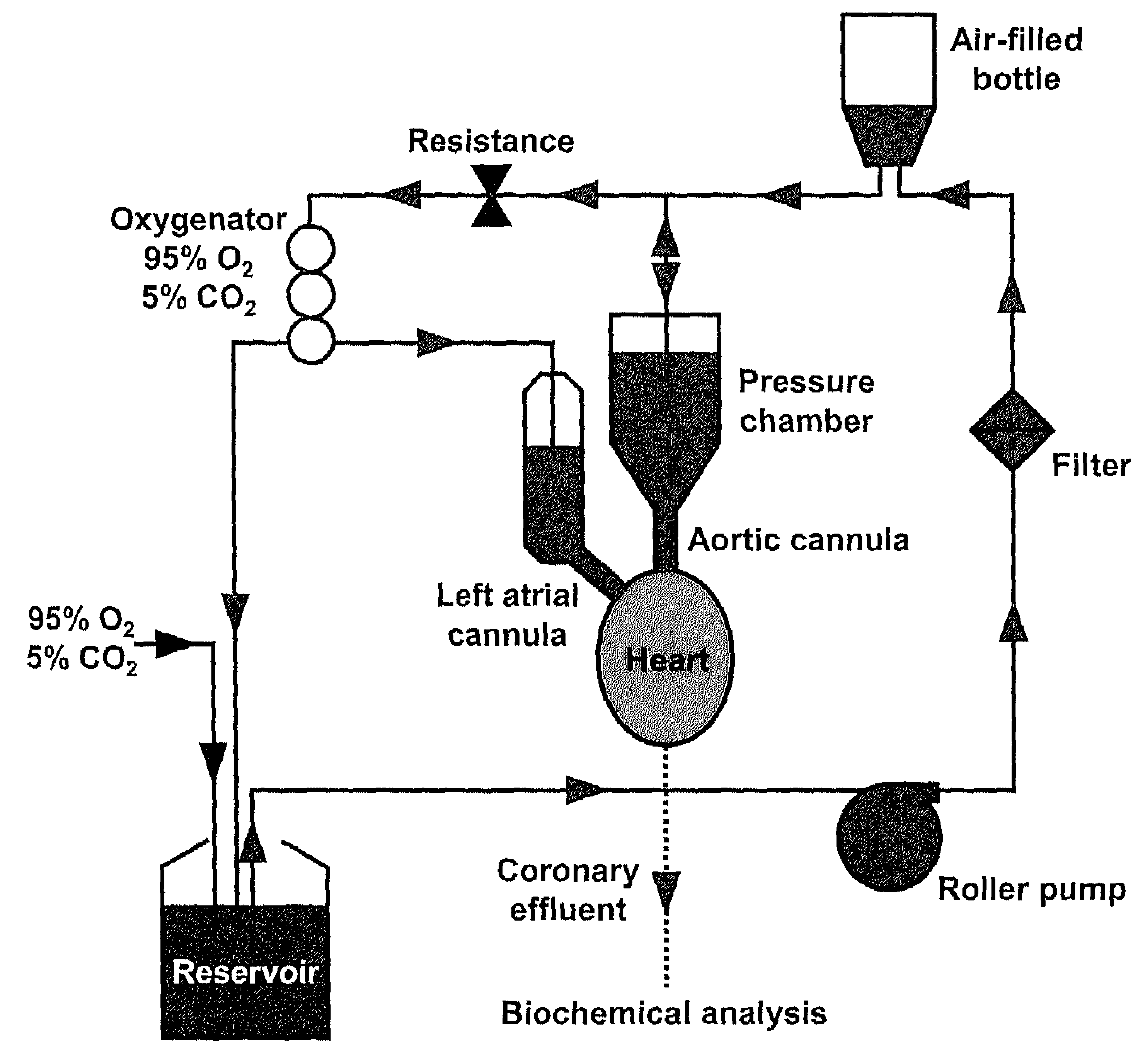

Figure 2.9 Schematic overview of the isolated ejecting heart set-up. The perfusion buffer (indicated in blue) is pumped from a reservoir into the system by a roller pump and subsequently passes through a filter. The passage through an air-filled bottle attenuates the pulses generated by the roller pump. The left atrium is cannulated to allow antegrade perfusion of the heart. In this working mode, the heart provides its own coronary perfusion by ejecting the perfusion buffer into the aorta. Left atrial filling pressure can be adjusted by varying the height of the fluid column above the left atrial cannula. By means of adjusting the resistance, aortic pressure is regulated. To measure aortic pressure, a pressure transducer is connected to the aortic cannula close to the heart. LV pressure is assessed by a pressure transducer connected to a plastic cannula in the LV. Aortic flow is assessed by means of a flow-probe. Cardiac output is calculated as the sum of aortic and coronary flow. Arrows indicate the direction of perfusate flow. 

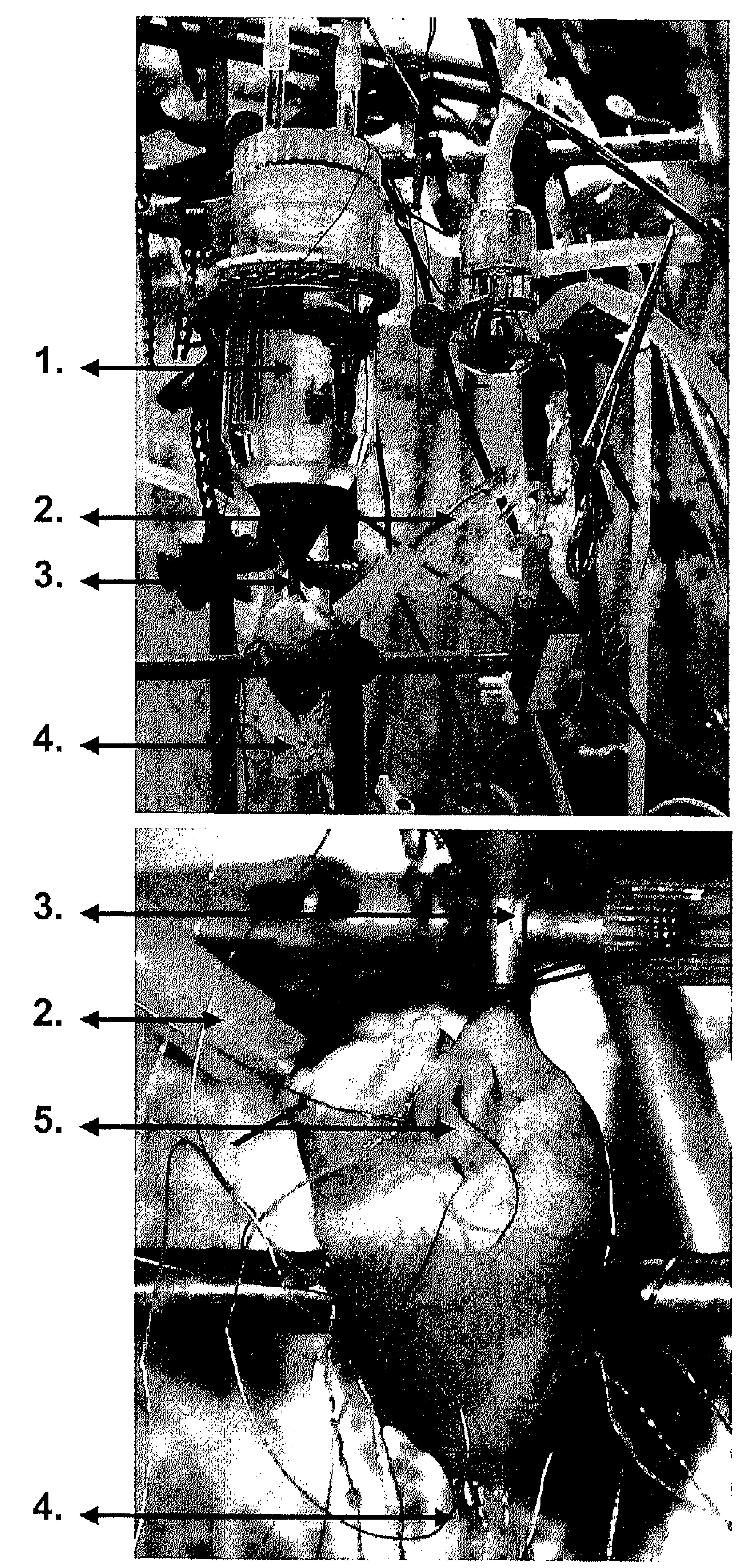

Figure 2.10 Isolated rabbit heart perfusion set-up. $1=$ pressure chamber, $2=$ left atrial cannula, $3=$ aortic cannula, $4=$ left ventricular pressure catheter, $5=$ right atrial pacing electrodes. 
Control

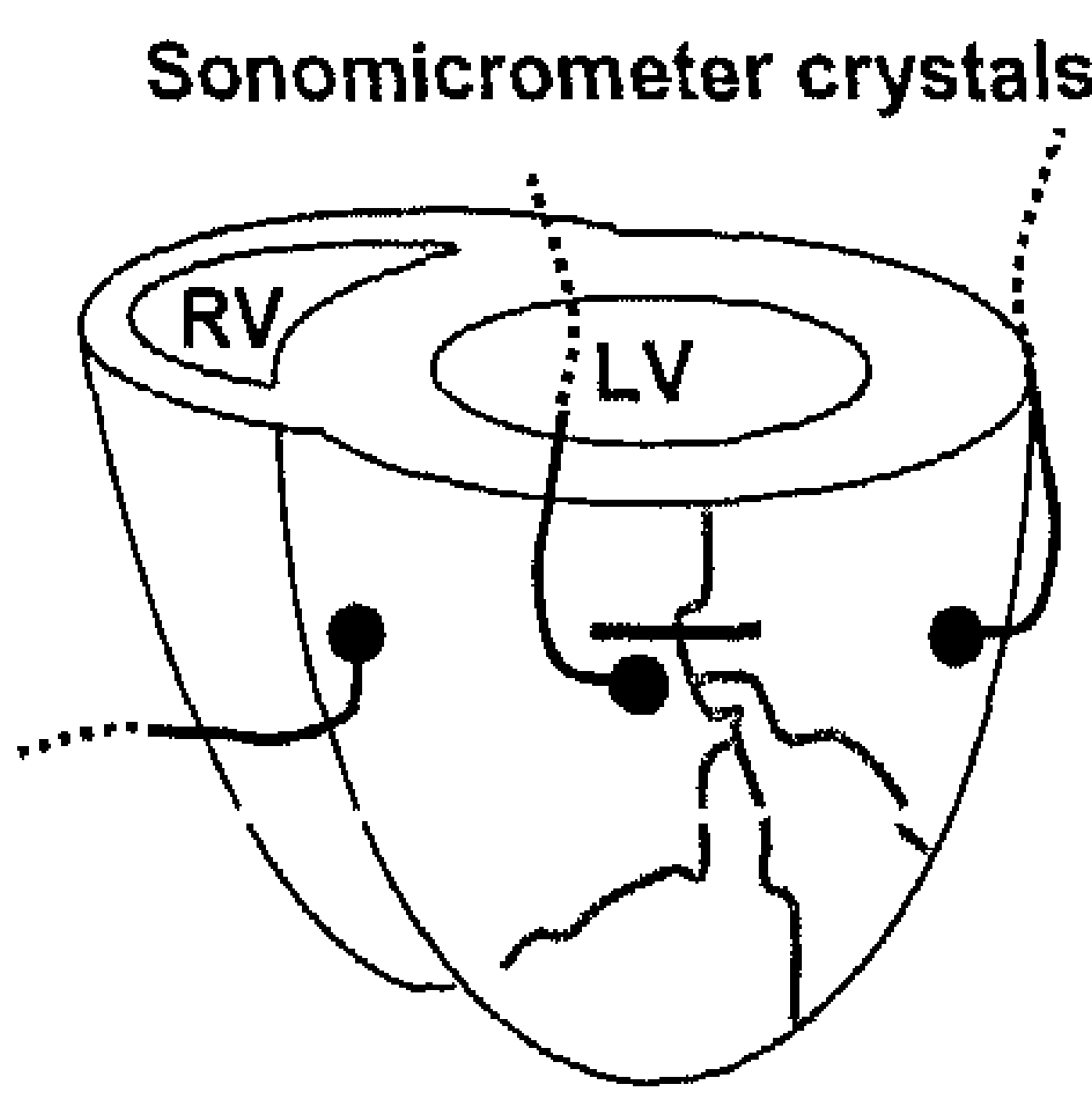

Posterior

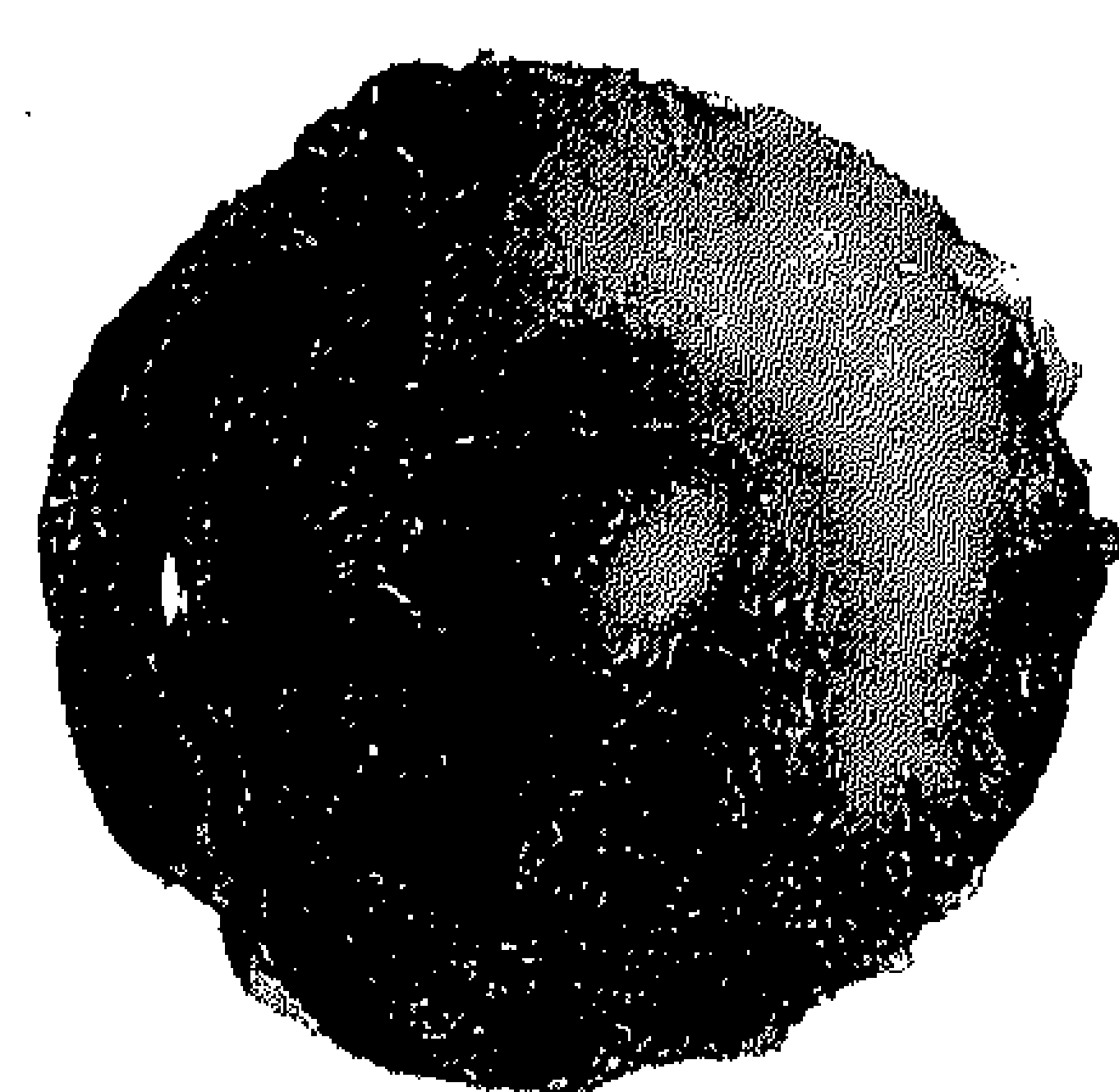

Anterior
Protected

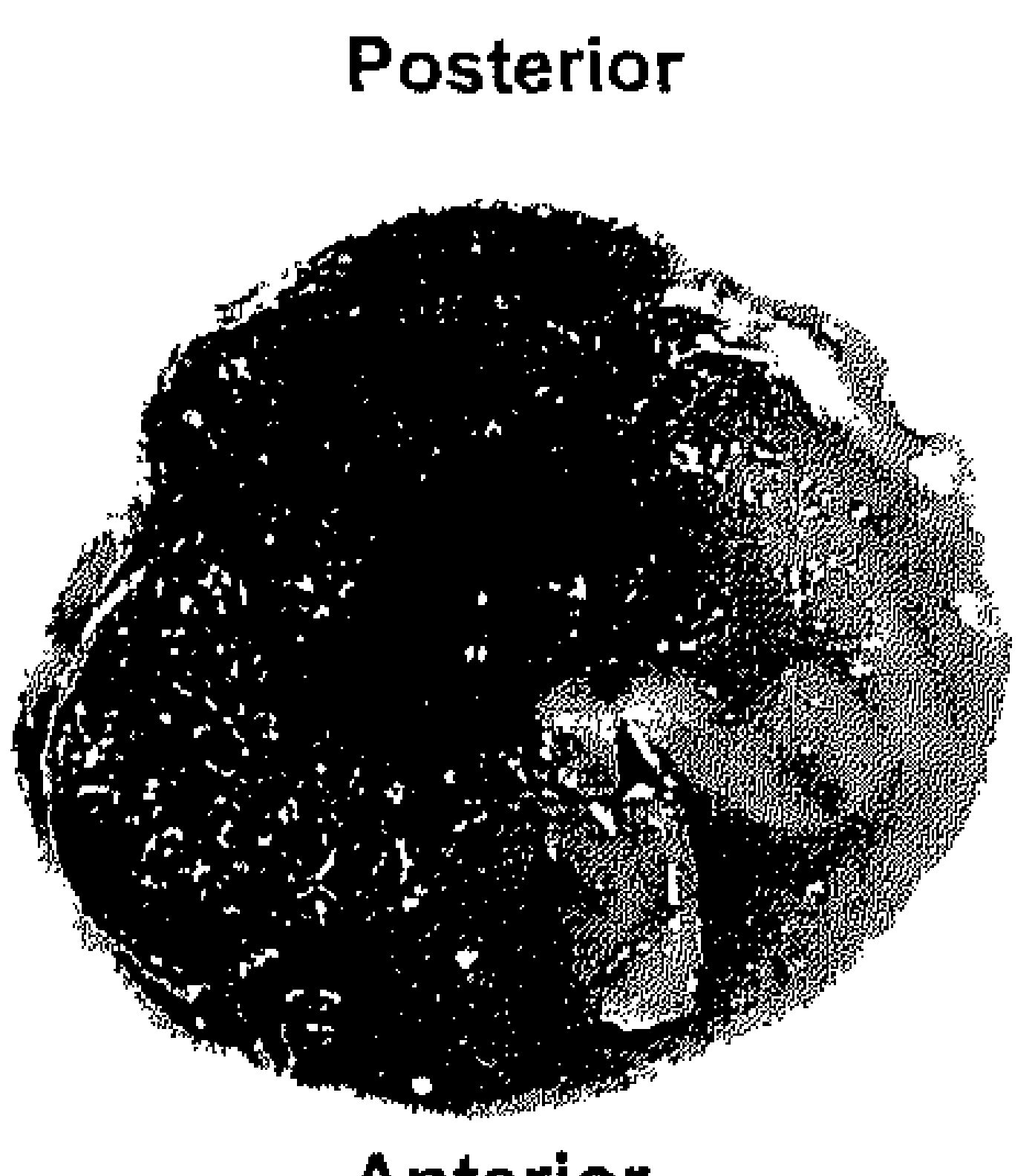

Anterior

Figure 2.11 Schematic representation of the placement of sonomicrometer crystals (left panel) and infarct size assessment (right panel). Four ultrasound crystals are implanted epicardially at $1 \mathrm{~cm}$ distances at the anterior, anterolateral, posterolateral and posterior left ventricular (LV) wall, approximately $1 \mathrm{~cm}$ below the base of the heart. Sonomicrometry is used to assess regional alterations in myocardial stretch and shortening. The area of the pressure - segment loop is calculated as a measure of regional segment work. Furthermore, end-diastolic segment length is derived from the pressure - segment length loop to quantify regional stretch. The black line indicates the level of coronary artery occlusion. The dashed line indicates the LV cross-sectional level of the representative examples from a control and a protected heart in the regional ischemia model. Infarct size, the primary outcome measure of our studies, is measured after staining with triphenyltetrazolium chloride (TTC) to differentiate viable from infarcted tissue. ${ }^{107}$ In hearts subjected to regional ischemia, staining using blue dye is performed to demarcate the area at risk. Infarct size is quantified by digital planimetry in all hearts. Blue staining $=$ area not at risk for infarction, red staining $=$ viable tissue within the area at risk, unstained (white) area $=$ infarcted myocardium, $R V=$ right ventricle.

\section{REFERENCES}

1. Prinzen FW, Peschar M. Relation between the pacing induced sequence of activation and left ventricular pump function in animals. Pacing Clin Electrophysiol 2002; 25:484-498.

2. Karpawich PP. Chronic right ventricular pacing and cardiac performance: the pediatric perspective. Pacing Clin Electrophysiol 2004; 27:844-849.

3. Murry CE, Jennings RB, Reimer KA. Preconditioning with ischemia: a delay of lethal cell injury in ischemic myocardium. Circulation 1986; 74:1124-1136.

4. Cornelussen R, Spiering W, Webers JH, De Bruin LG, Reneman RS, van der Vusse GJ, Snoeckx LH. Heat shock improves ischemic tolerance of hypertrophied rat hearts. Am J Physiol 1994; 267:H1941-1947.

5. Ovize M, Kloner RA, Przyklenk K. Stretch preconditions canine myocardium. Am J Physiol 1994; 266:H137-146.

6. Gysembergh A, Margonari H, Loufoua J, Ovize A, Andre-Fouet $X$, Minaire $Y$, Ovize M. Stretchinduced protection shares a common mechanism with ischemic preconditioning in rabbit heart. $\mathrm{Am} \mathrm{J}$ Physiol 1998; 274:H955-964. 
7. Huang $\mathrm{CH}$, Wang JS, Chiang SC, Wang YY, Lai ST, Weng ZC. Brief pressure overload of the left ventricle preconditions rabbit myocardium against infarction. Ann Thorac Surg 2004; 78:628-633.

8. lliodromitis EK, Gaitanaki C, Lazou A, Bofilis E, Karavolias GK, Beis I, Kremastinos DT. Dissociation of stress-activated protein kinase (p38-MAPK and JNKs) phosphorylation from the protective effect of preconditioning in vivo. J Mol Cell Cardiol 2002; 34:1019-1028.

9. de Cock CC, Giudici MC, Twisk JW. Comparison of the haemodynamic effects of right ventricular outflow-tract pacing with right ventricular apex pacing: a quantitative review. Europace 2003; 5:275278.

10. Karpawich PP, Mital S. Comparative left ventricular function following atrial, septal, and apical single chamber heart pacing in the young. Pacing Clin Electrophysiol 1997; 20:1983-1988.

11. Prinzen FW, Van Oosterhout MF, Vanagt WY, Storm C, Reneman RS. Optimization of ventricular function by improving the activation sequence during ventricular pacing. Pacing Clin Electrophysiol 1998; 21:2256-2260.

12. Tantengco MV, Thomas RL, Karpawich PP. Left ventricular dysfunction after long-term right ventricular apical pacing in the young. J Am Coll Cardiol 2001; 37:2093-2100.

13. Thambo JB, Bordachar P, Garrigue S, Lafitte $S$, Sanders $P$, Reuter $S$, Girardot R, et al. Detrimental ventricular remodeling in patients with congenital complete heart block and chronic right ventricular apical pacing. Circulation 2004; 110;3766-3772.

14. Manolis AS. The deleterious consequences of right ventricular apical pacing: time to seek alternate site pacing. Pacing Clin Electrophysiol 2006; 29:298-315.

15. Moak JP, Hasbani K, Ramwell C, Freedenberg V, Berger JT, DiRusso G, Callahan P. Dilated cardiomyopathy following right ventricular pacing for $A V$ block in young patients: resolution after upgrading to biventricular pacing systems. J Cardiovasc Electrophysiol 2006; 17:1068-1071.

16. Kim JJ, Friedman RA, Eidem BW, Cannon BC, Arora G, Smith EO, Fenrich AL, et al. Ventricular function and long-term pacing in children with congenital complete atrioventricular block. J Cardiovasc Electrophysiol 2007; 18:373-377.

17. Vatasescu R, Shalganov T, Paprika D, Kornyei L, Prodan Z, Bodor G, Szatmari A, et al. Evolution of left ventricular function in paediatric patients with permanent right ventricular pacing for isolated congenital heart block: a medium term follow-up. Europace 2007; 9:228-232.

18. Prinzen FW, Hunter WC, Wyman BT, McVeigh ER. Mapping of regional myocardial strain and work during ventricular pacing: experimental study using magnetic resonance imaging tagging. J Am Coll Cardiol 1999; 33:1735-1742.

19. Wyman BT, Hunter WC, Prinzen FW, Faris OP, McVeigh ER. Effects of single- and biventricular pacing on temporal and spatial dynamics of ventricular contraction. Am J Physiol Heart Circ Physio 2002; 282:H372-379.

20. van Oosterhout MF, Prinzen FW, Arts T, Schreuder JJ, Vanagt WY, Cleutjens JP, Reneman RS Asynchronous electrical activation induces asymmetrical hypertrophy of the left ventricular wall. Circulation 1998; 98:588-595.

21. Karpawich PP, Rabah R, Haas JE. Altered cardiac histology following apical right ventricular pacing in patients with congenital atrioventricular block. Pacing Clin Electrophysiol 1999; 22:1372-1377.

22. Karpawich PP, Justice $C D$, Cavitt $D L$, Chang $C H$. Developmental sequelae of fixed-rate ventricular pacing in the immature canine heart: an electrophysiologic, hemodynamic, and histopathologic evaluation. Am Heart J 1990; 119:1077-1083.

23. Deshmukh $P$, Casavant $D A$, Romanyshyn $M$, Anderson $K$. Permanent, direct His-bundle pacing: a novel approach to cardiac pacing in patients with normal His-Purkinje activation. Circulation 2000; 101:869-877.

24. Deshmukh PM, Romanyshyn M. Direct His-bundle pacing: present and future. Pacing Clin Electrophysiol 2004; $27: 862-870$.

25. Janousek J, Vojtovic P, Hucin B, Tlaskal T, Gebauer RA, Gebauer R, Matejka T, et al. Resynchronization pacing is a useful adjunct to the management of acute heart failure after surgery for congenital heart defects. Am J Cardiol 2001; 88:145-152. 
Ghates

26. Verbeek XA, Vernooy K, Peschar M, Cornelussen RN, Prinzen FW. Intra-ventricular resynchronization for optimal left ventricular function during pacing in experimental left bundle branch block. J Am Coll Cardiol 2003; 42:558-567.

27. Vernooy K, Verbeek XA, Cornelussen RN, Dijkman B, Crijns HJ, Arts T, Prinzen FW. Calculation of effective $\mathrm{W}$ interval facilitates optimization of $\mathrm{AV}$ delay and $\mathrm{W}$ interval in cardiac resynchronization therapy. Heart Rhythm 2007; 4:75-82.

28. Peschar $M$, de Swart $H$, Michels KJ, Reneman RS, Prinzen FW. Left ventricular septal and apex pacing for optimal pump function in canine hearts. J Am Coll Cardiol 2003; 41:1218-1226.

29. Blanc JJ, Etienne Y, Gilard M, Mansourati J, Munier S, Boschat J, Benditt DG, et al. Evaluation of different ventricular pacing sites in patients with severe heart failure: results of an acute hemodynamic study. Circulation 1997; 96:3273-3277.

30. Puggioni $E$, Brignole $M$, Gammage $M$, Soldati $E$, Bongiorni $M G$, Simantirakis $E N$, Vardas $P$, et al. Acute comparative effect of right and left ventricular pacing in patients with permanent atrial fibrillation. J Am Coll Cardiol 2004; 43:234-238.

31. Quintana M, Saha S, Rohani M, del Furia F, Roumina MS, Lind B, Hayashi S, et al. Electromechanical coupling, uncoupling, and ventricular function in patients with bundle branch block: a tissueDoppler echocardiographic study. Echocardiography 2004; 21:687-698.

32. Niu HX, Hua W, Zhang $S$, Sun $X$, Wang FZ, Chen KP, Wang $H$, et al. Assessment of cardiac function and synchronicity in subjects with isolated bundle branch block using Doppler imaging. Chin Med J (Engl) 2006; 119:795-800.

33. Zimmerman FJ, Starr JP, Koenig PR, Smith P, Hijazi ZM, Bacha EA. Acute hemodynamic benefit of multisite ventricular pacing after congenital heart surgery. Ann Thorac Surg 2003; 75:1775-1780.

34. Dubin AM, Janousek J, Rhee E, Strieper MJ, Cecchin F, Law IH, Shannon KM, et al. Resynchronization therapy in pediatric and congenital heart disease patients: an international multicenter study. J Am Coll Cardiol 2005; 46:2277-2283.

35. Rodriguez-Cruz E, Karpawich PP, Lieberman RA, Tantengco MV. Biventricular pacing as alternative therapy for dilated cardiomyopathy associated with congenital heart disease. Pacing Clin Electrophysiol 2001; 24:235-237.

36. Touiza A, Etienne $Y$, Gilard M, Fatemi M, Mansourati J, Blanc JJ. Long-term left ventricular pacing: assessment and comparison with biventricular pacing in patients with severe congestive heart failure. J Am Coll Cardiol 2001; 38:1966-1970

37. Cohen MV, Baines CP, Downey JM. Ischemic preconditioning: from adenosine receptor of KATP channel. Annu Rev Physiol 2000; 62:79-109.

38. Jenkins DP, Pugsley WB, Yellon DM. ischaemic preconditioning in a model of global ischaemia: infarct size limitation, but no reduction of stunning. J Mol Cell Cardiol 1995; 27:1623-1632.

39. Simkhovich BZ, Przyklenk $K$, Kloner RA. Role of protein kinase $C$ as a cellular mediator of ischemic preconditioning: a critical review. Cardiovasc Res 1998; 40:9-22.

40. Kloner RA, Jennings RB. Consequences of brief ischemia: stunning, preconditioning, and their clinical implications: part 2. Circulation 2001; 104:3158-3167.

41. Yellon DM, Downey JM. Preconditioning the myocardium: from cellular physiology to clinical cardiology. Physiol Rev 2003; 83:1113-1151.

42. Hausenloy DJ, Tsang A, Mocanu MM, Yellon DM. Ischemic preconditioning protects by activating prosurvival kinases at reperfusion. Am J Physiol Heart Circ Physiol 2005; 288:H971-976.

43. Gowda A, Yang CJ, Asimakis GK, Ruef J, Rastegar S, Runge MS, Motamedi M. Cardioprotection by local heating: improved myocardial salvage after ischemia and reperfusion. Ann Thorac Surg 1998, 65:1241-1247.

44. Cornelussen RN, Garnier AV, Vork MM, Geurten P, Reneman RS, van der Vusse GJ, Snoeckx LH. Heat stress protects aged hypertrophied and nonhypertrophied rat hearts against ischemic damage. Am J Physiol 1997; 273:H1333-1341.

45. Latchman DS. Heat shock proteins and cardiac protection. Cardiovasc Res 2001; 51:637-646.

46. Obadia JF, Ovize M, Maupoil V, Terrand J, Abadie C, Ovize A, Andre-Fouet $X$, et al. Beneficial actions of preconditioning and stretch on postischemic contractile function of isolated working rat heart: effects of staurosporine. J Cardiovasc Pharmacol 1997; 30:191-196. 
47. Vegh A, Szekeres L, Parratt JR. Transient ischaemia induced by rapid cardiac pacing results in myocardial preconditioning. Cardiovasc Res 1991; 25:1051-1053.

48. Szilvassy $Z$, Ferdinandy $P$, Bor $P$, Jakab I, Lonovics J, Koltai M. Ventricular overdrive pacinginduced anti-ischemic effect: a conscious rabbit model of preconditioning. Am J Physiol 1994; 266:H2033-2041.

49. Koning MM, Gho BC, van Klaarwater E, Opstal RL, Duncker DJ, Verdouw PD. Rapid ventricular pacing produces myocardial protection by nonischemic activation of KATP+ channels. Circulation 1996; 93:178-186.

50. Piriou V, Chiari P, Lhuillier F, Bastien O, Loufoua J, Raisky O, David JS, et al. Pharmacological preconditioning: comparison of desflurane, sevoflurane, isoflurane and halothane in rabbit myocardium. $\mathrm{Br} J$ Anaesth 2002; 89:486-491.

51. Piriou V, Chiari $P$, Knezynski S, Bastien O, Loufoua J, Lehot JJ, Foex $P$, et al. Prevention of isoflurane-induced preconditioning by 5-hydroxydecanoate and gadolinium: possible involvement of mitochondrial adenosine triphosphate-sensitive potassium and stretch-activated channels. Anesthesiology 2000; 93:756-764.

52. Ockaili R, Salloum F, Hawkins J, Kukreja RC. Sildenafil (Viagra) induces powerful cardioprotective effect via opening of mitochondrial K(ATP) channels in rabbits. Am J Physiol Heart Circ Physio 2002; 283:H1263-1269.

53. Otani $H$, Okada $T$, Fujiwara $H$, Uchiyama $T$, Sumida $T$, Kido $M$, Imamura $H$. Combined pharmacological preconditioning with a G-protein-coupled receptor agonist, a mitochondrial KATP channe opener and a nitric oxide donor mimics ischaemic preconditioning. Clin Exp Pharmacol Physiol 2003; 30:684-693.

54. Baxter GF, Ferdinandy P. Delayed preconditioning of myocardium: current perspectives. Basic Res Cardiol 2001; 96:329-344.

55. Hausenloy DJ, Yellon DM. The evolving story of "conditioning" to protect against acute myocardial ischaemia-reperfusion injury. Heart 2007; 93:649-651.

56. Cornelussen RN, Vanagt WY, Prinzen FW, Snoeckx LH. Proteins involved in salvage of the myocardium. Adv Exp Med Biol 2003; 543:277-291.

57. Zhao ZQ, Corvera JS, Halkos ME, Kerendi F, Wang NP, Guyton RA, Vinten-Johansen J. Inhibition of myocardial injury by ischemic postconditioning during reperfusion: comparison with ischemic preconditioning. Am J Physiol Heart Circ Physiol 2003; 285:H579-588.

58. Vinten-Johansen J, Yellon DM, Opie LH. Postconditioning: a simple, clinically applicable procedure to improve revascularization in acute myocardial infarction. Circulation 2005; 112:2085-2088.

59. Tsang A, Hausenloy DJ, Mocanu MM, Yellon DM. Postconditioning: a form of "modified reperfusion" protects the myocardium by activating the phosphatidylinositol 3-kinase-Akt pathway. Circ Res 2004; 95:230-232.

60. Argaud L, Gateau-Roesch O, Raisky O, Loufouat J, Robert D, Ovize M. Postconditioning inhibits mitochondrial permeability transition. Circulation 2005; 111:194-197.

61. Darling $C E$, Jiang $R$, Maynard M, Whittaker P, Vinten-Johansen J, Przyklenk K. Postconditioning via stuttering reperfusion limits myocardial infarct size in rabbit hearts: role of ERK1/2. Am J Physiol Heart Circ Physiol 2005; 289:H1618-1626.

62. Yang $X M$, Proctor JB, Cui L, Krieg T, Downey JM, Cohen MV. Multiple, brief coronary occlusions during early reperfusion protect rabbit hearts by targeting cell signaling pathways. J Am Coll Cardiol 2004; 44:1103-1110.

63. Zhu M, Feng J, Lucchinetti E, Fischer G, Xu L, Pedrazzini T, Schaub MC, et al. Ischemic postconditioning protects remodeled myocardium via the PI3K-PKB/Akt reperfusion injury salvage kinase pathway. Cardiovasc Res 2006; 72:152-162.

64. Staat P, Rioufol G, Piot C, Cottin Y, Cung TT, L'Huillier I, Aupetit JF, et al. Postconditioning the human heart. Circulation 2005; 112:2143-2148.

65. Darling CE, Solari PB, Smith CS, Furman MI, Przyklenk K. 'Postconditioning' the human heart: Multiple balloon inflations during primary angioplasty may confer cardioprotection. Basic Res Cardiol 2007; 102:274-278.

66. Heusch G. Postconditioning: old wine in a new bottle? J Am Coll Cardiol 2004; 44:1111-1112. 
67. Okamoto F, Allen BS, Buckberg GD, Bugyi $H$, Leaf J. Reperfusion conditions: importance of ensuring gentle versus sudden reperfusion during relief of coronary occlusion. J Thorac Cardiovasc Surg 1986; 92:613-620.

68. Mrak RE, Carry MM, Murphy ML, Peng CF, Straub KD. Reperfusion injury in ischemic myocardium: protective effect of controlled reperfusion. Am J Cardiovasc Pathol 1990; 3:217-224.

69. Bopassa JC, Ferrera R, Gateau-Roesch O, Couture-Lepetit E, Ovize M. PI 3-kinase regulates the mitochondrial transition pore in controlled reperfusion and postconditioning. Cardiovasc Res 2006; 69: $178-185$.

70. Chiari PC, Bienengraeber MW, Pagel PS, Krolikowski JG, Kersten JR, Warltier DC. Isoflurane protects against myocardial infarction during early reperfusion by activation of phosphatidylinositol-3kinase signal transduction: evidence for anesthetic-induced postconditioning in rabbits. Anesthesiology 2005; 102:102-109.

71. Weihrauch D, Krolikowski JG, Bienengraeber M, Kersten JR, Warltier DC, Pagel PS. Morphine enhances isoflurane-induced postconditioning against myocardial infarction: the role of phosphatidylinositol-3-kinase and opioid receptors in rabbits. Anesth Analg 2005; 101:942-949, table of contents.

72. Cohen MV, Yang XM, Downey JM. Smaller infarct after preconditioning does not predict extent of early functional improvement of reperfused heart. Am J Physiol 1999; 277:H1754-1761.

73. Kyriakides ZS, Psychari S, lliodromitis EK, Kolettis TM, Sbarouni E, Kremastinos DT. Hyperlipidemia prevents the expected reduction of myocardial ischemia on repeated balloon inflations during angioplasty. Chest 2002; 121:1211-1215.

74. Laskey WK. Brief repetitive balloon occlusions enhance reperfusion during percutaneous coronary intervention for acute myocardial infarction: a pilot study. Catheter Cardiovasc Interv 2005; 65:361367.

75. Lochner A, Genade S, Moolman JA. Ischemic preconditioning: infarct size is a more reliable endpoint than functional recovery. Basic Res Cardiol 2003; 98:337-346.

76. Couvreur N, Lucats L, Tissier R, Bize A, Berdeaux A, Ghaleh B. Differential effects of postconditioning on myocardial stunning and infarction; a study in conscious dogs and anesthetized rabbits. Am J Physiol Heart Circ Physiol 2006; 291:H1345-1350.

77. Lu EX, Chen SX, Yuan MD, Hu TH, Zhou HC, Luo WJ, Li GH, et al. Preconditioning improves myocardial preservation in patients undergoing open heart operations. Ann Thorac Surg 1997; 64:13201324.

78. Wu ZK, Pehkonen E, Laurikka J, Kaukinen L, Honkonen EL, Kaukinen S, Tarkka MR. Ischemic preconditioning protects right ventricular function in coronary artery bypass grafting patients experiencing angina within 48-72 hours. J Cardiovasc Surg (Torino) 2002; 43:319-326.

79. Przyklenk K, Bauer B, Ovize M, Kloner RA, Whittaker P. Regional ischemic 'preconditioning' protects remote virgin myocardium from subsequent sustained coronary occlusion. Circulation 1993; 87:893899 .

80. Dickson EW, Lorbar M, Porcaro WA, Fenton RA, Reinhardt CP, Gysembergh A, Przyklenk K. Rabbit heart can be "preconditioned" via transfer of coronary effluent. Am J Physiol 1999; 277:H2451-2457.

81. Kharbanda RK, Mortensen UM, White PA, Kristiansen SB, Schmidt MR, Hoschtitzky JA, Vogel M, et al. Transient limb ischemia induces remote ischemic preconditioning in vivo. Circulation 2002; 106:2881-2883

82. Andreka G, Vertesaljai M, Szantho G, Font G, Piroth Z, Fontos G, Juhasz ED, et al. Remote ischaemic postconditioning protects the heart during acute myocardial infarction in pigs. Heart 2007; 93:749-752.

83. Verdouw PD, Gho BC, Koning MM, Schoemaker RG, Duncker DJ. Cardioprotection by ischemic and nonischemic myocardial stress and ischemia in remote organs. Implications for the concept of ischemic preconditioning. Ann N Y Acad Sci 1996; 793:27-42.

84. Kerendi F, Kin H, Halkos ME, Jiang R, Zatta AJ, Zhao ZQ, Guyton RA, et al. Remote postconditioning. Brief renal ischemia and reperfusion applied before coronary artery reperfusion reduces myocardial infarct size via endogenous activation of adenosine receptors. Basic Res Cardiol 2005; 100:404-412. 
85. Loukogeorgakis SP, Panagiotidou AT, Broadhead MW, Donald A, Deanfield JE, MacAllister RJ. Remote ischemic preconditioning provides early and late protection against endothelial ischemiareperfusion injury in humans: role of the autonomic nervous system. $J$ Am Coll Cardiol 2005; 46:450456.

86. Gho BC, Schoemaker RG, van den Doel MA, Duncker DJ, Verdouw PD. Myocardial protection by brief ischemia in noncardjac tissue. Circulation 1996; 94:2193-2200.

87. Post MJ, Cornelussen RN, Prinzen FW. Pampering and priming the heart. Therapeutic neovascularization - Quo Vadis? Deindl E and Kupatt C. Springer 2007; 85-108.

88. Peart JN, Headrick JP. Adenosinergic cardioprotection: Multiple receptors, multiple pathways. Pharmacol Ther 2007; 114:208-221.

89. Baxter GF. Natriuretic peptides and myocardial ischaemia. Basic Res Cardiol 2004; 99:90-93.

90. D'Souza SP, Yellon DM, Martin C, Schulz R, Heusch G, Onody A, Ferdinandy P, et al. B-type natriuretic peptide limits infarct size in rat isolated hearts via KATP channel opening. Am J Physiol Heart Circ Physiol 2003; 284:H1592-1600.

91. Tsang A, Hausenloy DJ, Yellon DM. Myocardial postconditioning: reperfusion injury revisited. Am J Physiol Heart Circ Physiol 2005; 289:H2-7.

92. Hausentoy DJ, Yelion DM. Survival kinases in ischemic preconditioning and postconditioning. Cardiovasc Res 2006; 70:240-253.

93. Zhao ZQ, Vinten-Johansen J. Postconditioning: reduction of reperfusion-induced injury. Cardiovasc Res 2006; 70:200-211.

94. Hausenloy DJ, Mocanu MM, Yellon DM. Cross-talk between the survival kinases during early reperfusion: its contribution to ischemic preconditioning. Cardiovasc Res 2004; 63:305-312.

95. Argaud L, Gomez L, Gateau-Roesch O, Couture-Lepetit E, Loufouat J, Robert D, Ovize M. Trimetazidine inhibits mitochondrial permeability transition pore opening and prevents lethal ischemia-reperfusion injury. J Mol Cell Cardiol 2005; 39:893-899.

96. Gateau-Roesch O, Argaud L, Ovize M. Mitochondrial permeability transition pore and postconditioning. Cardiovasc Res 2006; 70:264-273.

97. Takeishi $Y$, Huang $Q$, Abe J, Glassman $M$, Che W, Lee JD, Kawakatsu $H$, et al. Src and multiple MAP kinase activation in cardiac hypertrophy and congestive heart failure under chronic pressureoverioad: comparison with acute mechanical stretch. J Mol Cell Cardiol 2001; 33:1637-1648.

98. Yamamoto $K$, Dang QN, Maeda Y, Huang $H$, Kelly RA, Lee RT. Regulation of cardiomyocyte mechanotransduction by the cardiac cycle. Circulation 2001; 103:1459-1464.

99. Spragg DD, Leclercq C, Loghmani M, Faris OP, Tunin RS, DiSilvestre D, McVeigh ER, et al. Regional alterations in protein expression in the dyssynchronous failing heart. Circulation 2003: 108:929-932.

100. Marais E, Genade S, Salie R, Huisamen B, Maritz S, Moolman JA, Lochner A. The temporal relationship between p38 MAPK and HSP27 activation in ischaemic and pharmacological preconditioning. Basic Res Cardiol 2005; 100:35-47.

101.Gross GJ, Auchampach JA. Reperfusion injury: does it exist? J Mol Cell Cardiol 2007; 42:12-18.

102.Pemberton $\mathrm{CJ}$, Johnson $M L$, Yandle TG, Espiner EA. Deconvolution analysis of cardiac natriuretic peptides during acute volume overload. Hypertension 2000; 36:355-359.

103. Marber MS, Walker DM, Eveson DJ, Walker JM, Yellon DM. A single five minute period of rapid atrial pacing fails to limit infarct size in the in situ rabbit heart. Cardiovasc Res 1993; 27:597-601.

104. Hale SL, Kloner RA. Elevated body temperature during myocardial ischemia/reperfusion exacerbates necrosis and worsens no-reflow. Coron Artery Dis 2002; 13:177-181.

105.Dote K, Wolff RA, Van Winkle DM. Hypothermia increases the threshold for ischemic preconditioning. J Thorac Cardiovasc Surg 1998; 116:319-326.

106. Miki T, Liu GS, Cohen MV, Downey JM. Mild hypothermia reduces infarct size in the beating rabbit heart: a practical intervention for acute myocardial infarction? Basic Res Cardiol 1998; 93:372-383.

107. Birnbaum Y, Hale SL, Kloner RA. Differences in reperfusion length following 30 minutes of ischemia in the rabbit influence infarct size, as measured by triphenyltetrazolium chloride staining. $J$ Mol Cell Cardiol 1997; 29:657-666. 


\title{
The left ventricular apex is the optimal site for pediatric pacing: Correlation with animal experience
}

\author{
Ward Y. Vanagt ${ }^{1,2}$, Xander A. Verbeek ${ }^{1}$, Tammo Delhaas ${ }^{1,2}$, \\ Luc Mertens ${ }^{3}$, Willem J. Daenen ${ }^{4}$ and Frits W. Prinzen ${ }^{1}$ \\ Departments of ${ }^{1}$ Physiology and ${ }^{2}$ Pediatrics, Cardiovascular \\ Research Institute Maastricht, Maastricht, The Netherlands \\ and Departments of ${ }^{3}$ Pediatric Cardiology and ${ }^{4}$ Cardiothoracic \\ Surgery, UZ Gasthuisberg, Catholic University of Leuven, \\ Leuven, Belgium
}

Pacing and Clinical Electrophysiology, 2004; 27:837 - 843. 


\section{ABSTRACT}

Introduction: Pacing at the commonly used right ventricular (RV) apex results in impaired ventricular performance. Previous animal studies indicated that the left ventricular (LV) apex is a superior pacing site. The purpose of this study was to investigate in dogs whether this good performance is associated with a more synchronous electrical activation pattern of the LV and whether the LV apex is also a good pacing site in children.

Methods: In 11 healthy dogs and 8 children undergoing cardiac surgery, dual chamber pacing was performed at the RV apex, LV apex and LV lateral free wall (LVFW). In dogs a basket electrode was inserted into the LV to assess pattern and timing of LV endocardial activation. In the children hemodynamic measurements were performed immediately after recovery from cardiopulmonary bypass.

Results: In dogs LV apex pacing resulted in synchronous activation around the LV circumference whereas RV apex and LVFW pacing resulted in asynchrony of activation between the interventricular septum and LVFW. In both canine and children's hearts most hemodynamic variables remained at sinus

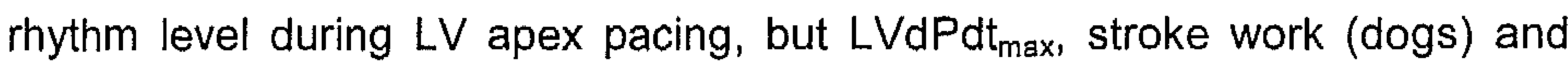
pulse pressure (children) were reduced as compared with sinus rhythm during RV apex and LVFW pacing.

Conclusions: LV apex pacing results in synchronous activation of the LV and is, in adult dogs and in children, associated with superior hemodynamic performance. 


\section{INTRODUCTION}

The right ventricular (RV) apex is the conventional pacing site in adults and children in whom a pacemaker is indicated for rate control (e.g. congenital or acquired AV-block). However, numerous studies show that RV apex pacing acutely reduces cardiac pump function (contractility, relaxation, and stroke volume) in laboratory animals, ${ }^{1}$ adults, ${ }^{2}$ and children. ${ }^{3}$ Moreover, cellular and subcellular abnormalities ${ }^{4}$ and diminished global left ventricular (LV) function ${ }^{5}$ have been observed in children after long-term RV apex pacing. Similarly, studies in adult pacemaker patients suggest that RV pacing facilitates the development of heart failure. ${ }^{6-9}$

Because experimental studies showed that the site of pacing is an important determinant of LV pump function, ${ }^{1}$ alternate pacing sites are being explored. In patients the most commonly studied site is the high RV septum, but hemodynamic benefits of high septal pacing relative to RV apex pacing are not consistent. ${ }^{2}$ A few studies have shown successful His-bundle pacing, ${ }^{10,11}$ but implantation of a lead in that area appears too complicated for frequent use, especially in children. Old ${ }^{12,13}$ and recent animal studies ${ }^{14,15}$ show that pacing from the LV apex results in clear improvement of LV function as compared with RV apex pacing. These studies did, however, not provide a mechanism for the good performance of LV apex pacing. In canine hearts with left bundle branch block, the degree of intra-LV asynchrony (intra-VA) during pacing correlated well with LV pump function." 17 Therefore, it seemed important to investigate whether intra-VA, measured with an intraventricular basket catheter, also predicts LV function during pacing in normal canine hearts. Moreover, it is still unknown whether the LV apex is also a preferable pacing site in human hearts.

Therefore the aims of the present study were to investigate 1) whether the hemodynamic effect of pacing at a site correlates with intra-LV electrical activation in canine hearts and 2) whether pacing at the LV apex also leads to good hemodynamics in children. To meet the first purpose ventricular electrical activation mapping and LV function measurements were performed during pacing from various sites in dogs. To investigate the performance of LV apex pacing in man invasive hemodynamic studies were performed during cardiac surgery in children. This approach was chosen because of the easy access to the LV apex in the open chest and because temporary epicardial leads are implanted routinely in the pediatric population. 
CHAPTER:3

\section{METHODS - ANIMAL STUDY}

In 11 healthy mongrel dogs, the heart was paced from different ventricular sites and hemodynamic measurements as well as electrical activation mapping were performed. Animal handling and treatment were according to the Dutch law on animal experimentation. The protocol was approved by the animal experimental committee of the Maastricht University, Maastricht, The Netherlands.

The dogs were premedicated with acepromazine $0.2 \mathrm{mg} / \mathrm{kg}$, atropine 0.1 $\mathrm{mg} / \mathrm{kg}$ and oxycodone $2 \mathrm{mg} / \mathrm{kg}$ (i.m.). Anaesthesia was induced with thiopental $15 \mathrm{mg} / \mathrm{kg}$ (i.v.) and maintained by ventilation with halothane (0.8-1\%) in a $1: 2$ mixture of $\mathrm{O}_{2}$ and $\mathrm{N}_{2} \mathrm{O}$. The chest and pericardium were opened and the heart was exposed.

Temporary epicardial pacing electrodes (type 6500, Medtronic Inc. Minneapolis, MN, USA) were attached to the right atrium (RA), LV apex and LV lateral free wall (LVFW). A Medtronic 5076 screw-in lead was introduced through the jugular vein and advanced until the endocardium of the RV apex. The various sites were paced in random order and alternated with sinus rhythm (SR). Dualchamber pacing was performed in the DDD-mode with atrioventricular (AV) delays of $25-40 \mathrm{~ms}$ in order to avoid intrinsic activation of the ventricles through the intact $\mathrm{AV}$-node and conduction system. Pacing was unipolar with an indifferent electrode attached to the intercostal muscles.

The surface ECG was recorded to quantify QRS-duration. For measurement of electrical intra-VA a basket catheter (EPT Constellation, Boston Scientific Corp., Natick, MA, USA) was inserted into the LV. ${ }^{16,17}$ The basket consists of 8 splines with 8 electrodes, equally distributed over the LV endocardium. The electrograms from the basal 2 electrodes of each spline were discarded due to common contact problems. The remaining electrograms were used to calculate the two-dimensional activation delay vector (ADV) as a measure of intra$V A$ in the circumferential direction. ${ }^{16,17}$ The ADV angle expresses the main direction of conduction (a positive value indicates impulse propagation from LVFW towards the septum) whereas the ADV amplitude is used for quantification of intra-VA. ${ }^{17}$

A 7F combined catheter-tip manometer and conductance catheter (CDLeycom, Zoetermeer, The Netherlands) was advanced into the LV for measurement of stroke work from the pressure-volume relationship and of the maximal rate of rise and fall of LV pressure (LVdPdt max $_{\text {ax }}$ and $L V d P d t_{\text {min }}$, respectively). LVdPdt $t_{\max }$ and $L V d P d t_{\min }$ were used as measures of LV contractility and relaxation, respectively. 


\section{METHODS - PEDIATRIC STUDY}

This part of the study was performed at the UZ (University Hospital) Gasthuisberg, Catholic University of Leuven, Leuven, Belgium, and was conducted in accordance with institutional guidelines.

Data were obtained from 8 patients, 6 male and 2 female, median age 1 year and 4 months (range 2 months -17 years and 8 months, table 3.1 ) with biventricular anatomy ( 4 individuals with atrial and/or ventricular septal defect, 2 with Tetralogy of Fallot, 1 with aortic stenosis and 1 with mitral valve prolapse). All patients had a systemic morphological LV and none of the patients was in heart failure or had been paced before the study protocol. After the cardiac surgical procedure for which the patient was operated upon but before closure of the chest, instrumentation for pacing and hemodynamic measurements was performed. A pair of temporary epicardial pacing electrodes (Flexon 3-0, Davis-Geck Inc., Danbury, CT, USA) was attached to the right atrial appendage for bipolar sensing and pacing. Unipolar temporary pacing electrodes (Flexon 3-0, Davis-Geck Inc.) were placed epicardially at the RV apex, LV apex and LVFW near the base of the ventricle. The indifferent pacing lead (Flexon 3-0, Davis-Geck Inc.) for ventricular pacing was attached in the caudal part of the incision in the chest where it was assured to make good tissue contact. Left and right fluid-filled ventricular pressure catheters (3F Pigtail, Cook Inc., Bloomington, IN, USA) were inserted in the left and right atria and passed through the mitral and tricuspid valves, respectively.

The pacing protocol was started after complete recovery from cardiopulmonary bypass. Dual-chamber pacing was performed in the DDD-mode with an external pacemaker (PM) (Medtronic model 5346 or 5388 , Minneapolis, MN, USA). The AV-delay was set at $50 \%$ of the intrinsic preoperative AV-interval to guarantee complete ventricular activation initiating from the pacing site. This short AV-delay was necessary since all patients in the study group had intact AVconduction. The lower rate limit of the pacemaker was temporarily increased above the intrinsic rate in 3 patients that had a fast nodal escape rhythm shortly after discontinuation of the cardiopulmonary bypass, where after they resumed normal SR (patients 2, 5, and 6 in table 3.1). During the pacing protocol, pacing sites were varied in random order, and alternated with SR. All measurements lasted 1 minute. During the entire pacing protocol, no surgical intervention was performed and no changes in intravenous medication or mechanical ventilation were made. Recordings were made both during SR and during pacing. All hemodynamic and electrophysiological data were monitored and recorded using Powerlab software (ADInstruments Ltd., Oxfordshire, UK) at a sampling rate of $200 \mathrm{~Hz}$. 
CHAPTEP 3

Table 3.1 Patient characteristics during sinus rhythm.

\begin{tabular}{|c|c|c|c|c|c|c|c|c|c|}
\hline Patient & $\mathrm{M} / \mathrm{F}$ & Age & Diagnosis & $\begin{array}{l}P Q \\
\text { (ms) }\end{array}$ & $\begin{array}{l}\text { QRS } \\
\text { (ms) }\end{array}$ & $\begin{array}{l}\text { LVP }_{\max } \\
(\mathrm{mmHg})\end{array}$ & $\begin{array}{l}\mathrm{LVdPdt} t_{\max } \\
(\mathrm{mmHg} / \mathrm{s})\end{array}$ & $\begin{array}{l}\text { LVEDP } \\
(\mathrm{mmHg})\end{array}$ & $\begin{array}{c}\mathrm{PP} \\
(\mathrm{mmHg})\end{array}$ \\
\hline 1 & $M$ & $17 y 8 m$ & $\begin{array}{l}\text { M!I } \\
\text { MP }\end{array}$ & 97 & 87 & 94 & 1012 & 13 & 59 \\
\hline 2 & $F$ & $7 m$ & ToF & 91 & 100 & 60 & 550 & 16 & 27 \\
\hline 3 & $M$ & $13 y 6 m$ & AS & 126 & 100 & 111 & 1678 & 10 & 53 \\
\hline 4 & $M$ & $2 y 11 \mathrm{~m}$ & $\begin{array}{l}\text { AVSD } \\
\text { (Down) }\end{array}$ & 145 & 87 & 76 & 884 & 13 & 36 \\
\hline 5 & $M$ & $2 m$ & $\begin{array}{l}\text { ASD / } \\
\text { VSD }\end{array}$ & 102 & 82 & 65 & 858 & 9 & 30 \\
\hline 6 & $M$ & $4 m$ & ToF & 70 & 105 & 61 & 808 & 10 & 25 \\
\hline 7 & $F$ & $2 y 1 m$ & ASD & 122 & 101 & 81 & 742 & 17 & 48 \\
\hline 8 & $M$ & $4 m$ & $\begin{array}{l}\text { VSD / } \\
\text { ASD/PS }\end{array}$ & 81 & 105 & 95 & 947 & 16 & 57 \\
\hline MeantSD & & $1 y 4 m$ & & $104 \pm 25$ & $96 \pm 9$ & $80 \pm 18$ & $935 \pm 331$ & $13 \pm 3$ & $42 \pm 14$ \\
\hline
\end{tabular}

Legend: $M=$ Male,$F=$ Female $y=$ year(s), $m=$ month(s), $V S D=$ ventricular septal defect, $M I=$ mitral insufficiency, $M P=$ mitral valve prolapse,$T o F=$ Tetralogy of Fallot,$A S=$ aortic stenosis, $A V S D=$ atrioventricular septal defect, $A S D=$ atrial septal defect, $P Q=P Q$-interval, $Q R S=Q R S-$ duration, $L V P_{\max }=$ maximal left ventricular $(\mathrm{LV})$ pressure, $L \mathrm{LVdPdt} \mathrm{max}_{\max }=$ maximal rate of rise of the $L V$ pressure curve, LVEDP $=$ LV end-diastolic pressure, $P P=$ pulse pressure.

Data analysis was performed off-line. AV-interval and QRS-duration were measured from the ECG tracing (lead II). The maximal rate of rise of the pressure curve from the RV pressure catheter (RVdPdt $\max$ ) was calculated as a measure of RV contractility. From the LV pressure signal, maximal (LVP $\left.P_{\max }\right)$ and end-diastolic LV pressure (LVEDP) were calculated. Furthermore, the maximal rate of rise $\left(L V d P d t_{\max }\right)$ and fall $\left(L \mathrm{dPdt}_{\min }\right)$ were assessed as measures of LV contractility and relaxation, respectively. Pulse pressure (PP) from the radial artery pressure tracing (maximal minus minimal radial artery pressure) was calculated as an index of cardiac output. ${ }^{18}$

Since the heart had only just resumed its function after cardiopulmonary bypass and some fluctuation in baseline values was still present, only the acute effects of turning the pacemaker on and off were assessed. The SR value was used as the baseline value and the average of the two obtained values for 
every pacing site was used for further statistical analysis ((SR $\rightarrow$ pacing + pacing $\rightarrow$ SR)/2).

In order to minimise the effects of ventilation on the results, the last complete ventilatory cycle before and the first complete ventilatory cycle after turning the PM on or off were analyzed (figure 3.1).

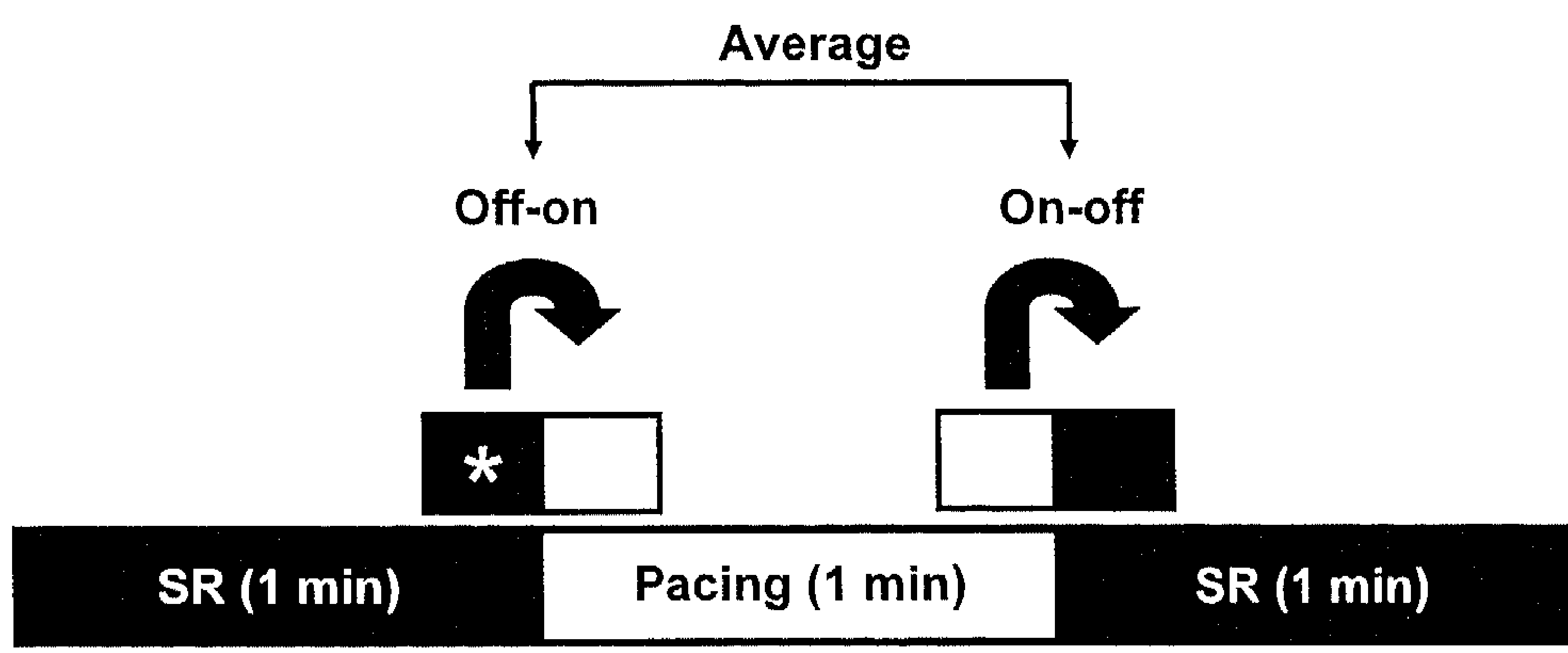

Figure 3.1 Ventricular pacing study protocol. $\mathrm{SR}=$ sinus rhythm,

* = one respiratory cycle.

\section{STATISTICAL ANALYSIS}

All hemodynamic data are presented as the percentage of change as compared with SR, unless specified otherwise. Electrophysiological data are presented as absolute values in $\mathrm{ms}$. A paired $\mathrm{t}$-test with post-hoc correction was used to compare different pacing sites. $\mathrm{P}<0.05$ was considered statistically significant.

\section{RESULTS - ANIMAL STUDY}

\section{Electrical activation pattern}

The pattern of electrical activation depended strongly on the ventricular pacing site. Figure 3.2 shows that pacing from the RV apex and LVFW resulted in an inhomogeneous spread of the electrical activation wave, especially in the circumferential direction. This is reflected by the great differences in grey levels in the left and right panels of figure 3.2. In contrast, pacing from the LV apex resulted in a rapid and uniform spread of electrical activation, similar to that during SR. ${ }^{17}$ 

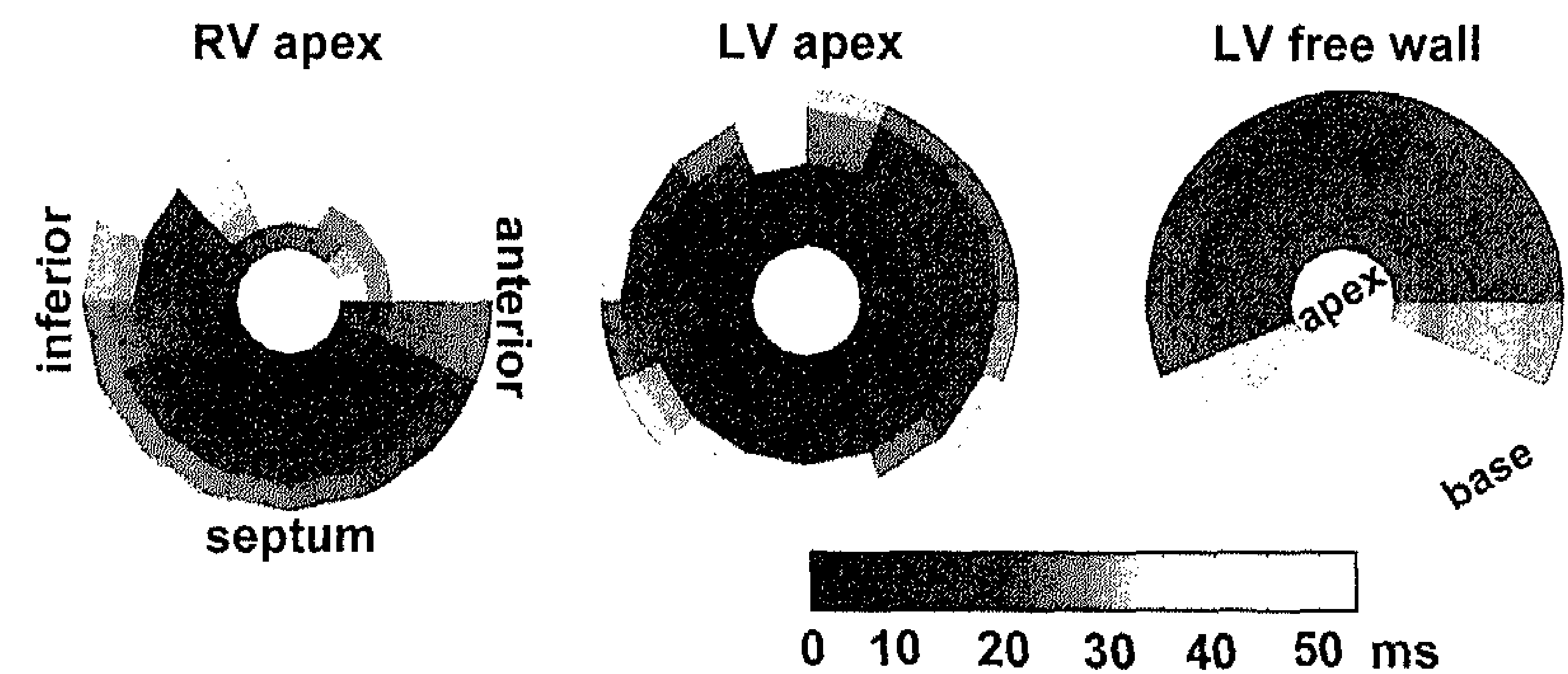

Figure 3.2 Electrical activation mapping during pacing from the RV apex, LV apex and LV free wall. The electrical activation maps are represented as bull's eye plots, in which the ventricular apex lies in the centre and the base lies at the outer boundaries of the circle. Furthermore, black indicates early activation, whereas dark and light grey colours indicate intermediate and late activation, respectively. The LV posterior wall is depicted in the top part of every bull's eye plot. Anterior = anterior $L V$ wall, Septum $=$ interventricular septum, Lateral $=$ lateral $L V$ wall.

The ADV was $\sim-20$ ms during RV apex pacing, indicating predominant activation from right to left, and was of equal size, but opposite in direction during LVFW pacing. During LV apex pacing the ADV was close to zero (table 3.2), indicating circumferentially synchronous activation. Figure 3.2 indicates earlier activation at the apex than at the base of the LV during LV apex pacing. Despite the synchronous $L V$ endocardial activation during $L V$ apex pacing, QRSduration was not shorter during LV apex pacing than during pacing from the RV apex or LVFW (table 3.2).

\section{Hemodynamic Changes}

Stroke work was significantly lower during RV apex pacing than during SR, LV apex and LVFW pacing (table 3.2). LVdPdt max $_{\text {max }}$ decreased significantly during RV apex and LVFW pacing, whereas it remained at SR level during LV apex pacing. Moreover, $L V d P d t_{\max }$ was significantly higher during $L V$ apex pacing than during RV apex and LVFW pacing. LVdPdt ${ }_{\text {min }}$ was significantly compromised when pacing was performed from any ventricular site. However, pacing from the LV apex still resulted in significantly higher absolute $L V d P d t_{\text {min }}$ values than during RV apex pacing. LVEDP slightly, but significantly increased during $R V$ apex and LVFW pacing as compared with SR but did not change significantly during $L V$ apex pacing. 
Table 3.2 Electrophysiological and hemodynamic data from the canine experiments.

\begin{tabular}{|c|c|c|c|c|}
\hline & SR & RV apex & LV apex & LVFW \\
\hline $\begin{array}{c}\text { QRS-duration } \\
\text { (ms) }\end{array}$ & $54 \pm 8$ & $100 \pm 33^{*} \#$ & $104 \pm 24^{*}+$ & $108 \pm 23^{\star}$ \\
\hline $\begin{array}{l}\text { ADV } \\
\text { (ms) }\end{array}$ & $5 \pm 2$ & $-21 \pm 2$ & $6 \pm 2$ & $21 \pm 4$ \\
\hline $\begin{array}{l}\text { Stroke Work } \\
(\mathrm{mmHg} \cdot \mathrm{ml})\end{array}$ & $2081 \pm 579$ & $1644 \pm 329^{\star} \#$ & $2268 \pm 499+$ & $2039 \pm 387 \#+$ \\
\hline $\begin{array}{l}\mathrm{LVdPdt} \text { max } \\
(\mathrm{mmHg} / \mathrm{s})\end{array}$ & $1192 \pm 251$ & $1109 \pm 78^{*} \#$ & $1180 \pm 71+$ & $1109 \pm 78^{*} \#$ \\
\hline $\begin{array}{l}\mathrm{LVdPdt}_{\min } \\
(\mathrm{mmHg} / \mathrm{s})\end{array}$ & $1293 \pm 202$ & $1034 \pm 134^{*} \#$ & $1164 \pm 116^{\star}+$ & $1086 \pm 119^{*}$ \\
\hline $\begin{array}{l}\text { LVEDP } \\
(\mathrm{mmHg})\end{array}$ & $10.0 \pm 4.0$ & $11.4 \pm 4.9^{*}$ & $11.0 \pm 4.0$ & $12.3 \pm 5.3^{*}$ \\
\hline
\end{tabular}

$N=11$ ( $n=3$ for activation delay vector (ADV), measured with left ventricular (LV) basket catheter) during sinus rhythm (SR) and pacing from the RV apex, LV apex and LV free wall (LVFW). Data are presented as mean \pm standard deviation. For legends see table $3.1 ; \mathrm{LVdPdt}_{\min }=$ maximal rate of fall of the LV pressure curve. ${ }^{*}=p<0.05$ vs $S R, \#=p<0.05$ vs LV apex pacing, $+=$ $p<0.05$ vs $R V$ apex pacing.

\section{RESULTS - PEDIATRIC STUDY}

\section{Acute hemodynamic changes with pacing}

Table 3.3 presents the relative changes in hemodynamics as compared with SR. As compared with SR, LVdPdt $t_{\max }$ and $P P$ decreased significantly during RV apex and LVFW pacing, but remained at SR level during LV apex pacing. $L V d P d t_{\max }$ was significantly higher during LV apex than during $R V$ apex and LVFW pacing (table 3.3 ).

Figures 3.3 and 3.4 show that this behavior was quite consistent, as it occurred in all patients but one (patient number 7 in table 3.1). During RV apex 


\section{CHATER 3}

pacing, $L V P_{\max }$ and $L V d P d t_{\min }$ were significantly compromised as compared with SR, whereas LV apex and LVFW pacing did not change these parameters significantly. Hemodynamic differences between pacing sites occurred without significant differences in LVEDP.

Table 3.3 Hemodynamic results from the pediatric study.

\begin{tabular}{|c|c|c|c|}
\hline & $\begin{array}{l}\text { RV apex } \\
\text { pacing }\end{array}$ & $\begin{array}{l}\text { LV apex } \\
\text { pacing }\end{array}$ & $\begin{array}{l}\text { LVFW } \\
\text { pacing }\end{array}$ \\
\hline$L V P_{\max }$ & $-4.6 \pm 3.8 \%$ * & $-0.9 \pm 4.0 \%$ & $-3.2 \pm 6.2 \%$ \\
\hline$L V d P d t_{\max }$ & $-10.4 \pm 6.4 \% * \#$ & $-1.7 \pm 6.8 \%$ & $-9.6 \pm 6.0 \% * \#$ \\
\hline $\mathrm{LVdPdt}_{\min }$ & $-5.9 \pm 7.1 \%$ * & $-1.3 \pm 8.8 \%$ & $-6.9 \pm 9.7 \%$ \\
\hline LVEDP $(\mathrm{mmHg})$ & $+1.5 \pm 3.1$ & $+0.6 \pm 6.7$ & $+2,2 \pm 6.7$ \\
\hline Pulse Pressure & $-9.8 \pm 8.5 \%{ }^{*} \#$ & $-1.6 \pm 9.5 \%$ & $-8.1 \pm 7.0 \%$ * \\
\hline$R V d P d t_{\text {max }}$ & $+1.2 \pm 10.2 \%$ & $-0.9 \pm 13.0 \%$ & $+6.3 \pm 12.3 \%$ \\
\hline
\end{tabular}

Values are expressed as percentage of change as compared with sinus rhythm (SR), except for LVEDP. For legends see table 3.1-3.2; $\mathrm{RVdPdt}_{\max }=$ maximal rate of rise of the $\mathrm{RV}$ pressure curve, * $=p<0.05$ vs $S R ; \#=p<0.05$ vs LV apex pacing.

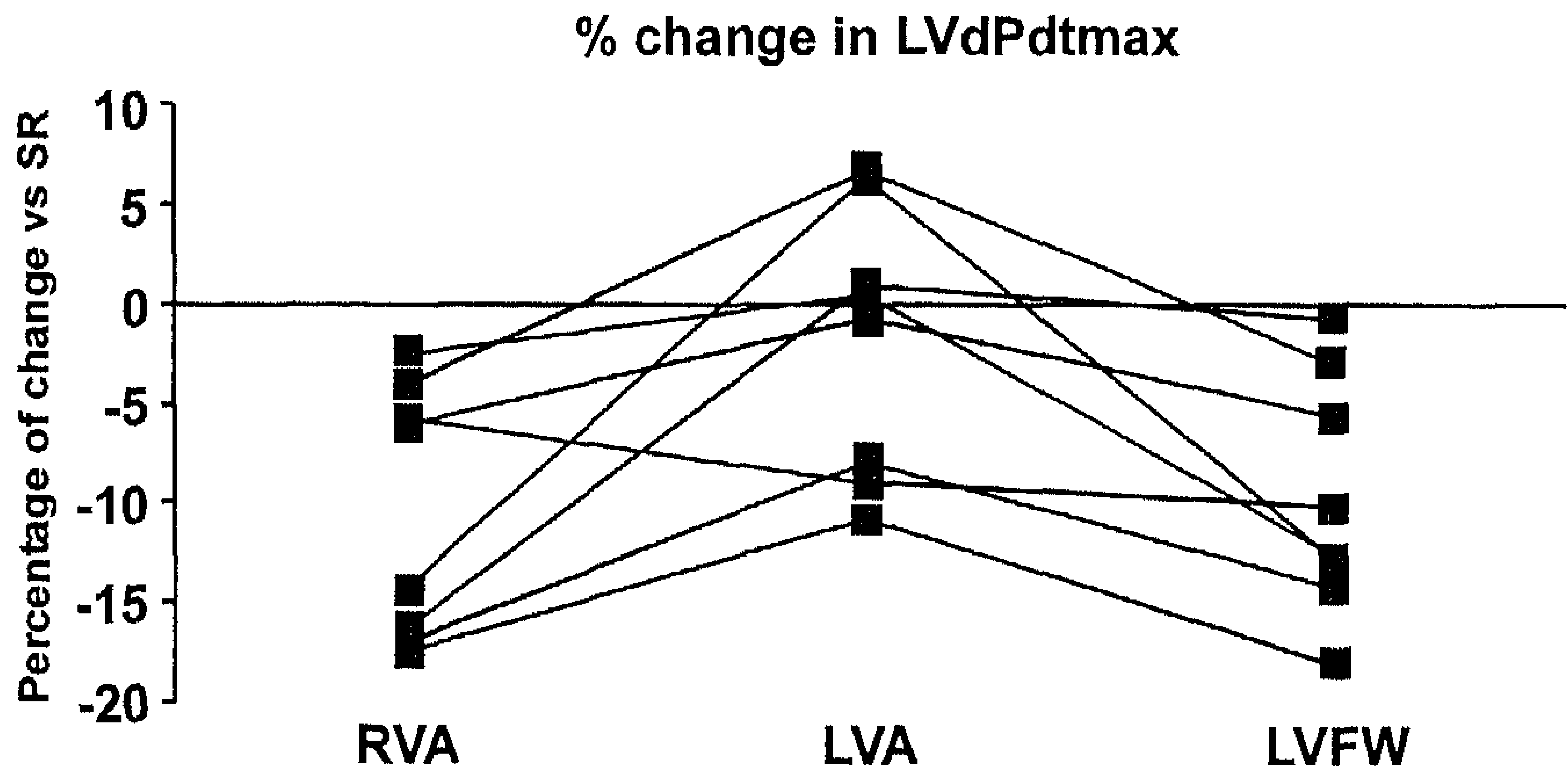

Figure 3.3 Individual changes in $\mathrm{LVdPdt}_{\max }$ relative to sinus rhythm (SR) in children. RVA = RV apex pacing, $L V A=L V$ apex pacing, $L V F W=L V$ free wall pacing. 
$\%$ change in Pulse Pressure

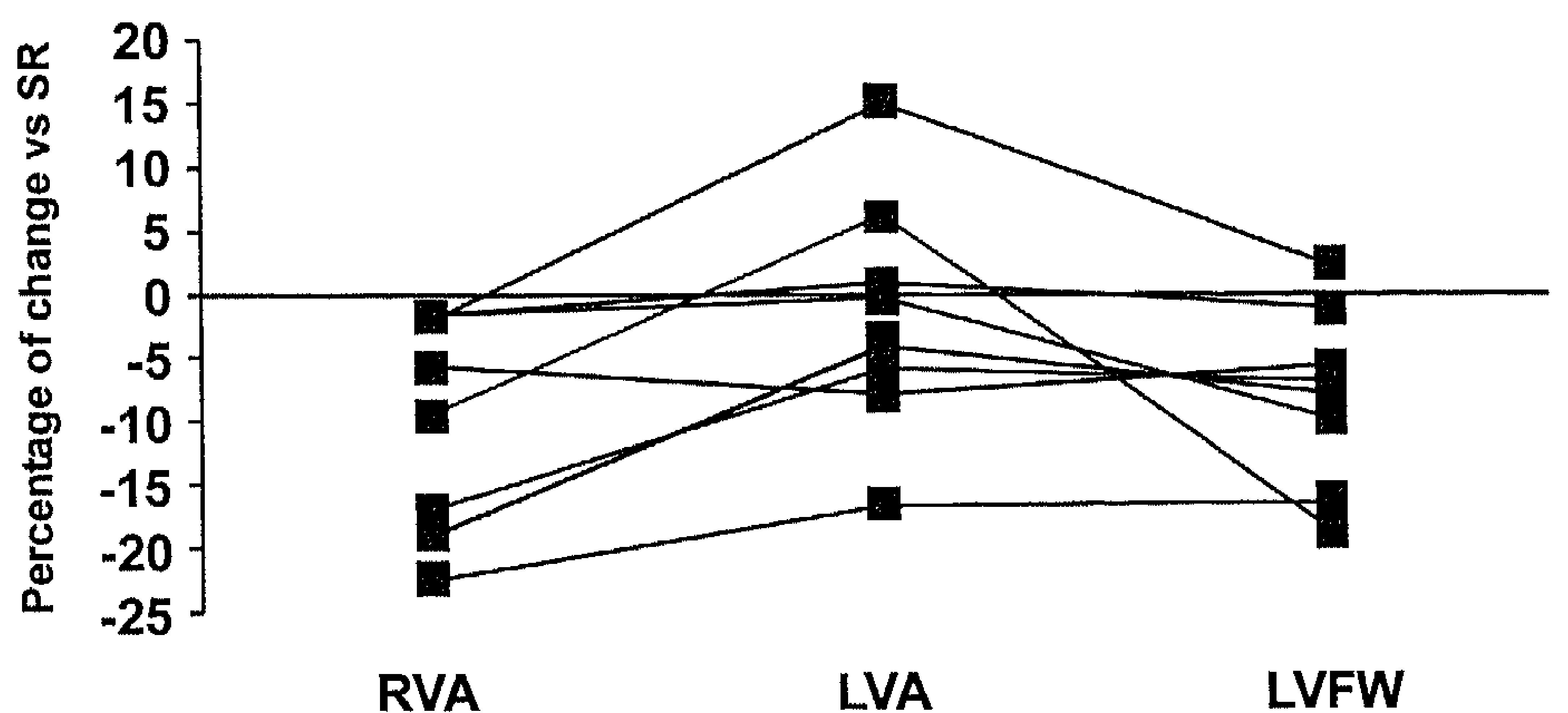

Figure 3.4 Individual changes in pulse pressure relative to sinus rhythm (SR) in children. RVA = RV apex pacing, $L V A=L V$ apex pacing, $L V F W=L V$ free wall pacing.

\section{Electrocardiographic changes}

Pacing at the LVFW significantly prolonged QRS-duration (from $96 \pm 9 \mathrm{~ms}$ during SR to $131 \pm 18 \mathrm{~ms}$ during LVFW pacing, $p<0.01)$. The increase in QRSduration during RV apex $(115 \pm 26 \mathrm{~ms})$ or LV apex $(115 \pm 29 \mathrm{~ms})$ pacing did not reach the level of significance (figure 3.5 ).

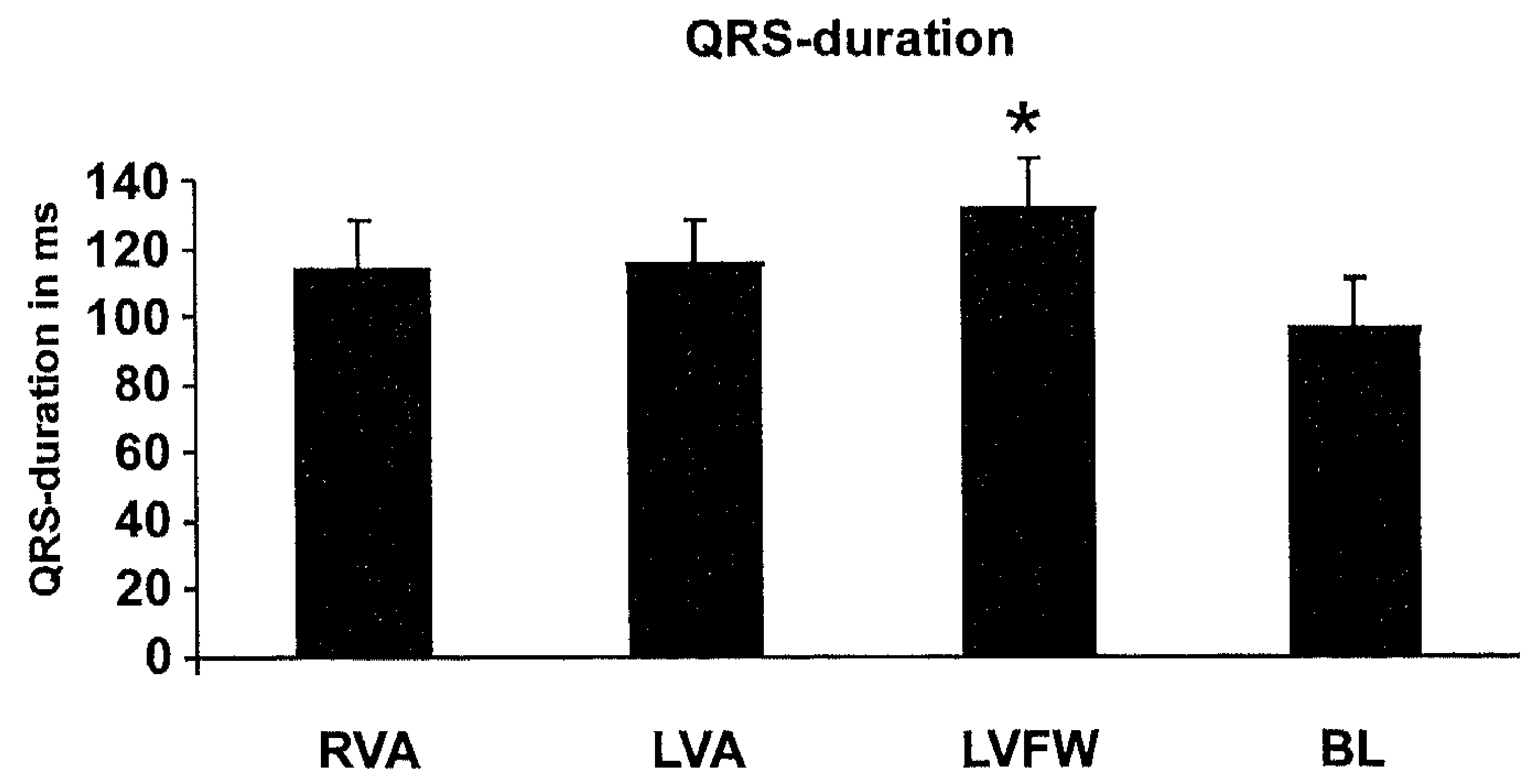

Figure 3.5 QRS-duration during ventricular pacing and during baseline $(B L)$ sinus rhythm in children. For legends see figure $3.2^{*}=p<0.05$ vs $B$. 
CHAPTER 3

\section{DISCUSSION}

The present study shows that in adult dogs and in children pacing at the LV apex prevents the loss of LV pump function relative to SR. This loss in pump function occurs when pacing from other sites, including the RV apex, the conventional pacing site. The good performance of the LV apex as pacing site is likely explained by a physiological, synchronous circumferential spread of electrical activation within the LV wall.

\section{LV apex as optimal pacing site}

The favorable hemodynamic effect of LV apex pacing has been described in animal experiments before ${ }^{12-15,19}$ but the finding that this is also the preferred pacing site in pediatric human hearts is novel. The fact that we studied a quite heterogeneous group of children with congenital heart disease suggests that the shape and structure of the heart is not critical in order to obtain the positive effects of $L V$ apex pacing.

The present study also provides a possible mechanism for the good performance of LV apex pacing, since the electrical maps in the canine hearts show near normal, synchronous circumferential endocardial activation during LV apex pacing. This activation pattern may be explained by the close proximity of distal parts of the Purkinje system to the LV apex. ${ }^{20,21}$ During normal SR, activation of the working myocardium starts at these exit points and proceeds in basal direction. ${ }^{22}$ The synchronous activation around the LV circumference can be understood by impulse propagation from the thin ventricular wall at the LV apex. From the epicardium of the LV apex the impulses can easily reach the LV endocardium and, from there, travel towards the base along the quite vertically directed and rapidly conducting endocardial myocytes. ${ }^{23}$ Therefore, the present data supports those from other studies that optimal LV function is obtained when the pacing electrode is in the proximity of the LV conduction system or its exit points by positioning the pacing electrode in the LV endocardium of the septum, ${ }^{15}$ the His-bundle ${ }^{3,11}$ and the LV apex.

The present study also shows that electrical activation and LV function are negatively affected by even a relatively small displacement of the pacing electrode from the LV to the RV apex. Even though the RV apex electrode may be close to distal endings of the RV Purkinje system, the conduction from septum to LV lateral wall requires much more time, resulting in considerable intra-VA. The excellent impulse conduction pattern also explains why pacing at the LV apex did not reduce LV systolic function as compared with SR.

The paced AV-delay in this study was relatively short. Such AV-delays were used to acquire complete ventricular capture and appear to be well-tolerated in 
non-failing hearts since end-diastolic pressure was similar during SR and ventricular pacing. These findings are in agreement with observations in nonfailing pediatric hearts that AV-synchrony is of minor importance. ${ }^{24}$

QRS-duration was similar during RV and LV apex pacing, but several studies have shown that QRS-duration is not a good predictor of the hemodynamic effect of pacing at a certain site. ${ }^{14,25}$

The synchronous LV endocardial activation during LV apex pacing may appear paradoxical with regards to the wide QRS complex, but the QRS complex reflects activation of $L V$ and $R V$ together. It is likely that during $L V$ apex pacing the $R V$ is activated abnormally and later than the LV, thus providing a wide QRS complex.

A limited number of studies have assessed the hemodynamic effects of multisite ventricular pacing in children with abnormal conduction or need for inotropic support. ${ }^{25}{ }^{26}$ Unfortunately, no functional comparison between single site and multisite pacing was made in these studies. However, in canine hearts with normal conduction LV apex pacing proved to result in LV pump function which is equal or better than during biventricular pacing. ${ }^{13,14,19}$ The slightly poorer performance of biventricular than LV apex pacing may be explained by the still fairly asynchronous activation during the former. When pacing the RV and the LV lateral wall (the way biventricular pacing is currently performed), two activation waves originate which meet halfway these pacing sites. This results in less asynchronous activation than when pacing one of these sites alone ${ }^{16}$ but still appears more asynchronous than observed in the present study during LV apex pacing. Therefore, at least in non-failing hearts without intraventricular conduction abnormalities, a single well chosen pacing site (LV apex) seems to be preferable above pacing from multiple sites.

Some studies suggest that pacing the LV generally provides better LV pump function than RV pacing. ${ }^{27,}{ }^{28}$ However, the present study shows that when intra-VA is similar (RV apex and LVFW) there is no clear hemodynamic difference between RV and LV pacing. This lack of significance could be explained by the smaller number of patients in our study, the variables used (LVdP/dt $t_{\max }$ and PP versus systolic blood pressure ${ }^{27}$ and ejection fraction ${ }^{28}$ ) or the category of patients (pediatric versus adult).

\section{Limitations}

The present study only assessed the acute hemodynamic consequences of pacing at different ventricular sites. However, it is known that hemodynamic effects of ventricular pacing persist for months or even years in children, ${ }^{5}$ adults, ${ }^{6}$ and animals. ${ }^{29}$ Caution should be taken to extrapolate these results to 


\section{CHAPIEA3}

the situation of enlarged, failing hearts, since Fei et al. showed differences in optimal pacing site(s) between non-failing and failing canine hearts. ${ }^{19}$

In the current study in children only LV pressure and arterial PP measurements were used to quantify LV pump function. In dogs a good correlation was found between effects of pacing at a site on $\mathrm{LVdP} / \mathrm{dt}_{\max }$ and stroke volume. In combination with the good correlation between PP and stroke volume in other studies, ${ }^{18}$ this indicates that also in pediatric patients LV apex pacing maintains optimal LV contractility and pump function.

\section{Possible clinical implications}

The most direct clinical implication of this study is that epicardial LV apex pacing is the preferred pacing site for short term back-up pacing in children with narrow QRS complex. Epicardial pacing is generally preferred over endocardial pacing in small children and in those in whom contra-indications to endocardial pacing (e.g. intracardiac shunts) exist. Further clinical application of LV apex pacing requires establishing whether the good hemodynamic performance is maintained over time and whether the LV apex is also a good pacing site in adult patients.

Even more interesting would be to investigate whether the structural abnormalities induced by RV pacing, potentially associated with increased risk for development of heart failure, ${ }^{5,8,9}$ can be prevented by LV apex pacing. The latter appears feasible, because Karpawich et al. have already shown in puppies that His-bundle pacing preserves normal ventricular structure in conjunction with hemodynamic performance. ${ }^{30}$

\section{CONCLUSION}

LV apex pacing induces a rapid and synchronous activation of the LV endocardium and maintains cardiac function at SR level in healthy adult dogs and children with congenital heart disease. Furthermore, LV apex pacing results in consistently better LV performance as compared with pacing at the RV apex, the most commonly used ventricular pacing site. Therefore, the LV apex is the site of choice for short-term ventricular pacing in children and probably also adults. Further studies are indicated to evaluate whether the acute benefits of LV apex pacing are maintained during chronic LV apex pacing. 


\section{ACKNOWLEDGEMENTS}

The authors are indebted to Arne van Hunnik, Maaike Peschar and Kevin Vernooy for their contributions to the animal experiments at the Department of Physiology, Maastricht University, The Netherlands. The investigators gratefully acknowledge Marc Gewillig, Bart Meyns, Patrick Wouters, Piet Claus and Jan D'Hooge at University Hospital Gasthuisberg, Catholic University of Leuven, Leuven, Belgium.

\section{REFERENCES}

1. Prinzen FW, Peschar M. Relation between the pacing induced sequence of activation and left ventricular pump function in animals. Pacing Clin Electrophysiol 2002; 25:484-498.

2. de Cock CC, Giudici MC, Twisk JW. Comparison of the haemodynamic effects of right ventricular outflow-tract pacing with right ventricular apex pacing: a quantitative review. Europace 2003; 5:275278.

3. Karpawich PP, Mital S. Comparative left ventricular function following atrial, septal, and apical singie chamber heart pacing in the young. Pacing Clin Electrophysiol 1997; 20:1983-1988.

4. Karpawich PP, Rabah R, Haas JE. Altered cardiac histology following apical right ventricular pacing in patients with congenital atrioventricular block. Pacing Clin Electrophysiol 1999; 22:1372-1377.

5. Tantengco MV, Thomas RL, Karpawich PP. Left ventricular dysfunction after long-term right ventricular apical pacing in the young. J Am Coll Cardiol 2001; 37:2093-2100.

6. Nielsen JC, Andersen HR, Thomsen PE, Thuesen L, Mortensen PT, Vesterlund T, Pedersen AK. Heart failure and echocardiographic changes during long-term follow-up of patients with sick sinus syndrome randomized to single-chamber atrial or ventricular pacing. Circulation 1998; 97:987-995.

7. Andersen HR, Nielsen JC, Thomsen PE, Thuesen $L$, Mortensen PT, Vesterlund T, Pedersen AK. Long-term follow-up of patients from a randomised trial of atrial versus ventricular pacing for sicksinus syndrome. Lancet 1997; 350:1210-1216.

8. Wilkoff BL, Cook JR, Epstein AE, Greene HL, Hallstrom AP, Hsia H, Kutalek SP, et al. Dual-chamber pacing or ventricular backup pacing in patients with an implantable defibrillator: the Dual Chamber and WI Implantable Defibrillator (DAVID) Trial. Jama 2002; 288:3115-3123.

9. Sweeney MO, Hellkamp AS, Ellenbogen KA, Greenspon AJ, Freedman RA, Lee KL, Lamas GA. Adverse effect of ventricular pacing on heart failure and atrial fibrillation among patients with normal baseline QRS duration in a clinical trial of pacemaker therapy for sinus node dysfunction. Circulation 2003; 107:2932-2937.

10. Rosenqvist M, Bergfeldt $L$, Haga $Y$, Ryden J, Ryden $L$, Owall $A$. The effect of ventricular activation sequence on cardiac performance during pacing. Pacing Clin Electrophysiol 1996; 19:1279-1286.

11. Deshmukh P, Casavant DA, Romanyshyn M, Anderson K. Permanent, direct His-bundle pacing: a novel approach to cardiac pacing in patients with normal His-Purkinje activation. Circulation 2000; 101:869-877.

12. Lister JW, Klotz DH, Jomain SL, Stuckey JH, Hoffman BF. Effect of Pacemaker Site on Cardiac Output and Ventricular Activation in Dogs with Complete Heart Block. Am J Cardiol 1964; 14:494503.

13. Tyers GF. Optimal electrode implantation site for asynchronous dipolar cardiac pacing. Ann Surg 1968; 167:168-179. 


\section{CHAPTER 3}

14. Prinzen FW, Van Oosterhout MF, Vanagt WY, Storm C, Reneman RS. Optimization of ventricular function by improving the activation sequence during ventricular pacing. Pacing Clin Electrophysiol 1998; 21:2256-2260.

15. Peschar $M$, de Swart $H$, Michels KJ, Reneman RS, Prinzen FW. Left ventricular septal and apex pacing for optimal pump function in canine hearts. J Am Coll Cardiol 2003; 41:1218-1226.

16. Wyman BT, Hunter WC, Prinzen FW, Faris OP, McVeigh ER. Effects of single- and biventricular pacing on temporal and spatial dynamics of ventricular contraction. Am J Physiol Heart Circ Physiol 2002; 282:H372-379.

17. Verbeek XA, Vernooy $K$, Peschar M, Cornelussen RN, Prinzen FW. Intra-ventricular resynchronization for optimal left ventricular function during pacing in experimental left bundle branch block. J Am Coll Cardiol 2003; 42:558-567.

18. Nelson GS, Berger RD, Fetics BJ, Talbot M, Spinelli JC, Hare JM, Kass DA. Left ventricular or biventricular pacing improves cardiac function at diminished energy cost in patients with dilated cardiomyopathy and left bundle-branch block. Circulation 2000; 102:3053-3059.

19. Fei L, Wrobleski D, Groh W, Vetter A, Duffin EG, Zipes DP. Effects of multisite ventricular pacing on cardiac function in normal dogs and dogs with heart failure. J Cardiovasc Electrophysiol 1999; 10:935-946.

20. Durrer D, van Dam RT, Freud GE, Janse MJ, Meijler FL, Arzbaecher RC. Total excitation of the isolated human heart. Circulation 1970; 41:899-912.

21. Spach MS, Barr RC. Ventricular intramural and epicardial potential distributions during ventricular activation and repolarization in the intact dog. Circ Res 1975; 37:243-257.

22. Myerburg RJ, Nilsson K, Gelband $\mathrm{H}$. Physiology of canine intraventricular conduction and endocardial excitation. Circ Res 1972; 30:217-243.

23. Frazier DW, Krassowska W, Chen PS, Wolf PD, Danieley ND, Smith WM, Ideker RE. Transmural activations and stimulus potentials in three-dimensional anisotropic canine myocardium. Circ Res 1988; 63:135-146.

24. Horenstein MS, Karpawich PP, Tantengco MV. Single versus dual chamber pacing in the young: noninvasive comparative evaluation of cardiac function. Pacing Clin Electrophysiol 2003; 26:12081211.

25. Zimmerman FJ, Starr JP, Koenig PR, Smith P, Hijazi ZM, Bacha EA. Acute hemodynamic benefit of multisite ventricular pacing after congenital heart surgery. Ann Thorac Surg 2003; 75:1775-1780.

26. Janousek J, Vojtovic P, Hucin B, Tlaskal T, Gebauer RA, Gebauer R, Matejka T, et al. Resynchronization pacing is a useful adjunct to the management of acute heart failure after surgery for congenital heart defects. Am J Cardiol 2001; 88:145-152.

27. Blanc JJ, Etienne Y, Gilard M, Mansourati J, Munier S, Boschat J, Benditt DG, et al. Evaluation of different ventricular pacing sites in patients with severe heart failure: results of an acute hemodynamic study. Circulation 1997; 96:3273-3277.

28. Puggioni $E$, Brignole $M$, Gammage $M$, Soldati $E$, Bongiorni MG, Simantirakis $E N$, Vardas $P$, et al. Acute comparative effect of right and left ventricular pacing in patients with permanent atrial fibrillation. J Am Coll Cardiol 2004; 43:234-238.

29. van Oosterhout MF, Prinzen FW, Arts T, Schreuder JJ, Vanagt WY, Cleutjens JP, Reneman RS, Asynchronous electrical activation induces asymmetrical hypertrophy of the left ventricular wall. Circulation 1998; 98:588-595.

30. Karpawich $P P$, Justice $C D$, Chang $C H$, Gause $C Y$, Kuhns LR. Septal ventricular pacing in the immature canine heart: a new perspective. Am Heart J 1991; 121:827-833. 
ACUTEEFHETS OF LVAPEXPACINS 


\title{
Left ventricular apex pacing cures overt right ventricular pacing-induced heart failure
}

\author{
Ward Y. Vanagt ${ }^{1,2}$, Frits W. Prinzen ${ }^{1}$, and Tammo Delhaas ${ }^{1,2}$ \\ Departments of ${ }^{1}$ Physiology and ${ }^{2}$ Pediatrics, Cardiovascular \\ Research Institute Maastricht, Maastricht University / University \\ Hospital Maastricht, Maastricht, The Netherlands
}

New England Journal of Medicine, 2007; in press. 


\section{ABSTRACT}

Children with congenital complete atrioventricular (AV) block often require lifelong pacemaker therapy. While pacemaker therapy restores normal heart rate, it also results in dyssynchronous left ventricular (LV) activation/contraction and compromises LV function. These effects are most pronounced during right ventricular (RV) pacing, the predominant pacing site in children and adults. Eventually, 6-7\% of chronically RV-paced children develop heart failure. The harmful effects of $R V$ pacing initiated the search for pacing modes that maintain or restore synchronous activation, e.g. bi-ventricular pacing and alternate single site ventricular pacing. Because we demonstrated that the physiological apex-to-base electrical activation sequence during LV apical pacing resulted in equally good hemodynamic responses as multisite pacing in canines and that it had favorable acute hemodynamic effects in children, a 2-year-old girl with congenital complete AV-block and RV pacing-induced heart failure was treated with LV apical pacing. In this patient, single site RV epicardial pacing (VVImode) was started one day after birth to treat symptomatic bradycardia. During $R V$ pacing, echocardiography showed dyssynchronous LV contraction, associated with progressive LV dilatation. After 2 years of RV pacing rapid deterioration towards congestive heart failure occurred: shortening fraction (SF) decreased to $\sim 20 \%$ and LVEDD precipitously increased. When the pacemaker was switched off, LV contraction was synchronous and SF increased to $36 \%$, but the ventricular escape rhythm of $40-50 \mathrm{bpm}$ was not well tolerated, despite additional furosemide treatment. Upon initiation of AV-sequential single site LV apical pacing, LV function increased immediately (SF 31\%). Echocardiography showed synchronous contraction around the LV short axis. Thereafter she was thriving well, LVEDD normalized gradually, and SF was maintained at $30-35 \%$. During her last visit 20 months after onset of treatment, LV function was assessed during pacing from different sites (DDD-mode; AV-delay $100 \mathrm{~ms}$ ) and during ventricular escape rhythm. During LV apical pacing, biventricular pacing and ventricular escape rhythm, ejection fraction ( $65 \%)$, SF $(\sim 35 \%)$, and septal to posterior wall motion delay (17 to $45 \mathrm{~ms}$ ) were similar, but deteriorated during RV pacing $(50 \%, 25 \%$, and $-311 \mathrm{~ms}$, respectively). This indicates that the effect of ventricular pacing site is far more important than restoration of AV-sequential activation. 


\section{INTRODUCTION}

Children with congenital complete atrioventricular (AV) block often require pacemaker therapy for their entire life. While pacemaker therapy restores normal heart rate, an important side effect is that the artificial stimulation on the ventricle induces abnormal patterns of electrical activation and contraction. Pacing at the conventional pacing site, the right ventricle (RV), results in dyssynchronous left ventricular (LV) activation and contraction. ${ }^{1-4}$ Evidence is growing that, like in adults, chronic RV pacing in children has also deleterious structural and functional effects on the LV. ${ }^{1,5}$ The harmful effects of RV apex pacing initiated the search for pacing modes that maintain the normal sequence of activation as much as possible. To this purpose bi-ventricular pacing is proposed as well as alternate single site ventricular pacing. We previously demonstrated that single site LV apex pacing resulted in equally good hemodynamic responses as multisite pacing in canine hearts ${ }^{6}$ and that it had favorable acute hemodynamic effects in children. ${ }^{3}$ Therefore, we decided to treat a 2-year-old girl, suspect of RV pacing-induced heart failure, with LV apex pacing.

\section{CASE PRESENTATION}

In a term female newborn (birth weight $3.3 \mathrm{~kg}$ ) with congenital complete AVblock due to maternal systemic lupus erythematosus (Ro SSA/SSB antibodies positive), ventricular pacing was started one day after birth for treatment of symptomatic bradycardia. Two ventricular pacing leads (one for back-up) were positioned at the anterior RV wall, connected to a pacemaker (Kappa KDR 921, Medtronic Inc., Minneapolis, MN, USA) and single chamber ventricular pacing $(\mathrm{Vl})$ was started. During RV pacing, echocardiography showed a dyssynchronous LV contraction pattern. This was associated with progressive LV dilatation as shown by the gradual enlargement of LV end-diastolic diameter (LVEDD) in figure 4.1. After 2 years of RV pacing, there was a sudden deterioration with shortening fraction decreasing to $\sim 20 \%$ and LVEDD increasing rapidly. She developed congestive heart failure and afterload reduction was started (lisinopril $0.2 \mathrm{mg} / \mathrm{kg} / \mathrm{day}$ ). It was first decided to stop pacing in order to evaluate the hemodynamic performance of the heart during intrinsic activation as described by Janousek et al. ${ }^{7}$ When the pacemaker was switched off, LV contraction was synchronous and shortening fraction increased to $36 \%$, but the ventricular escape rhythm of $40-50$ beats per minute was not well toler- 


\section{CHAPTEPA}

ated. After 1 week, progressive fatigue, irritability, poor feeding, pallor and liver enlargement developed despite additional diuretic treatment with oral furosemide ( $1 \mathrm{mg} / \mathrm{kg} /$ day). Considering that single site LV apex pacing resulted in equally good hemodynamic responses as multisite pacing in canine hearts ${ }^{6}$ and that it had favorable acute hemodynamic effects in children ${ }^{3}$ it was then decided to start AV-sequential LV apex pacing in the DDD-mode (atrial and ventricular sensing and pacing). Through a subxyphoidal incision, pacing leads were implanted at the LV apex and right atrium. The RV pacing lead was switched off but left in place for back-up pacing, and all leads were connected to a biventricular pacemaker system (Insync III, Medtronic Inc., Minneapolis, MN, USA).

During single site LV apex pacing, LV function increased immediately (shortening fraction $31 \%$ ). Furthermore, echocardiography showed synchronous contraction around the circumference of the LV wall. Lisinopril was continued at $0.1 \mathrm{mg} / \mathrm{kg} /$ day. During the following 20 months, LVEDD normalized gradually (figure 4.1) and shortening fraction was maintained at $30-35 \%$. After more than $1 \frac{1}{2}$ years of follow-up, the patient is thriving well and there have not been any pacemaker-related complications.

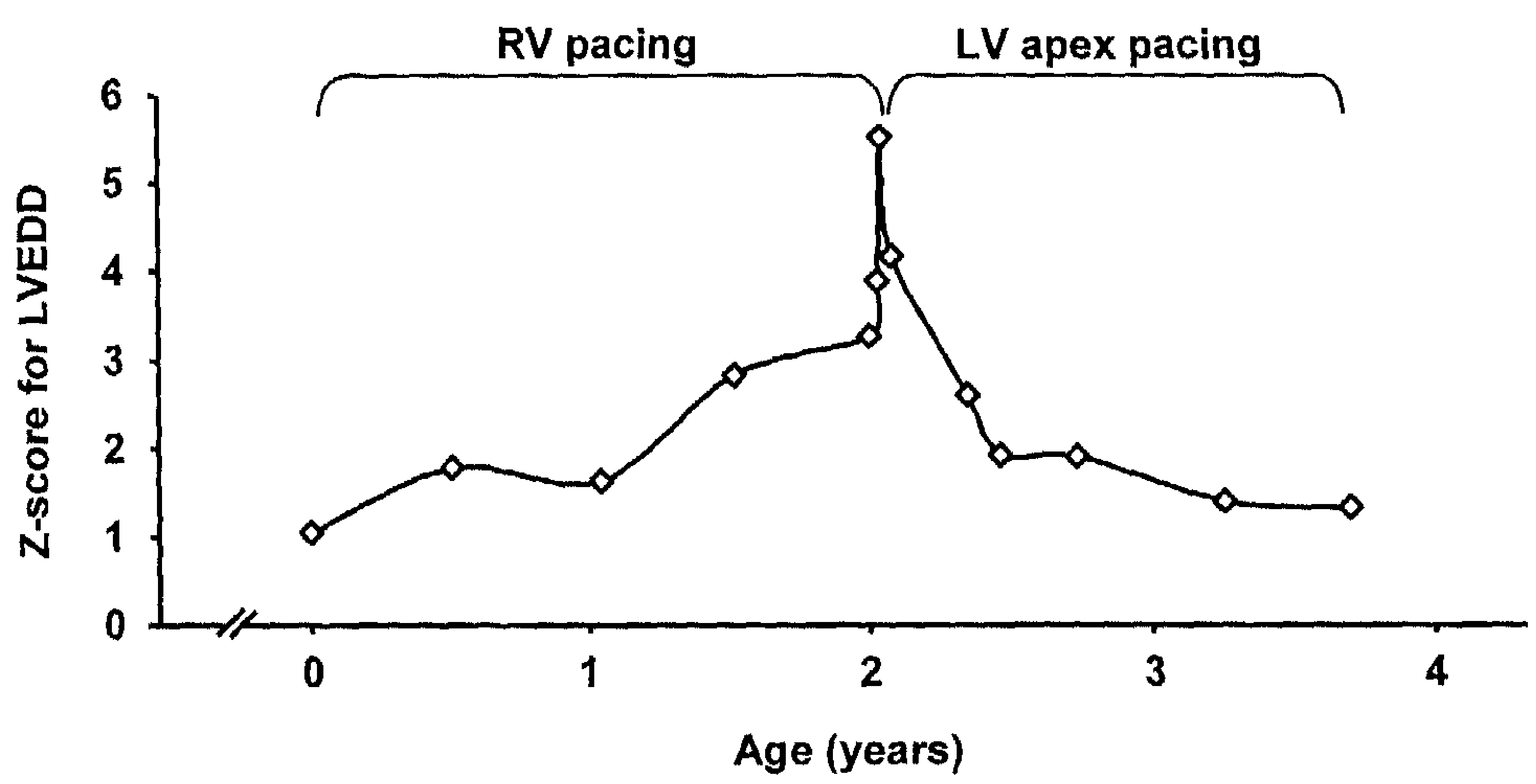

Figure 4.1 Evolution of left ventricular end-diastolic diameter (LVEDD) over time. Data is expressed as Z-score (number of standard deviations above average LVEDD-value for the corresponding body surface area). ${ }^{17,18} \mathrm{RV}=$ right ventricular, $L V=$ left ventricular. 


\section{Echocardiographic evaluation during pacing from different sites}

After 20 months of LV apex pacing (age 3 years and 8 months), echocardiography was performed during LV apex pacing, RV free wall pacing, biventricular pacing and intrinsic escape rhythm to assess hemodynamic performance and contractile synchrony (table 4.1). All ventricular pacing was performed in the DDD-mode with a programmed AV-delay of $100 \mathrm{~ms}$. During RV free wall pacing, hemodynamic performance decreased markedly as compared with LV apex pacing. During biventricular pacing and when the pacemaker was switched off, ejection fraction and shortening fraction were similar as during LV apex pacing. Mechanical intraventricular dyssynchrony was assessed from M-mode images by measuring septal to posterior wall motion delay (SPWM-delay) defined as the time delay between the earliest systolic peak inward movements of the septum and opposite LV posterior wall ${ }^{8}$ (figure 4.2). SPWM-delay was $-311 \mathrm{~ms}$ during RV free wall pacing (table 4.1). During LV apex and biventricular pacing, SPWM-delay was small $(<50 \mathrm{~ms})$ and similar to that during intrinsic escape rhythm.

Table 4.1 Echocardiographic parameters and QRS-duration after $\mathbf{2 0}$ months of left ventricular apex pacing.

$\begin{array}{lcccc} & \begin{array}{c}\text { LV apex } \\ \text { pacing }\end{array} & \begin{array}{c}\text { RV free wall } \\ \text { pacing }\end{array} & \begin{array}{c}\text { Biventricular } \\ \text { pacing }\end{array} & \begin{array}{c}\text { Intrinsic } \\ \text { rhythm }\end{array} \\ \text { LVEDD (cm) } & 3.7 & 4.0 & 3.8 & 4.3 \\ \text { LVESD (cm) } & 2.4 & 3.0 & 2.4 & 2.7 \\ \text { Shortening fraction (\%) } & 35 & 25 & 36 & 37 \\ \text { Ejection fraction (\%) } & 65 & 50 & 66 & 67 \\ \text { SPWM-delay (ms) } & 45 & -311 & 43 & 17 \\ \text { QRS-duration (ms) } & 160 & 160 & 150 & 80 \\ & & & \\ \text { LV = left ventricular, RV = right ventricular, LVEDD } & =\text { LV end-diastolic diameter, LVESD = LV end- } \\ \text { systolic diameter, SPWM-delay = septal to posterior wall motion delay. }\end{array}$



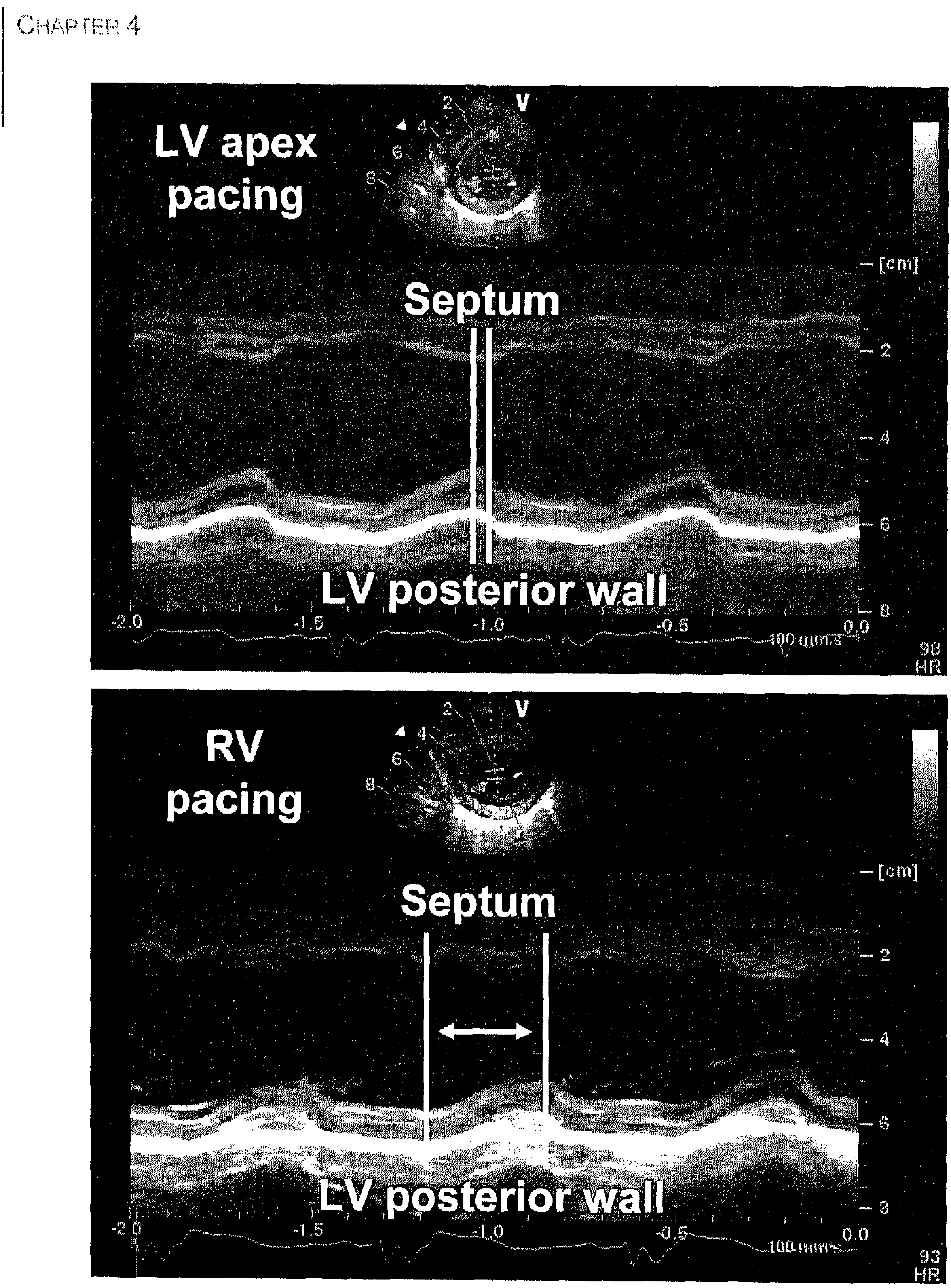

Figure 4.2 M-mode echocardiography images at the papillary muscle level during LV apex and RV pacing at the age of 3 years and 8 months. The images demonstrate dyssynchronous movement of the interventricular septum and the LV posterior wall during RV pacing but not during LV apex pacing. White lines indicate the timing of the earliest systolic peak of inward motion of the septum and LV posterior wall. The white arrow between the white lines indicates septal to posterior wall motion delay. 


\section{CONSIDERATIONS}

To our knowledge, this is the first patient with RV pacing-induced heart failure in which successful treatment consisted of single site LV apex pacing. After 20 months of LV apex pacing, the patient was doing well, LVEDD had returned to normal levels and there were no pacing-related complications. By alteration of the pacing therapy also AV-sequential activation was restored (switching from VVI to DDD pacing). However, table 4.1 shows that the effect of the ventricular pacing site is far more important. This is consistent with large trials in adults. ${ }^{4}$ In our patient, congestive heart failure occurred after 2 years of RV pacing. The unfavorable effects of chronic RV pacing on cardiac function in children are well recognized ${ }^{5,9}$ (for review see ${ }^{1}$ ), but the incidence of overt RV pacinginduced heart failure is less well documented. In recent publications, chronic $\mathrm{RV}$ pacing results in cardiac failure in $6-7 \%$ of children after an average pacing duration of 8 to 15 years. ${ }^{2,10}$ In another study, a child with congenital AV-block developed congestive heart failure after only 11 months of RV pacing. ${ }^{11}$ The harmful effects of RV pacing have initiated three approaches to avoid RV pacing-induced heart failure: minimization of ventricular pacing when AVconduction is still present, adding a LV pacing lead to resynchronize activation during RV pacing, and exploration of alternate single site ventricular pacing sites to maintain LV synchrony as much as possible. ${ }^{4}$ Examples of alternate pacing sites are the His-bundle, RV outflow tract, and LV apex. His-bundle pacing is superior to RV apex pacing in adults, ${ }^{12}$ but experience in children is lacking. RV outflow tract pacing offers a modest benefit over RV apex pacing in adults. ${ }^{13}$ In canine hearts single site LV apex pacing resulted in equally good hemodynamic responses as multisite pacing. ${ }^{6} \mathrm{LV}$ apex pacing in children acutely increased LV function as compared with RV pacing to levels close to sinus rhythm. ${ }^{3}$ The beneficial hemodynamic effect of $L V$ apex pacing is probably explained by the physiological apex-to-base sequence of electrical activation during pacing from this site, resulting in synchronous contraction around the circumference of the LV wall. ${ }^{3}$ The data from this case suggest that the acute hemodynamic benefits of LV apex pacing translate to long-term effects. Biventricular pacing in postoperative children with conduction delay acutely increases LV function. ${ }^{14,15}$ Chronic biventricular pacing effectively increases LV pump function in children with heart failure related to either intrinsic conduction delay or to pacing-induced dyssynchrony. ${ }^{2,16}$ The favorable effect of LV apex pacing in this report indicates that single optimal site pacing provides an alternative for biventricular pacing therapy. This idea is supported by the equally good LV pump function during LV apex and biventricular pacing during 
the follow-up measurement (table 4.1). This is an important issue, since implantation of a single pacing lead is advantageous over implanting multiple ventricular leads, especially with regard to factors such as surgical access routes, development of scar tissue, future growth of the child, and battery survival.

\section{CONCLUSION}

RV pacing-induced heart failure in a 2-year-old child was effectively treated using single site LV apex pacing. This case emphasizes that in children with a ventricular pacemaker, proper choice of the pacing site is of utmost importance. Considering the practical advantages of single site over multisite ventricular pacing, further studies on the use of LV apex pacing are indicated.

\section{REFERENCES}

1. Karpawich PP. Chronic right ventricular pacing and cardiac performance: the pediatric perspective. Pacing Clin Electrophysiol 2004; 27:844-849.

2. Moak JP, Hasbani K, Ramwell C, Freedenberg V, Berger JT, DiRusso G, Callahan P. Dilated cardiomyopathy following right ventricular pacing for $A V$ block in young patients: resolution after upgrading to biventricular pacing systems. J Cardiovasc Electrophysiol 2006; 17:1068-1071.

3. Vanagt WY, Verbeek XA, Delhaas T, Mertens L, Daenen WJ, Prinzen FW. The Left Ventricular Apex is the Optimal Site for Pediatric Pacing. Pacing Clin Electrophysiol 2004; 27:837-843.

4. Sweeney MO, Prinzen FW. A new paradigm for physiologic ventricular pacing. J Am Coll Cardio 2006; 47:282-288.

5. Tantengco MV, Thomas RL, Karpawich PP. Left ventricular dysfunction after long-term right ventricular apical pacing in the young. J Am Coll Cardiol 2001; 37:2093-2100.

6. Peschar $M$, de Swart $H$, Michels KJ, Reneman RS, Prinzen FW. Left ventricular septal and apex pacing for optimal pump function in canine hearts. J Am Coll Cardiol 2003; 41:1218-1226.

7. Janousek J, Tomek V, Chaloupecky V, Gebauer RA. Dilated cardiomyopathy associated with dualchamber pacing in infants: improvement through either left ventricular cardiac resynchronization or programming the pacemaker off allowing intrinsic normal conduction. $J$ Cardiovasc Electrophysiol 2004; $15: 470-474$.

8. Pitzalis MV, lacoviello $M$, Romito $R$, Massari F, Rizzon $B$, Luzzi G, Guida $P$, et al. Cardiac resynchronization therapy tailored by echocardiographic evaluation of ventricular asynchrony. J Am Coll Cardiol 2002; 40:1615-1622.

9. Thambo JB, Bordachar P, Garrigue S, Lafitte $S$, Sanders P, Reuter S, Girardot R, et al. Detrimental ventricular remodeling in patients with congenital complete heart block and chronic right ventricular apical pacing. Circulation 2004; 110:3766-3772.

10. Kim JJ, Friedman RA, Eidem BW, Cannon BC, Arora G, Smith EO, Fenrich AL, et al. Ventricular function and long-term pacing in children with congenital complete atrioventricular block. J Cardiovasc Electrophysiol 2007; 18:373-377.

11. Vatasescu $R$, Shalganov T, Paprika D, Kornyei L, Prodan Z, Bodor G, Szatmari A, et al. Evolution of left ventricular function in paediatric patients with permanent right ventricular pacing for isolated congenital heart block: a medium term follow-up. Europace 2007; 9:228-232. 
12. Deshmukh $P$, Casavant DA, Romanyshyn M, Anderson K. Permanent, direct His-bundle pacing: a novel approach to cardiac pacing in patients with normal His-Purkinje activation. Circulation 2000; 101:869-877.

13. de Cock CC, Giudici MC, Twisk JW. Comparison of the haemodynamic effects of right ventricular outflow-tract pacing with right ventricular apex pacing: a quantitative review. Europace 2003; 5:275278.

14. Janousek J, Vojtovic P, Hucin B, Tlaskal T, Gebauer RA, Gebauer R, Matejka T, et al. Resynchronization pacing is a useful adjunct to the management of acute heart failure after surgery for congenital heart defects. Am J Cardiol 2001; 88:145-152.

15. Zimmerman FJ, Starr JP, Koenig PR, Smith P, Hijazi ZM, Bacha EA. Acute hemodynamic benefit of multisite ventricular pacing after congenital heart surgery. Ann Thorac Surg 2003; 75:1775-1780.

16. Dubin AM, Janousek J, Rhee E, Strieper MJ, Cecchin F, Law IH, Shannon KM, et al. Resynchronization therapy in pediatric and congenital heart disease patients: an international multicenter study. $J$ Am Coll Cardiol 2005; 46:2277-2283.

17. Daubeney PE, Blackstone EH, Weintraub RG, Slavik Z, Scanion J, Webber SA. Relationship of the dimension of cardiac structures to body size: an echocardiographic study in normal infants and children. Cardiol Young 1999; 9:402-410.

18. Kouchoukos NT, Blackstone EH, Doty DB, Hanley FL, Karp RB. Kirklin/Barrat-Boyes cardiac surgery: morphology, diagnostic criteria, natural history, techniques, results, and indications. 3rd ed. Philadelphia: Churchill; 2003. 


\section{Structural and functional benefit of chronic left ventricular over right ventricular pacing in children}

Ward Y. Vanagt ${ }^{1,2}$, Irene E.G. Van Geldorp ${ }^{1,2}$, Urs Bauersfeld ${ }^{3}$, Maren Tomaske ${ }^{3}$, Frits W. Prinzen ${ }^{1}$, and Tammo Delhaas ${ }^{1.2}$

Departments of ${ }^{1}$ Physiology and ${ }^{2}$ Pediatrics, Division of Pediatric Cardiology, Maastricht University, Maastricht, Netherlands, and ${ }^{3}$ Department of Pediatric Cardiology, University Children's Hospital Zurich, Zurich, Switzerland

Pacing and Clinical Electrophysiology, 2007; submitted. 


\section{ABSTRACT}

Objectives: Chronic right ventricular (RV) pacing induces deleterious structural and functional cardiac changes. Because animal studies showed acute hemodynamic benefit of left ventricular (LV) over RV pacing, we compared the long-term effects of chronic RV and LV pacing in children.

Methods: Retrospectively, 2D short axis echocardiographic data were collected from healthy children (controls $n=18$, age $4.8 \pm 3.7 \mathrm{y}$ ) and from children undergoing chronic epicardial RV pacing $(n=7$, age $6.6 \pm 2.2 \mathrm{y}$, pacing duration $3.9 \pm 2.1 \mathrm{y})$ or LV lateral wall pacing $(n=7$, age $6.7 \pm 3.3 \mathrm{y}$, pacing duration $3.8 \pm 1.8 \mathrm{y}$ ). LV end-diastolic (LVEDWT) and end-systolic wall thickness (LVESWT), LV end-diastolic diameter (LVEDD) and LV end-systolic diameter (LVESD) were measured and normalized to body surface area. Shortening fraction (SF) and eccentricity index (=LVESD/(2*LVESWT)) were calculated as measures of LV function and eccentricity, respectively. QRS-duration was assessed as a measure of synchrony of electrical activation. $\mathrm{P}<0.05=$ significant.

Results: Age, LVEDD, LVESD, LVEDWT and LVESWT were not significantly different between the groups. However, SF was significantly lower in the RV paced $(21.7 \pm 6.0 \%)$ than in the LV paced $(32.2 \pm 5.2 \%)$ and control children $(29.3 \pm 4.3 \%)$. This was associated with a significantly larger end-systolic eccentricity index in RV paced $(1.8 \pm 0.2)$ than in LV paced $(1.4 \pm 0.1)$ and control (1.4 \pm 0.2$)$ children. QRS-duration was similarly prolonged in the RV (157 $\pm 10 \mathrm{~ms})$ and LV (158 $\pm 22 \mathrm{~ms}$ ) paced children as compared with control children ( $69 \pm 7 \mathrm{~ms}$ ).

Conclusions: Chronic LV pacing maintains LV structure and function at the level of healthy children, whereas chronic RV pacing results in significant deterioration of LV function and eccentricity. 


\section{INTRODUCTION}

In children ${ }^{1}$ and adults ${ }^{2}$ with congenital or acquired atrioventricular block (AVblock), the ventricular pacing lead is traditionally positioned at the right ventricle (RV). However, RV apex pacing results in an acute decrease in left ventricular (LV) function in animals, ${ }^{3}$ adults ${ }^{4}$ and children. ${ }^{5,6}$ During chronic RV pacing in children, LV function, morphology ${ }^{7,8}$ and histology ${ }^{9}$ deteriorate over time (for review see $^{1}$ ). Chronic RV pacing can eventually result in cardiac failure, which occurs in 6-7\% of children. ${ }^{10-12}$ Also in adults, chronic RV apex pacing has deleterious effects (for review $s e^{2}$ ) and increases the risk of heart failure. ${ }^{13,14}$

The recognition of the harmful effects of RV apex pacing initiated the search for alternative ventricular pacing sites, such as the RV outflow tract, Hisbundle, LV wall and biventricular pacing. Pacing at the His-bundle is likely the superior approach, ${ }^{15}$ but appears technically difficult, especially in children. RV outflow tract pacing does not provide a consistent beneficial hemodynamic effect over RV apex pacing. ${ }^{4}$ During pacing at different RV septal sites, hemodynamic function varies widely, and the location of the RV septal site that leads to the less pronounced decrease in pump function also varies between hearts. ${ }^{16}$ In adults with heart failure, LV lateral wall pacing ${ }^{17,{ }^{18}}$ as well as biventricular (RV apex + LV lateral wall) pacing ${ }^{18}$ acutely results in improved functional outcome as compared with RV apex pacing. Also in adults, LV pacing alone seems as effective as biventricular resynchronization therapy, both in the acute situation ${ }^{19}$ and after 6 months of pacing. ${ }^{20}$

The aim of the present study is to investigate the long-term functional and structural outcome of epicardial RV and LV pacing in children. The study was performed retrospectively on echocardiographic and electrocardiographic (ECG) data from children undergoing chronic RV or LV pacing and from healthy children (control).

\section{METHODS}

\section{Study population and pacing characteristics}

All children with normal cardiac anatomy and a ventricular pacemaker in the database of the University Children's Hospital in Zurich (Switzerland) were considered for inclusion. 
Table 5.1 Patient and pacemaker characteristics in the right ventricular pacing (RVP) and left ventricular pacing (LVP) groups.

\begin{tabular}{|c|c|c|c|c|c|c|}
\hline Patient & Pacing Indication & Sex & Age & $\begin{array}{l}\text { Pacing } \\
\text { duration }\end{array}$ & $\begin{array}{c}\% \text { Ventricular } \\
\text { pacing }\end{array}$ & Pacing mode \\
\hline RVP-1 & C-AVB III & $F$ & 8.7 & 6.9 & 100 & DDD \\
\hline RVP-2 & C-AVB III & $M$ & 9.4 & 2.2 & 99 & DDD \\
\hline RVP-3 & C-AVB III (Mat. SLE) & $\mathrm{F}$ & 6.3 & 6.3 & 100 & $\mathrm{WI}$ \\
\hline RVP-4 & $A-A V B \|$ & $F$ & 4.3 & 2.5 & 100 & $D D D$ \\
\hline RVP-5 & C-AVB III & $F$ & 4.4 & 2.3 & 99 & DDD \\
\hline RVP-6 & $A-A V B \|$ & $F$ & 8.4 & 2.5 & 99 & DDD \\
\hline RVP-7 & C-AVB III (Mat. SLE) & $\mathrm{F}$ & 4.9 & 4.9 & 100 & $\mathrm{Wl}$ \\
\hline LVP-1 & C-AVB III & $M$ & 6.8 & 5.5 & 100 & $\mathrm{WI}$ \\
\hline LVP-2 & A-AVB III & $F$ & 11.1 & 1.5 & 100 & DDD \\
\hline LVP-3 & AVB II, long QT & $F$ & 4.4 & 4.8 & 99 & DDD \\
\hline LVP-4 & $A V B \|$ & $M$ & 7.4 & 3.3 & 100 & DDD \\
\hline LVP-5 & C-AVB III & $M$ & 3.7 & 2.5 & 100 & DDD \\
\hline LVP-6 & A-AVB III & $F$ & 10.6 & 6.3 & 99 & DDD \\
\hline LVP-7 & C-AVB III (Mat. SLE) & $M$ & 2.8 & 2.8 & 100 & WI \\
\hline
\end{tabular}

Age and duration of pacing values (years) at end of the study period are presented. $A-A V B=$ acquired $A V$-block, $C-A V B=$ congenital $A V$-block, $\|=2^{\text {nd }}$ degree, $\| 1=3^{\text {rd }}$ degree, Mat. SLE = maternal systemic lupus erythematosus, $F=$ female, $M=$ male, $D D D=$ atrial and ventricular sensing and pacing, $W \mathrm{VI}=$ ventricular sensing and pacing. 
Included were the children with available echocardiographic and ECG data undergoing chronic epicardial RV or LV pacing for congenital or acquired AVblock. A minimum of $95 \%$ of paced beats was required for inclusion. Because the number of patients matching all inclusion criteria was limited and preimplantation echocardiography was unavailable in some children, echocardiographic and ECG data were studied retrospectively at a single time-point after chronic RV (RVP, $n=7$ ) or LV (LVP, $n=7$ ) pacing. This time-point was the moment of the most recent outpatient clinic visit. In children that underwent a pacing lead replacement, the last echocardiography and ECG data prior to pacing lead replacement were studied to exclude effects of changes in pacing site between the initiation of pacing and the moment the data were obtained. At the University Children's Hospital in Zurich (Switzerland), children are paced either at the RV or at the LV, pacing site being determined mainly on surgical preferences. Bipolar steroid eluting pacing leads (Medtronic CapSure Epi 10366 or 4968, Medtronic Inc., Minneapolis, MN, USA) were implanted in all children and connected to various pulse generators. Surgical access for RV leads was subxyphoidal or sternotomy, whereas for LV leads a left lateral thoracotomy was performed. The epicardial ventricular pacing lead was located at the RV apex or free wall (RVP group) or LV lateral wall (LVP group). Table 5.1 depicts the patient and pacemaker characteristics of the paced children. The control group consisted of 18 healthy children who visited the outpatient clinic for an innocent murmur. No patient received any cardiovascular drugs. This retrospective study was approved by the local ethical committee and performed according to their guidelines.

\section{Echocardiographic evaluation}

Echocardiographic data were obtained in the standard precordial positions with appropriate transducers $(7.5,5.0,3.5$, and $2.5 \mathrm{MHz}$, Vivid 7 , General Electric Healthcare, and Philips Sonos 5500, Philips, Netherlands).

Data were either digitally stored or stored on VHS videotapes and subsequently digitized off-line. End-diastolic and end-systolic frames of the parasternal short axis views were further analyzed using Matlab software (The Mathworks Inc, Natick, MA, USA). 


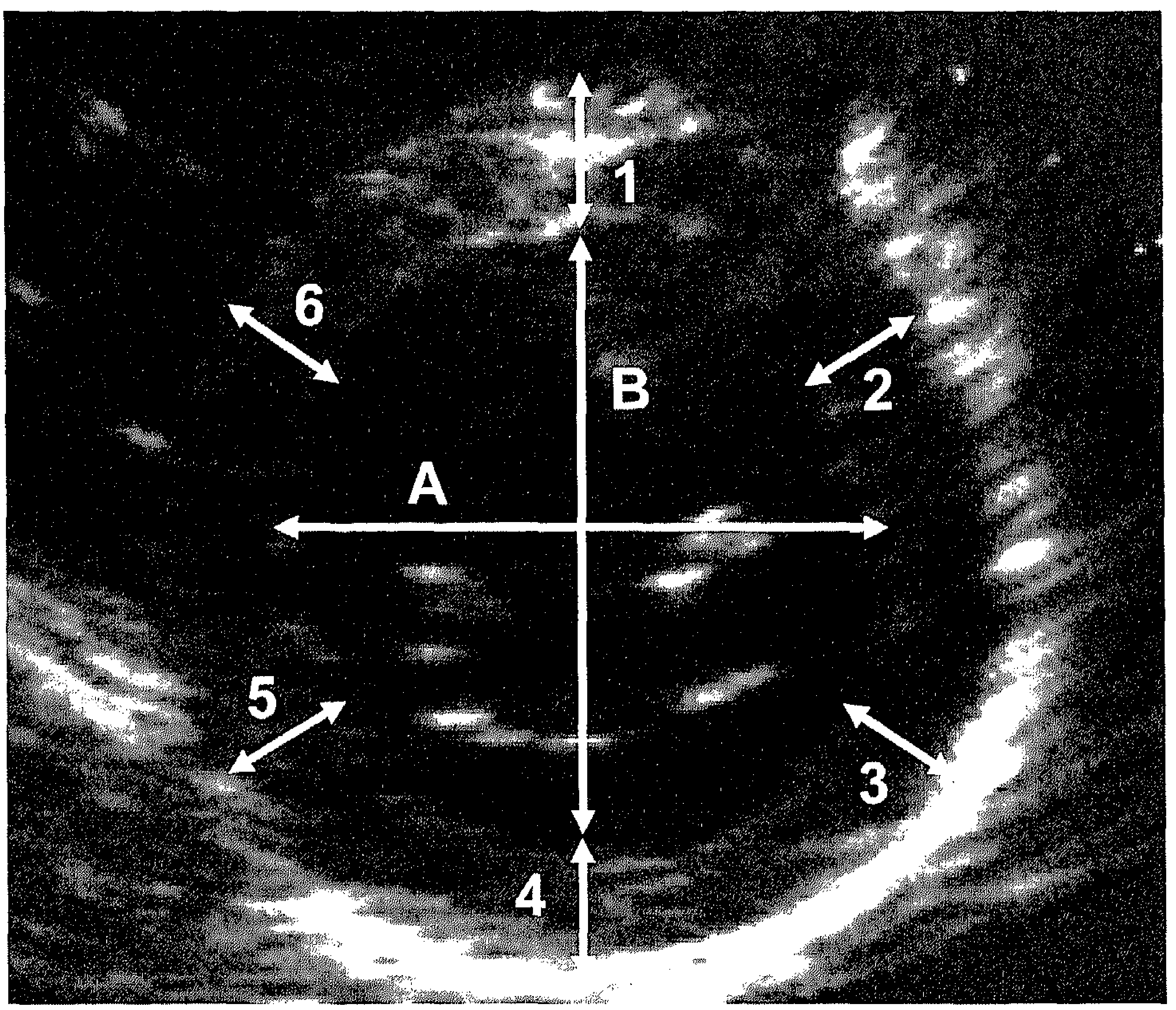

Figure 5.1 Representative echocardiographic short axis view. Indicated are the 6 regions for wall thickness determination (arrows) and the inner diameter of the left ventricle (LV). LV diameter was determined as the mean of diameters $A$ and $B$.

Two observers, blinded to the study group of the patient, each performed 3 independent measurements in random order for every patient. The average of the measurements performed by both observers was used for further analysis. A representative example of a processed echocardiographic image is depicted in figure 5.1 .

Body surface area was calculated using the formula of Du Bois and Du Bois ${ }^{21}$ for normalization of structural echocardiographic measures:

$$
\text { Body surface area }\left(\mathrm{m}^{2}\right)=0,20247 \times\left(\text { Length }(\mathrm{m})^{0,725}\right) \times\left(\text { Weight }(\mathrm{kg})^{0,425}\right)
$$

LV end-diastolic diameter (LVEDD) and LV end-systolic diameter (LVESD) were measured and corrected for body surface area by dividing the LV diameter $(\mathrm{mm})$ by body surface area $\left(\mathrm{m}^{2}\right)$. 
Shortening fraction (SF) as a measure of cardiac function was defined as:

$$
\text { SF }(\%)=((\text { LVEDD - LVESD }) / \text { LVEDD }) * 100
$$

Regional changes in LV wall thickness were assessed by measuring the LV wall in 6 consecutive regions on the short axis view (figure 5.1). The mean of these 6 regions was used as mean LV end-diastolic wall thickness (LVEDWT) and mean LV end-systolic wall thickness (LVESWT). LV wall thickness values were corrected for body surface area as described above.

The eccentricity index of the LV was calculated as:

LV eccentricity index $=$ LV diameter / $(2 *$ mean LV wall thickness $)$

\section{Electrocardiographic evaluation}

QRS-duration was assessed from the surface electrocardiogram (ECG) during sinus rhythm (control group), RV pacing (RVP group) and LV pacing (LVP group) and was used as a measure of synchrony of electrical ventricular activation.

\section{Statistical analysis}

Statistical analysis was performed using one-way analysis of variance (ANOVA) on every parameter. Only if ANOVA showed a significant difference, further analysis with Tukey comparison was used to identify statistical differences between the different study groups. A p-value of less than 0.05 was considered statistically significant. Data are presented as mean \pm standard deviation, unless specified otherwise. For echocardiographic measures, the inter-observer correlation ( $r$-value) was assessed by Pearson product moment correlation.

\section{RESULTS}

\section{Study population}

Patient and pacemaker characteristics of the RVP and LVP groups are presented in table 5.1. Age and body surface area were not significantly different between the groups (RVP $6.6 \pm 2.2$ years and $0.9 \pm 0.2 \mathrm{~m}^{2}$; LVP $6.7 \pm 3.3$ years and $0.9 \pm 0.3 \mathrm{~m}^{2}$; Control $4.8 \pm 3.7$ years and $0.7 \pm 0.3 \mathrm{~m}^{2}$, respectively). The duration of ventricular pacing was not significantly different between the two paced groups (RVP $3.9 \pm 2.1$ years; LVP $3.8 \pm 1.8$ years). 


\section{Structural echocardiographic outcome}

Inter-observer reproducibility was good for LVEDD ( $r=0.96)$, LVESD $(r=$ 0.95), mean LVEDWT $(r=0.90)$ and mean LVESWT $(r=0.94)$. LVEDD, LVESD, mean LVEDWT and mean LVESWT were not significantly different between the 3 study groups (table 5.2). There were no significant differences in LV wall thickness between different regions of the heart in any of the study groups (data not shown).

Table 5.2 Echocardiographic structural results.

$\begin{array}{lcccc} & \text { RV Pacing group } & \text { LV Pacing group } & \text { Control group } & \begin{array}{c}\text { P-value between } \\ \text { groups }\end{array} \\ \text { LVEDD }\left(\mathrm{mm} / \mathrm{m}^{2}\right) & 46.2 \pm 4.7 & 45.2 \pm 8.5 & 50.1 \pm 10.6 & 0.41 \\ \left.\text { LVESD (mm/m }{ }^{2}\right) & 36.2 \pm 4.7 & 30.6 \pm 6.3 & 35.3 \pm 7.6 & 0.24 \\ \text { LVEWWT }\left(\mathrm{mm} / \mathrm{m}^{2}\right) & 8.5 \pm 0.9 & 8.7 \pm 3.0 & 9.4 \pm 2.7 & 0.68 \\ \text { LVESWT }\left(\mathrm{mm} / \mathrm{m}^{2}\right) & 10.1 \pm 0.7 & 10.7 \pm 2.6 & 12.2 \pm 3.3 & 0.20\end{array}$

Presented are values conrected for body surface area. $R V=$ right ventricular $\mathrm{LV}=$ left ventricular, LVEDD = left ventricular end-diastolic diameter, LVESD = LV end-systolic diameter $L$ LVDWT = mean LV end-diastolic wall thickness, LVESWT = mean LV end-systolic wall thickness. No significant differences between groups.

\section{Functional echocardiographic outcome}

Shortening fraction was significantly lower in the RVP group $(21.7 \pm 6.0 \%)$ as compared with the LVP $(32.2 \pm 5.2 \%)$ and control groups $(29.3 \pm 4.3 \%$, n.s. between control and LVP groups, figure 5.2) At end-systole the LV eccentricity index was significantly higher in the RVP $(1.8 \pm 0.2)$ as compared with the LVP $(1.4 \pm 0.1)$ and control $(1.4 \pm 0.2)$ groups (n.s. between LVP and control groups, figure 5.3). At end-diastole, the LV eccentricity index was not significantly different between the study groups (RVP $2.7 \pm 0.3$, LVP $2.7 \pm 0.6$ and control $2.7 \pm 0.4)$. 


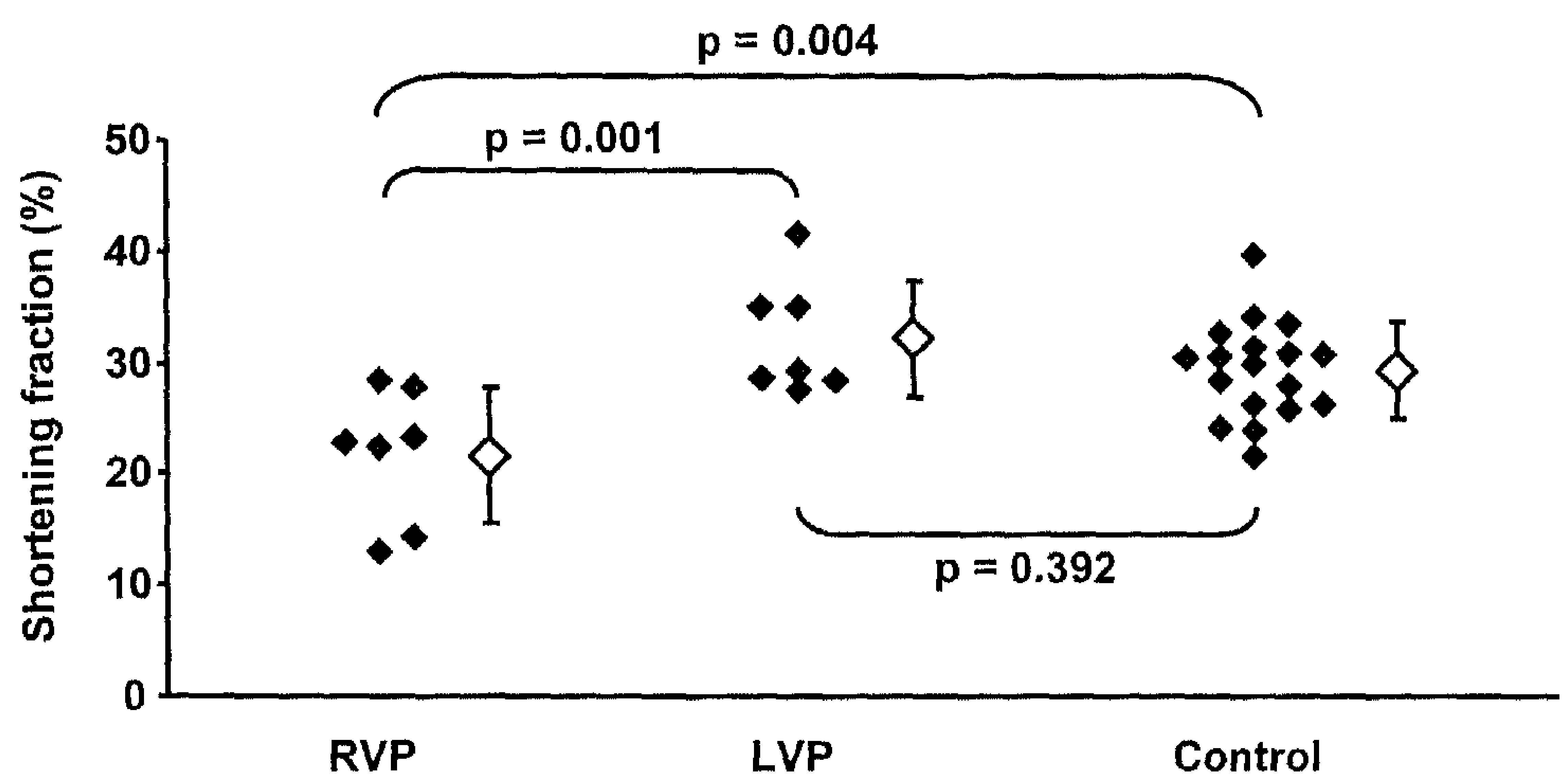

Figure 5.2 Shortening fraction in the 3 study groups. RVP = right ventricular pacing group, LVP $=$ left ventricular pacing group, closed symbols $=$ individual data, open symbols $=$ group average \pm standard deviation.

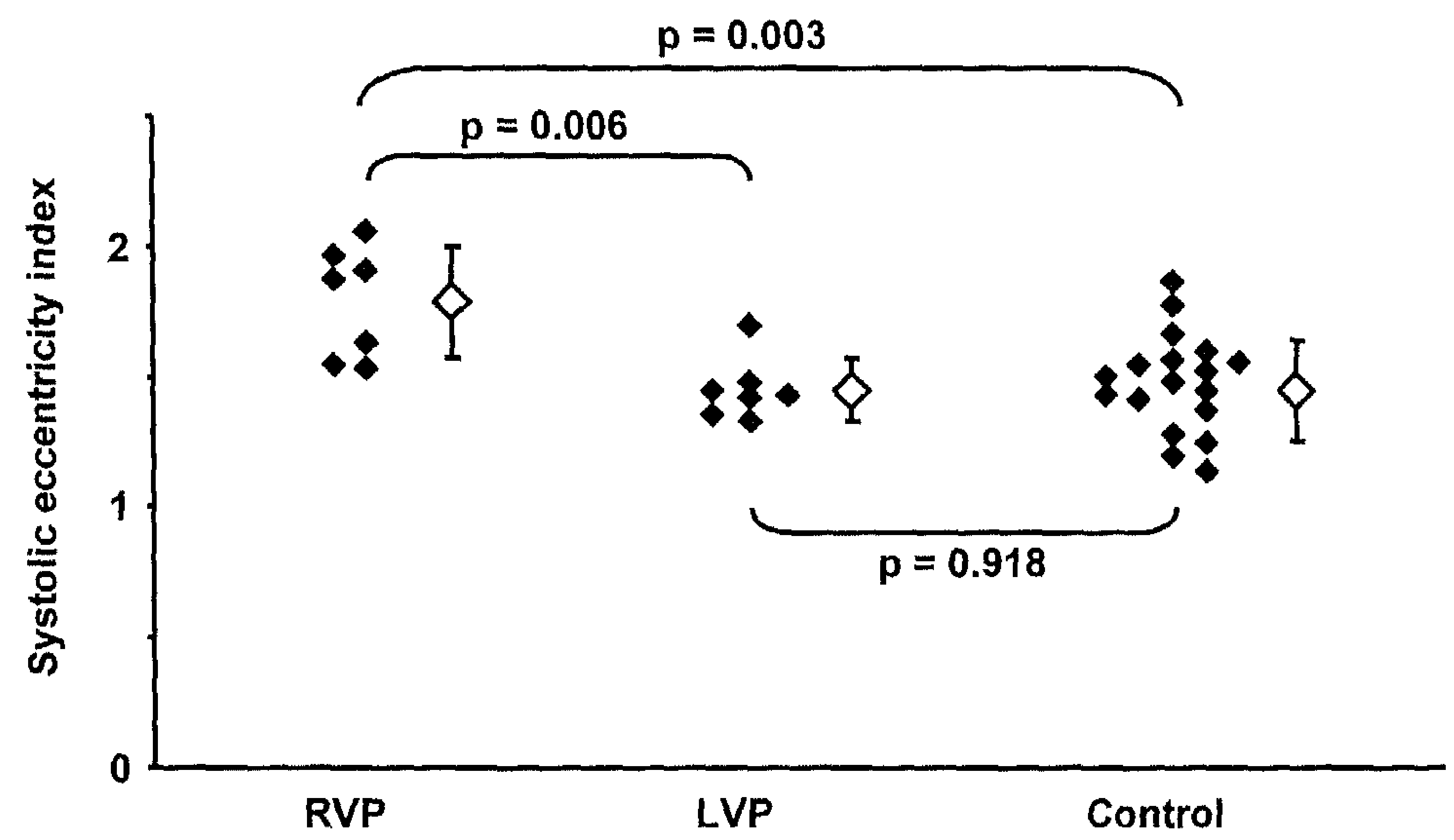

Figure 5.3 End-systolic LV eccentricity index in the 3 study groups. For legends see figure 5.2 .

\section{QRS-duration}

QRS-duration was $69 \pm 7 \mathrm{~ms}$ in the control group, and significantly longer in the RVP (157 $\pm 10 \mathrm{~ms}$ ) and LVP groups (158 $\pm 22 \mathrm{~ms}$, n.s. between RVP and LVP). 


\section{DISCUSSION}

To our knowledge, this is the first study comparing the long-term effects of RV and LV pacing in children. The present study confirms the findings of previous studies that chronic RV pacing is detrimental to the heart. ${ }^{1,2,7,8}$ Chronic RV pacing is associated with deleterious LV remodeling ${ }^{8,9}$ and decreased LV function ${ }^{7}$ in the young (for review see ${ }^{1}$ ) and in adults (for review see ${ }^{2}$ ). More importantly, chronic epicardial LV pacing (mean duration $>31 / 2$ years) maintains LV function and structure at the level of healthy control children. This finding negates the argument that the poor cardiac function in chronically RV paced children is exclusively due to the underlying heart disease. Therefore, this study indicates that pacing site is an important determinant for cardiac function and structure in children.

\section{Relation between pacing site and LV function}

In parallel with the acute decrease in cardiac pump function during RV pacing, ${ }^{5,6}$ chronic RV pacing significantly depressed shortening fraction in the current study. Furthermore, the LV eccentricity index was significantly increased after chronic RV pacing. Although neither LV nor aortic pressures were assessed in these children, the increased eccentricity index in RV paced children might indicate increased wall stress. The eccentricity index provides an approximation of wall stress, since fiber stress increases proportionally to the increment of the product of LV pressure and the ratio of LV cavity diameter to LV wall thickness. ${ }^{22,}{ }^{23} \mathrm{LV}$ pacing neither increased eccentricity index nor decreased shortening fraction after more than 3 years of pacing. The superior hemodynamic performance during LV pacing compared with RV pacing is probably caused by a more favorable balance between interventricular synchrony, ${ }^{24}$ intraventricular synchrony ${ }^{6}$ and the sequence of electrical ventricular activation $^{3}$ during LV pacing. During RV pacing, a left bundle branch blockpattern of activation is created. ${ }^{1-3,6}$ The observation that LV function is significantly more compromised in patients with isolated left bundle branch block as compared with patients with isolated right bundle branch block ${ }^{25}$ supports the idea that the sequence of activation is an important determinant of cardiac pump function. ${ }^{3,26}$

QRS-duration was not different between the two paced groups in our study, despite the significantly different hemodynamic performance. This is in accordance with other studies where QRS-duration during pacing was not related to cardiac function. ${ }^{6,26,27}$ It is important to bear in mind that QRS-duration reflects total biventricular activation time, whereas intraventricular electrical synchrony is probably a more important determinant of LV function. ${ }^{2,6}$ Given the absence 
of a consistent correlation between cardiac function and QRS-duration in acute and chronic pacing studies, we discourage the use of QRS-duration as a tool for the selection of an optimal epicardial pacing site in children.

\section{Clinical application}

In the current study, chronic LV pacing is superior to RV pacing in terms of LV function and relative systolic dimensions. We therefore advocate the use of LV pacing sites when chronic epicardial pacing is indicated in children. The optimal LV pacing site in children remains to be determined. In the acute situation, LV apex pacing increases pump function as compared with RV pacing, ${ }^{6}$ and biventricular pacing increases cardiac function after surgery for congenital heart disease as compared with intrinsic activation. ${ }^{24,} 27$ Experience with chronic biventricular pacing in children is sparse, but a multi-center study showed promising results regarding cardiac function after 4 months of resynchronization therapy, ${ }^{28}$ and biventricular pacing proved effective in treating 6 children with RV pacing-induced heart failure. ${ }^{10}$ In adults with congestive heart failure, chronic LV lateral wall pacing (single site) can be as effective as biventricular pacing. ${ }^{20}$ To our knowledge, the effect of chronic biventricular pacing in children has not been compared with LV lateral wall pacing alone.

The children described in this study all had surgically implanted epicardial leads, unlike most adult patients in whom an endovenous approach is generally chosen. Access to the LV epicardium using an endovenous approach has been described in children requiring a pacemaker, ${ }^{29}$ but possibly jeopardizes endovascular and especially coronary sinus integrity in children. Epicardial LV pacing sites are easily accessible through a left lateral thoracotomy, which is surgically reliable and provides excellent cosmetic and functional results in children. ${ }^{30}$

\section{Limitations of the study}

The patients in this study were not randomized due to the retrospective study design. Since the surgeon determined the ventricular pacing site, bias related to the selection of the ventricular pacing site by different surgeons cannot be excluded. The exact location of the epicardial RV and LV leads was not standardized, since anatomical, surgical and electrophysiological factors had to be taken into account at implantation. However, all paced children matching the inclusion criteria at a large institution were studied, and body surface area, age and duration of pacing were not different between the study groups. The number of studied patients was small as patients with structural heart disease were excluded. More studies in larger groups, comparing multiple alternative pacing 
sites are needed to identify the optimal pacing site(s) for chronic pacing in children.

\section{CONCLUSIONS}

Chronic RV pacing in children results in significant deterioration of LV function and relative systolic LV dilatation. These abnormalities can be prevented by positioning the pacing electrode at the LV lateral wall. QRS-duration is a poor predictor of the optimal epicardial pacing site in paced children.

\section{ACKNOWLEDGEMENTS}

The authors gratefully acknowledge Joost Lumens MSc at the Maastricht University for his contribution to the analysis of the data. We wish to thank St Jude Medical, Veenendaal, The Netherlands for financial support of the travel expenses related to this project.

\section{REFERENCES}

1. Karpawich PP. Chronic right ventricular pacing and cardiac performance: the pediatric perspective. Pacing Clin Electrophysiol 2004; 27:844-849.

2. Manolis AS. The deleterious consequences of right ventricular apical pacing: time to seek alternate site pacing. Pacing Clin Electrophysiol 2006; 29:298-315.

3. Prinzen FW, Peschar M. Relation between the pacing induced sequence of activation and left ventricular pump function in animals. Pacing Clin Electrophysiol 2002; 25:484-498.

4. de Cock CC, Giudici MC, Twisk JW. Comparison of the haemodynamic effects of right ventricular outflow-tract pacing with right ventricular apex pacing: a quantitative review. Europace 2003; 5:275278.

5. Karpawich PP, Mital S. Comparative left ventricular function following atrial, septal, and apical single chamber heart pacing in the young. Pacing Clin Electrophysiol 1997; 20:1983-1988.

6. Vanagt WY, Verbeek XA, Delhaas T, Mertens L, Daenen WJ, Prinzen FW. The Left Ventricular Apex is the Optimal Site for Pediatric Pacing. Pacing Clin Electrophysiol 2004; 27:837-843.

7. Tantengco $M V$, Thomas $R L$, Karpawich $P P$. Left ventricular dysfunction after long-term right ventricular apical pacing in the young. J Am Coll Cardiol 2001; 37:2093-2100.

8. Thambo JB, Bordachar P, Garrigue S, Lafitte $S$, Sanders $P$, Reuter $S$, Girardot R, et al. Detrimental ventricular remodeling in patients with congenital complete heart block and chronic right ventricular apical pacing. Circulation 2004; 110:3766-3772.

9. Karpawich PP, Rabah R, Haas JE. Altered cardiac histology following apical right ventricular pacing in patients with congenital atrioventricular block. Pacing Clin Electrophysiol 1999; 22:1372-1377.

10. Moak JP, Hasbani K, Ramwell C, Freedenberg V, Berger JT, DiRusso G, Callahan P. Dilated cardiomyopathy following right ventricular pacing for $A V$ block in young patients: resolution after upgrading to biventricular pacing systems. J Cardiovasc Electrophysiol 2006; 17:1068-1071.

11. Kim JJ, Friedman RA, Eidem BW, Cannon BC, Arora G, Smith EO, Fenrich AL, et al. Ventricular function and long-term pacing in children with congenital complete atrioventricular block. J Cardiovasc Electrophysiol 2007; 18:373-377. 
12. Vatasescu R, Shalganov T, Paprika D, Kornyei L, Prodan Z, Bodor G, Szatmari A, et al. Evolution of left ventricular function in paediatric patients with permanent right ventricular pacing for isolated congenital heart block: a medium term follow-up. Europace 2007; 9:228-232.

13. Sweeney MO, Hellkamp AS, Ellenbogen KA, Greenspon AJ, Freedman RA, Lee KL, Lamas GA. Adverse effect of ventricular pacing on heart failure and atrial fibrillation among patients with normal baseline QRS duration in a clinical trial of pacemaker therapy for sinus node dysfunction. Circulation 2003; 107:2932-2937.

14. Andersen HR, Nielsen JC, Thomsen PE, Thuesen L, Mortensen PT, Vesterlund T, Pedersen AK. Long-term follow-up of patients from a randomised trial of atrial versus ventricular pacing for sicksinus syndrome. Lancet 1997; 350:1210-1216.

15. Deshmukh P, Casavant DA, Romanyshyn M, Anderson K. Permanent, direct His-bundle pacing: a novel approach to cardiac pacing in patients with normal His-Purkinje activation. Circulation 2000; 101:869-877.

16. Peschar M, de Swart H, Michels KJ, Reneman RS, Prinzen FW. Left ventricular septal and apex pacing for optimal pump function in canine hearts. J Am Coll Cardiol 2003; 41:1218-1226.

17. Puggioni $E$, Brignole $M$, Gammage $M$, Soldati $E$, Bongiorni $M G$, Simantirakis $E N$, Vardas $P$, et al. Acute comparative effect of right and left ventricular pacing in patients with permanent atrial fibrillation. J Am Coll Cardiol 2004; 43:234-238.

18. Blanc JJ, Etienne $Y$, Gilard M, Mansourati J, Munier S, Boschat J, Benditt DG, et al. Evaluation of different ventricular pacing sites in patients with severe heart failure: results of an acute hemodynamic study. Circulation 1997; 96:3273-3277.

19. Nelson GS, Berger RD, Fetics BJ, Talbot M, Spinelli JC, Hare JM, Kass DA. Left ventricular or biventricular pacing improves cardiac function at diminished energy cost in patients with dilated cardiomyopathy and left bundle-branch block. Circulation 2000; 102:3053-3059.

20. Touiza A, Etienne $Y$, Gilard M, Fatemi M, Mansourati J, Blanc JJ. Long-term left ventricular pacing: assessment and comparison with biventricular pacing in patients with severe congestive heart failure. J Am Coll Cardiol 2001; 38:1966-1970.

21. Du Bois $D$, Du Bois EF. A formula to estimate the approximate surface area if height and weight be known. 1916. Nutrition 1989; 5:303-311; discussion 312-303.

22. Arts $T$, Bovendeerd PH, Prinzen FW, Reneman RS. Relation between left ventricular cavity pressure and volume and systolic fiber stress and strain in the wall. Biophys $J$ 1991; 59:93-102.

23. Delhaas $T$, Arts $T$, Bovendeerd PH, Prinzen FW, Reneman RS. Subepicardial fiber strain and stress as related to left ventricular pressure and volume. Am J Physiol 1993; 264:H1548-1559.

24. Janousek J, Vojtovic P, Hucin B, Tlaskal T, Gebauer RA, Gebauer R, Matejka T, et al. Resynchronization pacing is a useful adjunct to the management of acute heart failure after surgery for congenital heart defects. Am J Cardiol 2001; 88:145-152.

25. Quintana $M$, Saha $S$, Rohani $M$, del Furia F, Roumina MS, Lind B, Hayashi $S$, et al. Electromechanical coupling, uncoupling, and ventricular function in patients with bundle branch block: a tissueDoppler echocardiographic study. Echocardiography 2004; 21:687-698.

26. Prinzen FW, Van Oosterhout MF, Vanagt WY, Storm C, Reneman RS. Optimization of ventricular function by improving the activation sequence during ventricular pacing. Pacing Clin Electrophysiol 1998; 21:2256-2260.

27. Zimmerman FJ, Starr JP, Koenig PR, Smith P, Hijazi ZM, Bacha EA. Acute hemodynamic benefit of multisite ventricular pacing after congenital heart surgery. Ann Thorac Surg 2003; 75:1775-1780.

28. Dubin AM, Janousek J, Rhee $E$, Strieper MJ, Cecchin $F$, Law IH, Shannon KM, et al. Resynchronization therapy in pediatric and congenital heart disease patients: an international multicenter study. $J$ Am Coll Cardiol 2005; 46:2277-2283.

29. Blom NA, Bax JJ, Ottenkamp J, Schalij MJ. Transvenous biventricular pacing in a child after congenital heart surgery as an alternative therapy for congestive heart failure. J Cardiovasc Electrophysiol 2003; 14:1110-1112.

30. Dodge-Khatami A, Kadner $A$, Dave $H$, Rahn $M$, Pretre $R$, Bauersfeld $U$. Left heart atrial and ventricular epicardial pacing through a left lateral thoracotomy in children: a safe approach with excellent functional and cosmetic results. Eur J Cardiothorac Surg 2005; 28:541-545. 


\section{Pacing-induced dyssynchrony preconditions rabbit myocardium against ischemia / reperfusion injury}

Ward Y. Vanagt ${ }^{1,2}$, Richard N. Cornelussen ${ }^{1}$, Quincy P. Poulina ${ }^{1}$, Erik Blaauw ${ }^{1}$, Kevin Vernooy ${ }^{1}$, Jack P. Cleutjens ${ }^{3}$, Marc van Bilsen $^{1}$, Tammo Delhaas ${ }^{1,2}$, and Frits W. Prinzen ${ }^{1}$

${ }^{1}$ Departments of Physiology, ${ }^{2}$ Pediatrics, Division of Pediatric Cardiology, and ${ }^{3}$ Pathology, Cardiovascular Research Institute Maastricht, Maastricht, The Netherlands

Circulation, 2006; 114: $1264-1269$. 


\section{bhathes}

\section{ABSTRACT}

Background: Because increased mechanical load induces preconditioning (PC) and dyssynchrony increases loading in late-activated regions we investigated whether dyssynchrony induced by ventricular pacing (VP) at normal heart rate leads to cardioprotection.

Methods: Isolated working rabbit hearts were subjected to $35 \mathrm{~min}$ global ischemia and $2 \mathrm{~h}$ of reperfusion. Seven hearts underwent ventricular pacing preconditioning (VPPC, 3 periods of $5 \mathrm{~min}$ VP at the posterior left ventricular (LV) wall), 7 hearts underwent ischemic preconditioning (IPC, 3 periods of 5 min global ischemia) and 9 hearts served as control (C). LV pressure and sonomicrometry were used to assess global hemodynamics and segment work (SW) and end-diastolic segment length (EDSL) in anterior and posterior LV myocardium. Myocardial release of lactate and expression of proBNP mRNA were determined to gain insight in molecular processes involved in VPPC. ${ }^{*}=p<0.05$.

Results: Infarct size (TTC staining) was $18.3 \pm 13.0 \%$ in group $C$, and was uniformly reduced in the VPPC and IPC groups $\left(1.8 \pm 0.8 \% \%^{*}\right.$, and $3.5 \pm 3.1$ $\%^{*}$, respectively, N.S. between VPPC and IPC). LV posterior wall pacing (VPPC group) increased EDSL (by $6.3 \pm 5.8 \%^{*}$ ) and SW (to $335 \pm 207 \%{ }^{*}$ ) in the LV anterior wall while posterior wall SW decreased to negative values $\left(-23 \pm 63 \%^{*}\right)$. LV pacing did not significantly change lactate release and coronary flow but significantly increased proBNP mRNA expression in both anterior and posterior myocardium as compared with controls.

Conclusions: Intermittent dyssynchrony is equally cardioprotective as "classical" IPC. Stretch-mediated signaling is a more likely trigger for VPPC than ischemia. VPPC is potentially applicable in cardiac surgery. 


\section{INTRODUCTION}

Myocardium can be protected from the detrimental effects of ischemia and reperfusion by subjecting it to various stimuli prior to prolonged ischemia. This so-called preconditioning $(\mathrm{PC})$ has been achieved by, amongst others, brief ischemia, ${ }^{1}$ rapid pacing ${ }^{2,3}$ and increased cardiac preload ${ }^{4,5}$ and afterload. ${ }^{6}$ Dyssynchronous ventricular activation, as elicited by ventricular pacing, induces regional differences in myocardial mechanical work within the left ventricular (LV) wall. Early-activated regions shorten considerably during early systole, thereby stretching late-activated myocardium. As a consequence mechanical load is increased in the latter regions. ${ }^{7,8}$

We hypothesized that the abnormal regional mechanics due to dyssynchronous activation can induce myocardial preconditioning. This was investigated in isolated ejecting rabbit hearts by assessing the protective potency of intermittent LV pacing at normal heart rate, applied prior to global ischemia and subsequent reperfusion. The cardioprotective potency of ventricular pacing was compared with that of classical ischemic preconditioning and potential mechanisms were explored.

\section{MATERIALS AND METHODS}

Animal handling and treatment were according to the Dutch law on animal experimentation (WOD). The protocol was approved by the animal experimental committee of Maastricht University.

Female White New Zealand rabbits $(2.5-3.5 \mathrm{~kg})$ were sedated with Hypnorm® (fluanisole $10 \mathrm{mg} / \mathrm{ml}$ and fentanyl $0.2 \mathrm{mg} / \mathrm{ml}$, subcutaneously $0.5 \mathrm{ml} / \mathrm{kg}$ ) and anticoagulated with intravenous heparin (1500 IU). After cervical dislocation the heart was quickly removed, immersed in ice-cold perfusion buffer for removal of non-cardiac tissue and attached to the perfusion apparatus.

\section{Experimental setup}

The perfusion system was a modified Langendorff setup for the ejecting rabbit heart. The perfusate buffer consisted of (mmol/l): Sodium (153.9), Potassium (5.3), Calcium (2.2), Magnesium (1.1), Hydrogen Carbonate (24.0), Phosphate (1.2) and Glucose (11.0) and was oxygenated with a mixture of Oxygen (95\%) and $\mathrm{CO}_{2}(5 \%)$. pH was 7.35-7.45 and temperature $37.5 \pm 0.5^{\circ}$ Celsius. Aorta and left atrium were cannulated to allow antegrade perfusion. 
Four $1 \mathrm{~mm}$ sonomicrometer crystals (Sonometrics Corporation, London, Ontario, Canada) were placed at $\sim 10 \mathrm{~mm}$ distances at the anterior, anterolateral, posterolateral and posterior LV wall, $-1 \mathrm{~cm}$ below the base of the heart. Electrograms were recorded using pairs of electrodes attached to the right atrial (RA) appendage and LV posterior and anterior wall. Pairs of epicardial pacing electrodes were attached to the RA appendage and the posterior basal LV wall. LV pressure was measured using a cannula introduced into the LV apex. Preload was kept constant at $6 \mathrm{mmHg}$, afterload at $80 \mathrm{mmHg}$ and heart rate at 240 bpm (physiological heart rate for rabbits ${ }^{9}$ ) using RA pacing.

\section{Study protocol and groups}

Animals were divided into 3 study groups. In the control group $(n=9)$ a 50 min period preceded the index ischemia (figure 6.1). In the ventricular pacing preconditioning group (VPPC, $n=7$ ), LV pacing was performed during three $5 \mathrm{~min}$ periods, interspersed with 5 min RA pacing. Like RA pacing, ventricular pacing was performed using a stimulus strength $\sim 2 x$ threshold value. Ventricular pacing was performed at $240 \mathrm{bpm}$ using simultaneous atrioventricular (AV) pacing (AV-interval $=0 \mathrm{~ms}$ ). A group with classical ischemic preconditioning (IPC, three 5 min periods of global ischemia, interspersed with 5 min of reperfusion, $n=7$ ) served as a positive control.

\section{Control group}

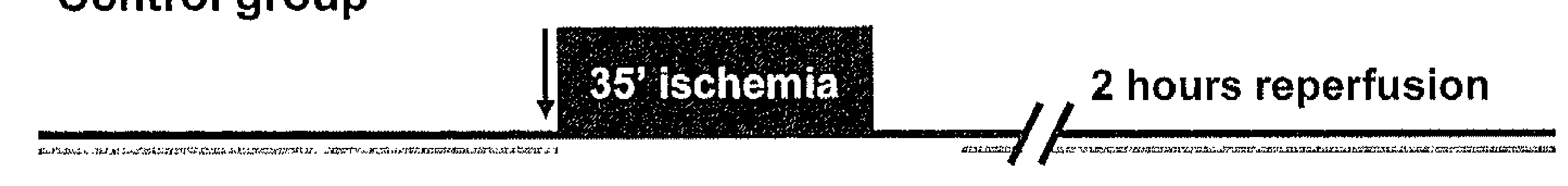

\section{Ventricular pacing preconditioning group (VPPC)}

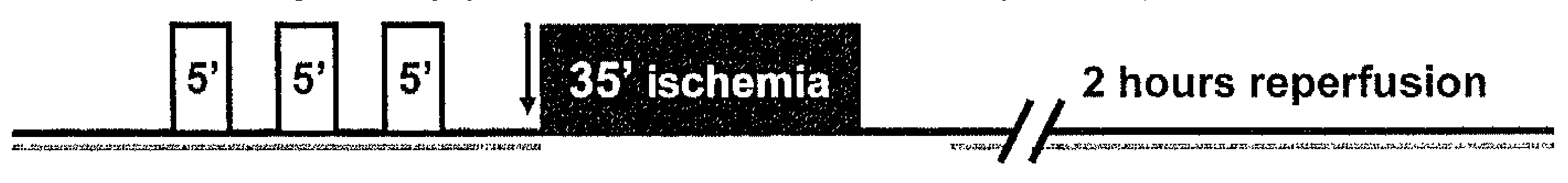

$$
\text { Ischemic preconditioning group (IPC) }
$$

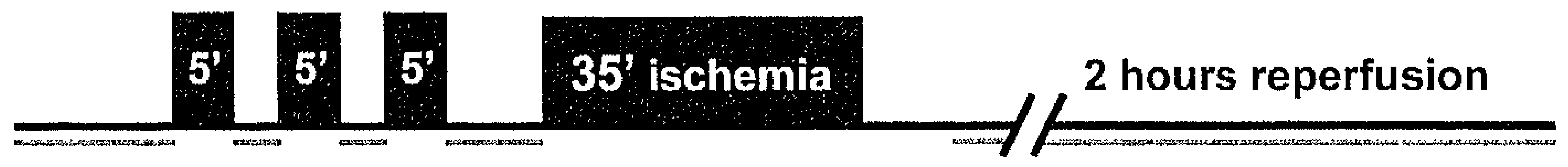

Figure 6.1 Experimental protocol for the 3 study groups. Black blocks = global ischemia, white blocks $=5$ min of left ventricular (LV) pacing at $240 \mathrm{bpm}$. Right atrial (RA) pacing (indicated by the grey line) at $240 \mathrm{bpm}$ was performed throughout the experiment, except during ischemia and the first $10 \mathrm{~min}$ of reperfusion after index ischemia. Arrows indicate the end of the additional experiments for analysis of proBNP mRNA. 
In the two preconditioning groups index ischemia started $10 \mathrm{~min}$ after ending the third preconditioning period (figure 6.1). The index ischemia consisted of 35 min of global normothermic $\left(37.5 \pm 0.5^{\circ}\right.$ Celsius $)$ ischemia. All hearts were reperfused for 2 hours. RA pacing was stopped during ischemia and resumed at $10 \mathrm{~min}$ after the index ischemia.

In order to explore molecular signaling in VPPC, additional experiments were performed according to the protocol in the control and VPPC groups. Experiments were stopped 10 min after the third preconditioning stimulus $(n=4)$ and at the corresponding time point in the control group $(n=5)$ (arrows in figure 6.1). From these hearts, samples from the posterior and anterior LV wall were frozen in liquid nitrogen and stored at $-80^{\circ}$ Celsius.

\section{Data, effluent and tissue collection and processing}

Hemodynamic, electrophysiological and sonomicrometry data were recorded on the Sonometrics system at a sampling rate of $500 \mathrm{~Hz}$. Signals were analyzed off-line. Hemodynamic data consisted of aortic and LV pressure and aortic flow (in-line aortic flow probe). Cardiac output was calculated as the sum of coronary and aortic flow. The area of the pressure-segment length loop was calculated and used as a measure of regional segment work in anterior and posterior LV myocardium. End-diastolic segment length (EDSL) was derived from the PL-loop to assess regional stretch.

Coronary effluent was collected for determination of lactate release. Samples were immediately frozen in liquid nitrogen and stored at $-80^{\circ} \mathrm{C}$. Lactate was determined by spectrophotometry using a Cobas Bio autoanalyzer (Roche Diagnostics, Almere, The Netherlands). ${ }^{10}$

After 2 hours of reperfusion the hearts were cut into $2 \mathrm{~mm}$ thick transverse slices, which were stained with $1 \%$ triphenyl tetrazolium chloride (TTC) and fixated in $4 \%$ formaldehyde. Infarct size was quantified 24 hours later using Leica Qwin software (Leica, Rijswijk, The Netherlands). Digitally acquired images of all slices were divided into 4 LV segments (anterior, lateral, posterior and septal) and all infarcted tissue was manually indicated on the image. Infarct size was expressed as percentage of the entire LV mass, because global ischemia was used.

Total RNA from the anterior and posterior region was extracted with TRIzol Reagent (Sigma, Zwijndrecht, The Netherlands) according to the manufacturer's protocol. RNA samples were dissolved in RNAse-free water. The $O D_{260: 280}$ ratio was controlled and visual inspection of the denaturing gels was made. Total RNA (500 ng) was used for DNAse treatment (Sigma) and subsequent reverse transcription (Iscript cDNA synthesis kit, Biorad Inc., Hercules, CA, USA). Gene expression analysis in the obtained CDNA was performed by 
quantitative PCR on an iCycler Real-Time PCR detection system using the $i Q$ SYBR Green supermix (Biorad). The following oligonucleotide primers for rabbit proBNP mRNA were used:

sense primer 5'-GTCTCCGGAACAAGGTCTCC

antisense primer 5'-TCTCTGGTCTCCTGGGTCTC.

The sequence of proBNP mRNA was a kind gift from A.A. Protter, Scios Inc., Sunnyvale, CA USA. All transcripts were normalized to Hypoxanthine phosphoribosyl-transferase and Cyclophilin.

\section{Data analysis}

Statistical analysis was performed on absolute values, even when presented relative to baseline (table 6.1). ProBNP mRNA data were analyzed using a two-sided T-test. Other data were evaluated by two-way analysis of variance (ANOVA) for repeated measures within each group (to compare different time points during the experiment or different segments after TTC staining) and between the groups. In case of a significant difference post-hoc analysis with Tukey correction was used for further comparison. $P<0.05$ was considered statistically significant. Mean values \pm S.D. are presented. The authors had full access to the data and take full responsibility for its integrity. All authors have read and agree to the manuscript as written.

\section{RESULTS}

\section{Infarct size}

TTC staining demonstrated a significantly smaller global infarct size in the VPPC group $(1.8 \pm 0.8 \%)$ and IPC group $(3.5 \pm 3.1 \%)$ than in the control group $(18.3 \pm 13.0 \%)$. There was no significant difference in infarct size between the VPPC and the IPC groups (figure 6.2). In the VPPC and IPC groups infarct size was equally small in all segments and significantly smaller in each segment as compared with the corresponding segment in the control group (figure $6.2)$.

\section{Hemodynamic function}

Table 6.1 shows hemodynamic data for all groups during the entire protocol. $L V$ pacing (VPPC group) significantly decreased $L V d P / d t_{\min }$, all other hemodynamic parameters remained essentially unaltered. After the IPC stimulus, $\mathrm{LVdP} / \mathrm{dt}_{\max }$ and $\mathrm{LVdP} / \mathrm{dt}_{\min }$ remained significantly depressed.

After the index ischemia cardiac output, $L V P_{\max }, L V d P / d t_{\max }$ and $L V d P / d t_{\min }$ remained significantly lower than at baseline in each group and postischemic values were not significantly different between the groups (table 6.1). 
Table 6.1 Hemodynamic parameters

\begin{tabular}{|c|c|c|c|c|c|}
\hline \multirow[t]{3}{*}{ Variable } & Group & $B L=R A O^{\prime}$ & PC 3 & RA $50^{\prime}$ & $\operatorname{Rep} 120^{\prime}$ \\
\hline & & $\begin{array}{c}\text { Absolute } \\
\text { values }\end{array}$ & \multicolumn{3}{|c|}{ Relative values ( $\%$ of $B L$ value) } \\
\hline & Control & $258 \pm 42$ & $104 \pm 4$ & $105 \pm 4$ & $9 \pm 29^{*}$ \\
\hline \multirow[t]{3}{*}{$\begin{array}{c}\text { Cardiac } \\
\text { output }\end{array}$} & VPPC & $263 \pm 62$ & $88 \pm 10$ & $102 \pm 9$ & $5 \pm 12^{*}$ \\
\hline & IPC & $250 \pm 61$ & $0 \pm 0 * t$ & $91 \pm 25$ & $5 \pm 5^{*}$ \\
\hline & Control & $90 \pm 4$ & $100 \pm 3$ & $100 \pm 3$ & $70 \pm 13$ * \\
\hline \multirow[t]{3}{*}{$L V P_{\max }$} & VPPC & $90 \pm 5$ & $95 \pm 5$ & $98 \pm 4$ & $77 \pm 11$ * \\
\hline & IPC & $96 \pm 8$ & $0 \pm 0^{*}+$ & $92 \pm 5$ & $64 \pm 13^{*}$ \\
\hline & Control & $3018 \pm 457$ & $93 \pm 6$ & $90 \pm 8$ & $39 \pm 13^{*}$ \\
\hline \multirow[t]{3}{*}{$\mathrm{LVdP} / \mathrm{dt}_{\max }$} & VPPC & $2605 \pm 204$ & $92 \pm 15$ & $92 \pm 6$ & $55 \pm 16$ * \\
\hline & IPC & $2748 \pm 697$ & $0 \pm 0^{*} \dagger$ & $79 \pm 14^{*} \dagger$ & $49 \pm 17^{*}$ \\
\hline & Control & $-2859 \pm 504$ & $98 \pm 12$ & $97 \pm 11$ & $23 \pm 8$ * \\
\hline \multirow[t]{2}{*}{$L V d P / d t_{\min }$} & VPPC & $-2553 \pm 509$ & $86 \pm 5 \dagger$ & $93 \pm 6 t$ & $32 \pm 10$ * \\
\hline & IPC & $-2699 \pm 185$ & $0 \pm 0^{*} \dagger$ & $78 \pm 14^{*} \dagger$ & $25 \pm 5 *$ \\
\hline
\end{tabular}

RA $O^{\prime}$ and $R A 50^{\prime}=$ right atrial (RA) pacing at beginning and end of the period prior to index ischemia, respectively, $\mathrm{PC} 3=$ third preconditioning period, Rep, $120^{\prime}=120 \mathrm{~min}$ reperfusion. $R A 0^{\prime}$ is defined as baseline (BL). Data are presented as absolute value at $\mathrm{BL}(\mathrm{ml} / \mathrm{min}$ for cardiac output, $\mathrm{mmHg}$ for maximal LV pressure ( $\left(\mathrm{VP}_{\max }\right), \mathrm{mmHg} / \mathrm{sec}$ for $\mathrm{LVdP} / \mathrm{dt}_{\max }$ and $\mathrm{LVdP} / \mathrm{dt}_{\min }$ ) and as \%BL for subsequent time points. Mean \pm standard deviation. ${ }^{*}=p<0.05$ as compared with $B L$ within group, $\dagger=p<0.05$ as compared with control group at corresponding time point (Two-way ANOVA for repeated measures with Tukey correction). 


\section{Infarct $\%$ of the LV wall}

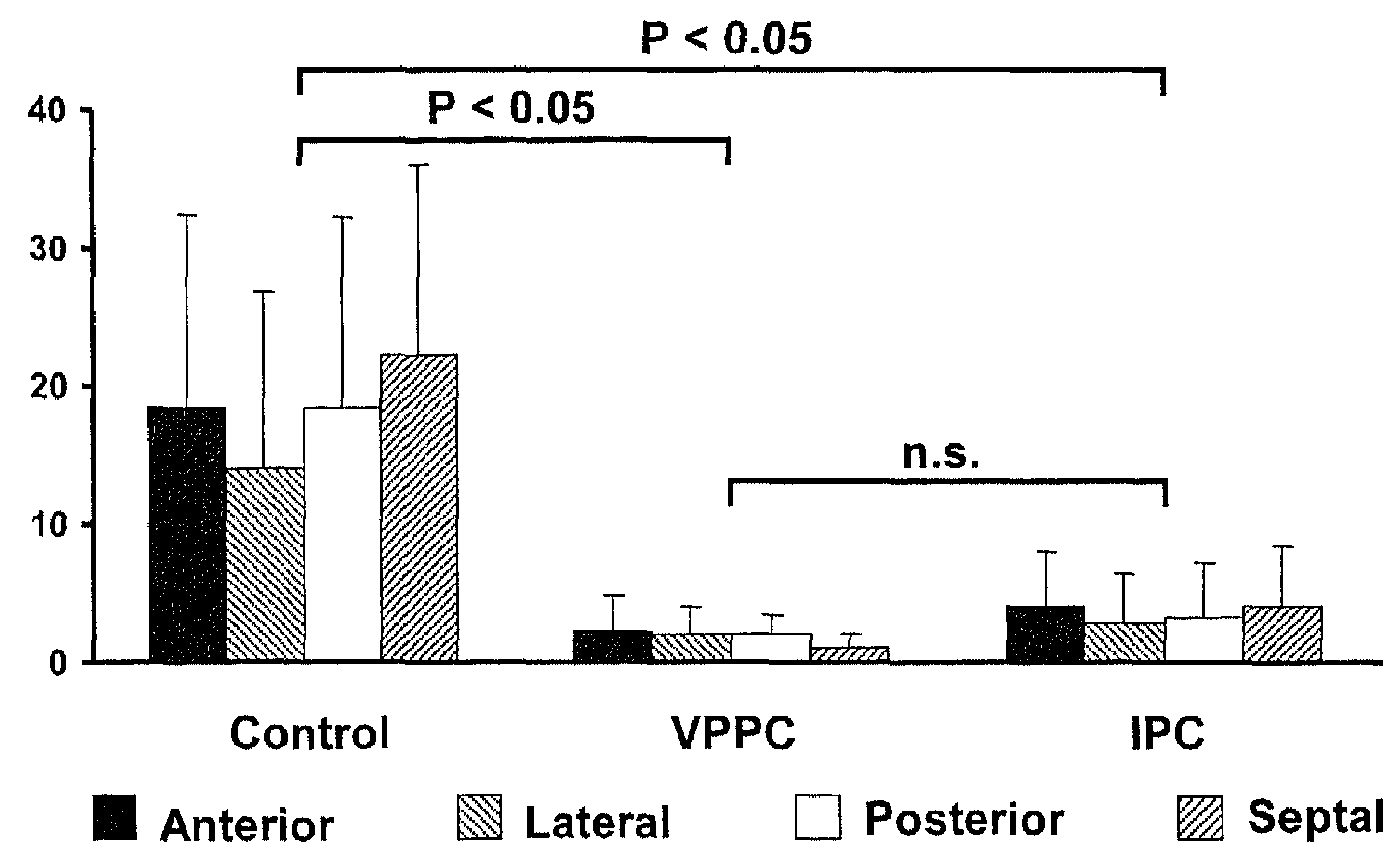

Figure 6.2 Infarct size as percentage of the left ventricular (LV) wall. The four bars indicate infarct size in the LV anterior, lateral, posterior and septal wall.

\section{Coronary flow}

LV pacing (VPPC group) did not significantly change coronary flow as compared with RA pacing (figure 6.3, upper panel). After each IPC stimulus, coronary flow returned to baseline values. After index ischemia coronary flow decreased significantly below baseline level in the control (at 60 and $120 \mathrm{~min}$ ) and IPC group (at $120 \mathrm{~min}$ ), but not within the VPPC group. However, coronary flow was not significantly different between the groups at corresponding time points.

\section{Lactate release and proBNP mRNA expression}

LV pacing (VPPC group) did not significantly change lactate release (figure 6.3, lower panel), whereas after each IPC stimulus lactate release increased $\sim 6$-fold. After index ischemia lactate release peaked within the first 5 min of reperfusion, with values not significantly different between the three groups (figure 6.3, lower panel). 

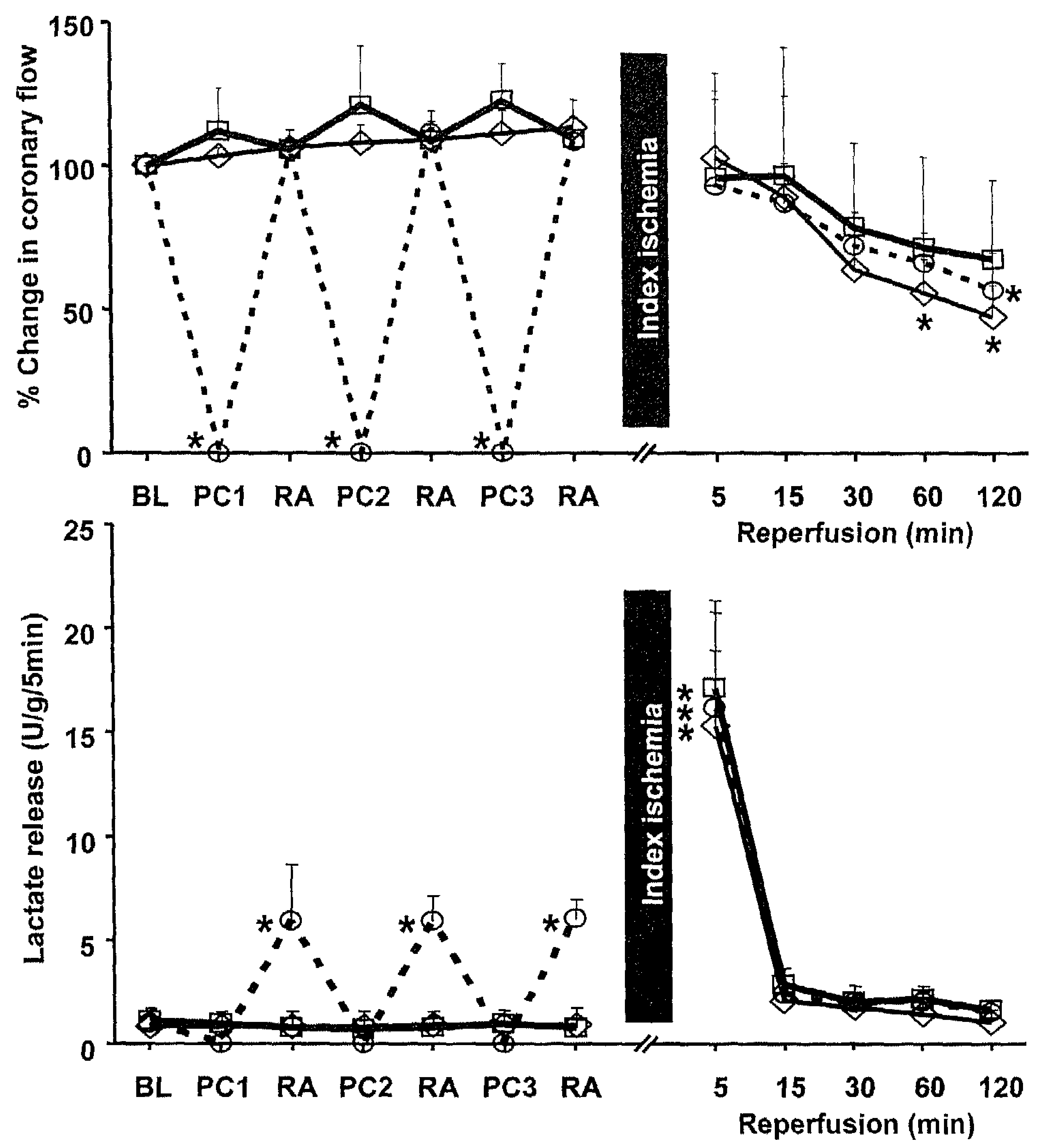

Figure 6.3 Time course of coronary flow (upper panel) and lactate release (lower panel). Coronary flow is expressed as percentage of baseline (BL). $\diamond=$ Control, $\square=V P P C, O=I P C$ group. RA=right atrial pacing, $P C=$ preconditioning stimulus, ${ }^{*}=p<0.05$ as compared with $B L$ within the same group. 
In the additional experiments it was found that proBNP mRNA was 3 to 4 -fold upregulated as compared with control $(p<0.05)$ in both the anterior and posterior LV wall ten min after the third VPPC period (figure 6.4).

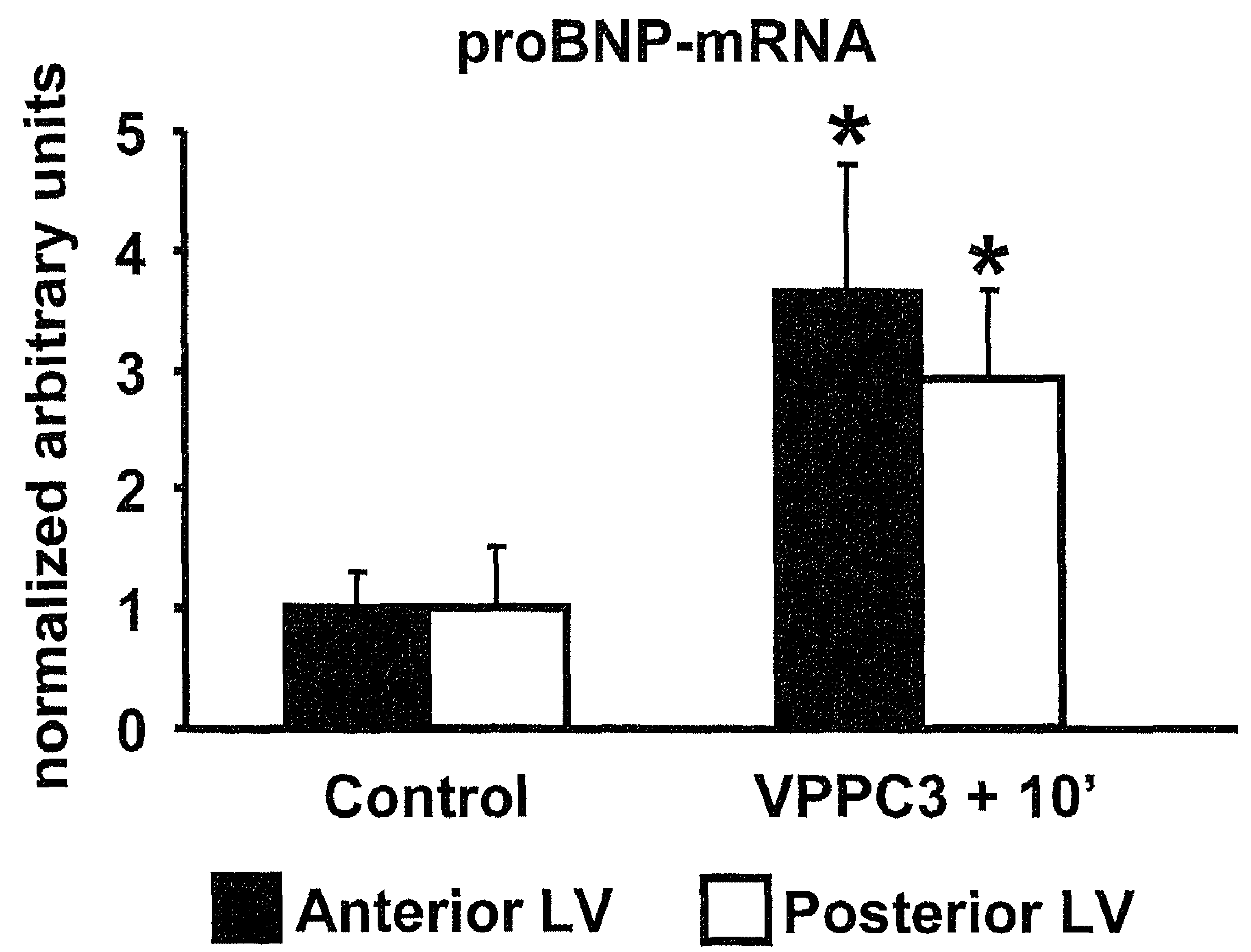

Figure 6.4 Relative change in proBNP mRNA expression in the anterior (late-activated during VPPC) and posterior (early-activated during VPPC) left ventricular (LV) wall in VPPC and control hearts. VPPC3 $+10^{\prime}=10$ min after PC3 in VPPC protocol, ${ }^{*}=p<0.05$ as compared with corresponding segment in the control group.

\section{Electrical and mechanical dyssynchrony during LV pacing}

QRS-duration was $\sim 25 \mathrm{~ms}$ during RA pacing and increased significantly to $48.5 \pm 5.1 \mathrm{~ms}$ during LV pacing. During LV pacing, segment work (PLLA) in the late-activated anterior LV wall increased significantly, whereas segment work decreased to negative values in the early-activated posterior segment (figures 6.5 and 6.6). In the latter region segment work became negative due to early-systolic shortening and late-systolic stretch. LV posterior wall pacing significantly increased EDSL in the anterior segment (figure 6.7) without significantly changing EDSL in the posterior segment (data not shown). 


\section{$\%$ Change in PL-loop area}
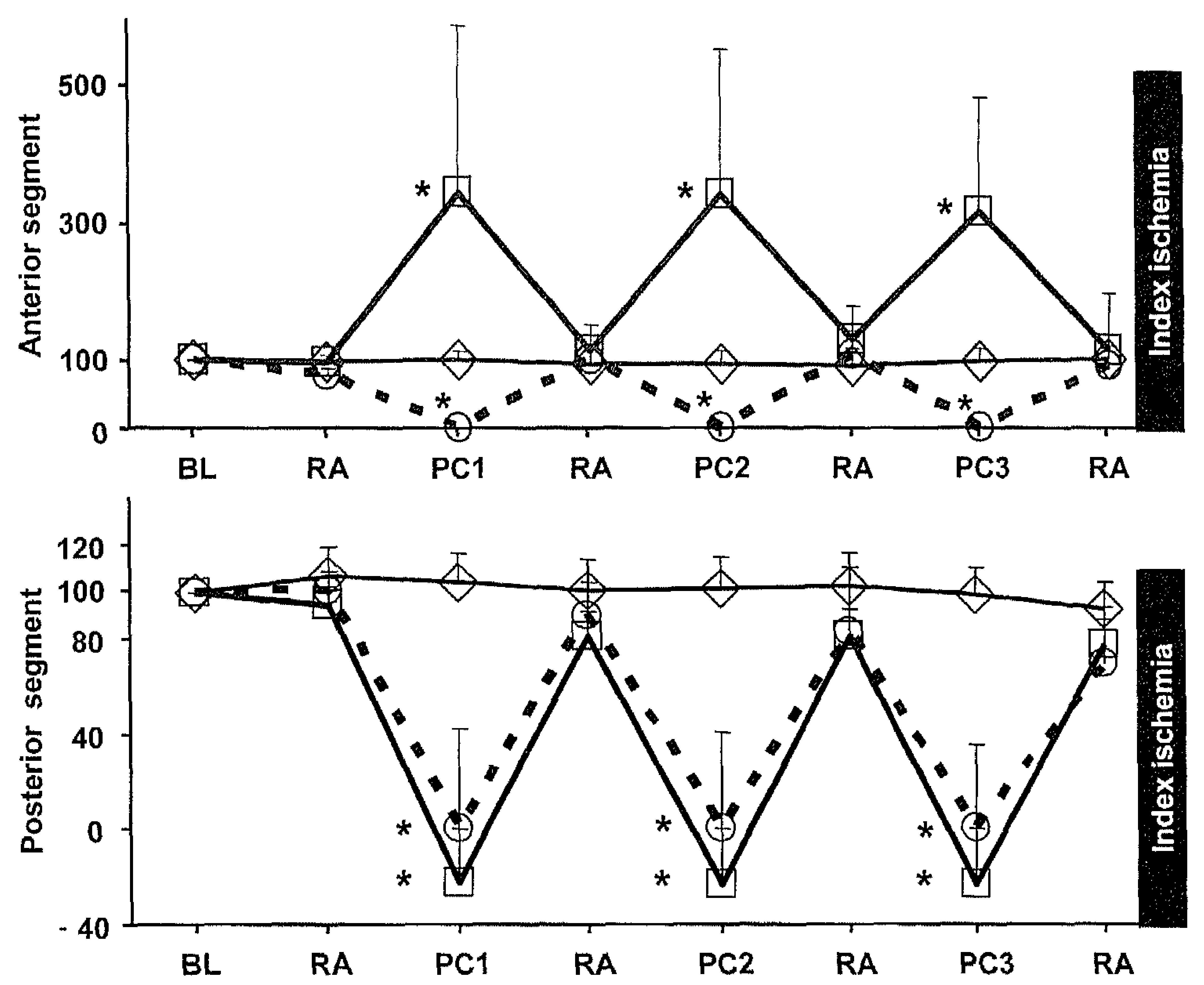

Figure 6.5 Change in pressure-length $(\mathrm{PL})$ loop area ( segment work) in the anterior and posterior LV wall, expressed as percentage of baseline (BL) during right atrial (RA) pacing and preconditioning $(P C)$. For further legends see figure 6.3.

\section{DISCUSSION}

The present study proves the concept that brief periods of cardiac dyssynchrony, induced by ventricular pacing at physiological heart rate, can reduce myocardial infarct size as much as classical ischemic preconditioning. The processes leading to dyssynchrony-induced preconditioning are more likely to be initiated by stretch than by ischemia. 
RA pacing
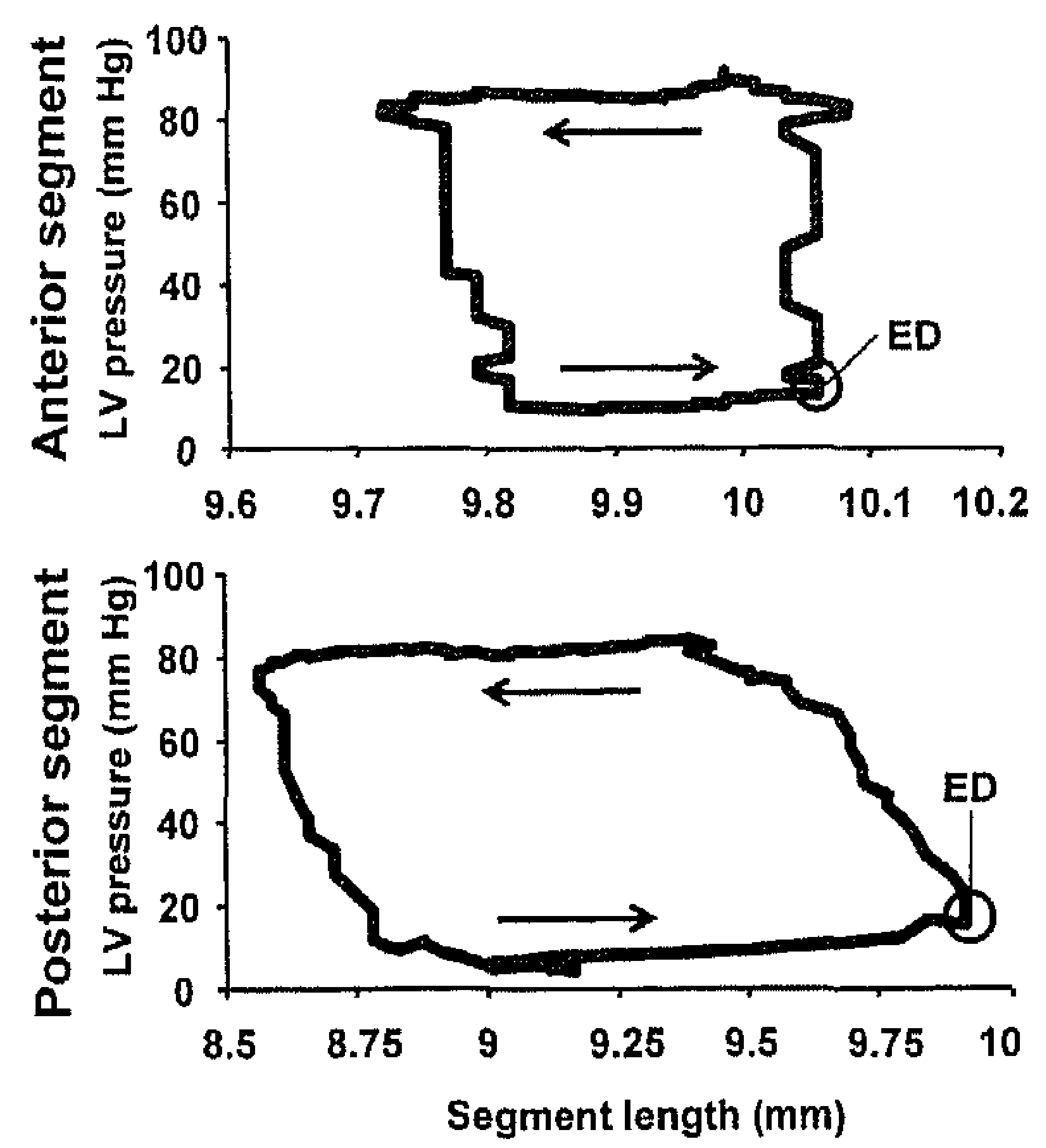

LV pacing
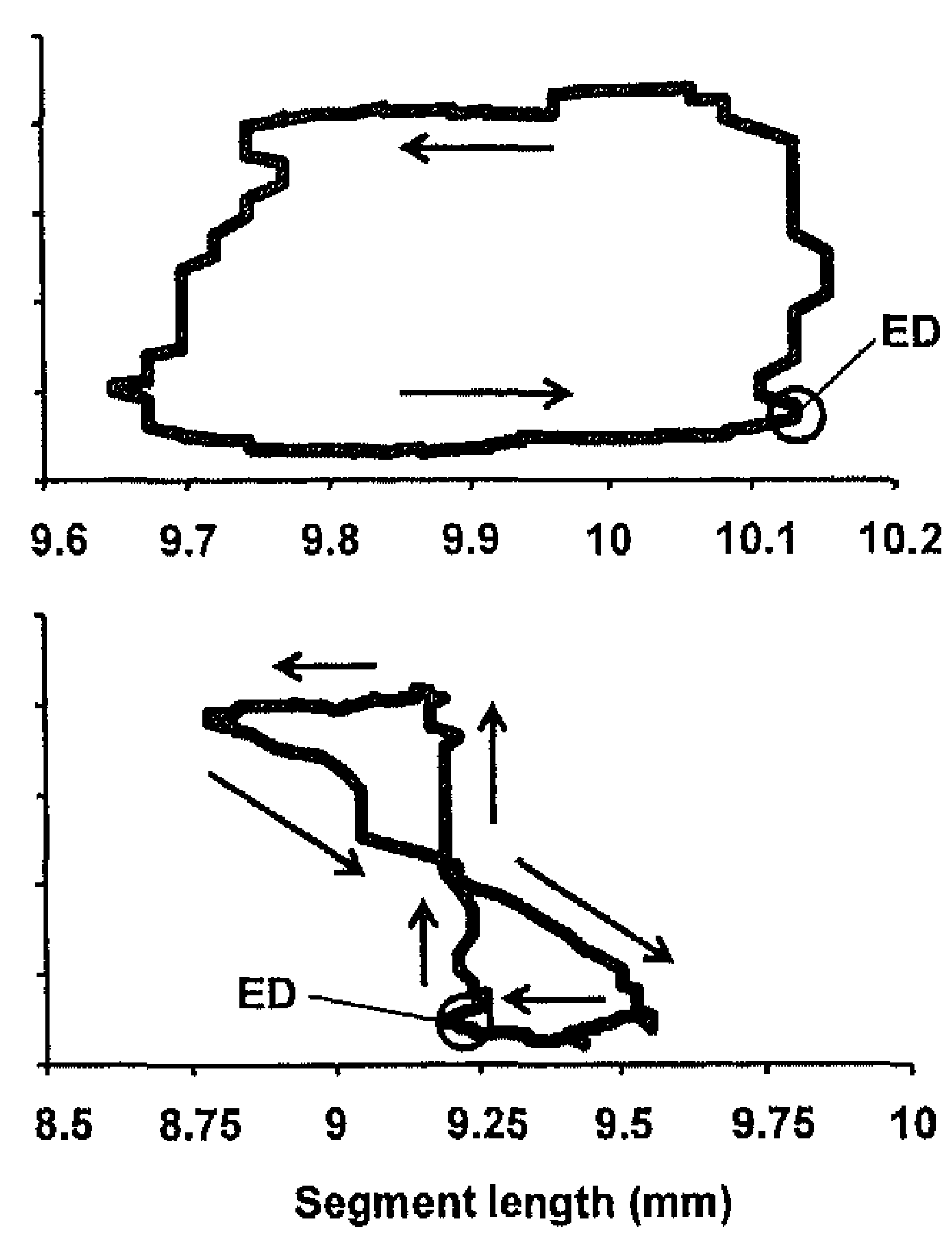

Figure 6.6 Pressure-length loops from a representative experiment in the VPPC group. Left panels: right atrial (RA) pacing, right panels: left ventricular (LV) posterior wall pacing. Upper panels: anterior segment, lower panels: posterior segment. Arrows indicate the course of the loop during the cardiac cycle. $\mathrm{ED}=$ end-diastole.

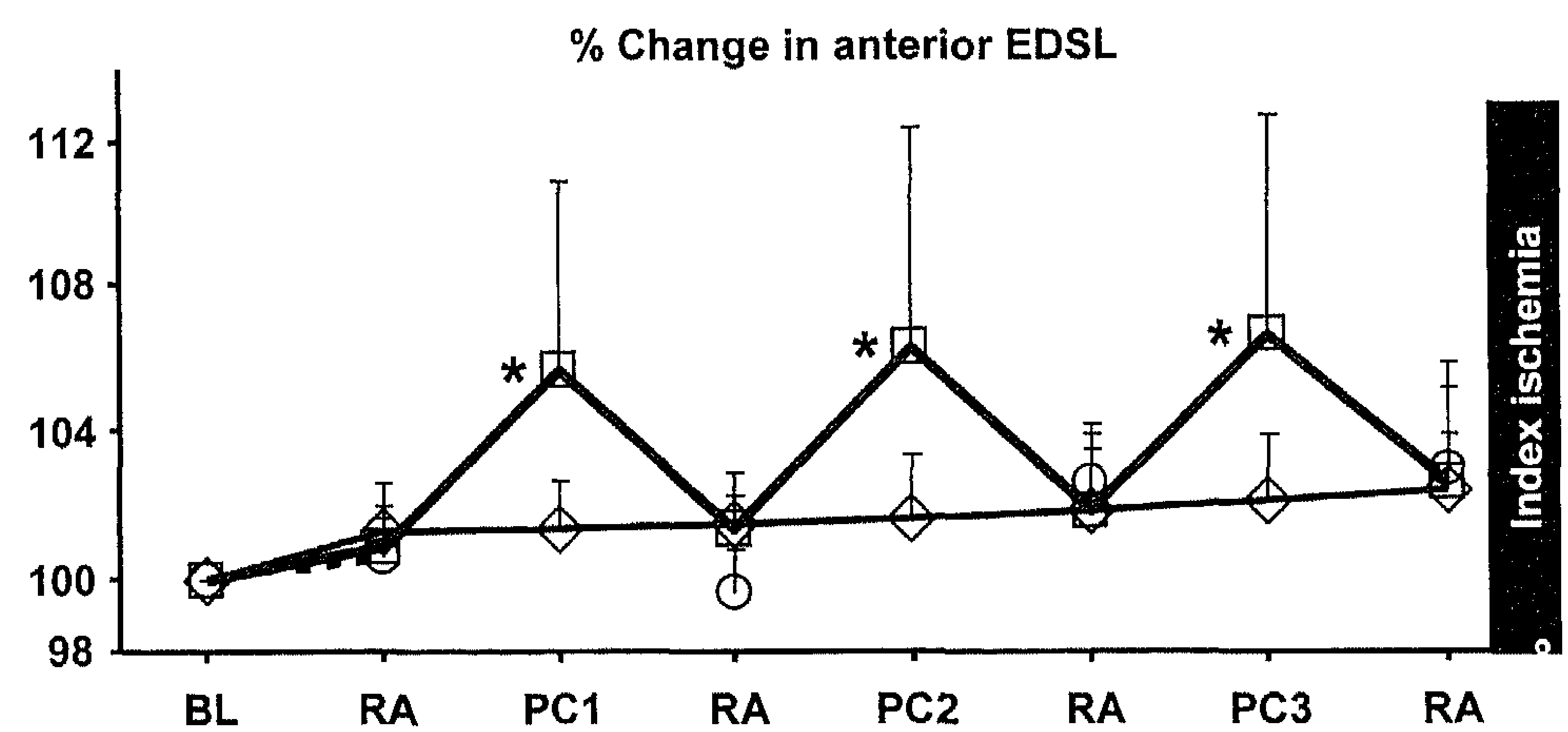

Figure 6.7 Change in end-diastolic segment length (EDSL) in the anterior segment in the 3 groups prior to index ischemia. For legends see figure 6.3. 


\section{Intermittent dyssynchrony as a preconditioning trigger}

In the present experimental setting the cardioprotection achieved by dyssynchrony is obtained while keeping heart rate, preload and afterload constant and with only moderate reduction in contractility. Also myocardial ischemia is not a likely trigger for dyssynchrony-induced preconditioning. After all, during LV pacing coronary flow and lactate release did not change. While lactate release from the whole heart was measured, also regional ischemia is unlikely. Since no lactate is present in the perfusion buffer, any lactate in the effluent indicates myocardial release and regional lactate release can not be concealed by lactate uptake in other regions. Moreover, previous studies in our group have shown that ventricular pacing causes a redistribution of mechanical work within the LV wall, but local lactate and oxygen extraction measurements did not show any sign of underperfusion in any region. ${ }^{11}$

A more likely trigger for dyssynchrony-induced preconditioning is the increased mechanical loading occurring in regions remote from the pacing site. Other studies already showed that increasing global load leads to preconditioning. ${ }^{4}$ The early-systolic prestretch in late-activated regions has been shown to be sufficient to lead to local hypertrophy during chronic ventricular pacing. ${ }^{12}$ Moreover, preliminary observations in 2 additional rabbit hearts, frozen immediately after the third VPPC period, show that ERK1/2 phosphorylation was increased 3 to 4-fold in the anterior, but not in the posterior LV wall as compared to 4 control hearts. ERK1/2 is known to be activated by stretch ${ }^{13}$ and is also a well known player in ischemic preconditioning. ${ }^{14}$

ProBNP mRNA expression is also increased due to stretch. ${ }^{15}$ Moreover, BNP is cardioprotective when administered to the heart. ${ }^{16}$ The increased proBNP mRNA expression as well as protection throughout the LV wall is remarkable, because the mechanical trigger presumably originates in the late-activated region. In this respect it is important to note that changes in the general loading conditions in our preparation are excluded as a cause of proBNP mRNA upregulation. Protection in myocardium remote from a triggered zone is referred to as "remote preconditioning," and is known to occur in regions distant from a previously preconditioned region. ${ }^{14,17}$

The results from the present study do not offer conclusive evidence about a causal relation between proBNP mRNA expression, ERK1/2 phosphorylation and dyssynchrony-induced cardioprotection and certainly do not exclude other players. Clearly, further studies are required to investigate the underlying mechanisms of dyssynchrony-induced preconditioning. 
CMapteas

Pacing preconditioning: heart rate or dyssynchrony?

In the past, several studies have shown the cardioprotective effects of rapid ventricular pacing. ${ }^{2,3,18}$ Except by one group of investigators, ${ }^{18}$ protection by rapid ventricular pacing has been attributed to concomitant myocardial ischemia. Interestingly, rapid atrial pacing does not induce preconditioning, ${ }^{19}$ even though coronary flow, hemodynamics and electrophysiological variables were affected to a similar degree as during rapid ventricular pacing. With hindsight these publications support our hypothesis that dyssynchrony rather than high heart rate induces preconditioning.

A cardioprotective effect of intermittent dyssynchrony has also been found in isolated chick embryo hearts. Intermittent ventricular pacing for 12 hours reduced the incidence of arrhythmias after ischemia. ${ }^{20}$ In the present study we followed a "classical" preconditioning scheme in mammalian hearts, and used infarct size as the principal end point.

\section{Potential clinical application}

The experimental set-up of global myocardial ischemia is comparable to the situation during cardiac surgery. Under these circumstances, pacing leads are often attached to the heart for back-up pacing in case of accidental AV-block. Results from preconditioning studies in isolated rabbit hearts have been shown to apply well to in vivo situations in other species, including man. ${ }^{14}$ Therefore, it seems worthwhile and feasible to explore the protective effects of intermittent ventricular pacing in cardiac surgery.

Dyssynchrony-induced preconditioning is easier to apply and less counterintuitive than ischemic preconditioning. Its value as compared with administration of drugs, like anesthetics ${ }^{21}$ needs to be determined. This also holds for the possibility to combine dyssynchrony-induced preconditioning with other triggers in order to increase the protective effect, as shown for combining ischemic preconditioning with drug administration. ${ }^{22}$

\section{CONCLUSION}

Intermittent dyssynchrony, induced by ventricular pacing at physiological heart rate, induces uniform preconditioning in rabbit hearts. The observed cardioprotective effect is unlikely to be triggered by ischemia. Ventricular pacing preconditioning is clinically feasible and potentially useful in cardiac surgery. 


\section{ACKNOWLEDGEMENTS}

We gratefully acknowledge the contributions of Arne Van Hunnik, Marion Kuiper, Xander Verbeek PhD, and Roeland Van Kerckhoven PhD (Department of Physiology, Maastricht University, The Netherlands) to this study. The authors are grateful to Julio Spinelli PhD, Tamara Baynham PhD, and Joe Pastore PhD at Boston Scientific (St Paul, MN, USA) for their continued interest.

\section{CONFLICT OF INTEREST DISCLOSURES}

The study was financially supported by Boston Scientific (St Paul, MN, USA). FW Prinzen is an advisor of Boston Scientific (St Paul, MN, USA) and Medtronic Inc. (Minneapolis, MN, USA). 


\section{REFERENCES}

1. Murry CE, Jennings RB, Reimer KA. Preconditioning with ischemia: a delay of lethal cell injury in ischemic myocardium. Circulation 1986; 74:1124-1136.

2. Vegh A, Szekeres L, Parratt JR. Transient ischaemia induced by rapid cardiac pacing results in myocardial preconditioning. Cardiovasc Res 1991; 25:1051-1053.

3. Szilvassy Z, Ferdinandy P, Bor P, Jakab I, Lonovics J, Koltai M. Ventricular overdrive pacinginduced anti-ischemic effect: a conscious rabbit model of preconditioning. Am J Physiol 1994; 266:H2033-2041.

4. Ovize M, Kloner RA, Przyklenk K. Stretch preconditions canine myocardium. Am J Physiol 1994; 266:H137-146.

5. Gysembergh A, Margonari $H$, Loufoua J, Ovize A, Andre-Fouet $X$, Minaire $Y$, Ovize M. Stretchinduced protection shares a common mechanism with ischemic preconditioning in rabbit heart. Am J Physiol 1998; 274:H955-964.

6. Huang $\mathrm{CH}$, Wang JS, Chiang SC, Wang YY, Lai ST, Weng ZC. Brief pressure overload of the left ventricle preconditions rabbit myocardium against infarction. Ann Thorac Surg 2004; 78:628-633.

7. Prinzen FW, Hunter WC, Wyman BT, MCVeigh ER. Mapping of regional myocardial strain and work during ventricular pacing: experimental study using magnetic resonance imaging tagging. J Am Coll Cardiol 1999; 33:1735-1742.

8. Delhaas $T$, Arts $T$, Prinzen FW, Reneman RS. Relation between regional electrical activation time and subepicardial fiber strain in the canine left ventricle. Pflugers Arch 1993; 423:78-87.

9. Blombery PA, Korner PI. Role of aortic and carotid sinus baroreceptors on Valsalva-like vasoconstrictor and heart rate reflexes in the conscious rabbit. J Auton Nerv Syst 1982; 5:303-315.

10. Apstein CS, Puchner E, Brachfeld N. Improved automated lactate determination. Anal Biochem 1970; 38:20-34.

11. Delhaas $T$, Arts $T$, Prinzen FW, Reneman RS. Regional fibre stress-fibre strain area as an estimate of regional blood flow and oxygen demand in the canine heart. J Physiol 1994; 477 (Pt 3):481-496.

12. van Oosterhout MF, Prinzen FW, Arts T, Schreuder JJ, Vanagt WY, Cleutjens JP, Reneman RS. Asynchronous electrical activation induces asymmetrical hypertrophy of the left ventricular wall. Circulation 1998; 98:588-595.

13. Takeishi $Y$, Huang Q, Abe J, Glassman M, Che W, Lee JD, Kawakatsu $H$, et al. Src and multiple MAP kinase activation in cardiac hypertrophy and congestive heart failure under chronic pressureoverload: comparison with acute mechanical stretch. J Mol Cell Cardiol 2001; 33:1637-1648.

14. Yellon DM, Downey JM. Preconditioning the myocardium: from cellular physiology to clinical cardiology. Physiol Rev 2003; 83:1113-1151.

15. Baxter GF. Natriuretic peptides and myocardial ischaemia. Basic Res Cardiol 2004; 99:90-93.

16. D'Souza SP, Yellon DM, Martin C, Schulz R, Heusch G, Onody A, Ferdinandy P, et al. B-type natriuretic peptide limits infarct size in rat isolated hearts via KATP channel opening. Am J Physiol Heart Circ Physiol 2003; 284:H1592-1600.

17. Gowda A, Yang CJ, Asimakis GK, Ruef J, Rastegar S, Runge MS, Motamedi M. Cardioprotection by local heating: improved myocardial salvage after ischemia and reperfusion. Ann Thorac Surg 1998; 65:1241-1247.

18. Koning MM, Gho BC, van Klaarwater E, Opstal RL, Duncker DJ, Verdouw PD. Rapid ventricular pacing produces myocardial protection by nonischemic activation of KATP+ channels. Circulation 1996; 93:178-186.

19. Marber MS, Walker DM, Eveson DJ, Walker JM, Yellon DM. A single five minute period of rapid. atrial pacing fails to limit infarct size in the in situ rabbit heart. Cardiovasc Res 1993; 27:597-601.

20. Rosa A, Maury JP, Terrand J, Lyon X, Kucera P, Kappenberger L, Raddatz E. Ectopic pacing at physiological rate improves postanoxic recovery of the developing heart. Am J Physiol Heart Circ Physiol 2003; 284:H2384-2392. 
21. Piriou V, Chiari $P$, Lhuillier F, Bastien O, Loufoua J, Raisky O, David JS, et al. Pharmacological preconditioning: comparison of desflurane, sevoflurane, isoflurane and halothane in rabbit myocardium. Br J Anaesth 2002; 89:486-491.

22. Ninomiya $H$, Otani $H, L u K$, Uchiyama $T$, Kido $M$, Imamura $H$. Enhanced IPC by activation of pertussis toxin-sensitive and -insensitive $G$ protein-coupled purinoceptors. Am J Physiol Heart Circ Physiol 2002; 282:H1933-1943. 
7

\section{Pacing-induced dyssynchrony during early reperfusion reduces infarct size}

Ward Y. Vanagt ${ }^{1,2}$, Richard N. Cornelussen 1 , Tamara C. Baynham $^{3}$, Arne Van Hunnik ${ }^{1}$, Quincy P. Poulina ${ }^{1}$, Fawzi Babiker ${ }^{1}$, Julio Spinelli ${ }^{3}$, Tammo Delhaas ${ }^{1,2}$, and Frits W. Prinzen ${ }^{1}$

Departments of ${ }^{1}$ Physiology and ${ }^{2}$ Pediatrics, Cardiovascular Research Institute Maastricht, Maastricht, The Netherlands, and ${ }^{3}$ Boston Scientific, St Paul, Minnesota, USA.

Journal of the American College of Cardiology, 2007; 49: 1813 1819. 
onstist

\section{Abstract}

Background: Intermittent dyssynchrony, induced by ventricular pacing, preconditions myocardium. Considering the recent discovery of postconditioning, we investigated whether intermittent dyssynchrony immediately upon reperfusion induces cardioprotection too.

Methods: Isolated ejecting rabbit hearts were subjected to 30 minutes coronary occlusion and 2 hours reperfusion. Studied were control, left ventricular (LV) pacing preconditioning (LVPpreC, $3 \times 5$ minutes LV pacing) and LV pacing postconditioning (LVPpostC, $10 \times 30$ seconds LV pacing during early reperfusion) groups. Mechanical effects of LV pacing were determined using local pressure-length loops (sonomicrometry) while effects on myocardial lactate release and coronary flow were assessed from coronary effluent and fluorescent microspheres, respectively. Anesthetized pigs underwent 60 minutes coronary occlusion and 3 hours reperfusion in control and right ventricular (RV) pacing postconditioning groups (RVPpostC, $10 \times 30$ seconds RV pacing during early reperfusion). In all hearts, area at risk and infarct size were determined with blue dye and triphenyltetrazolium chloride staining, respectively.

Results: Infarct size, normalized to area at risk, was $47.0 \pm 12.3 \%$ in control rabbit hearts, but significantly smaller in LVPpreC $(17.8 \pm 6.4 \%)$ and LVPpostC hearts $(17.9 \pm 4.4 \%)$. LV pacing significantly altered regional mechanical work, but did not affect coronary flow nor lactate release. In pigs, infarct size was significantly smaller in RVPpostC $(9.8 \pm 3.0 \%)$ than in control $(20.6 \pm 2.2 \%)$ animals.

Conclusions: Intermittent dyssynchrony during early reperfusion reduces infarct size in two different animal models. Dyssynchrony-induced postconditioning cannot be attributed to graded reperfusion but may be induced by modulation of local myocardial workload. Dyssynchrony-induced postconditioning opens new possibilities for cardioprotection in the clinical setting. 


\section{INTRODUCTION}

We recently demonstrated in globally ischemic rabbit hearts that intermittent mechanical dyssynchrony, induced by ventricular pacing at physiological heart rate, limits infarct size as much as ischemic preconditioning and causes upregulation of pro-brain natriuretic peptide (proBNP) mRNA. ${ }^{1}$ This protection was most likely due to the dyssynchrony-induced abnormal myocardial stretch and contraction patterns, ${ }^{1}$ since alterations in myocardial stretch ${ }^{2,3}$ and afterload ${ }^{4}$ are known preconditioning triggers.

Clinical application of any kind of preconditioning has been limited by the unexpectedness of most ischemic events. The recent discovery that preconditioning stimuli can also be cardioprotective, when applied during early reperfusion (postconditioning ${ }^{5,6}$ ), has started a new era of cardioprotection. The demonstration of ischemic postconditioning in human hearts during percutaneous coronary intervention $(\mathrm{PCl})$ procedures ${ }^{7}$ clearly shows the great clinical potential of postconditioning. Also various pharmacological agents have been shown to be cardioprotective in animals when applied in the reperfusion period. ${ }^{6,8,9}$

The aim of the present study was to investigate whether dyssynchrony can induce postconditioning and, if so, whether this protective effect is equal to that of dyssynchrony-induced preconditioning. Experiments were performed in isolated ejecting rabbit hearts and in anesthetized pigs. The former model allowed some insight in the mechanisms of dyssynchrony-induced postconditioning, the latter was used to evaluate dyssynchrony-induced postconditioning in a clinically relevant larger animal model.

\section{MATERIALS AND METHODS - ISOLATED RABBIT HEARTS}

\section{Animals and instrumentation}

Animal handling and treatment were according to the Dutch law on animal experimentation. The protocol was approved by the Maastricht University animal ethical committee. Hearts were isolated from female White New Zealand rabbits after sedation (intramuscular ketamine (50 mg/kg) / xylazine $(5 \mathrm{mg} / \mathrm{kg}$ )) and cervical dislocation by a blow in the neck, and subsequently attached to the perfusion apparatus as described in detail before. ${ }^{1}$ The aorta and a pulmonary vein were cannulated to allow antegrade perfusion (ejecting mode) of the isolated heart.

The heart was instrumented with epicardial pacing electrodes on the right atrial (RA) appendage and posterior basal left ventricular (LV) wall, a catheter to 
measure LV pressure and four sonomicrometer crystals (Sonometrics Corporation, London, Ontario, Canada) to measure regional segment length in the anterior and posterior LV wall. ${ }^{1}$ Epicardial electrographic electrodes were attached to the RA and LV anterior and posterior basal wall for determination of electrical dyssynchrony. The left descending coronary artery was encircled by a snare and a deflated standard percutaneous transluminal angioplasty balIoon (PTCA) balloon catheter was positioned through the snare. Throughout the experiment preload was kept constant at $6 \mathrm{mmHg}$, afterload at $80 \mathrm{mmHg}$ and heart rate at $240 \mathrm{bpm}$ (physiological heart rate for rabbits ${ }^{10}$ ).

\section{Study protocol and groups}

Rabbits were divided into 3 study groups: control $(n=12)$, LV pacing preconditioning (LVPpreC, $n=8$ ) and LV pacing postconditioning (LVPpostC, $n=12$ ) group (figure 7.1). All hearts were subjected to 30 minutes coronary artery occlusion (induced by inflating the balloon catheter), followed by reperfusion.

\section{Control group}

\section{0' Ischemia}

2 hours reperfusion

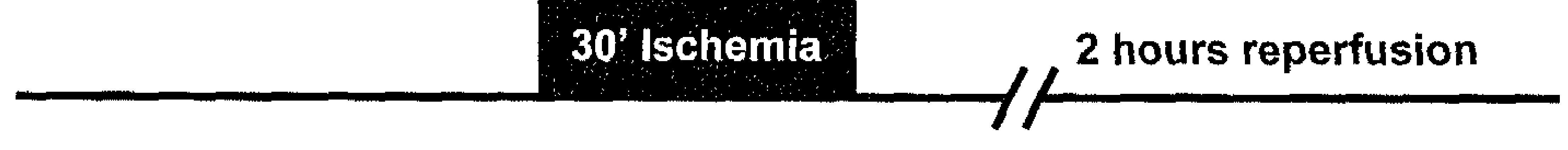

Left ventricular pacing preconditioning group (LVPpreC)

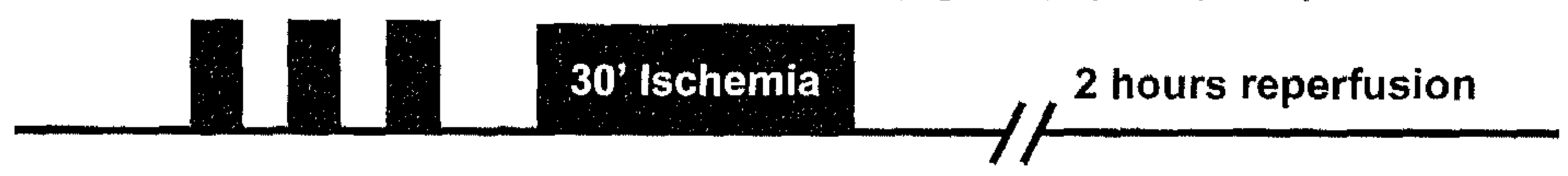

Left ventricular pacing postconditioning group (LVPpostC)

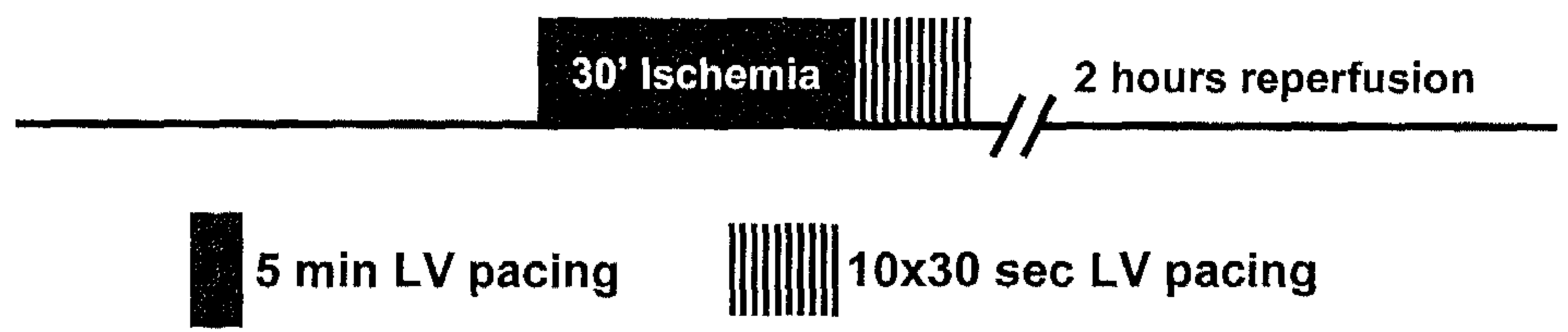

Figure 7.1 Study protocol in isolated rabbit hearts. Rabbit hearts were paced at the right atrium (RA) throughout the experiment. Dyssynchrony-induced preconditioning was induced by 3 cycles of 5 minutes left ventricular (LV) pacing, followed by 5 minutes RA pacing. Dyssynchrony-induced postconditioning was induced by 10 cycles of 30 seconds LV pacing, interspersed with 30 seconds RA pacing. 
In the LVPpreC group, ventricular pacing was performed during three 5 minute periods, interspersed with 5 minutes of RA pacing. After the last ventricular pacing period, 10 minutes of RA pacing preceded the index ischemia. In the LVPpostC group, postconditioning was performed during the first 10 minutes of reperfusion using 10 cycles of 30 seconds LV pacing and 30 seconds RA pacing at $240 \mathrm{bpm}$. LV pacing was performed using simultaneous atrioventricular pacing (atrio-ventricular interval $=0 \mathrm{~ms}$ ) to ensure complete ventricular activation initiating from the pacing electrode.

Coronary artery occlusion was followed by 2 hours of reperfusion $(n=8$ per group) for determination of postischemic cardiac function, global coronary flow, myocardial lactate release and quantification of infarct size. Additional experiments (control and LVPpostC, $n=4$ per group) were performed to measure regional myocardial perfusion during the postconditioning period using fluorescent microspheres.

\section{Data, effluent and tissue collection and processing}

Hemodynamic, mechanical and electrophysiological data were recorded at a sampling rate of $500 \mathrm{~Hz}$ using a Sonometrics system (Sonometrics Corporation, London, Ontario, Canada). Signals were analyzed off-line using Sonometrics, Matlab (The Mathworks Inc., Natick, MA, USA) and Hemo (home-made) software. Hemodynamic data consisted of aortic and LV pressure and aortic flow. Cardiac output was calculated by adding coronary to aortic flow (ml/minute).

Coronary effluent was collected for determination of lactate release as a marker of anaerobic metabolism. All samples were immediately frozen in liquid nitrogen and subsequently stored at $-80^{\circ}$ Celsius. Determination of lactate was performed by spectrophotometry using a Cobas Bio autoanalyzer (Roche Diagnostics, Almere, The Netherlands) according to Apstein et al. ${ }^{11}$ and expressed in $\mathrm{U} / 5$ minutes/gram of tissue at risk.

LV intraventricular electrical dyssynchrony was assessed from the epicardial electrographic electrodes as the posterior-anterior activation delay.

Regional myocardial mechanical work (stroke work) was calculated as the area of the regional LV pressure-segment length loop, derived from the LV pressure signal and sonomicrometry data. ${ }^{1}$ This measure is sensitive to dyssynchrony of contraction. ${ }^{1,12}$ Pressure-length loop areas were calculated in the posterior and anterior LV wall to compare regional stroke work in earlyand late-activated myocardium during LV posterior wall pacing, respectively.

At the end of the 2 hours reperfusion protocol, the coronary artery was reoccluded and the heart was perfused with $1 \%$ methylene blue dye to delineate 
the area at risk. The heart was stored over night at $-20^{\circ}$ Celsius and cut into transverse $2 \mathrm{~mm}$ slices, which were stained with $1 \%$ triphenyltetrazolium chloride (TTC) at $37^{\circ}$ Celsius for 15 minutes and fixed in $4 \%$ formaldehyde solution for 24 hours. Finally, in all slices the area of the LV, the region at risk and the infarct region were determined by digital planimetry using Leica $Q$ win software (Leica, Rijswijk, The Netherlands).

In the additional 4 control and 4 LVPpostC experiments, fluorescent microspheres ( $15 \mu \mathrm{m}$ spheres, 50.000 spheres, Dye-Trak, Triton Technology, San Diego, CA, USA) were injected through the LV cannula twice at 30 second intervals during RA ( 2 injections in control group of which the average is presented, 1 injection in LVPpostC group) and LV pacing (1 injection in LVPpostC group) at 10 minutes reperfusion. These experiments were stopped thereafter. Tissue from reperfused (LV apex) and non-ischemic (outside region at risk during coronary artery occlusion) myocardium were digested for isolation of the microspheres and fluorescence was determined as described previously. ${ }^{13,}$

${ }^{14}$ Absolute regional flow ( $\mathrm{ml} /$ minute/g) was calculated by calibration of total fluorescence to the coronary effluent flow and dividing tissue flow by the weight of the tissue sample.

\section{Statistical analysis}

Data are presented as mean \pm standard deviation. Statistic analysis was performed on absolute values. One-way analysis of variance (ANOVA) was performed to compare weight and planimetry data. Two-way ANOVA for repeated measures within each group and between the groups was performed for hemodynamic, sonomicrometry, coronary flow and lactate release data. If analysis of variance showed a significant difference, post-hoc analysis with Tukey test was used for further comparison. For fluorescent microsphere data, comparison within and between groups was performed using paired and nonpaired T-tests, respectively. $P<0.05$ was considered statistically significant.

\section{MATERIALS AND METHODS - IN VIVO PIG HEARTS}

Eight female swine used in this study were treated in accordance with National Institutes of Health Guidelines for the Care and Use of Laboratory Animals. The protocol was reviewed and approved by the Guidant Institutional Animal Care and Usage Committee (Guidant Corp. / Boston Scientific, St Paul, MN, USA). During thiopental sodium anesthesia, pacing leads (Guidant Corp., St Paul, MN, USA) were positioned at the endocardium of the right ventricular (RV) apex and RA. After thoracotomy, myocardial ischemia was created by 
ligating the left anterior descending coronary artery (LAD). Index ischemia consisted of 60 minutes of LAD occlusion, followed by 3 hours reperfusion.

In the control group $(n=4)$ hearts were allowed to beat in sinus rhythm (SR) throughout the experiment (figure 7.2). In the RV pacing postconditioning (RVPpostC, $n=4$ ) group, postconditioning was performed during the first 10 minutes of reperfusion using 10 cycles of 30 seconds RV pacing and 30 seconds SR. RV pacing was performed in the VDD-mode (atrial sense-ventricular pace) using an atrio-ventricular interval of $50 \%$ of intrinsic $P Q$-time to obtain complete electrical activation of the ventricles by the pacemaker.

\section{Control group}

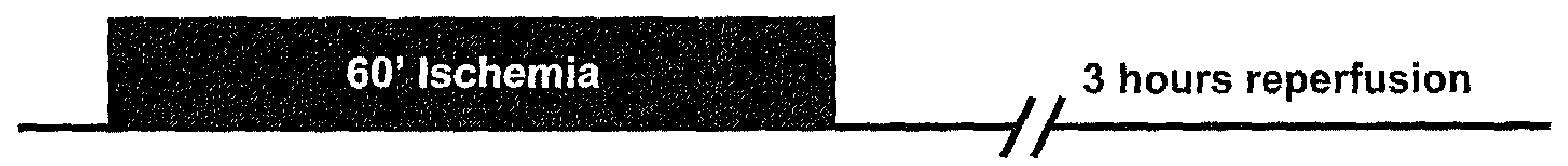

\section{Right ventricular pacing postconditioning group (RVPpostC)}

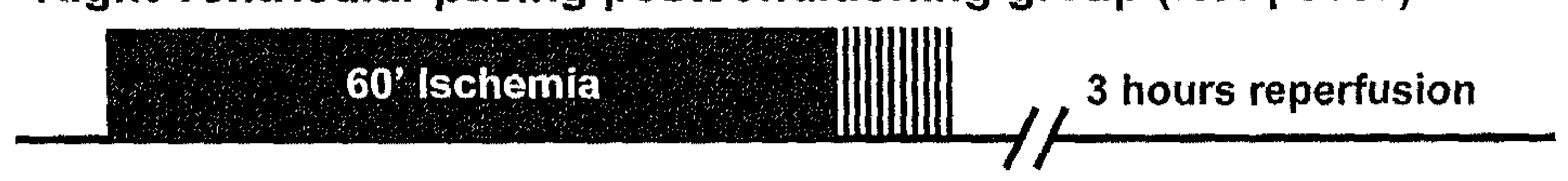
$\||\||\||\||=10 \times 30$ sec $\mathrm{RV}$ pacing postconditioning

Figure 7.2 Study protocol in anesthetized pigs. Pig hearts were beating at sinus rhythm (SR) throughout the protocol. Dyssynchrony-induced postconditioning was induced by 10 cycles of 30 seconds right ventricular (RV) pacing (atrial sense, ventricular pace), interspersed with 30 seconds SR.

\section{Infarct size determination}

After clamping the aorta and re-occlusion of the $L A D$, area at risk was determined by injection of Evan's blue dye ( $1 \mathrm{ml} / \mathrm{kg}$ body weight). The ventricles were serially sectioned from apex to base in $\sim 1 \mathrm{~cm}$ slices. The heart slices were incubated for 15 minutes in $1 \%$ TTC solution at $37^{\circ}$ Celsius. Area of infarct, area at risk and total LV area were determined using an image processing program, (ImageJ, National Institutes of Health).

All data are presented as mean \pm standard deviation. Groups were compared using a two-sided $T$-test. $P<0.05$ was considered statistically significant. 
RESULTS - ISOLATED RABBIT HEARTS

\section{Infarct size}

Bodyweights $(3.1 \pm 0.4 \mathrm{~kg})$ and heart weights $(8.5 \pm 1.0 \mathrm{~g})$ were not significantly different between the 3 study groups. The area at risk of the LV was similar in the 3 study groups (Control $42.1 \pm 9.4 \%$, LVPpreC $39.3 \pm 12.9 \%$, LVPpostC $41.8 \pm 12.5 \%$ ).

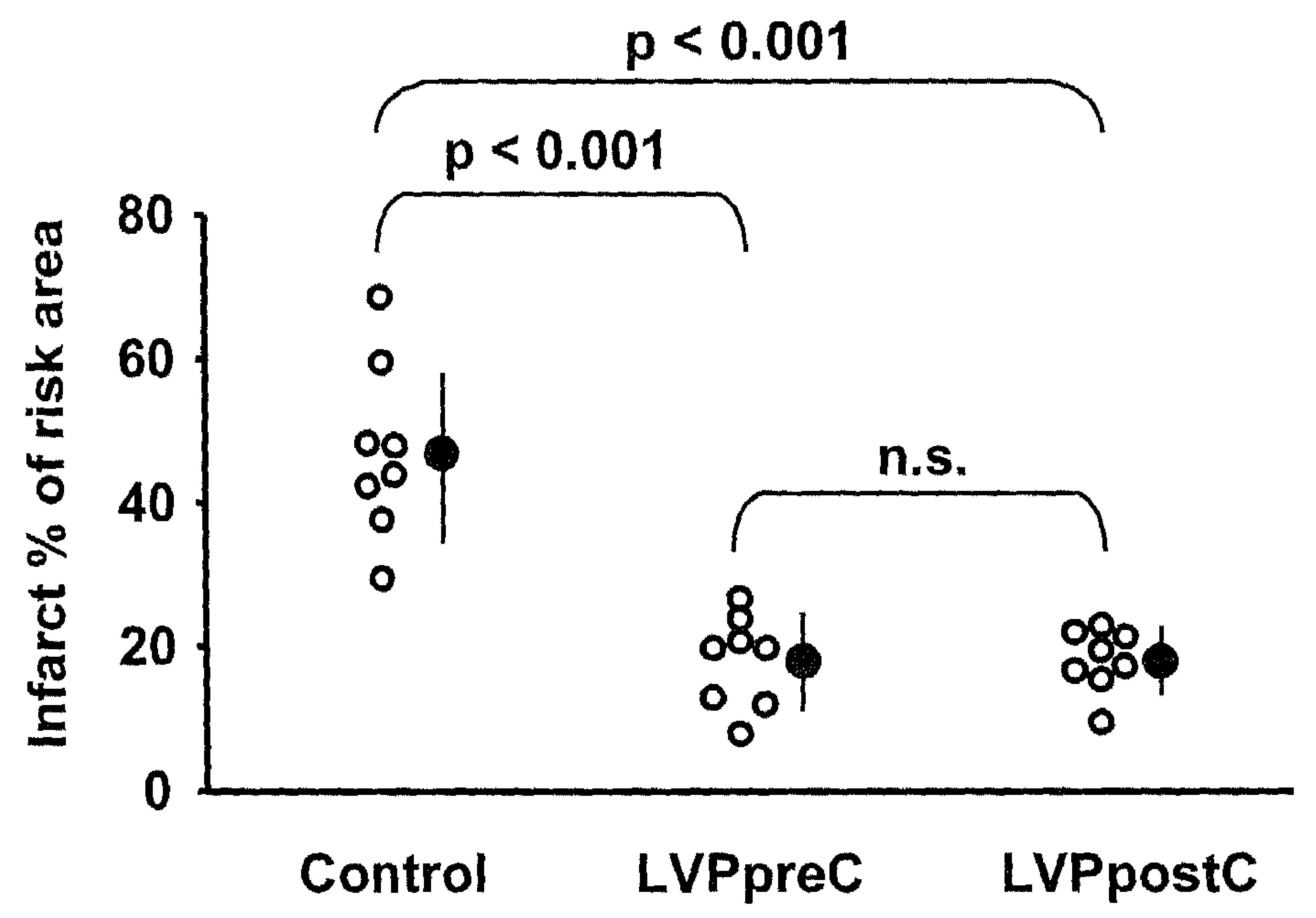

Figure 7.3 Percentage infarction of left ventricular risk area in rabbit hearts in the control, left ventricular pacing preconditioning (LVPpreC) and postconditioning (LVPpostC) groups. Open symbols = individual data, closed symbols = group average \pm standard deviation.

Infarct size, normalized to area at risk (figure 7.3), was $47.0 \pm 12.3 \%$ in the control group, but significantly smaller in the LVPpreC $(17.8 \pm 6.4 \%, p<0.05)$ and LVPpostC groups $(17.9 \pm 4.4 \%, p<0.05$, n.s. between LVPpreC and LVPpostC groups). Infarcted myocardium was uniformly distributed within the LV area at risk in all groups (figure 7.4). 


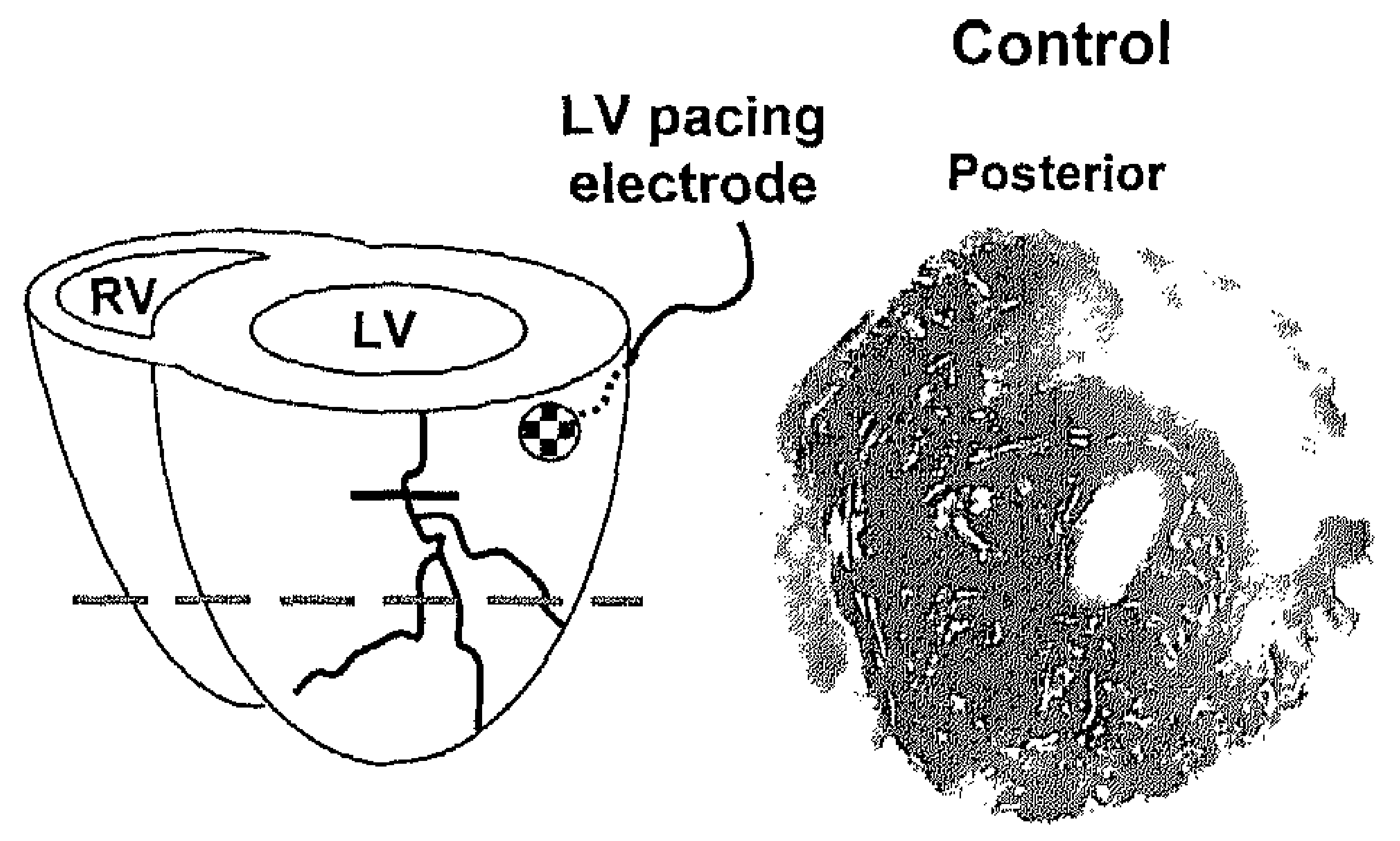

Anterior

\section{LVPpostC}

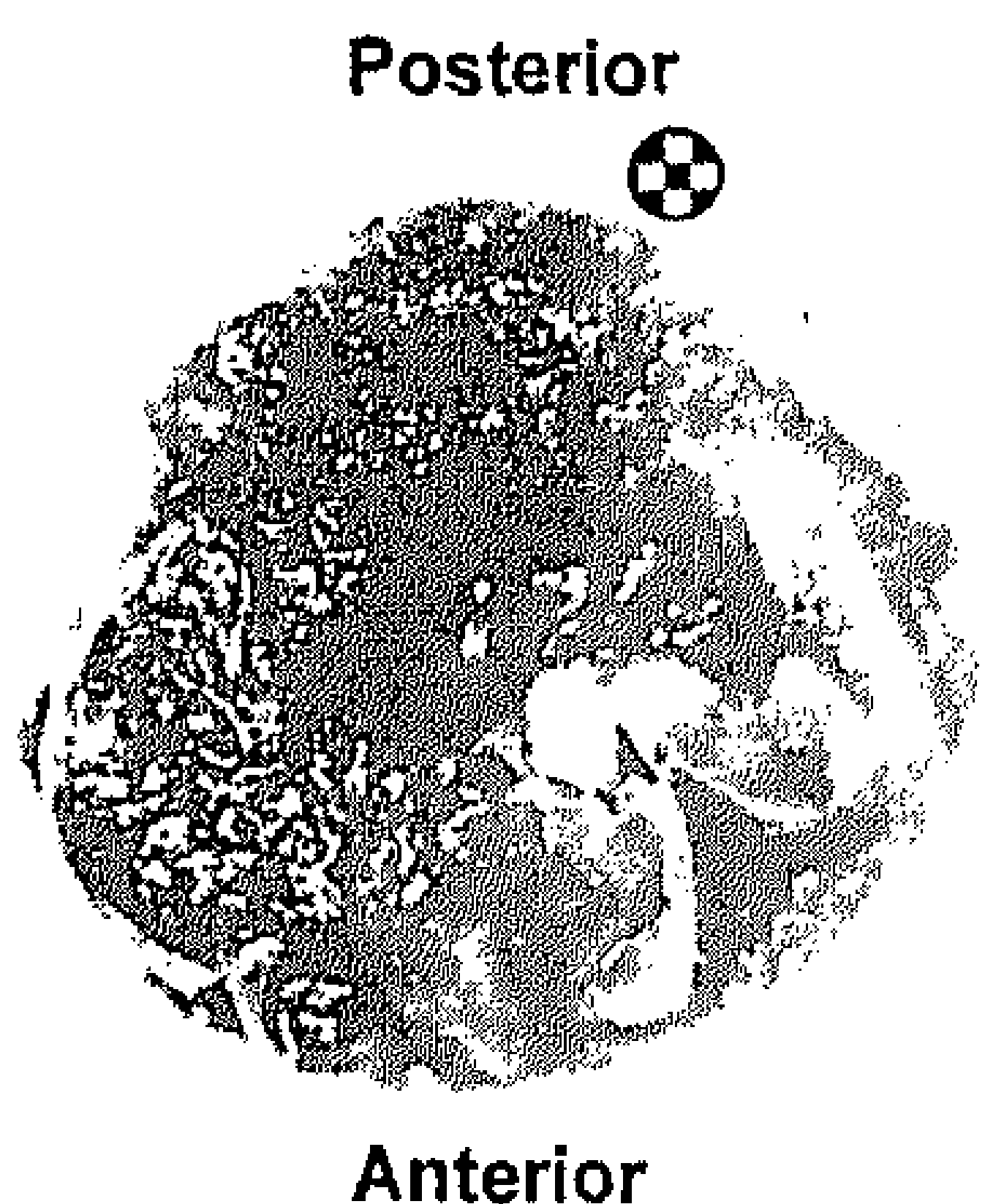

Anterior

Figure 7.4 Blue dye (black area, non-ischemic tissue) and TC staining (white area, infarcted tissue) in representative short axis slices from hearts in the control and left ventricular (LV) pacing postconditioning (LVPpostC) groups. Note the uniform distribution of infarcted myocardium throughout the LV area at risk. Interrupted line $=$ cross-sectional level of the presented slices, black line $=$ level of coronary artery occlusion, $\mathrm{RV}=$ right ventricle. For representation in colour see figure 2.11 , page 32.

\section{Cardiac dyssynchrony and function}

During RA pacing at reperfusion, $P Q$-time was $83 \pm 8 \mathrm{~ms}$ and QRS-duration was $25.6 \pm 4.3 \mathrm{~ms}$. Electrical LV posterior - anterior delay ( electrical dyssynchrony) was $1 \pm 6 \mathrm{~ms}$ during RA pacing, and increased significantly during LV pacing (LVPpreC $29 \pm 5 \mathrm{~ms}$, LVPpostC $34 \pm 6 \mathrm{~ms}$, n.s. between LVPpreC and LVPpostC groups). Since the AV-delay was set at $0 \mathrm{~ms}$ during LV pacing, the entire ventricular mass was depolarized by the electrical activation wave started at the LV pacing electrode.

Average regional stroke work was $25.9 \pm 4.1 \mathrm{mmHg} \cdot \mathrm{mm}$ in posterior and 26.7 $\pm 11.7 \mathrm{mmHg} \cdot \mathrm{mm}$ in anterior myocardium at the start of the experiment during RA pacing. LV posterior wall pacing significantly decreased regional stroke work to negative values in the LV posterior wall (early-activated during LV pacing) and increased regional stroke work in the late-activated anterior LV wall (figure 7.5). These changes occurred both when LV pacing was performed before ischemia (LVPpreC group) and upon reperfusion (LVPpostC group), albeit that the amplitude of changes was smaller during reperfusion (figure 7.5). 


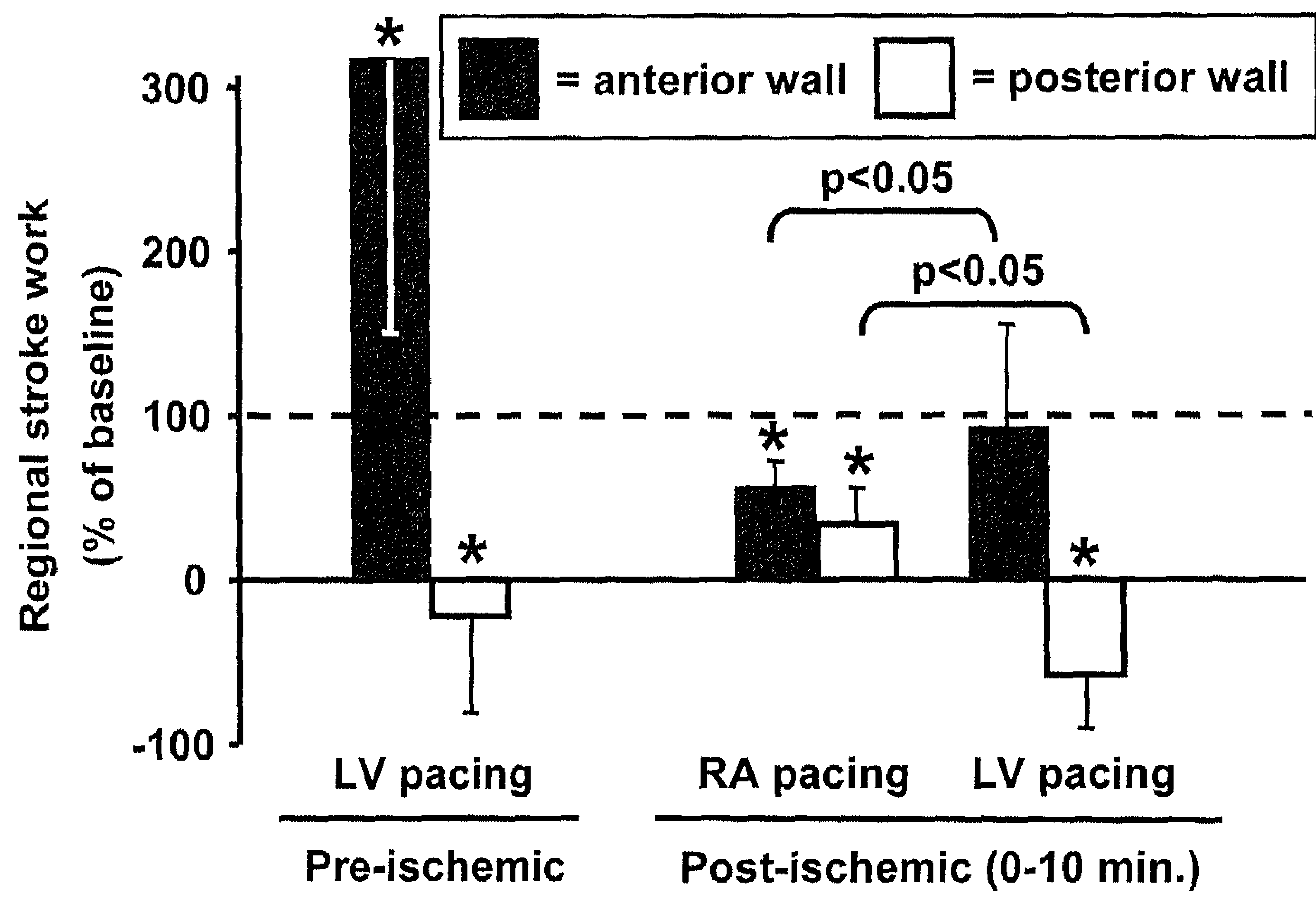

Figure 7.5 Relative change in regional stroke work (pressure-length loop area) as compared with baseline $(t=0)$ right atrial $(R A)$ pacing (dotted line) in the left ventricular (LV) anterior (closed bars) and LV posterior (open bars) wall. Depicted are values during LV pacing prior to ischemia in the LVPpreC group and values during RA and LV pacing in early reperfusion (LVPpostC group). Note that during LV pacing in the early reperfusion phase (0-10 minutes), regional stroke work increased significantly in the anterior $L V$ wall and decreased significantly in the posterior LV wall as compared with RA pacing. ${ }^{*}=p<0.05$ versus baseline RA pacing $(t=0)$ in same segment.

Cardiac output and $\mathrm{LVdP} / \mathrm{dt}_{\max }$ were similar in all groups at baseline during RA pacing, and were not significantly different between the groups at any corresponding time point during the protocol (table 7.1). Cardiac output and $\mathrm{LVdP} / \mathrm{dt}_{\text {max }}$ were significantly depressed in all groups during and after ischemia as compared with baseline. During early reperfusion in the LVPpostC group, LV pacing did neither significantly change cardiac output nor $L V d P d t_{\max }$ as compared with RA pacing.

Ventricular fibrillation occurred in one rabbit in the control group (at 2 minutes reperfusion) and in one rabbit in the LVPpostC group (during LV pacing at 1 minute reperfusion, n.s. between groups). 
Table 7.1 LVdP/dt $\mathrm{Lax}_{\max }$ and cardiac output in isolated rabbit hearts.

\begin{tabular}{|c|c|c|c|c|c|c|c|}
\hline & & Pre-is & emia & Ischemia & & & $120^{\prime}$ Rep. \\
\hline & & RA pacing & LV pacing & RA pacing & RA pacing & LV pacing & RA pacing \\
\hline & Control & $1776 \pm 237$ & - & $1396 \pm 190^{*}$ & $1354 \pm 140^{*}$ & . & $1304 \pm 140^{*}$ \\
\hline $\begin{array}{l}\mathrm{LVdP} / \mathrm{dt}_{\max } \\
\text { (mmHhysecond) }\end{array}$ & LVPpreC & $1708 \pm 114$ & $1546 \pm 174$ & $1379 \pm 126^{\star}$ & $1290 \pm 119^{*}$ & - & $1260 \pm 135 *$ \\
\hline & LVPposiC & $2036 \pm 454$ & - & $1355 \pm 433^{*}$ & $1281 \pm 133^{*}$ & $1446 \pm 570^{*}$ & $1350 \pm 310^{*}$ \\
\hline & Control & $272 \pm 32$ & - & $163 \pm 80^{*}$ & $153 \pm 89^{*}$ & - & $116 \pm 89^{*}$ \\
\hline $\begin{array}{c}\text { Cardiac } \\
\text { output }\end{array}$ & IVPnreC & $250+\Delta 7$ & $197+33$ & $177+43^{*}$ & $166+5 n^{*}$ & - & $151+10 *$ \\
\hline & LVPpostC & $229 \pm 72$ & - & $104 \pm 81^{*}$ & $109 \pm 53^{*}$ & $112 \pm 69^{*}$ & $94 \pm 48^{*}$ \\
\hline
\end{tabular}

$R A=$ right atrial, $L V=$ left ventricular, $L V P p r e C=L V$ pacing preconditioning, $L V P p o s t C=L V$ pacing postconditioning, Rep. $=$ reperfusion, ${ }^{*}=p<0.05$ versus baseline value within same group, no significant differences between groups at corresponding time points.

\section{Coronary flow, myocardial perfusion and lactate release}

Coronary effluent flow was similar between the groups at corresponding time points (at baseline RA pacing: control $71 \pm 9 \mathrm{ml} /$ minute, LVPpreC $81 \pm 10$ $\mathrm{ml} /$ minute, LVPpostC $80 \pm 12 \mathrm{ml} /$ minute). LV pacing did not significantly change coronary effluent flow in the LVPpreC group ( $82 \pm 18 \mathrm{ml} /$ minute) as compared with baseline RA pacing. During early reperfusion in the LVPpostC group, coronary flow was similar during LV $(70 \pm 10 \mathrm{ml} / \mathrm{minute})$ and RA (69 \pm $15 \mathrm{ml} /$ minute) pacing.

Regional myocardial perfusion, measured using fluorescent microspheres (figure 7.6), was similar in the control and LVPpostC groups in both reperfused and non-ischemic myocardium. In the LVPpostC group, myocardial perfusion was similar during RA and LV pacing.

Lactate release (figure 7.7) was not significantly different between the three groups at any corresponding time point and increased significantly during early reperfusion as compared with baseline within each group. Compared to RA pacing, LV pacing did not change lactate release, neither when performed before ischemia (LVPpreC group) nor during the early reperfusion phase (LVPpostC group). 


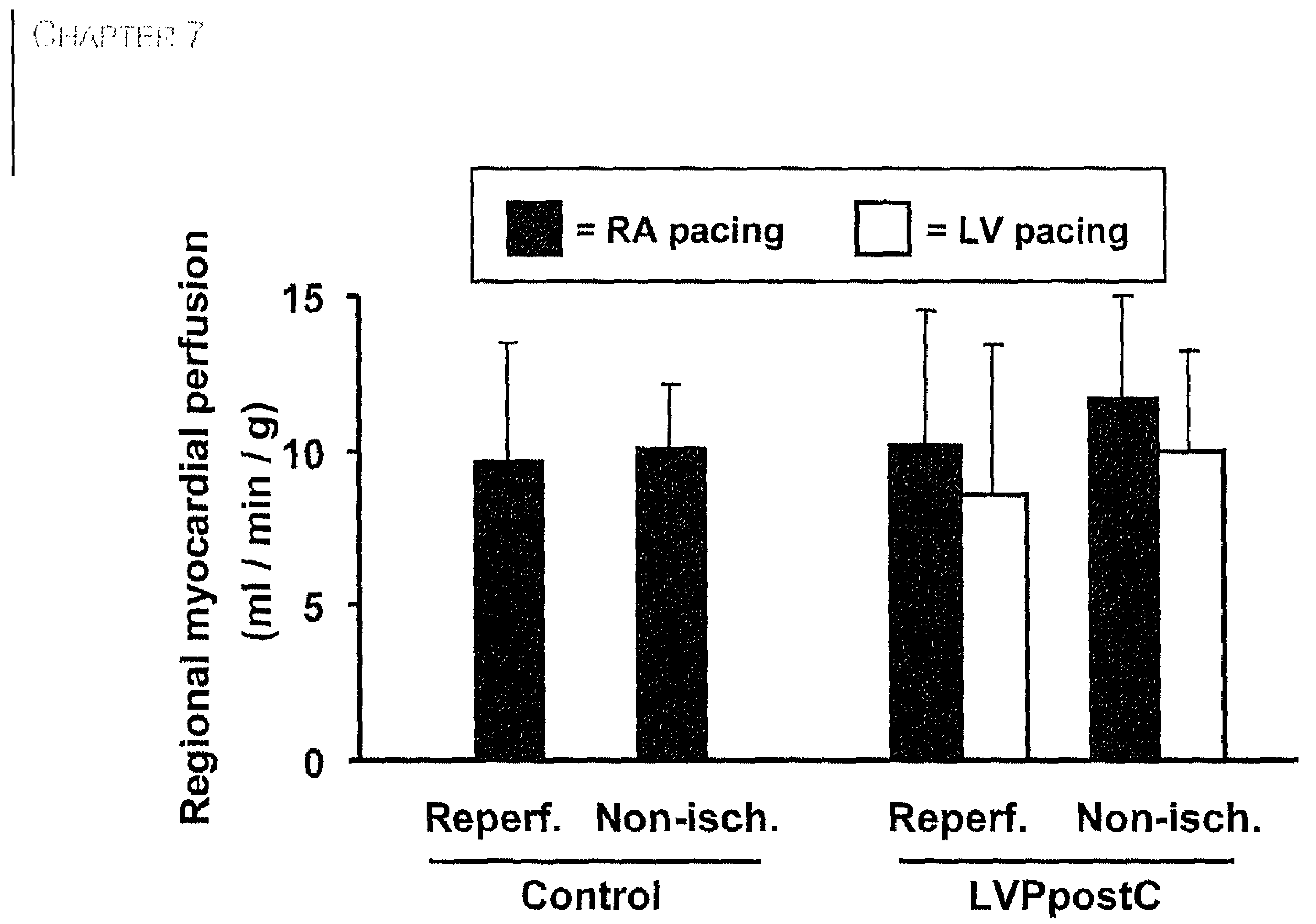

Figure 7.6 Regional perfusion of rabbit hearts in $\mathrm{ml} /$ minute/g (fluorescent microspheres) at 10 minutes reperfusion in the control and LV postconditioning (LVPpostC) groups in reperfused (Reperf.) and non-ischemic (Non-isch.) myocardium. N.S. between and within groups.

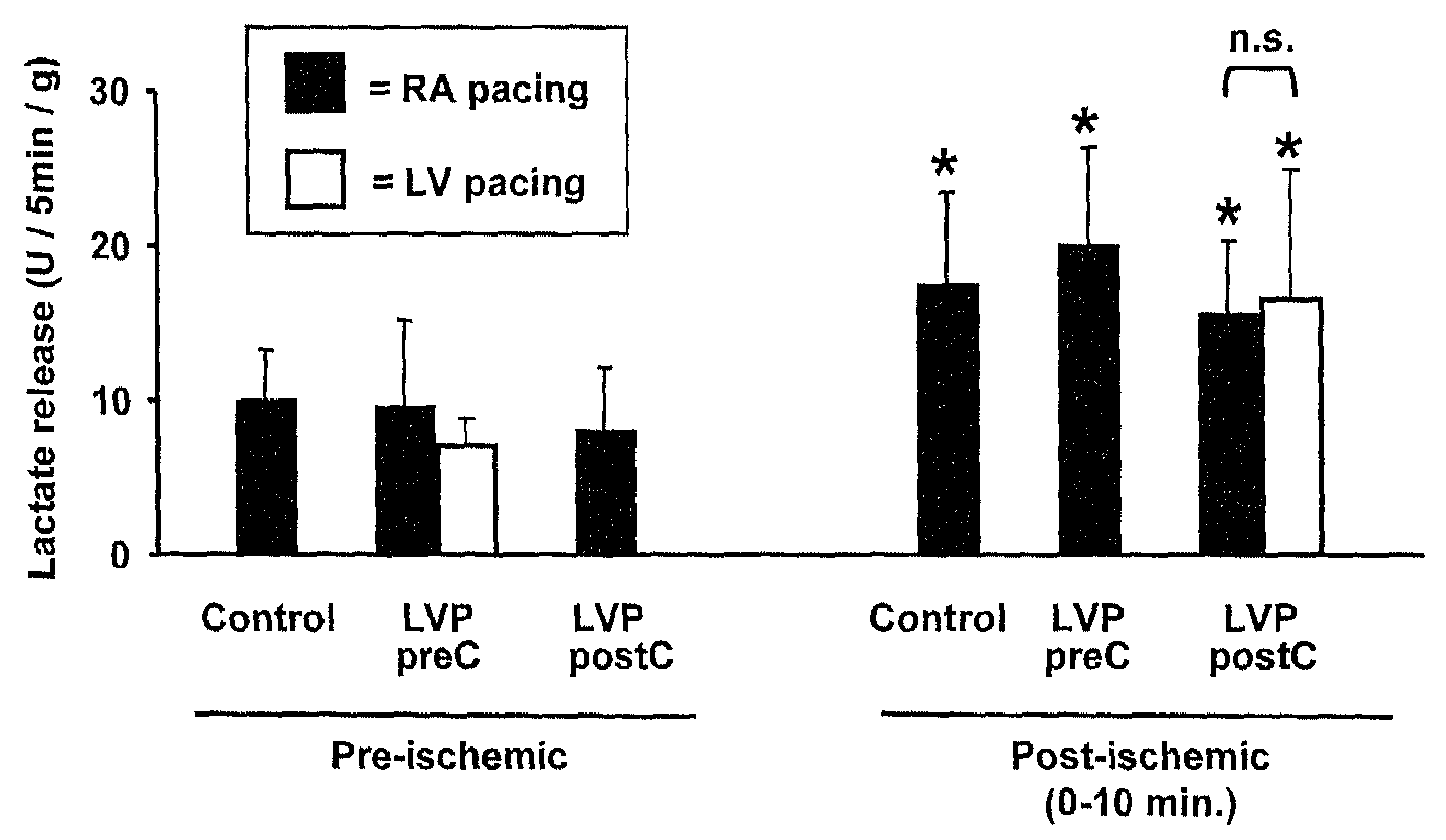

Figure 7.7 Lactate release (U/5 minutes/g) from rabbit hearts. $L V=$ left ventricular, $L V P p r e C=L V$ pacing preconditioning group, LVPpostC $=\mathrm{LV}$ pacing postconditioning group, $R A=$ right atrial. ${ }^{*}=P$ $<0.05$ versus baseline RA pacing within the same group. During LV pacing, lactate release was not significantly altered as compared with RA pacing at corresponding time points. 


\section{Results - In vivo pig hearts}

Heart weight and area at risk were similar in the control $(208.8 \pm 30.9 \mathrm{~g}$ and $55.8 \pm 7.9 \%$, respectively) and RVPpostC $(218.8 \pm 12.5 \mathrm{~g}$ and $49.6 \pm 4.9 \%$, respectively) groups. Infarct size was significantly smaller in the RVPpostC $(9.8 \pm 3.0 \%)$ than in the control group $(20.6 \pm 2.2 \%, p<0.05$, figure 7.8$)$.

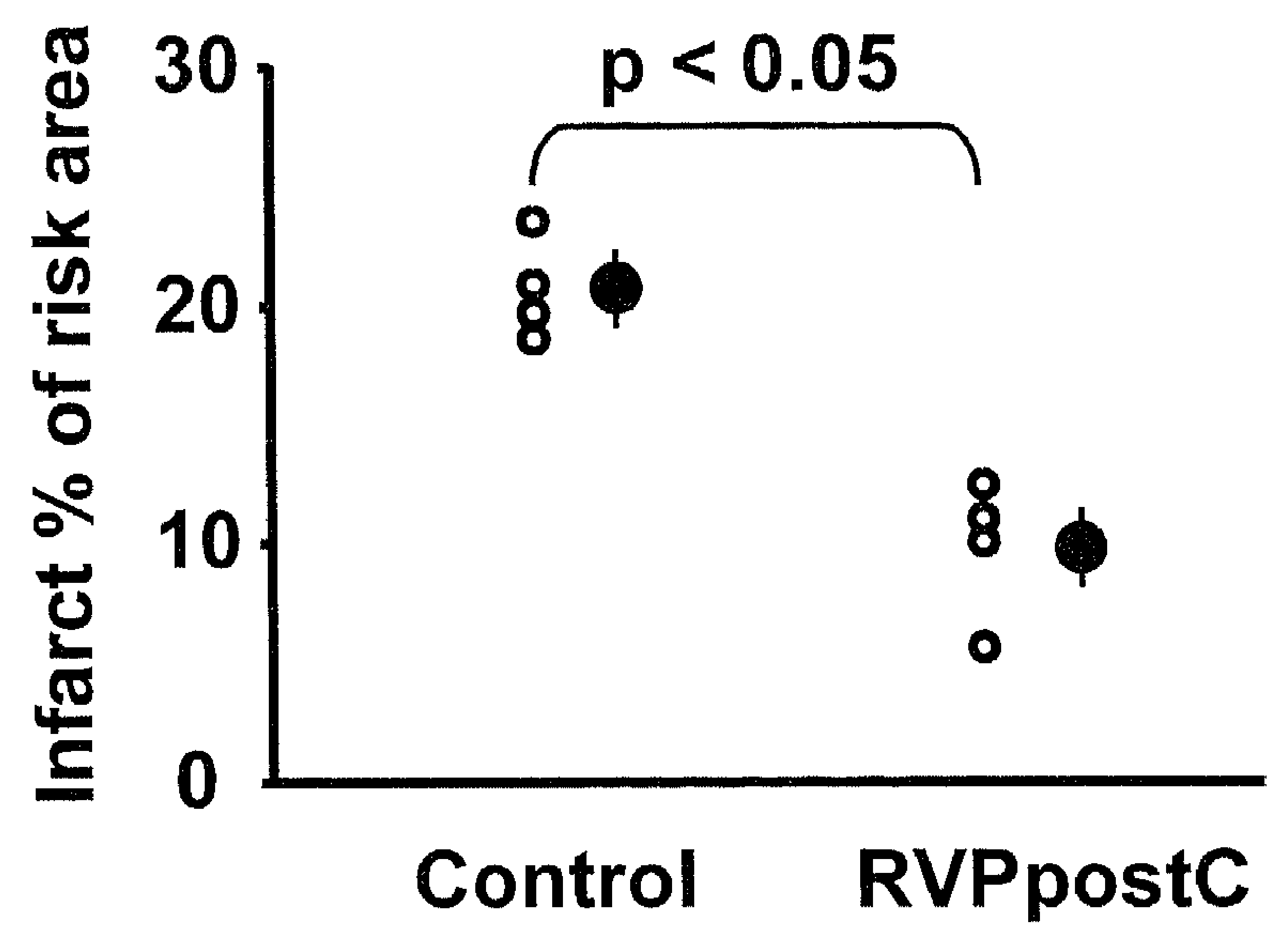

Figure 7.8 Percentage infarction of left ventricular risk area in pig hearts in the control and right ventricular postconditioning (RVPpostC) groups. Open symbols = individual data, closed symbols $=$ group average \pm standard deviation.

During sinus rhythm at reperfusion $P Q$-time and QRS-duration were similar in the control (106 $\pm 4 \mathrm{~ms}$ and $44 \pm 3 \mathrm{~ms}$, respectively) and RVPpostC groups (110 $\pm 12 \mathrm{~ms}$ and $43 \pm 2 \mathrm{~ms}$, respectively). During RV pacing, QRS-duration increased to $63 \pm 6 \mathrm{~ms}$. Considering an AV-delay of $\sim 55 \mathrm{~ms}$, it can be envisioned that almost all ventricular tissue was activated from the pacing site, rather than through intrinsic conduction, arriving $\sim 110 \mathrm{~ms}$ after atrial activation. In none of the pigs ventricular fibrillation occurred during the experiment.

\section{DISCUSSION}

The current animal studies demonstrate for the first time that myocardial infarct size after regional ischemia is reduced by intermittent dyssynchrony during early reperfusion, as induced by ventricular pacing. Dyssynchrony-induced postconditioning equals the protective potency of dyssynchrony-induced pre- 
Giapter?

conditioning, used as a positive control in this study. This complies with the data of the original demonstration of ischemic postconditioning by Zhao et al., ${ }^{5}$ and later by others, ${ }^{15}$ where ischemic postconditioning was as effective as ischemic preconditioning.

Data from the current studies illustrate that dyssynchrony-induced postconditioning is not limited to a single species and can be evoked in isolated, bufferperfused hearts as well as in blood-perfused hearts in vivo.

\section{Possible mechanism of dyssynchrony-induced postconditioning}

The finding that switching from RA to LV pacing in the early reperfusion phase does not change coronary flow, lactate release and myocardial perfusion practically rules out the possibility that dyssynchrony-induced postconditioning is caused by "graded reperfusion", which is known to reduce infarct size considerably. ${ }^{16,17}$ Ischemic postconditioning has therefore been suggested to be a "new bottle" for the "old wine" of graded reperfusion, ${ }^{18}$ and the possibility that ischemic postconditioning is a modified form of graded reperfusion has not been completely ruled out. ${ }^{18,}{ }^{19}$ Accordingly, low-pressure reperfusion was equally protective as ischemic postconditioning in rat hearts. ${ }^{20}$ Data from the present study, however, provide evidence that infarct size can be reduced by interventions in the early reperfusion period even if coronary perfusion is restored abruptly and completely.

In the isolated rabbit heart preparation preload, afterload and heart rate are well-controlled. In the absence of these possible triggers of postconditioning, intermittent changes in local stretch and loading appear a likely trigger of dyssynchrony-induced postconditioning. The present study and a previous study in dogs ${ }^{21}$ show that ventricular pacing induces regional alterations in myocardial loading and stretch during reperfusion, qualitatively similar to those in non-ischemic hearts. ${ }^{1}$ During LV posterior wall pacing, early-activated myocytes contract during early-systole while LV pressure is low, resulting in decreased work load in the posterior LV wall. Late-activated myocytes, however, are stretched during early-systole and subsequently contract while LV pressure is high, resulting in increased work load in the anterior LV wall. Furthermore, the strong contraction of late-activated myocytes results in systolic stretching of the early-activated myocardium (eccentric contraction ${ }^{1}$ ). Previous studies have shown that increased myocardial stretch $^{2,3}$ and workload ${ }^{4}$ are cardioprotective.

In the present study, the ischemic region comprises myocardium which is activated early as well as late during LV pacing in rabbits (figure 7.4) and early- to intermediate-activated in pigs (anterior ischemia with RV apex pacing). 
The occurrence of dyssynchrony-induced postconditioning and the uniform distribution of infarcted myocardium within the risk area in both animal models suggest that the exact site of pacing is not critical for achieving this effect. This is in agreement with a previous study in globally ischemic hearts where ventricular pacing preconditioning decreased infarct size, both in proximity of as well as remote from the ventricular pacing site. ${ }^{1}$ One possible explanation is that changes in stretch and workload during ventricular pacing are not limited to the late-activated myocardium alone (see above). Alternatively, remote cardioprotection within the heart, as was previously described for preconditioning, ${ }^{22,23}$ may play a role in protecting myocardium remote from the triggered zone.

\section{Comments on the experimental set-up}

The two species were chosen because data on preconditioning and postconditioning from rabbits and pigs translate well to humans. ${ }^{72}$ The isolated rabbit heart setup was used because we previously discovered dyssynchronyinduced preconditioning in this preparation. ${ }^{1}$ Moreover, the isolated heart preparation has the advantage that the controlled setup rules out several potential triggers of protection (see above). The experiments in pigs serve as extrapolation of the findings from an isolated to an in vivo model, which is more comparable to the clinical situation.

Several postconditioning studies in isolated hearts ${ }^{20,24}$ used ventricular pacing in order to control heart rate throughout the experiment in all experimental groups. Ventricular pacing was not intermittent in these studies, and other studies were performed during atrial pacing ${ }^{25}$ or sinus rhythm. ${ }^{26}$ it is unclear whether continuous ventricular pacing allowed some degree of cardioprotection, since no data is available comparing sinus rhythm, atrial and ventricular pacing for rate control during postconditioning studies. However, data from our study indicate that using ventricular pacing for rate control in experimental studies on pre- and postconditioning may introduce a confounding factor.

Regional myocardial perfusion in blood-perfused in vivo rabbit hearts is generally $\sim 3 \mathrm{ml} / \mathrm{minute} / \mathrm{g}$, whereas higher values are described in the present study $(\sim 10 \mathrm{ml} / \mathrm{minute} / \mathrm{g})$. This difference can most likely be ascribed to the lower oxygen content and the lower viscosity of the crystalloid perfusate as compared with blood. This idea is supported by coronary flow values of $\sim 6.6$ $\mathrm{ml} / \mathrm{minute} / \mathrm{g}$ in isolated buffer-perfused hearts with a lower hemodynamic load than in the present study. ${ }^{27}$ The high absolute myocardial perfusion in the present study does not invalidate the observation that cardioprotection by ventricular pacing is achieved in the absence of reduction in myocardial perfusion. 
Possible clinical applications

Findings of the present study open new possibilities for myocardial postconditioning in the clinical setting. Recently, ischemic postconditioning has been demonstrated using repetitive re-inflation of the PTCA balloon. ${ }^{7}$ Ischemic postconditioning reduced infarct size by $-30 \%$ in acute myocardial infarct patients during $\mathrm{PCl}$ procedures. This important finding strongly indicates that reperfusion damage occurs in humans ${ }^{6}$ and salvage of human myocardium at risk is possible in this clinical setting. ${ }^{7}$ Intermittent ventricular pacing is easy, controllable and does not carry the risk of re-inflation induced vascular damage. ${ }^{19}$ Postconditioning effects have also been shown for various pharmacological agents, ${ }^{6,8,9}$ but these drugs may have undesirable side effects.

The present, small study shows no pro-arrhythmogenic or adverse hemodynamic effects of intermittent ventricular pacing during the early reperfusion phase. Obviously, application of dyssynchrony-induced postconditioning in patients requires careful evaluation in clinical trials.

\section{ACKNOWLEDGEMENTS}

We gratefully acknowledge the contributions of Arne Van Hunnik, Marion Kuiper, and Roeland Van Kerckhoven PhD (Department of Physiology, Maastricht University, The Netherlands) to this study. The study was financially supported by Boston Scientific (St Paul, MN, USA).

\section{REFERENCES}

1. Vanagt WY, Cornelussen RN, Poulina QP, Blaauw E, Vernooy $K$, Cleutjens JP, van Bilsen $M$, et al. Pacing-induced dys-synchrony preconditions rabbit myocardium against ischemia/reperfusion injury. Circulation 2006; 114:1264-269.

2. Ovize M, Kloner RA, Przyklenk K. Stretch preconditions canine myocardium. Am J Physiol 1994; 266:H137-146.

3. Gysembergh $A$, Margonari $H$, Loufoua J, Ovize $A$, Andre-Fouet $X$, Minaire $Y$, Ovize M. Stretchinduced protection shares a common mechanism with ischemic preconditioning in rabbit heart. Am J Physiol 1998; 274:H955-964.

4. Huang CH, Wang JS, Chiang SC, Wang YY, Lai ST, Weng ZC. Brief pressure overload of the left ventricle preconditions rabbit myocardium against infarction. Ann Thorac Surg 2004; 78:628-633.

5. Zhao ZQ, Corvera JS, Halkos ME, Kerendi F, Wang NP, Guyton RA, Vinten-Johansen J. Inhibition of myocardial injury by ischemic postconditioning during reperfusion: comparison with ischemic preconditioning. Am J Physiol Heart Circ Physiol 2003; 285:H579-588.

6. Vinten-Johansen J, Yellon DM, Opie LH. Postconditioning: a simple, clinically applicable procedure to improve revascularization in acute myocardial infarction. Circulation 2005; 112:2085-2088.

7. Staat P, Rioufol G, Piot C, Cottin Y, Cung TT, L'Huillier I, Aupetit JF, et al. Postconditioning the human heart. Circulation 2005; 112:2143-2148.

8. Chiari PC, Bienengraeber MW, Pagel PS, Krolikowski JG, Kersten JR, Warltier DC. Isoflurane protects against myocardial infarction during early reperfusion by activation of phosphatidylinositol-3. 
kinase signal transduction: evidence for anesthetic-induced postconditioning in rabbits. Anesthesiology 2005; 102:102-109.

9. Weihrauch D, Krolikowski JG, Bienengraeber M, Kersten JR, Warltier DC, Pagel PS. Morphine enhances isoflurane-induced postconditioning against myocardial infarction: the role of phosphatidylinositol-3-kinase and opioid receptors in rabbits. Anesth Analg 2005; 101:942-949, table of contents.

10. Blombery PA, Korner PI. Role of aortic and carotid sinus baroreceptors on Valsalva-like vasoconstrictor and heart rate reflexes in the conscious rabbit. J Auton Nerv Syst 1982; 5:303-315.

11. Apstein CS, Puchner E, Brachfeld N. Improved automated lactate determination. Anal Biochem 1970; 38:20-34.

12. Prinzen FW, Hunter WC, Wyman BT, MCVeigh ER. Mapping of regional myocardial strain and work during ventricular pacing: experimental study using magnetic resonance imaging tagging. $\mathrm{J}$ Am Coll Cardiol 1999; 33:1735-1742.

13. van Oosterhout MF, Arts T, Bassingthwaighte JB, Reneman RS, Prinzen FW. Relation between local myocardial growth and blood flow during chronic ventricular pacing. Cardiovasc Res 2002; 53:831840.

14. Vernooy $K$, Verbeek XA, Peschar M, Crijns HJ, Arts $T$, Cornelussen RN, Prinzen FW. Left bundle branch block induces ventricular remodelling and functional septal hypoperfusion. Eur Heart $J$ 2005; 26:91-98.

15. Argaud L, Gateau-Roesch O, Raisky O, Loufouat J, Robert D, Ovize M. Postconditioning inhibits mitochondrial permeability transition. Circulation 2005; 111:194-197.

16. Okamoto F, Allen BS, Buckberg GD, Bugyi $H$, Leaf J. Reperfusion conditions: importance of ensuring gentle versus sudden reperfusion during relief of coronary occlusion. J Thorac Cardiovasc Surg 1986; 92:613-620.

17. Mrak RE, Carry MM, Murphy ML, Peng CF, Straub KD. Reperfusion injury in ischemic myocardium: protective effect of controlled reperfusion. Am J Cardiovasc Pathol 1990; 3:217-224.

18. Heusch $G$. Postconditioning: old wine in a new bottle? J Am Coll Cardiol 2004; 44:1111-1112.

19. Tsang A, Hausenloy DJ, Yellon DM. Myocardial postconditioning: reperfusion injury revisited. Am J Physiol Heart Circ Physiol 2005; 289:H2-7.

20. Bopassa JC, Ferrera R, Gateau-Roesch O, Couture-Lepetit E, Ovize M. PI 3-kinase regulates the mitochondrial transition pore in controlled reperfusion and postconditioning. Cardiovasc Res 2006; 69:178-185.

21. Lewis $C W$, Owen $C H$, Zipprich DA, Sabiston DC, Jr., Smith PK, Glower DD. The effects of local ventricular pacing on recovery from regional myocardial ischemia. J Surg Res 1993; 54:360-367.

22. Gowda A, Yang CJ, Asimakis GK, Ruef J, Rastegar S, Runge MS, Motamedi M. Cardioprotection by local heating: improved myocardial salvage after ischemia and reperfusion. Ann Thorac Surg 1998; 65:1241-1247.

23. Yellon DM, Downey JM. Preconditioning the myocardium: from cellular physiology to clinical cardiology. Physiol Rev 2003; 83:1113-1151.

24. Darling $C E$, Jiang $R$, Maynard $M$, Whittaker $P$, Vinten-Johansen J, Przyklenk K. Postconditioning via stuttering reperfusion limits myocardial infarct size in rabbit hearts: role of ERK1/2. Am J Physiol Heart Circ Physiol 2005; 289:H1618-1626.

25. Serviddio $G$, Di Venosa N, Federici A, D'Agostino D, Rollo T, Prigigallo $F$, Altomare $E$, et al. Brief hypoxia before normoxic reperfusion (postconditioning) protects the heart against ischemiareperfusion injury by preventing mitochondria peroxyde production and glutathione depletion. Faseb J 2005; 19:354-361.

26. Tsang A, Hausenloy DJ, Mocanu MM, Yellon DM. Postconditioning: a form of "modified reperfusion" protects the myocardium by activating the phosphatidylinositol 3-kinase-Akt pathway. Circ Res 2004; 95:230-232.

27. Schwanke U, Deussen A, Heusch G, Schipke JD. Heterogeneity of local myocardial flow and oxidative metabolism. Am J Physiol Heart Circ Physiol 2000; 279:H1029-1035. 


\section{General discussion}




\section{INTRODUCTION}

The present studies show the ambiguous effects of ventricular pacing.

On the one hand, right ventricular pacing was associated with a decrease in cardiac function. In the pediatric studies in chapter 3-5, we have shown the acute and long-term benefits of single site left ventricular (LV) pacing as opposed to right ventricular (RV) pacing.

On the other hand intermittent dyssynchrony, induced by ventricular pacing, was found to exert cardioprotective effects against ischemia / reperfusion injury (chapter 6-7).

In the general discussion, the results of the studies described in this thesis will be put into a broader perspective. Furthermore, ideas for future investigations are discussed. 


\section{Part I. Pacing-induced dyssynchrony, curse for hemodynamic performance}

\section{PACING IN CHILDREN}

\section{LV apex pacing}

In the postoperative children studied in chapter 3, left ventricular (LV) apex pacing maintains LV pump function at sinus rhythm level, whereas right ventricular (RV) apex and LV lateral wall pacing acutely decrease LV contractility. These beneficial hemodynamic effects of LV apex pacing are in agreement with observations in laboratory animals in the 1960's ${ }^{1,2}$ and in several more recent animal studies. ${ }^{3-6}$ The animal experiments described in chapter 3 confirm the observations made by Verbeek et al. ${ }^{5}$ that LV apex pacing results in synchronous electrical activation around the LV circumference. A recent study by Cojoc et al. supports these observations, showing that LV apex pacing in immature pig hearts with atrioventricular (AV) block results in LV intraventricular contractile synchrony as compared with RV pacing. ${ }^{6}$ Our data from animal experiments and postoperative pediatric patients correlate well and strongly suggest that the LV apex is the preferred site for short-term ventricular pacing in children. Extensive experience in the area of a related therapy (cardiac resynchronization therapy) indicates that there is a relatively good correlation between short-term hemodynamic and long-term functional and clinical effects of ventricular pacing. This correlation is supported by our observations in the patient with RV pacing-induced heart failure (chapter 4), where the favorable effects of LV apex pacing on hemodynamic performance and intraventricular contractile synchrony persist over time. Clearly, long-term studies in children with LV apex pacing are warranted in order to further investigate whether the LV apex is the preferred pacing site for chronic pacing in children. It also remains to be determined whether chronic LV apex pacing is feasible and safe in large groups of children in terms of LV function, lead stability, pacing thresholds and complications. Specific attention will have to be addressed to the long-term behavior of the RV, since this part of the heart is late-activated and has been reported to show dyssynchronous motion during LV apex pacing. ${ }^{6}$

\section{LV lateral wall pacing}

The study described in chapter 5 provides further support for the idea that chronic RV pacing has detrimental effects on LV function. LV lateral wall pac- 
Gimptes:

ing, however, maintains LV function at the normal level. This finding is of great importance, because heart failure is reported to occur in $6-7 \%$ of chronically RV paced children after an average of 8 to 15 years of pacing..$^{7.9}$ Our data indicate that heart failure in this patient population might be related to the ventricular pacing site and should not be attributed solely to the underlying heart disease. The differences in long-term outcome between LV and RV pacing are consistent with data from acute hemodynamic studies in animals ${ }^{10}$ and adults ${ }^{11,12}$ where LV lateral wall pacing is superior to RV pacing. Another study in adults with heart failure shows increased cardiac function after 1 year of LV lateral wall pacing. ${ }^{13}$ Interestingly, in the acute hemodynamic study in chapter 3, LV lateral wall pacing did not improve LV contractility as compared with RV apex pacing, whereas chronic LV lateral wall pacing in the study in chapter 5 maintains LV function and dimensions at the level of healthy children. The discrepancy between these acute hemodynamic data and the long-term outcome observed in chapter 5 could be explained by the small number of patients in both studies and the different study environment (recovery from cardiac surgery versus outpatient clinic visit). Furthermore, the pacing lead was located closer to the base of the LV in the acute hemodynamic study as compared with the chronic study. Other differences between the studies in chapter 3 and 5 are the patient characteristics (structural heart defects versus normal anatomy) and the outcome measures used to assess LV function ( $\left(\mathrm{VdP} / \mathrm{dt}_{\max }\right.$ and pulse pressure versus shortening fraction and LV eccentricity index).

\section{CLINICAL APPLICATIONS}

\section{Ventricular pacing in children with bradycardia}

In children with congenital or acquired AV-block, ventricular pacing is often indicated for rate control. In order to minimize the adverse effects of ventricular pacing on cardiac function and structure, the ventricular pacing lead should be positioned at the optimal pacing site. Considering the favorable hemodynamic effects of LV apex and LV lateral wall pacing as opposed to RV apex pacing in children, we advocate the use LV pacing sites for rate control in children with AV-block. QRS-duration during ventricular pacing did not correlate well with cardiac pump function in studies from our group and by others. ${ }^{3,6,14,15}$ Therefore, we suggest to test several LV pacing sites during the implantation procedure, and to implant the permanent pacing electrode at the site that results in the best hemodynamic performance (chapter 2). 


\section{Ventricular pacing in children with heart failure}

In children with prolonged QRS-duration and heart failure, several investigators have studied cardiac resynchronization therapy by biventricular pacing. ${ }^{16}$ In parallel with experience in adults, biventricular pacing has good hemodynamic effects in children. ${ }^{14.17-21}$ It has to be mentioned, however, that pediatric and adult heart failure patients differ in several ways. The adult cardiology population mainly consists of patients with structurally normal hearts and acquired myocardial tissue pathology. In contrast, the pediatric cardiology population predominantly comprises children with congenital structural heart defects and normal myocardial tissue. Furthermore, adults with heart failure and left bundle branch block differ from young patients in whom intraventricular conduction disorders, if present, largely consist of right bundle branch block. ${ }^{14}$ It therefore has to be studied to what extent the current indications for cardiac resynchronization therapy in adults (i.e. prolongation of the QRS complex, contractile dyssynchrony, severity of heart failure) could be applied in juvenile patients.

In children with heart failure, it is currently unknown whether biventricular pacing provides a benefit over optimal single site ventricular pacing. In adults with prolonged QRS-duration and congestive heart failure, acute ${ }^{11,22}$ and chronic ${ }^{23}$ single site LV lateral wall pacing is equally effective as biventricular pacing in improving LV pump function. Similar results are found in laboratory animals in the absence ${ }^{3}$ or presence ${ }^{5}$ of left bundle branch block, where especially LV apex pacing results in hemodynamic performance as good as biventricular pacing. At present, it is not possible to provide evidence-based recommendations for the decision whether to pace at one or more ventricular sites in young heart failure patients. However, single site pacing has several practical advantages over biventricular pacing in children. Pacemaker system and lead replacements should be expected since children grow and pacing is usually protracted for several decades. Therefore, factors such as the limitation of the number of necessary access routes to different parts of the heart, scar tissue formation and pacemaker battery usage are even more relevant than in adults. Epicardial LV pacing leads can be positioned through a left lateral thoracotomy, which is surgically reliable and provides excellent cosmetic and functional results in juvenile patients. ${ }^{24}$ In adults, the LV pacing lead is usually implanted using an endovenous approach. This is also a possible access route in children, ${ }^{17}$ but potentially jeopardizes endovascular integrity. ${ }^{25}$ 


\section{FUTURE PERSPECTIVES}

In order to evaluate whether biventricular pacing provides benefits over single site LV pacing in children, further studies are needed. These studies will have to be performed in children and in immature animals, considering the abovementioned differences between pediatric and adult cardiology patients. Furthermore, the immature heart is by nature still subjected to growth, and previous studies in puppies ${ }^{26}$ and children ${ }^{27}$ have demonstrated dramatic histopathological changes such as dystrophic calcifications, fiber disarray, abnormal mitochondria, fat deposition and fibrosis following RV pacing. ${ }^{25}$ Such alterations have never been demonstrated in adult animal or human hearts. This data suggest that the immature heart is more sensitive to dyssynchrony than adult hearts, but this concept still has to be proven.

In the light of the discussion on optimal ventricular pacing for rate control in children, a follow-up study in children with AV-block is recommended to compare biventricular pacing with optimal site LV pacing in terms of maintaining LV contractile function, mechanical synchrony and dimensions. This can be studjed using (tissue Doppler) echocardiographic follow-up. ${ }^{9}$ In an animal model, a similar approach is possible following the creation of AV-block. In animals, however, valuable additional information can be obtained using more invasive assessment techniques, histological examination of cardiac tissue and diffusion tensor imaging (MRI) for 3-dimensional assessment of fiber architecture. In young heart failure patients the application of biventricular pacing therapy is currently advocated by several investigators. ${ }^{9}, 14,16-21$ (e.g children with heart failure with or without conduction disorders and with or without contractile dyssynchrony). However, the functional and structural effects of biventricular, LV lateral wall and LV apex pacing should be compared. In these children, it should also be studied whether the indications for cardiac resynchronization therapy in adults are applicable in young heart failure patients.

Our studies have demonstrated the presence of an association between pacing site, dyssynchrony and ventricular function in animals and children with normal biventricular anatomy. However, the pediatric cardiology population also comprises patients with complex structural cardiac abnormalities in whom the morphologic RV instead of the LV provides cardiac output into the aorta. This abnormal configuration of the heart and circulatory system is referred to as the "systemic RV". It would also be interesting to investigate how ventricular pacing site and cardiac function relate in children with a systemic $R V$, since the optimal pacing site in these children possibly differs from the optimal site in children with normal biventricular anatomy. 


\title{
Part II. Pacing-induced dyssynchrony, blessing for ischemic tolerance
}

\author{
Infarct-reducing effect of intermittent pacing \\ The study in chapter 6 shows that brief periods of cardiac dyssynchrony, in- \\ duced by ventricular pacing at physiological heart rate prior to ischemia, can \\ reduce myocardial infarct size as much as classical ischemic preconditioning. \\ Moreover, the experiments in rabbit and pig hearts in chapter 7 demonstrate \\ that myocardial infarct size after regional ischemia is reduced by intermittent \\ ventricular pacing-induced dyssynchrony during early reperfusion. Dyssyn- \\ chrony-induced postconditioning equals the cardioprotective power of dyssyn- \\ chrony-induced preconditioning, used as an interventional control in this study. \\ This is in accordance with the findings of animal studies on ischemic postcon- \\ ditioning, where the protective effects of ischemic pre- and postconditioning \\ are similar. ${ }^{28-31}$
}

\section{Pacing-induced cardioprotection: heart rate or dyssynchrony?}

Our data on protection by pacing-induced dyssynchrony have been acquired using ventricular pacing at unchanged heart rate. Rapid ventricular pacing was already known to lead to preconditioning since the 1990s. ${ }^{32-34}$ However, the protection afforded by rapid ventricular pacing was generally attributed to concomitant myocardial ischemia during pacing. Koning et al. performed elegant experiments, which already indicated that ischemia is not the trigger of rapid ventricular pacing-induced protection. ${ }^{34}$ Moreover, rapid atrial pacing does not induce preconditioning, ${ }^{35}$ even though coronary flow is affected to a similar degree as during rapid ventricular pacing. Furthermore, intermittent ventricular pacing for 12 hours reduces the incidence of arrhythmias after ischemia in isolated chick embryo hearts. ${ }^{36}$ With hindsight these publications support our hypothesis that dyssynchrony rather than high heart rate induces cardioprotection. While the studies mentioned above focused on preconditioning properties, an interesting study in cats already mentioned postconditioning during early reperfusion in $1996 .{ }^{37}$ In this study by $\mathrm{Na}$ et al., a combined postconditioning trigger consisting of ventricular extrasystole (dyssynchrony) and intermittent ischemia was cardioprotective in terms of arrhythmogenicity. However, this study did not elicit a broader interest in postconditioning procedures, possibly due to the lack of infarct size data as an outcome measure of the study. ${ }^{37}$ 
Intermittent dyssynchrony as a non-ischemic cardioprotective trigger

Our findings also further support the idea by Koning et al. ${ }^{34}$ that the mechanism of dyssynchrony-induced protection does not involve an ischemic trigger. Myocardial perfusion (assessed by fluorescent microspheres), coronary flow and lactate release did not change during ventricular pacing in rabbit hearts. Moreover, previous studies in our group did not show any sign of underperfusion in any LV region during ventricular pacing. ${ }^{38}$ Therefore, myocardial ischemia is a highly unlikely stimulus for dyssynchrony-induced pre- and postconditioning. This also indicates that the postconditioning effect in chapter 7 can not be attributed to "graded reperfusion", which is known to attenuate ischemia / reperfusion damage considerably. ${ }^{30,39-42}$

\section{Mechanisms of pacing-induced pre- and postconditioning}

In the isolated rabbit heart experiments, cardioprotection against ischemia / reperfusion injury is obtained by intermittent ventricular pacing while keeping constant several variables that are known cardioprotective triggers such as temperature, ${ }^{43-46}$ global preload ${ }^{47-49}$ and afterload. ${ }^{50,51}$ From previous studies it is known that increased global preload ${ }^{47-49}$ and afterload ${ }^{50,51}$ induce preconditioning. Therefore, the altered regional loading conditions during ventricular pacing are likely triggers of dyssynchrony-induced pre- and postconditioning. Early-systolic stretch in late-activated regions during ventricular pacing has been observed in other studies ${ }^{52-54}$ and is known to be sufficient to lead to local cardiac hypertrophy. ${ }^{55}$ In the study in chapter 6 , we demonstrate that the late-activated region during ventricular pacing is subjected to early-systolic stretch as expressed by the increased end-diastolic segment length. Furthermore, during pacing-induced pre- and postconditioning (chapter 6-7), local segment work (pressure-length loop area) is significantly increased in lateactivated and decreased in early-activated regions.

\section{Influence of the ventricular pacing site}

Our studies provide various indications that the protection against ischemia / reperfusion injury by ventricular pacing is independent of the ventricular pacing site. In the global ischemia model in isolated rabbit hearts, infarct size is equally reduced in early- and late-activated myocardium (chapter 6 ). In the regional ischemia experiments in rabbits (chapter 7), the ischemic region comprises myocardium which is activated early as well as late during LV pacing (LV posterior wall pacing, occlusion of the lateral descending artery). In pigs, the ischemic region is located in early- to intermediate-activated myocardium ( $R V$ pacing and occlusion of the left anterior descending artery). Experiments in an additional series of rabbits have been performed to test the hypothesis 
that cardioprotection is independent of the pacing site. In the isolated rabbit heart setup described in chapter 7 , we have compared the preconditioning effect of endocardial RV apex and epicardial LV pacing (figure 8.1).

\section{Control group $(n=8)$}

\section{0 ' Ischemia} 2 hours reperfusion

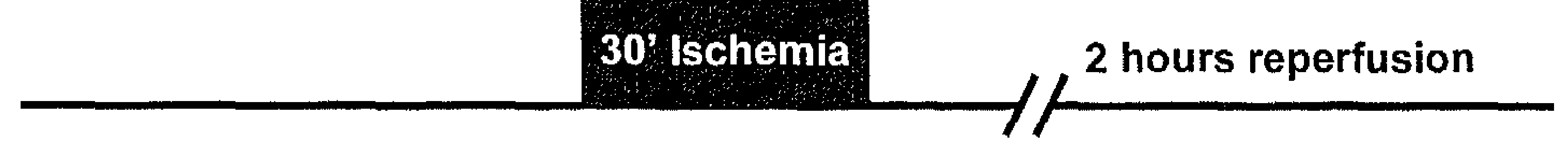

Left ventricular pacing preconditioning group (LVPpreC, $n=8$ )

$5^{\prime} 5^{\prime} 5^{\prime}, 5,5,10^{\prime} 30^{\prime}$ ischemia 2 hours reperfusion

Right ventricular pacing preconditioning group ( $R$ VPreC, $n=8$ ) $5,5,5^{\prime}, 5^{\prime}, 10,30$ ' Ischemia 2 hours reperfusion

Figure 8.1 Study protocol in isolated rabbits hearts. Black 5 ' blocks represent 5 minutes of ventricular pacing at normal heart rate, followed by atrial pacing. Large black blocks represent 30 minutes of regional index ischemia.

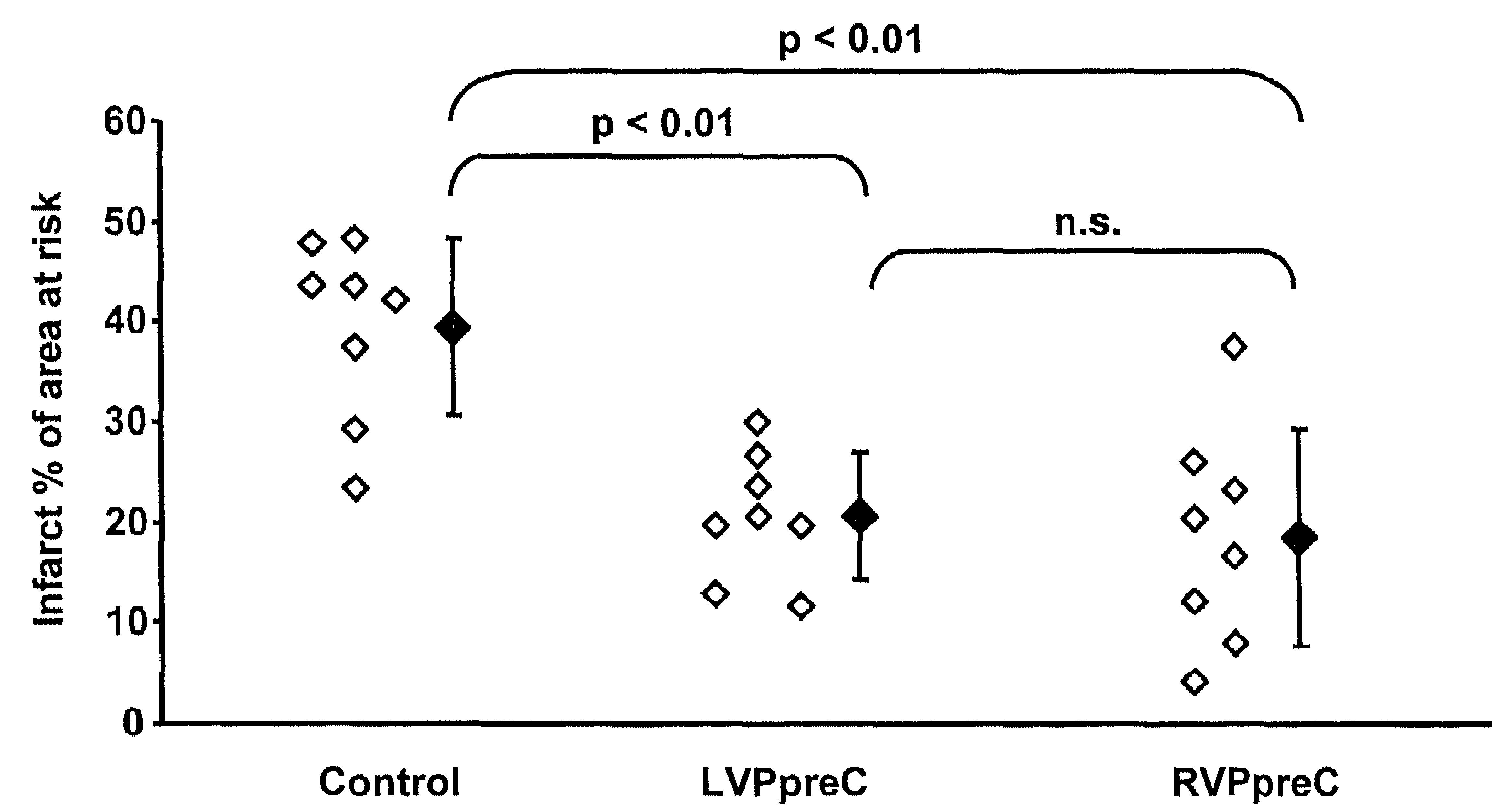

Figure 8.2 Infarct size. LVPpreC = left ventricular pacing preconditioning, RVPpreC = right ventricular pacing preconditioning. n.s. = no significant difference between groups. 
Chate:

In these experiments, both intermittent RV and LV pacing prior to regional ischemia significantly reduce infarct size as compared with control rabbits (figure 8.2). In combination with the data on postconditioning in rabbits and pigs (chapter 7), these additional findings suggest that the exact site of pacing is not critical for achieving a pre- and postconditioning effect. However, all of the above tested pacing sites give rise to significant dyssynchrony. Since we hypothesize that dyssynchrony-induced changes in myocardial stretch and contraction are the stimulus for protection, it would be interesting to investigate whether ventricular pacing using other sites (e.g. LV apex) or modes (e.g. biventricular pacing) is less cardioprotective. Such studies may contribute to the understanding of ventricular pacing-induced cardioprotection. Despite the regional alterations in myocardial stretch and contraction during ventricular pacing, the infarct-limiting effect is expressed throughout the LV wall. One way to explain the uniform protection induced by ventricular pacing is that a protective stimulus originates from a region with a particular mechanical load (for example the most pre-stretched, late-activated one) and that molecular signals are transported throughout the myocardial wall. In this way, "remote conditioning" would occur within the heart. Such remote cardioprotection has previously been described for preconditioning. ${ }^{43,56,57}$ The mechanisms of remote preconditioning have been attributed to hormonal mediators (e.g circulating endorphins ${ }^{57}$ or adenosine ${ }^{58}$ ) or the recruitment of a neural pathway. ${ }^{59}$ Support for the involvement of the latter comes from the observation that remote preconditioning can be abolished by ganglion blockade, ${ }^{60,61}$ but the exact nature of the involved neural pathway has not been elucidated.

\section{Influence of the duration of ischemia}

A recent study has shown that the infarct-reducing effects of ischemic postconditioning largely depend on the duration of index ischemia. ${ }^{62}$ Surprisingly, ischemic postconditioning after short index ischemia increases infarct size in rat hearts. ${ }^{62}$ It therefore deserves to be investigated whether dyssynchronyinduced postconditioning also causes a paradoxical increase in infarct size when used after a short ischemic episode.

On the other hand, postconditioning procedures can not be expected to be of benefit when the ischemic episode has been long enough to cause widespread lethal ischemic injury. Studies in acute myocardial infarct patients have found postconditioning effects after ischemic episodes of several hours, indicating that salvage of myocardial tissue is still possible at this time point. ${ }^{63-66}$ The duration of the ischemic insult to the hearts used in our animal studies (30 to 35 minutes in rabbits, 1 hour in pigs) is shorter than in the average myocardial infarct patient, even if the higher heart rate in the animals is taken into ac- 
count. This implies that the extrapolation of the data from our animal studies to clinical practice should always take the duration of the ischemic episode into account.

\section{Putative molecular mechanisms of dyssynchrony-induced cardioprotection}

As mentioned above, we hypothesized that abnormal mechanical load during ventricular pacing may be the stimulus for the signaling pathway involved in pacing-induced cardioprotection. One of the ways that mechanical load is transmitted to molecular signals is through stretch-activated ion channels (SAC). Therefore, we investigated whether SAC-blockade using gadolinium and streptomycin abrogated the beneficial effects of intermittent pacing. Unfortunately, gadolinium caused precipitation in Krebs-Henseleit buffer. ${ }^{67}$ Gadolinium dissolved properly in HEPES buffer ${ }_{1}^{67}$ but depressed LV function severely, ${ }^{68}$ also in our set-up (Vanagt, Babiker, unpublished data). Following administration of the SAC blocker streptomycin, ${ }^{69}$ LV function decreased dramatically, ${ }^{70}$ also in our isolated heart preparation (Vanagt, Babiker, unpublished data). These technical problems precluded the use of SAC blockers in our isolated heart set-up. Therefore, the possible involvement of SAC still needs to be explored in future studies.

However, the observation that pro-brain natriuretic peptide (BNP) mRNA expression is increased after intermittent pacing in rabbit hearts (chapter 6) supports the hypothesis that stretch is involved in pacing-induced preconditioning. Administration of BNP is cardioprotective, ${ }^{71}$ and altered mechanical loading conditions and myocardial stretch cause a rapid release of BNP followed by de novo peptide synthesis. ${ }^{72,73}$ After peptide binding of BNP to natriuretic peptide receptor type A (NPR-A), the effects of BNP are mediated through an increase in intracellular cGMP levels. ${ }^{72}$ The abrogation of the protective effect of BNP by selective blocking of the mitochondrial but not sarcolemmal $\mathrm{K}_{\text {ATP }}^{+}$channel in rats is consistent with a mechanism involving opening of the mitochondrial $\mathrm{K}_{\text {ATP }}^{+}$channel. ${ }^{71}$ It is currently not possible to inhibit the NPR-A to study the contribution of the interaction between BNP and this receptor to the infarctreducing effect of BNP. Unlike the receptors for adenosine and opioids, the NPR-A is not $G$ protein coupled, and BNP may therefore trigger an alternative signaling cascade. ${ }^{71,72}$ In a recent study in our laboratory by Babiker et al., blocking the adenosine receptor did not abrogate the infarct-reducing effect of pacing-induced postconditioning (unpublished data). However, downstream mediators in the signaling cascade are shown to be involved in dyssynchronyinduced protection, since the pacing-induced postconditioning effect is lost by selectively blocking the mitochondrial $\mathrm{K}_{\text {ATP }}^{+}$channel using 5- 
hydroxydecanoate. Also following the administration of chelerythrine, a protein kinase $\mathrm{C}$ blocker and wortmannin, a phosphatidyl-inositol 3-kinase (PI3K) blocker, the protection conferred by dyssynchrony-induced postconditioning is completely abrogated (Babiker et al., unpublished data). PI3K is one of the members of the reperfusion injury survival kinase (RISK) pathway that is involved in myocardial pre- and postconditioning..$^{747}$ In a small series of preliminary experiments in our laboratory, intermittent ventricular pacing also increases the phosphorylation of ERK1/2, another constituent of the RISK pathway.

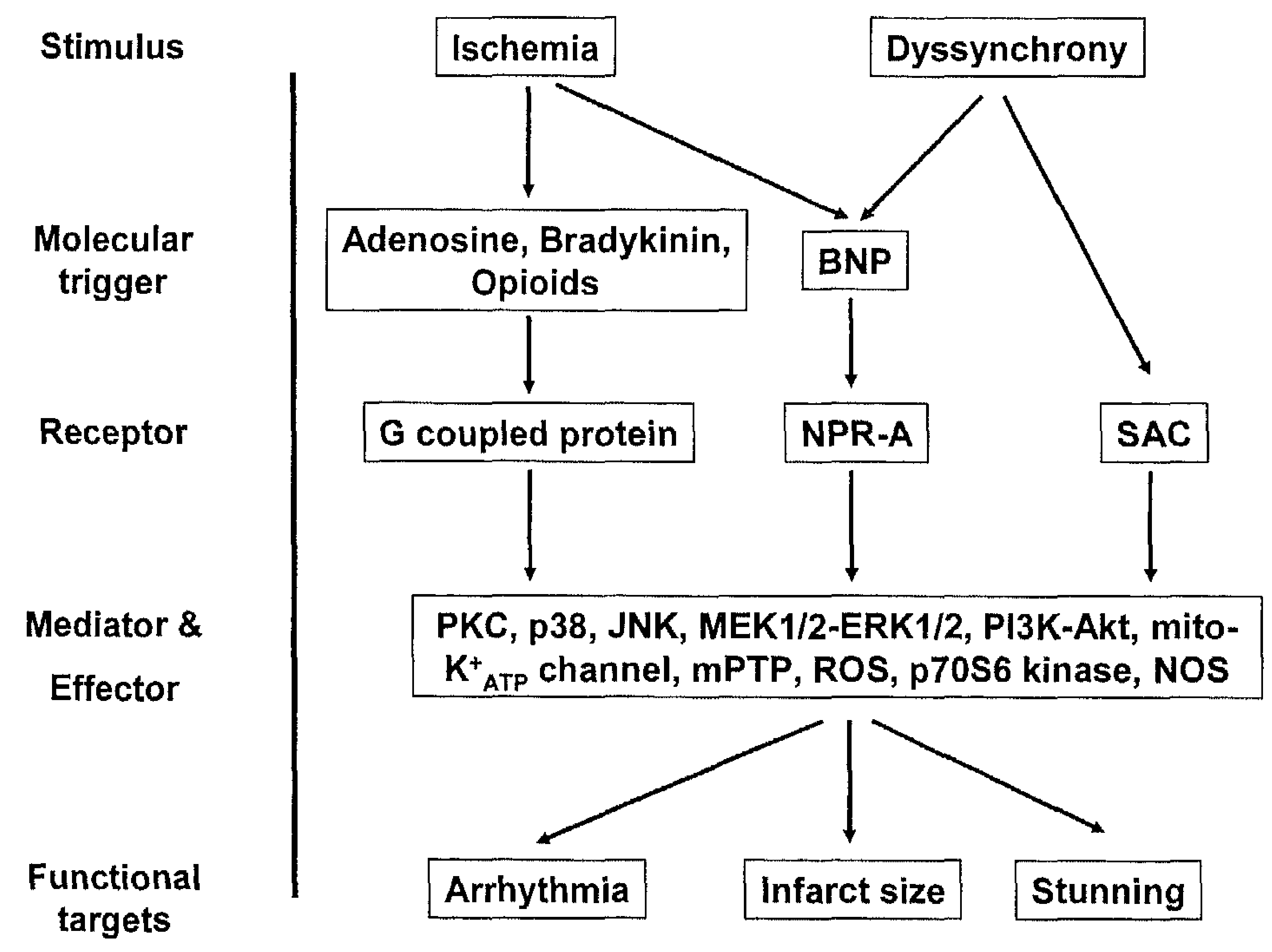

Figure 8.3 Simplified representation of possible signal transduction pathways. BNP = brain natriuretic peptide, NPR-A = natriuretic peptide receptor type $A, S A C=$ stretch-activated channel, $P K C=$ protein kinase $\mathrm{C}, \mathrm{JNK}=\mathrm{C}$-Jun- $\mathrm{N}$-terminal kinase, $\mathrm{ERK}=$ extracellular signal-regulated kinase, mito$\mathrm{K}_{\text {ATP }}^{+}$channel $=$mitochondrial $\mathrm{K}_{\text {ATP }}^{+}$channel, $\mathrm{MPTP}=$ mitochondrial permeability transition pore, ROS $=$ reactive oxygen species, NOS $=$ nitric oxide synthase.

The results from the studies in chapter 6-7 do not elucidate the molecular signaling pathways involved in dyssynchrony-induced cardioprotection in full de- 
tail. However, taken together, our data suggest that the signaling cascade is triggered by BNP (activation of NPR-A) rather than by adenosine (activation of $G$ coupled protein receptors), and that the activation of downstream mediators such as the mitochondrial $\mathrm{K}_{\text {ATP }}^{+}$channel, ERK1/2, PKC and PI3K is involved in the protective signaling cascade. Figure 8.3 illustrates the possible outline of the cardioprotective pathways of pacing-induced dyssynchrony. Knowledge regarding regulatory mechanisms of signal transduction pathways and crosstalk between mediators is emerging, ${ }^{78}$ but at present the exact relationship between the "mediators \& effectors" in figure 8.3 remains to be elucidated. Clearly, further studies are required to investigate the underlying mechanisms of dyssynchrony-induced pre- and postconditioning.

\section{Perspectives for laboratory studies}

Although ventricular pacing at any site induces electrical and contractile dyssynchrony as compared with physiological circumstances, the extent to which dyssynchrony occurs depends on the ventricular pacing site (chapter 2). Therefore, it would be most interesting to investigate whether optimal site (e.g. LV apex) or biventricular pacing results in sufficient dyssynchrony to induce cardioprotection. This possibly provides an answer to the question whether the observed infarct-reducing effect is truly attributable to pacing-induced dyssynchrony. Although we hypothesize that dyssynchrony induces cardioprotection and various abovementioned cardioprotective triggers are excluded in the isolated heart preparation, it is yet to be determined whether the electric pacing stimulus itself confers myocardial protection against ischemia / reperfusion injury. To investigate the possible pre- or postconditioning potential of the electrical stimulus itself without causing alterations in regional stretch and contraction, one could apply a pacing stimulus during the refractory period of the heart. In this way, the same electrical stimulus is delivered without the mechanical consequences of ventricular pacing.

The intermittent pacing stimuli applied in our studies are sufficient to induce preconditioning and postconditioning. However, it is currently unknown whether a smaller number of cycles or a shorter duration of the cycles still confers dyssynchrony-induced cardioprotection. The necessary length of each cycle appears to be related to the size of the animal. ${ }^{79}$ New studies have to be performed to determine the threshold level of intermittent ventricular pacing for the induction of an infarct-limiting effect. Similarly, the timing of the application of the pacing trigger has to be studied in more detail. In classical preconditioning schemes, the protective effect is generally conserved for $3-4$ hours, ${ }^{57,59}$ but it is unknown if this is also the case with dyssynchrony-induced preconditioning. There is increasing evidence that postconditioning stimuli have to be ap- 
Chatres

plied within the first minutes of reperfusion to be effective. ${ }^{31,76,79,80}$ Presumably, dyssynchrony-induced postconditioning also has to be delivered as soon as possible after the start of reperfusion and this will be investigated in future studies.

The value of dyssynchrony-induced cardioprotection as compared with pharmacological preconditioning ${ }^{81-83}$ and postconditioning ${ }^{84-86}$ remains to be determined, although these drugs may have undesirable side effects. Possibly, combining pharmacological interventions with intermittent dyssynchrony could increase the resultant cardioprotective effect, as previously shown for the combination of pharmacological agents and ischemic preconditioning ${ }^{87}$ or postconditioning. ${ }^{85}$

Our experiments are performed using young healthy animals, in contrast with most myocardial infarct patients that are older and present with severe coronary artery disease. Furthermore, these patients often have co-morbidities and risk factors for cardiovascular disease ${ }^{88}$ (e.g. diabetes, hypertension and hypercholesterolemia). The benefit of ischemic preconditioning appears to decrease in elderly patients, ${ }^{89}$ but is preserved by a high level of physical activity. ${ }^{90}$ Diabetes affects the efficiency of ischemic preconditioning since hyperglycemia can abolish the ischemic preconditioning effect ${ }^{91}$ and glibenclamide, a commonly used drug in patients with diabetes, inhibits $\mathrm{K}_{\text {ATP }}^{+}$channels. ${ }^{92}$ The preconditioning effect of rapid ventricular pacing is lost in rabbits with hypercholesterolemia. ${ }^{93}$ In another rabbit model, the effect of ischemic preconditioning is abolished by a high cholesterol diet, but is restored after the administration of pravastatin. ${ }^{94}$ Further studies should therefore also be undertaken in animals with co-morbidities that more closely resemble the human population at risk for myocardial ischemia.

\section{Perspectives for clinical studies and applications}

The experimental set-up of global myocardial ischemia used in the study on pacing preconditioning in chapter 6 is comparable to the situation during cardiac surgery. Therefore, intermittent ventricular pacing could be used to induce preconditioning in pediatric and adult patients undergoing cardiac surgical procedures. Dyssynchrony-induced preconditioning is easier to apply than ischemic preconditioning. However, myocardial preconditioning is infrequently employed in patients, in part because current cardioplegic techniques and cooling are often considered adequate enough to protect the myocardium during cardiac surgery. ${ }^{92}$ Furthermore, some events such as anginal attacks ${ }^{92}$ and exercise ${ }^{90}$ preceding the major ischemic insult may already have caused protection in patients, thus concealing or exhausting the benefit created by preconditioning. Finally, the unexpectedness of most ischemic events has ham- 
pered the use of preconditioning in clinical practice since it requires intervention prior to the onset of ischemia. ${ }^{59}$

Clearly, postconditioning has considerably greater clinical potential, especially in the setting of acute myocardial infarction. Our findings on pacing-induced postconditioning open new possibilities for applications in clinical cardiology. Ischemic postconditioning has already been demonstrated in human subjects with an acute myocardial infarction. ${ }^{63-65,95}$ These studies indicate that reperfusion injury occurs in humans ${ }^{84,96}$ and that salvage of human myocardium at risk is possible. ${ }^{63,}{ }^{64}$ Ischemic postconditioning carries the risk of re-inflation induced vascular damage. ${ }^{97}$ It seems a major advantage of intermittent ventricular pacing as a postconditioning stimulus that this procedure does not jeopardize the coronary vasculature. However, further studies will be needed to investigate the potential arrhythmogenic effects of ventricular pacing during early reperfusion in humans.

Current pacing techniques require the introduction of a separate pacing lead to perform pacing-induced postconditioning. Precious time could therefore be saved by applying the pacing stimulus using the guidewire or balloon catheter that is already inserted to perform the percutaneous coronary intervention.

To investigate the potential cardioprotective effect of dyssynchrony-induced postconditioning in humans, a randomized controlled trial is currently being performed at the Department of Cardiology, University Hospital of Maastricht, The Netherlands. This so-called PROTECT-trial studies patients with a first acute myocardial infarction and complete occlusion of the affected coronary artery segment. The pacing protocol is the same as in our animal experiments described in chapter 7 ( $10 \times 30 \mathrm{sec}$ ventricular pacing at $30 \mathrm{sec}$ intervals). The primary endpoint of this study is infarct size, quantified by cardiac enzyme release. In order to monitor potential arrhythmias during and after the postconditioning procedure, continuous Holter registration during the first 24 hours after reperfusion is also included in the study protocol. Furthermore, cardiac magnetic resonance imaging (MRI) is performed after 4 days, 4 months and 12 months to determine infarct size (late enhancement Gadolinium scans), LV function and remodeling. The results of this trial will indicate whether the outcome of our animal experiments (chapter 6-7) translates into the adult cardiology population. 


\section{REFERENCES}

1. Lister JW, Klotz DH, Jomain SL, Stuckey JH, Hoffman BF. Effect of Pacemaker Site on Cardiac Output and Ventricular Activation in Dogs with Complete Heart Block. Am J Cardiol 1964; 14:494503.

2. Tyers GF. Optimal electrode implantation site for asynchronous dipolar cardiac pacing. Ann Surg 1968; 167:168-179.

3. Prinzen FW, Van Oosterhout MF, Vanagt WY, Storm C, Reneman RS. Optimization of ventricular function by improving the activation sequence during ventricular pacing. Pacing Clin Electrophysiol 1998; 21:2256-2260.

4. Peschar M, de Swart $H$, Michels KJ, Reneman RS, Prinzen FW. Left ventricular septal and apex pacing for optimal pump function in canine hearts. J Am Coll Cardiol 2003; 41:1218-1226.

5. Verbeek XA, Vernooy $K$, Peschar $M$, Cornelussen RN, Prinzen FW. Intra-ventricular resynchronization for optimal left ventricular function during pacing in experimental left bundle branch block. J Am Coll Cardiol 2003; 42:558-567.

6. Cojoc A, Reeves JG, Schmarkey L, Strieper MJ, Joyner RW, Wagner MB, Campbell RM, et al. Effects of single-site versus biventricular epicardial pacing on myocardial performance in an immature animal model of atrioventricular block. J Cardiovasc Electrophysiol 2006; 17:884-889.

7. Kim JJ, Friedman RA, Eidem BW, Cannon BC, Arora G, Smith EO, Fenrich AL, et al. Ventricular function and long-term pacing in children with congenital complete atrioventricular block. J Cardiovasc Electrophysiol 2007; 18:373-377.

8. Vatasescu R, Shalganov T, Paprika D, Kornyei L, Prodan Z, Bodor G, Szatmari A, et al. Evolution of left ventricular function in paediatric patients with permanent right ventricular pacing for isolated congenital heart block: a medium term follow-up. Europace 2007; 9:228-232.

9. Moak JP, Hasbani K, Ramwell C, Freedenberg V, Berger JT, DiRusso G, Callahan P. Dilated cardiomyopathy following right ventricular pacing for AV block in young patients: resolution after upgrading to biventricular pacing systems. J Cardiovasc Electrophysiol 2006; 17:1068-1071.

10. Prinzen FW, Peschar M. Relation between the pacing induced sequence of activation and left ventricular pump function in animals. Pacing Clin Electrophysiol 2002; 25:484-498.

11. Blanc JJ, Etienne $Y$, Gilard M, Mansourati J, Munier S, Boschat J, Benditt DG, et al. Evaluation of different ventricular pacing sites in patients with severe heart failure: results of an acute hemodynamic study. Circulation 1997; 96:3273-3277.

12. Puggioni $E$, Brignole $M$, Gammage $M$, Soldati $E$, Bongiorni $M G$, Simantirakis $E N$, Vardas $P$, et al. Acute comparative effect of right and left ventricular pacing in patients with permanent atrial fibrillation. J Am Coll Cardiol 2004; 43:234-238.

13. Blanc JJ, Bertault-Valls V, Fatemi M, Gilard M, Pennec PY, Etienne Y. Midterm benefits of left univentricular pacing in patients with congestive heart failure. Circulation 2004; 109:1741-1744.

14. Zimmerman FJ, Starr JP, Koenig PR, Smith P, Hijazi ZM, Bacha EA. Acute hemodynamic benefit of multisite ventricular pacing after congenital heart surgery. Ann Thorac Surg 2003; 75:1775-1780.

15. Vanagt WY, Verbeek XA, Delhaas T, Mertens L, Daenen WJ, Prinzen FW. The Left Ventricular Apex is the Optimal Site for Pediatric Pacing. Pacing Clin Electrophysiol 2004; 27:837-843.

16. Karpawich PP. Pediatric cardiac resynchronization pacing therapy. Curr Opin Cardiol 2007; 22:7276.

17. Blom NA, Bax JJ, Ottenkamp J, Schalij MJ. Transvenous biventricular pacing in a child after congenital heart surgery as an alternative therapy for congestive heart failure. $\mathrm{J}$ Cardiovasc Electrophysiol 2003; 14:1110-1112.

18. Roofthooft MT, Blom NA, Rijlaarsdam ME, Bokenkamp R, Ottenkamp J, Schalij MJ, Bax JJ, et al. Resynchronization therapy after congenital heart surgery to improve left ventricular function. Pacing Clin Electrophysiol 2003; 26:2042-2044. 
19. Janousek J, Vojtovic P, Hucin B, Tlaskal T, Gebauer RA, Gebauer R, Matejka T, et al. Resynchronization pacing is a useful adjunct to the management of acute heart failure after surgery for congenital heart defects. Am J Cardiol 2001; 88:145-152.

20. Janousek J, Tomek V, Chaloupecky V, Gebauer RA. Dilated cardiomyopathy associated with dualchamber pacing in infants: improvement through either left ventricular cardiac resynchronization or programming the pacemaker off allowing intrinsic normal conduction. J Cardiovasc Electrophysiol $2004 ; 15: 470-474$.

21. Dubin AM, Janousek J, Rhee E, Strieper MJ, Cecchin F, Law IH, Shannon KM, et al. Resynchronization therapy in pediatric and congenital heart disease patients: an international multicenter study. $J$ Am Coll Cardiol 2005; 46:2277-2283.

22. Nelson GS, Berger RD. Fetics BJ, Talbot M, Spinelli JC, Hare JM, Kass DA. Left ventricular or biventricular pacing improves cardiac function at diminished energy cost in patients with dilated cardiomyopathy and left bundle-branch block. Circulation 2000; 102:3053-3059.

23. Touiza $A$, Etienne $Y$, Gilard $M$, Fatemi $M$, Mansourati J, Blanc JJ. Long-term left ventricular pacing: assessment and comparison with biventricular pacing in patients with severe congestive heart failure. J Am Coll Cardiol 2001; 38:1966-1970.

24. Dodge-Khatami A, Kadner A, Dave $H$, Rahn $M$, Pretre $R$, Bauersfeld U. Left heart atrial and ventricular epicardial pacing through a left lateral thoracotomy in children: a safe approach with excellent functional and cosmetic results. Eur J Cardiothorac Surg 2005; 28:541-545.

25. Karpawich PP. Chronic right ventricular pacing and cardiac performance: the pediatric perspective. Pacing Clin Electrophysiol 2004; 27:844-849.

26. Karpawich PP, Justice $C D$, Cavitt $D L$, Chang $\mathrm{CH}$. Developmental sequelae of fixed-rate ventricular pacing in the immature canine heart: an electrophysiologic, hemodynamic, and histopathologic evaluation. Am Heart J 1990; 119:1077-1083.

27. Karpawich PP, Rabah R, Haas JE. Altered cardiac histology following apical right ventricular pacing in patients with congenital atrioventricular block. Pacing Clin Electrophysiol 1999; 22:1372-1377.

28. Zhao ZQ, Corvera JS, Haikos ME, Kerendi F, Wang NP, Guyton RA, Vinten-Johansen J. Inhibition of myocardial injury by ischemic postconditioning during reperfusion: comparison with ischemic preconditioning. Am J Physiol Heart Circ Physiol 2003; 285:H579-588.

29. Argaud L, Gateau-Roesch O, Raisky O, Loufouat J, Robert D, Ovize M. Postconditioning inhibits mitochondrial permeability transition. Circulation 2005; 111:194-197.

30. Tsang A, Hausenloy DJ, Mocanu MM, Yellon DM. Pastconditioning: a form of "modified reperfusion" protects the myocardium by activating the phosphatidylinositol 3-kinase-Akt pathway. Circ Res 2004; 95:230-232.

31. Yang XM, Proctor JB, Cui L, Krieg T, Downey JM, Cohen MV. Multiple, brief coronary occlusions during early reperfusion protect rabbit hearts by targeting cell signaling pathways. J Am Coll Cardiol 2004; 44:1103-1110.

32. Vegh A, Szekeres L, Parratt JR. Transient ischaemia induced by rapid cardiac pacing results in myocardial preconditioning. Cardiovasc Res 1991; 25:1051-1053.

33. Szilvassy Z, Ferdinandy P, Bor P, Jakab I, Lonovics J, Koltai M. Ventricular overdrive pacinginduced anti-ischemic effect: a conscious rabbit model of preconditioning. Am J Physiol 1994; 266:H2033-2041.

34. Koning MM, Gho BC, van Klaarwater E, Opstal RL, Duncker DJ, Verdouw PD. Rapid ventricular pacing produces myocardial protection by nonischemic activation of KATP+ channels. Circulation 1996; $93: 178-186$.

35. Marber MS, Walker DM, Eveson DJ, Walker JM, Yellon DM. A single five minute period of rapid atrial pacing fails to limit infarct size in the in situ rabbit heart. Cardiovasc Res 1993; 27:597-601.

36. Rosa A, Maury JP, Terrand J, Lyon X, Kucera P, Kappenberger L, Raddatz E. Ectopic pacing at physiological rate improves postanoxic recovery of the developing heart. Am J Physiol Heart Circ Physiol 2003; 284:H2384-2392.

37. Na HS, Kim YI, Yoon YW, Han HC, Nahm SH, Hong SK. Ventricular premature beat-driven intermittent restoration of coronary blood flow reduces the incidence of reperfusion-induced ventricular fibrillation in a cat model of regional ischemia. Am Heart $J$ 1996; 132:78-83. 
38. Delhaas $T$, Arts $T$, Prinzen FW, Reneman RS. Regional fibre stress-fibre strain area as an estimate of regional blood flow and oxygen demand in the canine heart. J Physiol 1994; 477 ( Pt 3):481-496.

39. Heusch G. Postconditioning: old wine in a new bottle? J Am Coll Cardiol 2004; 44:1111-1112.

40. Bopassa JC, Ferrera R, Gateau-Roesch O, Couture-Lepetit E, Ovize M. PI 3-kinase regulates the mitochondrial transition pore in controlled reperfusion and postconditioning. Cardiovasc Res 2006; 69:178-185.

41. Mrak RE, Carry MM, Murphy ML, Peng CF, Straub KD. Reperfusion injury in ischemic myocardium: protective effect of controlled reperfusion. Am J Cardiovasc Pathol 1990; 3:217-224.

42. Okamoto $F$, Allen BS, Buckberg GD, Bugyi $H$, Leaf J. Reperfusion conditions: importance of ensur. ing gentle versus sudden reperfusion during relief of coronary occlusion. J Thorac Cardiovasc Surg 1986; 92:613-620.

43. Gowda A, Yang CJ, Asimakis GK, Ruef J, Rastegar S, Runge MS, Motamedi M. Cardioprotection by local heating: improved myocardial salvage after ischemia and reperfusion. Ann Thorac Surg 1998; 65:1241-1247.

44. Cornelussen R, Spiering W, Webers JH, De Bruin LG, Reneman RS, van der Vusse GJ, Snoeckx $\mathrm{LH}$. Heat shock improves ischemic tolerance of hypertrophied rat hearts. Am J Physiol 1994; 267:H1941-1947.

45. Dote $K_{1}$ Wolff RA, Van Winkle DM. Hypothermia increases the threshold for ischemic preconditioning. J Thorac Cardiovasc Surg 1998; 116:319-326.

46. Miki T, Liu GS, Cohen MV, Downey JM. Mild hypothermia reduces infarct size in the beating rabbit heart: a practical intervention for acute myocardial infarction? Basic Res Cardiol 1998; 93:372-383.

47. Ovize M, Kloner RA, Przyklenk K. Stretch preconditions canine myocardium. Am J Physiol 1994; 266: $\mathrm{H} 137-146$.

48. Obadia JF, Ovize $M$, Maupoil V, Terrand $J$, Abadie $C$, Ovize A, Andre-Fouet $X$, et al. Beneficial actions of preconditioning and stretch on postischemic contractile function of isolated working rat heart: effects of staurosporine. J Cardiovasc Pharmacol 1997; 30:191-196.

49. Gysembergh A, Margonari $H$, Loufoua J, Ovize A, Andre-Fouet $X$, Minaire $Y$, Ovize M. Stretchinduced protection shares a common mechanism with ischemic preconditioning in rabbit heart. Am J Physiol 1998; 274:H955-964.

50. Huang $\mathrm{CH}$, Wang JS, Chiang SC, Wang YY, Lai ST, Weng ZC. Brief pressure overload of the left ventricle preconditions rabbit myocardium against infarction. Ann Thorac Surg 2004; 78:628-633.

51. Iliodromitis EK, Gaitanaki $C$, Lazou A, Bofilis E, Karavolias GK, Beis I, Kremastinos DT. Dissociation of stress-activated protein kinase (p38-MAPK and JNKs) phosphorylation from the protective effect of preconditioning in vivo. J Mol Cell Cardiol 2002; 34:1019-1028.

52. Wyman BT, Hunter WC, Prinzen FW, Faris OP, McVeigh ER. Effects of single- and biventricular pacing on temporal and spatial dynamics of ventricular contraction. Am J Physiol Heart Circ Physiol 2002; 282:H372-379.

53. Prinzen FW, Hunter WC, Wyman BT, McVeigh ER. Mapping of regional myocardial strain and work during ventricular pacing: experimental study using magnetic resonance imaging tagging. J Am Coll Cardiol 1999; 33:1735-1742.

54. Lewis CW, Owen CH, Zipprich DA, Sabiston DC, Jr., Smith PK, Glower DD. The effects of local ventricular pacing on recovery from regional myocardial ischemia. J Surg Res 1993; 54:360-367.

55. van Oosterhout MF, Prinzen FW, Arts T, Schreuder JJ, Vanagt WY, Cleutjens JP, Reneman RS. Asynchronous electrical activation induces asymmetrical hypertrophy of the left ventricular wall. Circulation 1998; 98:588-595.

56. Przyklenk K, Bauer B, Ovize M, Kloner RA, Whittaker P. Regional ischemic 'preconditioning' protects remote virgin myocardium from subsequent sustained coronary occlusion. Circulation 1993; 87:893899.

57. Yellon DM, Downey JM. Preconditioning the myocardium: from cellular physiology to clinical cardiology. Physiol Rev 2003; 83:1113-1151.

58. Kerendi $F$, Kin H, Halkos ME, Jiang R, Zatta AJ, Zhao ZQ, Guyton RA, et al. Remote postconditioning. Brief renal ischemia and reperfusion applied before coronary artery reperfusion reduces myo- 
cardial infarct size via endogenous activation of adenosine receptors. Basic Res Cardiol 2005; 100:404-412.

59. Hausenloy DJ, Yellon DM. The evolving story of "conditioning" to protect against acute myocardial ischaemia-reperfusion injury. Heart 2007; 93:649-651.

60. Loukogeorgakis SP, Panagiotidou AT, Broadhead MW, Donald A, Deanfield JE, MacAllister RJ. Remote ischemic preconditioning provides early and late protection against endothelial ischemiareperfusion injury in humans: role of the autonomic nervous system. J Am Coll Cardiol 2005; 46:450456.

61. Gho BC, Schoemaker RG, van den Doel MA, Duncker DJ, Verdouw PD. Myocardial protection by brief ischemia in noncardiac tissue. Circulation 1996; 94:2193-2200.

62. Manintveld $O C, T e$ Lintel Hekkert $M$, van den Bos EJ, Suurenbroek GM, Dekkers $D H$, Verdouw $P D$, Lamers $J \mathrm{M}$, et al. Cardiac effects of postconditioning depend critically on the duration of index ischemia. Am J Physiol Heart Circ Physiol 2007; 292:H1551-1560.

63. Staat P, Rioufol G, Piot C, Cottin Y, Cung TT, L'Huillier I, Aupetit JF, et al. Postconditioning the human heart. Circulation 2005; 112:2143-2148.

64. Darling CE, Solari PB, Smith CS, Furman MI, Przyklenk K. 'Postconditioning' the human heart: Multiple balloon inflations during primary angioplasty may confer cardioprotection. Basic Res Cardiol 2007; 102:274-278.

65. Ma X, Zhang X, Li C, Luo M. Effect of postconditioning on coronary blood flow velocity and endothelial function and LV recovery after myocardial infarction. J Interv Cardiol 2006; 19:367-375.

66. Thibault H, Piot C, Ovize M. Postconditioning in man. Heart Fail Rev 2007; 12:245-248.

67. Caldwell RA, Clemo HF, Baumgarten $\mathrm{CM}$. Using gadolinium to identify stretch-activated channels: technical considerations. Am J Physiol 1998; 275:C619-621.

68. Ward $\mathrm{H}$, White $\mathrm{E}$. Reduction in the contraction and intracellular calcium transient of single rat ventricular myocytes by gadolinium and the attenuation of these effects by extracellular $\mathrm{NaH} 2 \mathrm{PO}$. Exp Physiol 1994; 79:107-110.

69. Eckardt L, Kirchhof $P$, Monnig G, Breithardt G, Borggrefe M, Haverkamp W. Modification of stretchinduced shortening of repolarization by streptomycin in the isolated rabbit heart. $\mathrm{J}$ Cardiovasc Pharmacol 2000; 36:711-721.

70. Sohn YZ, Katz RL. Effects of certain antibiotics on isometric contractions of isolated rat heart muscle. Can Anaesth Soc J 1978; 25:291-296.

71. D'Souza SP, Yellon DM, Martin C, Schulz R, Heusch G, Onody A, Ferdinandy P, et al. B-type natriuretic peptide limits infarct size in rat isolated hearts via KATP channel opening. Am J Physiol Heart Circ Physiol 2003; 284:H1592-1600.

72. Baxter GF. Natriuretic peptides and myocardial ischaemia. Basic Res Cardiol 2004; 99:90-93.

73. Woods RL. Cardioprotective functions of atrial natriuretic peptide and B-type natriuretic peptide: a brief review. Clin Exp Pharmacol Physiol 2004; 31:791-794.

74. Hausenloy DJ, Tsang A, Mocanu MM, Yellon DM. Ischemic preconditioning protects by activating prosurvival kinases at reperfusion. Am J Physiol Heart Circ Physiol 2005; 288:H971-976.

75. Hausenloy DJ, Yellon DM. Survival kinases in ischemic preconditioning and postconditioning. Cardiovasc Res 2006; 70:240-253.

76. Darling CE, Jiang $R$, Maynard $M$, Whittaker $P$, Vinten-Johansen J, Przyklenk K. Postconditioning via stuttering reperfusion limits myocardial infarct size in rabbit hearts: role of ERK1/2. Am J Physiol Heart Circ Physiol 2005; 289:H1618-1626.

77. Post MJ, Cornelussen RN, Prinzen FW. Pampering and priming the heart. Therapeutic neovascularization - Quo Vadis? Deindl E and Kupatt C. Springer 2007; 85-108.

78. Hausenloy DJ, Mocanu MM, Yellon DM. Cross-talk between the survival kinases during early reperfusion: its contribution to ischemic preconditioning. Cardiovasc Res 2004; 63:305-312.

79. Crisostomo PR, Wairiuko GM, Wang M, Tsai BM, Morrell ED, Meldrum DR. Preconditioning versus postconditioning: mechanisms and therapeutic potentials. J Am Coll Surg 2006; 202:797-812.

80. Kin $H$, Zhao ZQ, Sun HY, Wang NP, Corvera JS, Halkos ME, Kerendi $F$, et al. Postconditioning attenuates myocardial ischemia-reperfusion injury by inhibiting events in the early minutes of reperfusion. Cardiovasc Res 2004; 62:74-85. 
81. Piriou V, Chiari P, Lhuillier F, Bastien O, Loufoua J, Raisky $O$, David JS, et al. Pharmacological preconditioning: comparison of desflurane, sevoflurane, isoflurane and halothane in rabbit myocardium. Br J Anaesth 2002; 89:486-491.

82. Otani $H$, Okada $T$, Fujiwara $H$, Uchiyama $T$, Sumida $T$, Kido $M$, Imamura $H$. Combined pharmacological preconditioning with a G-protein-coupled receptor agonist, a mitochondrial KATP channel opener and a nitric oxide donor mimics ischaemic preconditioning. Clin Exp Pharmacol Physiol 2003; 30:684-693.

83. Ockaili R, Salloum F, Hawkins J, Kukreja RC. Sildenafil (Viagra) induces powerful cardioprotective effect via opening of mitochondrial K(ATP) channels in rabbits. Am J Physiol Heart Circ Physiol 2002; 283:H1263-1269.

84. Vinten-Johansen J, Yellon DM, Opie LH. Postconditioning: a simple, clinically applicable procedure to improve revascularization in acute myocardial infarction. Circulation 2005; 112:2085-2088.

85. Chiari PC, Bienengraeber MW, Pagel PS, Krolikowski JG, Kersten JR, Warltier DC. Isoflurane protects against myocardial infarction during early reperfusion by activation of phosphatidylinositol-3kinase signal transduction: evidence for anesthetic-induced postconditioning in rabbits. Anesthesiology 2005; 102:102-109.

86. Weihrauch D, Krolikowski JG, Bienengraeber M, Kersten JR, Warltier DC, Pagel PS. Morphine enhances isoflurane-induced postconditioning against myocardial infarction: the role of phosphatidylinositol-3-kinase and opioid receptors in rabbits. Anesth Analg 2005; 101:942-949, table of contents.

87. Ninomiya $H$, Otani $H$, Lu $K$, Uchiyama $T$, Kido $M$, Imamura $H$. Enhanced IPC by activation of pertussis toxin-sensitive and -insensitive $G$ protein-coupled purinoceptors. Am J Physiol Heart Circ Physiol 2002; 282:H1933-1943.

88. Zhao ZQ, Vinten-Johansen J. Postconditioning: reduction of reperfusion-induced injury. Cardiovasc Res 2006; 70:200-211.

89. Abete P, Ferrara N, Cacciatore F, Madrid A, Bianco S, Calabrese C, Napoli C, et al. Angina-induced protection against myocardial infarction in adult and elderly patients: a loss of preconditioning mechanism in the aging heart? J Am Coll Cardiol 1997; 30:947-954.

90. Abete $P$, Ferrara N, Cacciatore F, Sagnelii E, Manzi M, Carnovale V, Calabrese $C$, et al. High level of physical activity preserves the cardioprotective effect of preinfarction angina in elderly patients. $J$ Am Coll Cardiol 2001; 38:1357-1365.

91. Kersten JR, Schmeling TJ, Orth KG, Pagel PS, Warltier DC. Acute hyperglycemia abolishes ischemic preconditioning in vivo. Am J Physiol 1998; 275:H721-725.

92. Kloner RA, Rezkalla SH. Preconditioning, postconditioning and their application to clinical cardiology. Cardiovasc Res 2006; 70:297-307.

93. Szilvassy Z, Ferdinandy P, Szilvassy J, Nagy I, Karcsu S, Lonovics J, Dux L, et al. The loss of pacing-induced preconditioning in atherosclerotic rabbits: role of hypercholesterolaemia. J Mol Cell Cardiol 1995; 27:2559-2569.

94. Ueda $Y$, Kitakaze $M$, Komamura $K$, Minamino $T$, Asanuma $H$, Sato $H$, Kuzuya $T$, et al. Pravastatin restored the infarct size-limiting effect of ischemic preconditioning blunted by hypercholesterolemia in the rabbit model of myocardial infarction. J Am Coll Cardiol 1999; 34:2120-2125.

95. Laskey WK. Brief repetitive balloon occlusions enhance reperfusion during percutaneous coronary intervention for acute myocardial infarction: a pilot study. Catheter Cardiovasc Interv 2005; 65:361367.

96. Gross GJ, Auchampach JA. Reperfusion injury: does it exist? J Mol Cell Cardiol 2007; 42:12-18.

97. Tsang A, Hausenloy DJ, Yellon DM. Myocardial postconditioning: reperfusion injury revisited. Am J Physiol Heart Circ Physiol 2005; 289:H2-7. 
Summary 
The title of this thesis "Pacing-induced dyssynchrony, blessing or curse?" refers to the ambiguous effects of pacing-induced dyssynchrony. The rationales for the studies mentioned in this thesis are introduced briefly in chapter 1. Under physiological circumstances, the ventricular myocardium is activated rapidly through the specialized conduction system of the heart. This synchronous electrical activation, followed by synchronous contraction of ventricular myocytes, is an important determinant of cardiac pump function. When the conduction system is bypassed, such as occurs during ventricular pacing, impulse propagation through the myocardium is much slower and results in dyssynchronous electrical activation and abnormal myocardial mechanical performance (pacing-induced dyssynchrony).

"Curse" refers to the immediate and persistent decrease in left ventricular (LV) pump function by pacing-induced dyssynchrony. Ventricular pacing from any site induces dyssynchrony, but the extent of the decrease in cardiac function varies between different pacing sites. The pacing site used most frequently in patients, the right ventricle (RV), is among the ones that cause the most pronounced abnormalities. While such effects are already known to be detrimental in adults with pacemakers, the situation seems to be even more dramatic in children, because they require pacing for a more extended period of time.

"Blessing" refers to potential positive effects of pacing on the tolerance of the myocardium to ischemia / reperfusion injury, the subject of the second half of this thesis. Ventricular pacing substantially alters regional myocardial stretch and contraction patterns. The reports from other laboratories that increased myocardial stretch and afterload mitigate myocardial ischemia / reperfusion injury initiated the idea that ventricular pacing also may reduce infarct size.

In chapter 2, the effects of ventricular pacing on LV stretch, contraction and pump function are described. Furthermore, the background of our studies concerning pacing sites in children (chapter 3-5) and pacing-induced cardioprotection against ischemia / reperfusion injury (chapter 6-7) is presented. Finally, our choice for the animal models used in our studies is explained.

Pacing at the commonly used RV apex results in impaired ventricular performance, whereas previous animal studies have shown that the LV apex is a superior pacing site. Therefore, in chapter 3 the acute hemodynamic effects of pacing at different ventricular sites are compared in a canine model at Maastricht University and in children during cardiac surgery at the University Hospital Gasthuisberg Leuven (Belgium). Dual chamber pacing was performed at the RV apex, LV apex and LV lateral wall. In the dogs, a basket electrode was inserted into the LV to measure endocardial activation times and to assess the (dys)synchrony of activation. LV apex pacing resulted in activation of the LV wall from apex to base, with synchronous activation around the LV circumference. In contrast, RV apex and LV lateral wall pacing resulted in dyssynchrony of activation between the septum and LV free wall. In both canine and children's hearts, LV pump function was unchanged during LV apex pacing as compared with sinus rhythm, whereas pump function was reduced during RV 
apex and LV lateral wall pacing. We therefore advocate the use of the LV apex as the site of choice for short-term ventricular pacing in children.

Considering the beneficial acute hemodynamic effects of LV apex pacing in children, we decided to use this pacing site to treat a 2-year old girl that developed overt RV pacing-induced heart failure. This patient is described in the case-report in chapter 4. LV apex pacing resulted in an immediate increase in cardiac function and in a gradual normalization of LV dimensions. The favorable effect of LV apex pacing indicates that further studies are warranted to investigate the use of $L V$ apex pacing in children with heart failure.

Animal studies from various laboratories showed that not only the LV apex, but also other LV sites result in better hemodynamics than RV pacing. Therefore, the chronic effects of LV lateral wall pacing and RV pacing were compared in the study in chapter 5 . Retrospectively, echocardiographic data were collected from children undergoing chronic epicardial RV or LV pacing and from healthy control children at the University Children's Hospital in Zurich (Switzerland). Chronic LV pacing maintained LV diameter, geometry and function (fractional shortening) at the level of healthy children, whereas chronic RV pacing resulted in significant LV dilation and in deterioration of LV function. Therefore, left rather than right ventricular pacing sites are advisable when permanent epicardial pacing in children is indicated.

We hypothesized that ventricular pacing has beneficial effects on ischemia / reperfusion damage due to altered regional mechanical performance. This was investigated in isolated ejecting rabbit hearts subjected to temporary global ischemia in the study in chapter 6 . When, prior to ischemia, $3 \times 5$ min ventricular pacing (VP preconditioning, VPPC) or intermittent ischemia (ischemic preconditioning, IPC) was applied, infarct size was significantly smaller as compared with control $(C)$ rabbits $(2 \%, 4 \%$, and $18 \%$ for VPPC, IPC, and C, respectively). Surprisingly, this infarct-sparing effect was not limited to prestretched regions during ventricular pacing, but was expressed throughout the LV wall. Coronary flow and lactate release were normal during ventricular pacing in rabbit hearts. Therefore, intermittent ischemia is a highly unlikely trigger for dyssynchrony-induced preconditioning. In tissue samples taken $10 \mathrm{~min}$ after the $3 \times 5$ min pacing preconditioning protocol, pro-BNP mRNA expression was $\sim 3$ times increased, suggesting a role for this stretch-sensitive protein.

While preconditioning procedures might be of general scientific interest and could be applied in the cardiac surgery setting, widespread clinical application of preconditioning has been hampered by the unexpectedness of most ischemic events. A few years ago, it was demonstrated in animal studies that brief intermittent ischemia during early reperfusion (termed ischemic postconditioning) reduced infarct size to the same extent as ischemic preconditioning. Therefore, we studied the infarct-reducing potential of pacing-induced dyssynchrony during early reperfusion in two animal models, namely isolated rabbit hearts and pig hearts in vivo (chapter 7). In both animal models infarct size 
was reduced by more than $50 \%$ as compared with controls if the heart was subjected to intermittent ventricular pacing immediately upon reperfusion $(10 \mathrm{x}$ 30 seconds at 30 seconds intervals). This protection was found to be independent of the site of ventricular pacing. In the rabbit heart it was demonstrated that the degree of protection was as large as that obtained by preconditioning. Using the fluorescent microsphere method it was shown that regional myocardial perfusion and coronary flow were not affected by ventricular pacing in the early reperfusion period. This data indicate that dyssynchrony-induced postconditioning cannot be attributed to more gradual restoration of perfusion after ischemia ("graded reperfusion").

In the general discussion in chapter $\mathbf{8}$, the studies mentioned above are put into a broader perspective, and some ideas for future investigations are presented.

Long-term prospective studies are indicated to identify the optimal LV pacing site in children requiring a ventricular pacemaker for rate control. In children with compromised LV function, further studies are needed to assess whether optimal single site pacing is as effective as biventricular pacing therapy for heart failure.

The molecular signaling pathways involved in cardiac pre- and postconditioning are progressively being unraveled and aim at understanding the cellular and subcellular mechanisms of myocardial protection against ischemia / reperfusion injury. Future studies in our laboratory will therefore focus on the signal transduction pathways of dyssynchrony-induced pre- and postconditioning. Considering the potential clinical applications of dyssynchrony-induced postconditioning, a clinical study assessing the protective effect of intermittent ventricular pacing during early reperfusion is currently being undertaken (Department of Cardiology, University Hospital Maastricht, The Netherlands). 


\section{Samenvatting}


SARENATINC

De titel van dit proefschrift "Pacing-geïnduceerde dyssynchronie, vloek of zegen?" doelt op de ambivalente gevolgen van pacing-geïnduceerde dyssynchronie. De onderliggende gedachten voor de studies in dit proefschrift worden kort uiteengezet in hoofdstuk 1.

Onder normale omstandigheden worden de hartspiercellen electrisch geactiveerd door het gespecialiseerde geleidingssysteem van het hart. Dit resulteert in snelle, nagenoeg synchrone (gelijktijdige) activatie van de hartspiercellen en is zeer belangrijk voor een goede pompfunctie van het hart. Wanneer het geleidingssysteem omzeild wordt, zoals tijdens ventriculair pacen (electrische stimulatie van het hart door een pacemaker), dan vindt de electrische prikkelgeleiding van spiercel tot spiercel plaats. Deze prikkelgeleiding verloopt veel trager en leidt tot dyssynchrone electrische activatie gevolgd door dyssynchrone contractie van het linker ventrikel (hartkamer). Deze pacing-geïnduceerde dyssynchronie leidt tot een verminderde pompfunctie van het hart, de "vloek" van pacing-geïnduceerde dyssynchronie.

De mate waarin de hartfunctie afneemt is echter afhankelijk van de plaats op de hartkamers waar de pacemaker-electrode geplaatst wordt. De meest gebruikte paceplaats bij mensen, de rechter kamer (ventrikel, RV) apex, is ook een van de plaatsen die geassocieerd is met de grootste afname in pompfunctie van het hart. Deze negatieve gevolgen van RV pacen zijn bekend bij volwassenen, maar kunnen bij kinderen met een pacemaker des te meer uitgesproken zijn vanwege de vaak levenslange noodzaak tot ventriculair pacen in deze groep jonge patiënten.

Daartegenover staat dat wij denken dat pacing-geïnduceerde dyssynchronie ook een "zegen" kan zijn. "Zegen" doelt hierbij op de gunstige effecten van ventriculair pacen op de vermindering van schade aan hartspiercellen door ischemie (zuurstofgebrek) en reperfusie (het herstellen van de bloedtoevoer na een periode van ischemie). Ventriculair pacen beïnvloedt de rek-en contractiepatronen van het hart. Andere onderzoekers hebben aangetoond dat rek en drukoverbelasting van de hartspier de ontwikkeling van ischemie- en reperfusieschade beperken. Daarom hebben wij onderzocht in hoeverre ook ventriculair pacen gebruikt kan worden om infarctschade te beperken. Deze mogelijk gunstige effecten worden besproken in het tweede deel van het proefschrift.

In hoofdstuk 2 worden de gevolgen van ventriculair pacen op rek en contractie van de hartspier in meer detail beschreven. Tevens wordt meer achtergrondinformatie gepresenteerd met betrekking tot onze studies op het gebied van pacen bij kinderen (hoofdstuk 3-5) en pacing-geînduceerde bescherming van het hart tegen ischemie- en reperfusieschade (hoofdstuk 67). Tenslotte wordt het door ons gebruikte proefdiermodel toegelicht.

Pacing op de RV apex, de meest gebruikte paceplaats, leidt tot een verminderde pompfunctie van het hart. Eerdere dierexperimentele studies hebben aangetoond dat de linker ventrikel (LV) apex een betere paceplaats is. Het was echter nog niet bekend of LV apex pacing ook in mensen geassocieerd is met een betere functie van het hart in vergelijking met RV 
pacing. In hoofdstuk 3 worden de acute hemodynamische gevolgen van ventriculair pacen op verschillende plaatsen op het hart (LV apex, LV vrije wand en RV apex) beschreven. Deze studie werd verricht in honden (Universiteit Maastricht) en in kinderen tijdens hartchirurgie (Universitair Ziekenhuis Gasthuisberg Leuven, België). In de honden werd tevens het electrische activatiepatroon van het LV gemeten. Daarbij bleek dat er tijdens LV apex pacen een synchrone electrische activatie optrad rondom de wand van het LV. Tijdens RV apex pacen en LV vrije wand pacen was er echter een duidelijke dyssynchronie tussen het interventriculaire septum en de LV vrije wand. Zowel in kinderen als in honden was de functie van het hart normaal tijdens LV apex pacen, maar nam de pompfunctie af tijdens pacen op de RV apex of de LV vrije wand. Daarom raden wij aan om de pacing-electrode in kinderen op de LV apex te plaatsen wanneer er kortdurend behoefte is aan een ventriculaire pacemaker.

Chronisch RV pacen kan leiden tot hartfalen. Bij een 2-jarig meisje met RV pacen-geïnduceerd hartfalen besloten wij de paceplaats te wijzigen en te gaan pacen op de LV apex. Deze patiënt wordt beschreven in het case-report in hoofdstuk 4. De behandeling met LV apex pacing leidde onmiddellijk tot een verbeterde pompfunctie en tot een geleidelijke normalisatie van de afmetingen van het hart.

Verscheidene dierexperimentele studies hebben aangetoond dat pacen op de LV apex of LV vrije wand leidt tot een verbeterde functie van het hart in vergelijking met pacen op de RV apex. Daarom hebben we de chronische effecten van LV en RV pacen in kinderen vergeleken in de studie in hoofdstuk 5. In deze retrospectieve studie werden echocardiografische gegevens verzameld van gezonde kinderen en van kinderen die chronisch RV of LV pacen ondergingen (Universitair Kinderziekenhuis Zürich, Zwitserland). Chronisch RV pacen was geassocieerd met ongunstige veranderingen in LV afmetingen en functie. Bij chronisch LV pacen in kinderen daarentegen werden normale afmetingen en een normale pompfunctie van het hart gemeten. Wanneer chronisch ventriculair pacen geïndiceerd is bij kinderen is het daarom aan te raden de pace-electrode op het LV te plaatsen.

In hoofdstuk 6 werd de hypothese getoetst dat pacing-geïnduceerde dyssynchronie de ischemie- en reperfusieschade reduceert door het veroorzaken van abnormale rek- en contractiepatronen in het hart. Dit is onderzocht in geïsoleerde, werkende konijnenharten. Na langdurige ischemie was de infarctgrootte beduidend kleiner in harten die vooraf blootgesteld waren aan pacing-geïnduceerde dyssynchronie (ventriculair pacing preconditioning, $2 \%$ infarcering) of aan kortdurende ischemie (ischemische preconditioning, $4 \%$ infarcering) in vergelijking met controleharten $(18 \%$ infarcering). Tijdens ventriculair pacen waren de doorstroming van de coronairvaten en de productie van lactaat normaal. Daarom is het zeer onwaarschijnlijk dat ventriculair pacing preconditioning veroorzaakt wordt door een ischemische prikkel. 


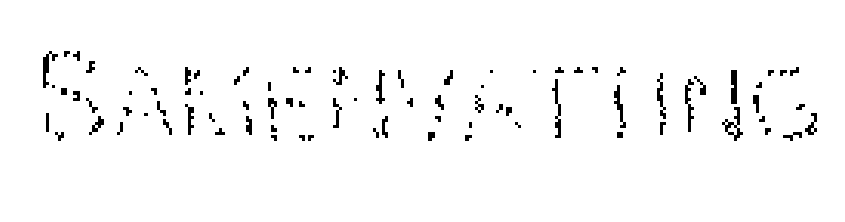

Preconditioning procedures zijn wetenschappelijk interessant en toepasbaar in situaties waarin ischemie van het hart verwacht wordt, zoals tijdens hartoperaties. Verdere klinische toepassing van preconditioning wordt echter grotendeels belemmerd omdat ischemie meestal onverwachts optreedt. Enkele jaren geleden werd beschreven dat ook interventies tijdens de vroege reperfusiefase na afloop van de ischemische periode de infarctgrootte beduidend kunnen verkleinen. Het infarct-reducerende effect van de zogenaamde ischemische postconditioning was zelfs even groot als dat van ischemische preconditioning. Daarom onderzochten wij of pacinggeïnduceerde dyssynchronie tijdens de vroege reperfusiefase (ventriculair pacing postconditioning) eveneens de infarctgrootte beperkt (hoofdstuk 7). Dit onderzoek werd verricht in geïsoleerde konijnenharten en in varkens in vivo. In beide diermodellen reduceerde ventriculair pacing postconditioning de infarctgrootte met meer dan $50 \%$. In konijnenharten werd aangetoond dat de mate van bescherming gelijk was aan die van pacing-geïnduceerde preconditioning. Pacing-geinduceerde postconditioning veroorzaakte géén geleidelijke verandering van de perfusie van het hart na ischemie, wat wel als werkingsmechanisme genoemd wordt bij ischemische postconditioning.

In de algemene discussie in hoofdstuk 8 worden de eerder genoemde studies besproken en in een breder perspectief geplaatst. Tevens worden enkele ideeën voor vervolgonderzoek gepresenteerd.

In kinderen die een ventriculaire pacemaker dienen te krijgen vanwege een te traag hartritme zijn langdurige prospectieve studies nodig om de meest optimale LV paceplaats te identificeren. In kinderen met hartfalen zijn verdere studies geïndiceerd om te onderzoeken of het gebruik van één optimale paceplaats voordeel biedt boven het gebruik van biventriculair pacen.

De moleculair-biologische achtergronden van pre- en postconditioning worden geleidelijk ontrafeld met als doel de cellulaire en subcellulaire processen van ischemie- en reperfusieschade beter te begrijpen. Daarom zullen onze vervolgstudies zich mede richten op de zogenaamde signaaltransductie van pacing-geïnduceerde pre- en postconditioning. Gezien de mogelijke klinische toepassing van pacing-geïnduceerde postconditioning is er een studie opgestart die het protectieve effect van ventriculair pacen tijdens de reperfusiefase in patiënten met een hartinfarct onderzoekt (Afdeling Cardiologie, academisch ziekenhuis Maastricht, Nederland). 


\section{Curriculum vitae}




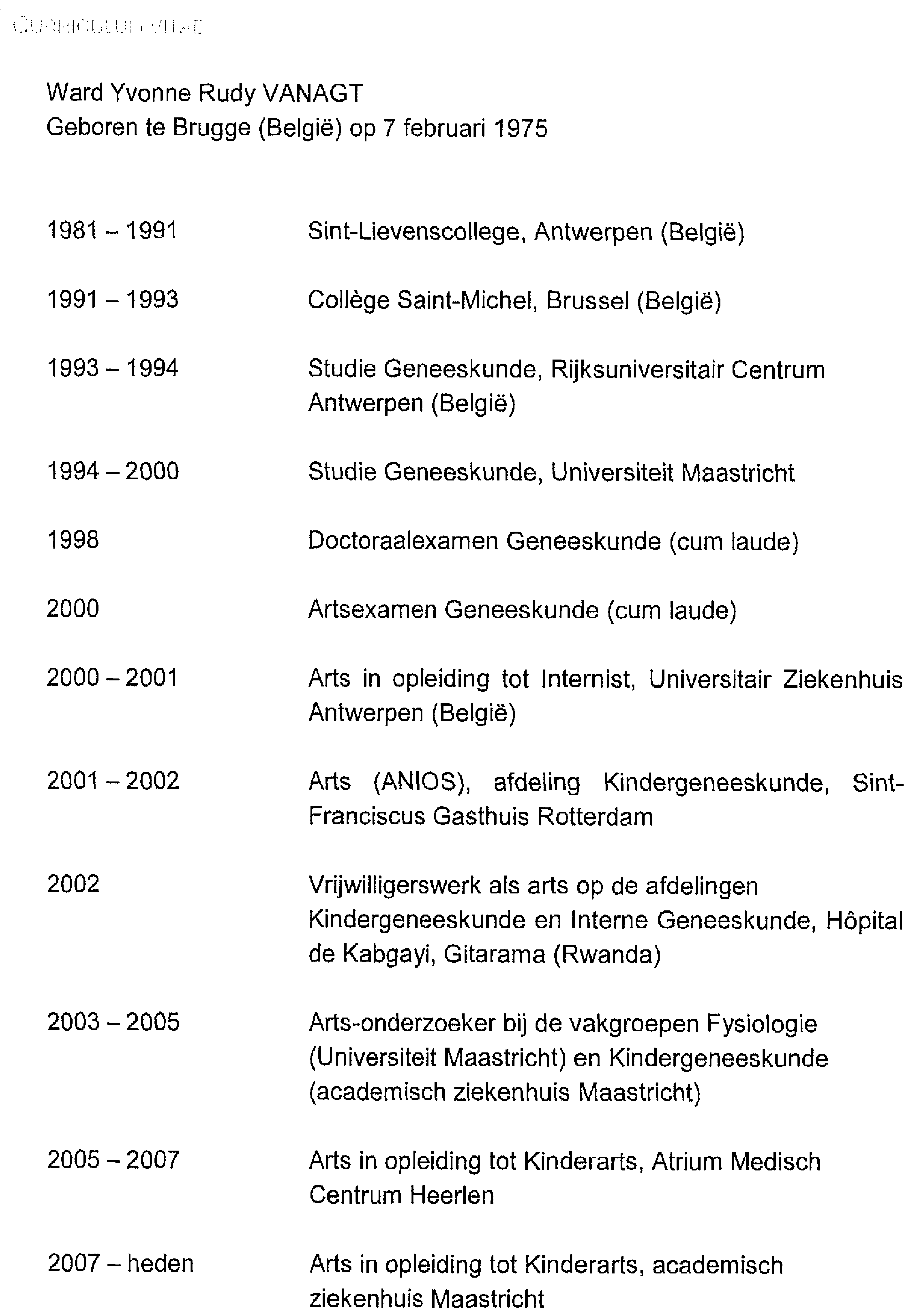


Ward Yvonne Rudy VANAGT

Born in Bruges (Belgium) on February $7^{\text {th }}, 1975$

$\begin{array}{ll}1981-1991 & \begin{array}{l}\text { Primary School and High School, "Sint- } \\ \text { Lievenscollege", Antwerp (Belgium) }\end{array} \\ 1991-1993 & \begin{array}{l}\text { High School, "Collège Saint-Michel", Brussels } \\ \text { (Belgium) }\end{array} \\ 1993-1994 & \begin{array}{l}\text { Study at the Faculty of Medicine, Antwerp } \\ \text { University (Belgium) }\end{array} \\ 1994-2000 & \begin{array}{l}\text { Study at the Faculty of Medicine, Maastricht } \\ \text { University (cum laude) }\end{array} \\ 2000-2001 & \begin{array}{l}\text { Resident in Internal Medicine, University Hospital } \\ \text { Antwerp (Belgium) }\end{array} \\ 2001-2002 & \begin{array}{l}\text { Resident in Pediatrics, "Sint-Franciscus Gasthuis", } \\ \text { Rotterdam }\end{array} \\ 2002 & \begin{array}{l}\text { Volunteer at the Pediatrics and Internal Medicine } \\ \text { wards at "Hôpital de Kabgayi", Gitarama (Rwanda) }\end{array} \\ 2003-2005 & \begin{array}{l}\text { Research Fellow at the Departments of Physiology } \\ \text { (Maastricht University) and Pediatrics (University } \\ \text { Hospital Maastricht) }\end{array} \\ & \begin{array}{l}\text { Resident in Pediatrics, "Atrium Medisch Centrum", } \\ \text { Heerlen }\end{array} \\ & \text { Resident in Pediatrics, University Hospital Maastricht } \\ 2005-2007 & \begin{array}{l}\text { present } \\ 2003\end{array} \\ & \end{array}$




\section{Publications}


JOURNAL ARTICLES

1. Stals FS, Wagenaar SS, Kloover JS, Vanagt WY, Bruggeman CA. Combinations of ganciclovir and antibody for experimental CMV infections. Antiviral Res 1996; 29:61-64.

2. Kloover JS, Vanagt WY, Stals FS, Bruggeman CA. Effective treatment of experimental cytomegalovirus-induced encephalo-meningitis in immunocompromised rats with HPMPC. Antiviral Res 1997; 35:105112.

3. van Oosterhout MF, Prinzen FW, Arts T, Schreuder JJ, Vanagt WY, Cleutjens JP, Reneman RS. Asynchronous electrical activation induces asymmetrical hypertrophy of the left ventricular wall. Circulation 1998; 98:588-595.

4. Prinzen FW, Van Oosterhout MF, Vanagt WY, Storm C, Reneman RS. Optimization of ventricular function by improving the activation sequence during ventricular pacing. Pacing Clin Electrophysiol 1998; 21:2256-2260.

5. Peschar M, Vernooy $K$, Vanagt WY, Reneman RS, Vos MA, Prinzen FW. Absence of reverse electrical remodeling during regression of volume overload hypertrophy in canine ventricles. Cardiovasc Res 2003; 58:510-517.

6. Cornelussen RN, Vanagt WY, Prinzen FW, Snoeckx LH. Proteins involved in salvage of the myocardium. Adv Exp Med Biol 2003; 543:277-291.

7. Vanagt $W Y$, Verbeek XA, Delhaas T, Mertens L, Daenen WJ, Prinzen FW. The Left Ventricular Apex is the Optimal Site for Pediatric Pacing. Pacing Clin Electrophysiol 2004; 27:837-843.

8. Vanagt WY, Daenen WJ, Delhaas T. Propionibacterium acnes endocarditis on an annuloplasty ring in an adolescent boy. Heart 2004; 90:e56.

9. Vanagt WY, Verbeek XA, Delhaas T, Gewillig M, Mertens L, Wouters $\mathrm{P}$, Meyns $\mathrm{B}$, et al. Acute hemodynamic benefit of left ventricular apex pacing in children. Ann Thorac Surg 2005; 79:932-936.

10. Vanagt WY, Pulles-Heintzberger CF, Vernooy K, Cornelussen RN, Delhaas $T$. Asystole during outbursts of laughing in a child with Angelman syndrome. Pediatr Cardiol 2005; 26:866-868.

11. Vanagt WY, Delhaas $T$, Maleux $G$, Gewillig $M$. Coil reduction of the right ventricular cavity in a boy with pulmonary atresia, intact 
ventricular septum, and an aneurysmal coronary sinusoid. Catheter Cardiovasc Interv 2006; 67:276-278.

12. Vanagt WY, Cornelussen RN, Poulina QP, Blaauw E, Vernooy $K$, Cleutjens JP, van Bilsen $\mathrm{M}$, et al. Pacing-induced dyssynchrony preconditions rabbit myocardium against ischemia/reperfusion injury. Circulation 2006; 114:1264-269.

13. Vanagt WY, Cornelussen RN, Baynham TC, Van Hunnik A, Poulina $\mathrm{QP}$, Babiker F, Spinelli J, et al. Pacing-induced dyssynchrony during early reperfusion reduces infarct size. J Am Coll Cardiol 2007; 49:1813-1819.

14. Vernooy $K$, Cornelussen RN, Verbeek XA, Vanagt WY, van Hunnik $A$, Arts $T$, Kuiper $M$, et al. Cardiac resynchronization therapy cures dyssynchronopathy in canine left bundle-branch block hearts. Eur Heart J 2007; 28:2148-2155.

15. Vanagt WY, Prinzen FW, Delhaas T. Physiology of cardiac pacing in children - the importance of the ventricular pacing site. Pacing Clin Electrophysiol 2007; in press.

16. Vanagt $W Y$, Prinzen FW, Delhaas T. Single site LV apex pacing cures overt RV pacing-induced heart failure. New Engl J Med 2007; in press.

17. Vanagt WY, Van Geldorp IEG, Bauersfeld U, Tomaske M, Prinzen FW, Delhaas T. Structural and functional benefit of chronic left ventricular over right ventricular pacing in children. Pacing Clin Electrophysiol 2007; submitted.

\section{BOOK CHAPTER}

1. Prinzen FW, Vernooy $K$, Verbeek $X A$, Vanagt $W Y$, Cornelussen $R N$. Remodeling of the asynchronous heart. In NM Van Hemel et al. (eds): Exclusion or targeting? 2005, pp. 157-166.

\section{PATENTS PENDING}

Ward Y. Vanagt, Richard N. Cornelussen and Frits W. Prinzen are coinventors of three patents pending as a result of the work described in this thesis. 
Dankwoord

\&

Acknowledgements 


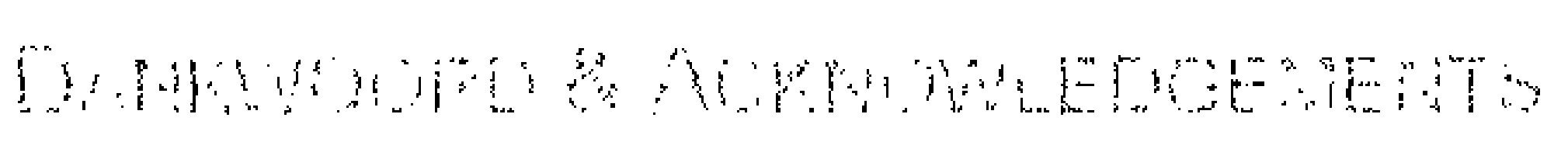

Tot slot het meest gelezen deel van dit proefschrift. Dankbaar wil ik hier van uw aandacht gebruik maken om een aantal mensen extra in de schijnwerpers te zetten. Dit proefschrift is het resultaat van de bijdragen van vele mensen, waarvoor mijn hartelijke dank.

Allereerst wil ik Dr. Frits Prinzen, copromotor en inspirator van dit promotieonderzoek bedanken. Beste Frits, al tijdens mijn studie raakte ik betrokken bij jouw onderzoeksgroep, om er na een tussenstop terug te keren voor dit promotie-onderzoek. Onder de enthousiaste begeleiding van een ervaren marathonloper werd dit al met al een lang traject, waarbij je steeds de tijd maakte voor overleg. Bedankt voor de leerzame en leuke tijd waarin er altijd ruimte was voor het bespreken van nieuwe ideeën.

Dr. Tammo Delhaas, copromotor. Beste Tammo, ik was jouw eerste promovendus, zeg maar proefkonijn op dit gebied. Ik wil je graag bedanken voor je brede kijk op het gehele onderzoekstraject en voor de mogelijkheden die je gecreëerd hebt om ook klinisch onderzoek in het project te betrekken. Jouw blik beperkt zich niet alleen tot wat er in dit proefschrift staat, ook bij het zoeken en kopen van een huis had je steeds goede tips en kleine verhuizers paraat.

Prof. dr. Ger van der Vusse, promotor. Beste Ger, met je frisse blik op dit onderzoek heb je nog duidelijk je stempel op mijn proefschrift geplaatst. Hartelijk bedankt voor je begeleiding.

Dr. Richard Cornelussen. Beste Richard, jouw bijdrage, steun en begeleiding gedurende de afgelopen jaren waren essentieel. $\mathrm{lk}$ ben blij dat je tijdens de verdediging als corona-lid op zal treden. Steeds bijzonder kritisch en motiverend, bedankt voor al je hulp.

De leden van de beoordelingscommissie Prof. dr. Waltenberger (voorzitter), Prof. dr. Arts, Prof. dr. Duncker, Prof. dr. Gewillig en Prof. dr. Snoeckx wil ik bedanken voor het kritisch doorlezen en beoordelen van dit proefschrift.

Prof. dr. R. Donckerwolcke ben ik zeer erkentelijk voor het mogelijk maken van de combinatie tussen wetenschappelijk onderzoek en een klinische opleiding. Voorts verdienen ook mijn opleiders Dr. J. Dankert-Roelse en Prof. dr. L. Zimmermann een woord van dank voor hun bijdrage aan mijn specialisatie tot Kinderarts. 
Mijn interesse voor onderzoek werd gewekt toen ik samen met Jeroen Kloover bij de Afdeling Medische Microbiologie (azM) deel mocht nemen aan een project van Dr. Frans Stals. We hadden er naast de studie veel plezier en ook de prettige begeleiding door Gert Grauls en Prof. dr. Cathrien Bruggeman is me altijd bijgebleven.

Alle leden van de Vakgroep Fysiologie en de Afdeling Kindergeneeskunde wil ik danken voor hun getoonde interesse en steun bij mijn onderzoek.

Gedurende de afgelopen jaren werd ik bijgestaan en begeleid door collega's bij de Vakgroep Fysiologie, die allemaal op hun eigen manier mee richting hebben gegeven aan dit proefschrift. Matthijs van Oosterhout, Xander Verbeek, Maaike Peschar, Robert Mills, Marloes Gelissen, Roeland Van Kerckhoven en Fawzi Babiker, bedankt voor jullie bijdragen.

In het bijzonder wil ik Kevin Vernooy bedanken voor de plezierige tijd als kamergenoten en op congressen, alsook voor alle inhoudelijke feed-back. Beste Kevin, ik bel je nog wel eens vanuit de lift.

Irene Van Geldorp ben ik veel dank verschuldigd voor al het werk dat ze deed in Zwitserland en Maastricht. Beste Irene, het doet me plezier dat je inmiddels aan een AGIKO-traject begonnen bent en hoop dat we daarin nog vaker zullen kunnen samenwerken.

Mijn gebrek aan technisch vernuft bij het opbouwen en draaiend houden van een perfusie-opstelling werd ruimschoots gecompenseerd door Arne Van Hunnik. Naast Arne wil ik ook Marion Kuiper bedanken voor alle hulp bij de experimenten.

Sonia Froidmont en Vivian Schellings van het secretariaat Fysiologie wil ik bedanken voor alle hulp gedurende de afgelopen jaren.

Bijzondere gezelligheid kwam niet alleen vanuit de eigen onderzoeksgroep, maar ook van een aantal "buurtgenoten". Jacqueline Bastiaanse kan ik niet genoeg danken voor haar betrokkenheid bij het lief en leed van dit project. Tijdens het werk of op een Jazz-festival, altijd daar met goede raad. Ook Andries Gilde kwam ik regelmatig tegen na kantooruren in en nabij de koffiekamer van de Vakgroep Fysiologie. Andries, bedankt voor je aanmoedigingen op de momenten dat ik die het best kon gebruiken. 


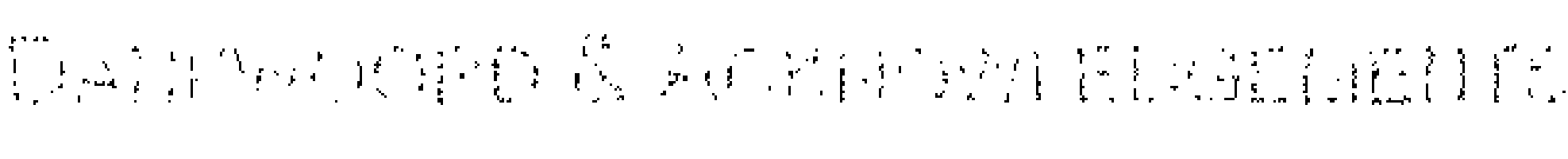

Cher Julien, je tiens à te remercier pour ton amitié. Ont été pour moi très précieux les moments où nous allions ensemble prendre l' air.

Joyce, Petra, Noortje en Frans van de Centrale Proefdiervoorziening hebben de afgelopen jaren steeds goede zorg gedragen voor "onze" konijnen, op een manier waar ik veel bewondering voor heb.

I would like to thank Julio Spinelli PhD, Tamara Baynham PhD, Joseph Pastore PhD, Douglas Daum PhD, and Eric Mokelke PhD at Boston Scientific (St Paul, MN, USA) for their continued interest and support of our work. I think our collaboration has been very special and hope that we can continue working together in the future.

In het Universitair Ziekenhuis Gasthuisberg te Leuven werd een deel van ons onderzoek verricht tijdens hartchirurgie bij kinderen. Prof. dr. Marc Gewillig, Prof. dr. Luc Mertens, Prof. dr. Patrick Wouters, Prof. dr. Dirk Vlasselaers, Prof. dr. Bart Meyns en Prof. dr. Willem Daenen wil ik dan ook danken voor de gastvrijheid op de Leuvense operatiekamers en de prettige samenwerking.

I wish to express my thanks to Urs Bauersfeld MD, and Maren Tomaske MD at the University Children's Hospital in Zurich for their contribution to the clinical study in chapter 5 .

Ik ben blij dat Jasper Van Aalst en Meindert Palmen aan mijn zijde zullen staan bij de verdediging van dit proefschrift. Beste Jasper, bedankt dat je er altijd was met een luisterend oor en een goede dosis humor bij de ontelbare momenten met Spa Rood en Spa Blauw. Beste Meindert, bedankt voor je vriendschap en voor je onbeperkte gastvrijheid bij mijn terugkeer naar Maastricht.

Mijn familie wil ik in het bijzonder danken voor hun blijvende interesse en steun. Beste Paps en Kris, Toon en Eva, Katleen en Martin, Sarah en Pieter, Tante Françoise, Pieter en Vanessa, bedankt voor jullie betrokkenheid over de jaren heen. Mijn zus Sarah verdient alle lof voor de omslag van dit proefschrift.

Lieve Véronique, jouw steun en begrip voor dit werk zijn enorm geweest. Inmiddels zijn we samen aan het volgende project begonnen. Ik kijk ernaar uit daar nu de volle aandacht en energie aan te kunnen schenken. 